\title{
The molecular basis of APC-resistance: role of coagulation factor abnormalities
}

Citation for published version (APA):

Brugge, J. M. (2006). The molecular basis of APC-resistance: role of coagulation factor abnormalities. [Doctoral Thesis, Maastricht University]. Datawyse / Universitaire Pers Maastricht. https://doi.org/10.26481/dis.20060224jb

Document status and date:

Published: 01/01/2006

DOI:

10.26481/dis.20060224jb

Document Version:

Publisher's PDF, also known as Version of record

\section{Please check the document version of this publication:}

- A submitted manuscript is the version of the article upon submission and before peer-review. There can be important differences between the submitted version and the official published version of record.

People interested in the research are advised to contact the author for the final version of the publication, or visit the DOI to the publisher's website.

- The final author version and the galley proof are versions of the publication after peer review.

- The final published version features the final layout of the paper including the volume, issue and page numbers.

Link to publication

\footnotetext{
General rights rights.

- You may freely distribute the URL identifying the publication in the public portal. please follow below link for the End User Agreement:

www.umlib.nl/taverne-license

Take down policy

If you believe that this document breaches copyright please contact us at:

repository@maastrichtuniversity.nl

providing details and we will investigate your claim.
}

Copyright and moral rights for the publications made accessible in the public portal are retained by the authors and/or other copyright owners and it is a condition of accessing publications that users recognise and abide by the legal requirements associated with these

- Users may download and print one copy of any publication from the public portal for the purpose of private study or research.

- You may not further distribute the material or use it for any profit-making activity or commercial gain

If the publication is distributed under the terms of Article $25 \mathrm{fa}$ of the Dutch Copyright Act, indicated by the "Taverne" license above, 
The Molecular Basis of APC-Resistance:

Role of Coagulation Factor Abnormalities 
(ㄷ) J.M. Brugge, Maastricht 2006 ISBN 90-5278-511-2

Printed by: Datawyse Maastricht

Cover design by Liesbeth N.F. Brugge-Hermans 


\title{
The Molecular Basis of APC-Resistance:
}

\section{Role of Coagulation Factor Abnormalities}

\author{
PROEFSCHRIFT \\ ter werkrijging van de graad doctor \\ aan de Universiteit Maastricht, \\ op gezag van de Rector Magnificus, \\ Prof. mr. G.P.M.F. Mols, \\ volgens het besluit van het College van Decanen, \\ in het openbaar te verdedigen op \\ vrijdag 24 februari 2006 om 14.00 uur \\ door \\ Jeroen Martijn Brugge
}

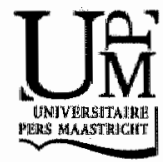




\section{PROMOTOR}

Prof. dr. J. Rosing

\section{CO-PROMOTORES}

Dr. G. Tans

Dr. E. Castoldi

\section{BEOORDELINGSCOMMISSIE}

Prof. dr. G.J. van der Vusse (voorzitter)

Prof. dr. J.W. Cohen Tervaert

Prof. dr. J.P.M. Geraedts

Prof. dr. P.W. de Leeuw

Prof. dr. K. Mertens (Universiteit Utrecht)

The study described in this thesis was supported by a grant of the Netherlands Heart Foundation (NHS-2000B21).

Financial support by the Netherlands Heart Foundation for the publication of this thesis is gratefully acknowledged.

I would also like to thank Instrumentation Laboratory and the Dr. Ir. van de Laar Foundation of their generous financial support. 


\section{Table of contents}

\begin{tabular}{|c|c|c|}
\hline Chapter 1 & General Introduction & 7 \\
\hline Chapter 2 & $\begin{array}{l}\text { Theoretical and experimental study of the } \\
\text { D2194G mutation in the C2-domain of } \\
\text { coagulation factor } V\end{array}$ & 43 \\
\hline Chapter 3 & $\begin{array}{l}\text { Impaired APC cofactor activity of factor } V \\
\text { plays a major role in the APC resistance } \\
\text { associated with the factor } V \text { Leiden ( } R 506 \mathrm{Q}) \\
\text { and } R 2(\mathrm{H} 1299 \mathrm{R}) \text { mutations }\end{array}$ & 73 \\
\hline Chapter 4 & $\begin{array}{l}\text { Expression of the normal factor } V \text { allele } \\
\text { modulates the APC resistance phenotype in } \\
\text { heterozygous carriers of the factor } V \text { Leiden } \\
\text { mutation }\end{array}$ & 95 \\
\hline Chapter 5 & $\begin{array}{l}\text { Protein } \mathrm{S} \text { levels modulate the activated protein } \\
\text { C resistance phenotype induced by elevated } \\
\text { prothrombin levels }\end{array}$ & 115 \\
\hline Chapter 6 & General Discussion & 137 \\
\hline \multirow[t]{5}{*}{ Chapter 7} & Summary & 159 \\
\hline & Samenvatting & 163 \\
\hline & List of publications & 167 \\
\hline & Curriculum vitae & 169 \\
\hline & Darıkwoord & 171 \\
\hline
\end{tabular}




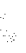




\section{CHAPTER 1}

\section{General Introduction}


-- 


\subsection{Introduction}

Blood is a vital component of the human body, that functions as a carrier of substances like nutrients, metabolites "oxygen and waste products. It flows through the vascular system, thereby reaching all organs and tissues in our body.

When the vascular system is damaged, blood will leak out. At this point it is very important that the bleeding is stopped and tissue repair can start. Therefore, at the place of injury, blood is converted from a fluid phase into a solid phase, thereby preventing further blood loss. The process whereby blood is maintained fluid under normal conditions but is allowed to clot when and where necessary is regulated by a large variety of components present in both our plasma and the vessel wall: this delicate balance is called haemostasis.

The haemostatic balance is the result of two opposite forces: the procoagulant pathway, which promotes coagulation and results in the formation of a clot and the anticoagulant pathway, which keeps the blood fluid. Under normal circumstances haemostasis is shifted in favor of the anticoagulant pathway, allowing blood to circulate through the body. Once blood coagulation is activated, however, the haemostatic balance shifts towards the procoagulant pathway, allowing a clot to be formed at the site of injury.

\subsection{Blood coagulation}

\section{Platelets}

Blood coagulation is a complex process that involves cells present in the circulation (platelets) and proteins present in both blood and in the vessel wall. After vascular damage the vessel wall constricts immediately resulting in a reduction of the blood flow. This slows down the circulating platelets and makes it possible for them to adhere to the subendothelial structures (e.g. collagen, fibronectin) that have become exposed to the bloodstream. Platelet adhesion occurs primarily via receptor-mediated interactions. The receptor involved during platelet adhesion, however, may differ depending on the shear rate in the blood vessel. Overall, initially the platelet receptor glycoprotein lb (GPIb) binds to von Willebrand factor (WWF) [1], a protein that is exposed when endothelial damage occurs, followed by expression and activation of a whole range of other receptors resulting in an immobilized platelet on the subendothelial surface [26]. Upon binding, platelets are activated and undergo several changes, making them procoagulant. The phospholipid composition of the platelet membrane 
changes, resulting in the exposure of negatively charged phosphatidylserine (PS) on the outer leaflet of the platelet membrane $[7,8]$. The platelet membrane and these negatively charged phospholipids play an important role in coagulation reactions. Simultaneously the content of the $\alpha$-granules and the dense bodies is released. The $\alpha$-granules contain several clotting factors such as factor $\mathrm{V}$, factor $X I I I$, fibrinogen, WWF but also other proteins like platelet factor 4, whereas the dense bodies contain a variety of platelets agonists [9-11]. The activation of platelets and the effect of platelet agonists released from the dense bodies make the platelets even more procoagulant, as they express a new receptor now, integrin $\alpha_{116} \beta_{3}$. Thanks to the $\alpha_{11 b} \beta_{3}$ receptor, together with the released platelet agonists and the presence of fibrinogen or fibrin, activated platelets will bind and activate other platelets [12-14]. This process is called aggregation and resuits in the formation of a primary thrombus at the site of injury, which however is unstable. This platelet plug stops the bleeding temporarily, but for a complete and stable thrombus to be formed additional (coagulation) reactions are required.

\section{Coagulation cascade}

The coagulation cascade is a waterfall sequence of enzymatic reactions involving several different plasma proteins. The goal of this system is, once activated by a small amount of trigger, to amplify this initial signal and eventually generate a large amount of thrombin $[15,16]$. Thrombin, in turn, converts fibrinogen into fibrin which forms a fibrin network and thereby stabilizes the primary platelel thrombus. Such a stepwise system has the advantage that it can easily be regulated at different levels, but also has the disadvantage that when one or more components are missing, this will affect all reactions lying downstream of the missing components (e.g. hemophilia A and B).

Most enzymes involved in coagulation are vitamin K-dependent proteins, belonging to the family of serine proteases. Their catalytic domains are highly homologous. Furthermore they contain several conserved structural motifs (such as Gla-domains, EGF-like domains, Kringle domains) that are involved in interactions with other proteins and with membranes [17]. All vitamin $K$-dependent proteins contain a Gla-domain which mediates binding to a negatively charged (procoagulant) membrane. For this binding calcium ions are required. These proteases circulate in bload as inactive pro-enzymes, also coagulation reactions. Zymogen activation occurs by limited proteolysis on a negatively charged membrane surface in the presence of calcium ions. Such a 
membrane surface is provided by the activated platelets. Other coagulation factors, such as factor $V$ and factor VIII function as non-enzymatic cofactors, increasing the catalytic efficiency of the enzyme to which they bind (factor $\mathrm{Xa}$ and Factor IXa respectively). These cofactors show considerable similarities in both structure and function [18].

Historically the coagulation cascade has been divided into two parts, the intrinsic pathway and the extrinsic pathway, based on the way coagulation is initiated in clotting assays performed in clinical laboratories. The extrinsic pathway is initiated following exposure of the membrane protein tissue factor to the blood after damage of the vessel wall, while the intrinsic pathway is triggered when blood comes into contact with (artificial) negatively charged surfaces such as glass. Nowadays it is generally accepted that in vivo initiation of coagulation is achieved by the extrinsic pathway, while the intrinsic pathway is recruited at a later stage and ensures the amplification (propagation) of the coagulation reactions via several feedback loops $[19,20]$.

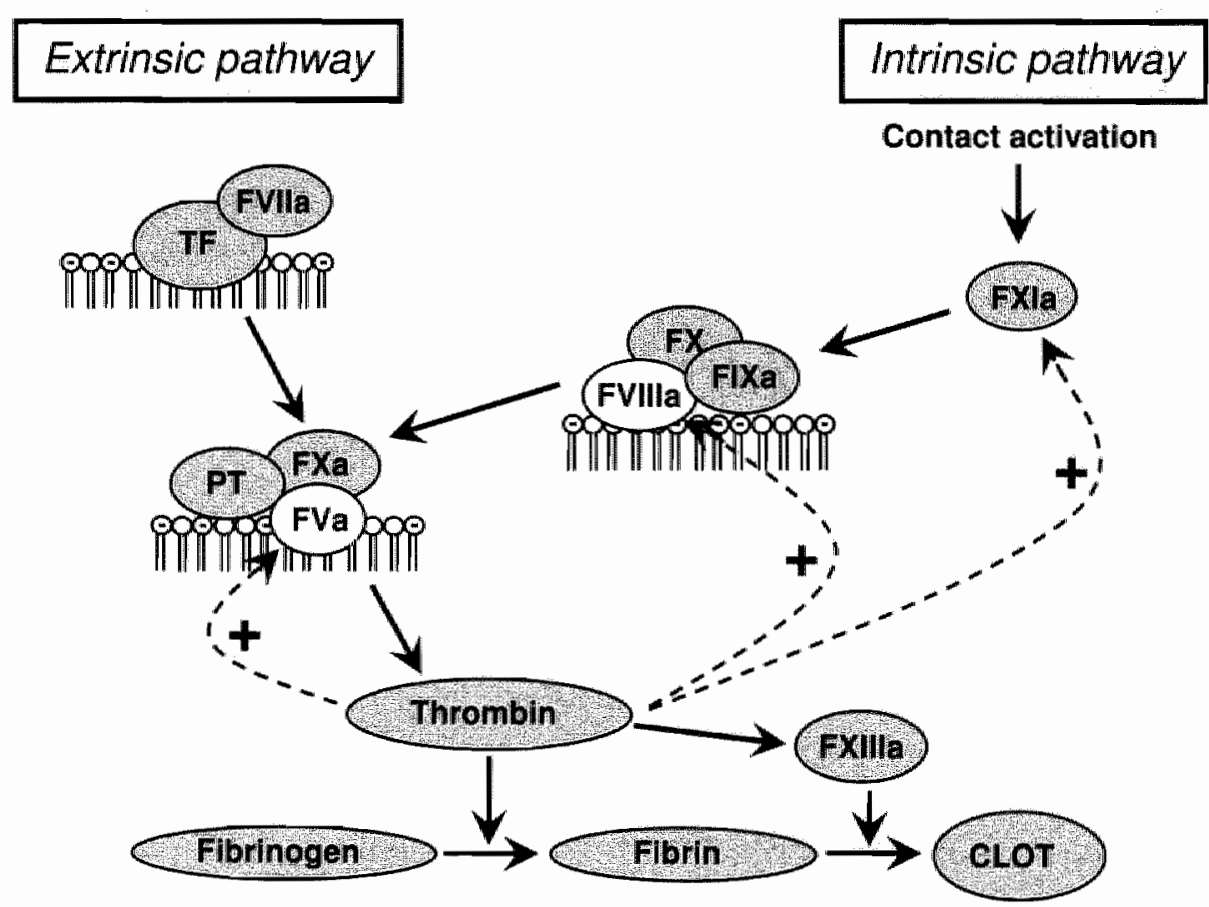

Fiqure 1: Schematic representation of the coagulation cascade 


\section{Extrinsic pathway}

The extrinsic pathway plays the major role in the initiation of blood coagulation after vascular injury. Tissue factor (TF) is an integral membrane glycoprotein present in sub-endothelial tissues that functions as a receptor for factor VII (FVII) and FVIla once the vessel wall has been damaged $[21,22]$. TF binds to FVII to form a one-to-one complex, thereby facilitating the activation of FVII to FVIla by plasma serine proteases. FVIla only has physiological activity when complexed to TF [23]. The TF-FVIla complex will activate factor $X(F X)$ to factor Xa (FXa), by cleavage of a single peptide bond in the heavy chain of FX. The TF-FVIla complex is also capable of activating factor IX by limited proteolysis [24]. This reaction is particularly of importance when only a small amount of TF-FVIla complex is generated after vascular injury. Under these conditions, the intrinsic pathway is recruited via factor IXa (FIXa). Next, FXa cleaves the pro-cofactor factor $V(F V)$ by limited proteolysis, yielding the active cofactor factor $\mathrm{Va}$ (FVa) $[25,26]$. FXa forms a complex with $\mathrm{FVa}$ in the presence of calcium ions and a negatively charged phospholipid membrane. This complex, called the prothrombinase complex, is able to very effectively convert prothrombin into thrombin $[27,28]$. Thrombin is a key player in coagulation; it converts fibrinogen into fibrin, but it also activates platelets and is responsible for several important feedback reactions. For instance, thrombin is the predominant activator of the pro-cofactors factor $V$ [29] and factor VIII, it activates factor $X I$ [30] thereby recruiting the intrinsic pathway and it also activates factor XIII. Factor XIIIa is a transglutaminase which covalently crosslinks the monomeric and polymeric fibrin strands into a tough insoluble
fibrin network that stabilizes the primary platelet plug [31].

\section{Intrinsic pathway}

The extrinsic coagulation pathway is effectively inhibited by a plasma protease inhibitor called tissue factor pathway inhibitor (TFPI) [32]. This is a factor Xa-dependent inhibitor of the TF-FVIla complex and blocks additional thrombin formation via the extrinsic pathway. However, the small amount of thrombin generated by the extrinsic pathway can activate factor $X I$, thereby
recruiting part of the intrinsic pathway.

Activated factor XI (FXla) activates factor IX (FIX) to factor IXa (FIXa) that forms a complex with factor VIlla (FVIIla) in the presence of calcium ions and a negatively charged phospholipid membrane. The FVIlla is derived from the feedback activation of factor VIII by thrombin generated by the extrinsic pathway. This complex, the tenase complex, will subsequently activate factor $X$ 
to factor Xa. In this way, the intrinsic pathway takes over FXa generation after the extrinsic pathway has been shut down by TFPI.

To be complete, the intrinsic pathway includes a number of reactions that will also lead to the activation of FXI. When blood comes into contact with an artificial negatively charged surface such as glass or kaolin, kallikrein will activate factor XII (FXII). Activated FXII (FXIla), together with kallikrein and the cofactor high molecular weight kininogen (HMWK), will then activate factor $X I$ (FXI) to factor Xla (FXla). The physiological importance of these first reaction steps is not completely understood and it is currently thought that ${ }_{j}$ under physiological conditions, FXI is predominantly activated via a feedback loop by thrombin, formed via the extrinsic pathway.

\section{Regulation of coagulation}

The formation of a stable plug by platelet aggregation and fibrin polymerization following vascular injury is a very rapid and important process that prevents extensive blood loss. However, since it is not dlesirable that the blood vessel becomes completely occluded, totally blocking further blood flow to the organs and tissues lying downstream of the occlusion, nature has provided us with severai ways to effectively regulate blood coagulation.

\section{Coagulation inhibitors}

Plasma contains a number of proteins that are able to inhibit certain serine proteases involved in blood coagulation. Some of these inhibitors, the socalled serpins, are substrate analogues that rapidly form equimolar complexes with the target protease. The formation of the inhibitor-protease complex is irreversible as a covalent bond is formed between both proteins. This inactive complex is efficiently removed from the circulation.

Antithrombin (AT) is the primary inhibitor of thrombin and therefore controls the amount of fibrin formed and the numerous feedback loops involving thrombin. The rate of thrombin inhibition by AT is rather slow, but is increased several orders of magnitude by heparin, a commonly used drug for anticoagulant treatment but which is also present in small amounts in free circulation [33], or by binding of AT to heparinoids on the vascular endothelium [34]. In addition, AT is a very potent inhibitor of FXa and FIXa, a reaction that is also stimulated by heparin.

Heparin cofactor II is similar to AT in its ability to inhibit thrombin in a heparin-dependent manner. However, whereas AT is only potentiated by certain 
subspecies of heparin, $\mathrm{HCll}$ is stimulated by a large variety of polyanions [35]. $\mathrm{HCll}$ also shows a higher selectivity towards thrombin as compared to AT.

$\alpha 2$-macroglobulin ( $\alpha 2 \mathrm{M}$ ) is another thrombin inhibitor, but since it is not a serpin $\alpha 2 \mathrm{M}$ has a different mechanism of action. When thrombin cleaves $\alpha 2 \mathrm{M}$ via limited proteolysis in the bait region of the molecule, $\alpha 2 \mathrm{M}$ undergoes a large-scale conformational change, entrapping thrombin inside the molecule $[36,37]$. However, the active site of thrombin is not occupied by the inhibitor, which explains why the $\alpha 2 M$-thrombin complex retains the ability to cleave small substrates (like chromogenic substrates), but shows no proteolytic activity towards larger macromolecules (e.g. fibrinogen).

Tissue factor pathway inhibitor (TFPI) is aiso not a member of the serpin family, but belongs to the family of Kunitz-type inhibitors. As mentioned earlier, TFPI inhibits the TF-FVlla complex. However, TFPI requires the presence of catalytically active FXa in order to exert its inhibitory function. So, in fact, TFPI inhibits the extrinsic pathway by a dual mechanism: it binds and inhibits FXa directly and the TFPI-FXa complex is an effective inhibitor of the TF-FVIla complex, blocking additional FXa formation by the extrinsic pathway $[32,38]$.

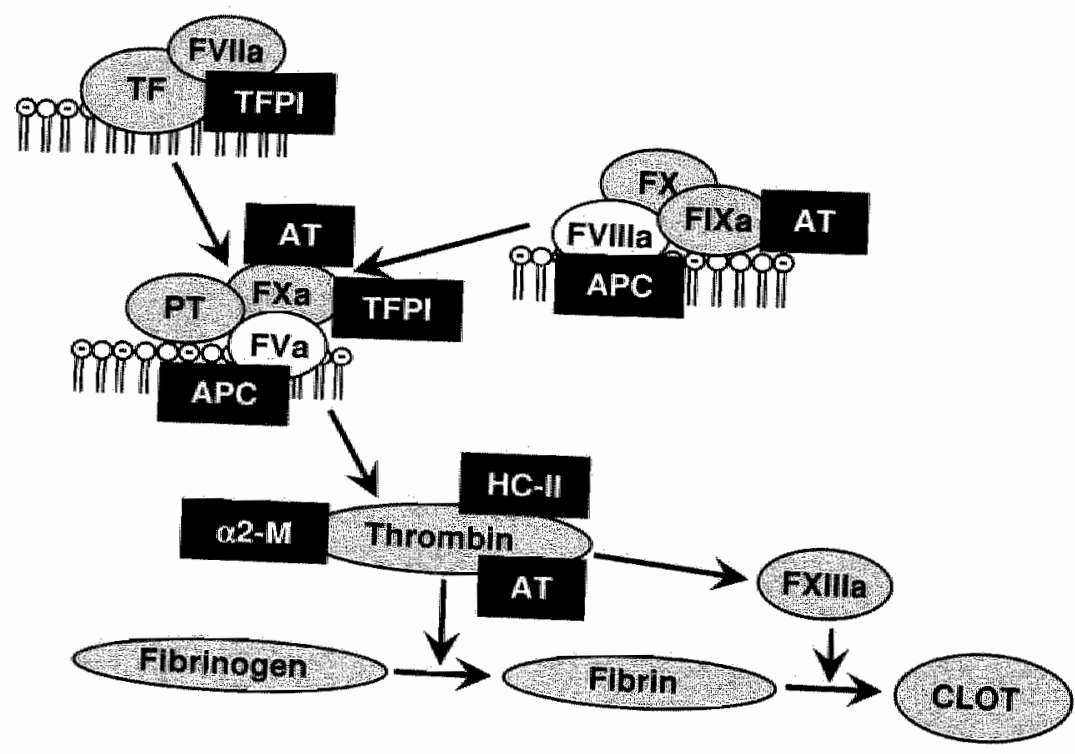

\section{Fiqure 2: The most important coagulation inhibitors in plasma.}

system. This schematic overviow is achieved by specific inhibitors and the protein $C$ and indicates where each inhibitor exhibis the most important inhibitors as black squares 


\section{The protein C pathway}

Besides the protease inhibitors, there is another very efficient and important negative regulator of the coagulation cascade, the protein $C$ pathway. In contrast to most coagulation inhibitors that directly inhibit a specific serine protease, the protein $\mathrm{C}$ pathway regulates the amount of thrombin formed by proteolytic inactivation of the cofactors of the tenase complex and the prothrombinase complex, FVIIla and $\mathrm{FVa}$ respectively $[39,40]$. These inactivation reactions are accomplished by activated protein $C$ (APC) and are stimulated by protein $S$, a non-enzymatic protein that functions as a cofactor of APC [41,42]. The inactivated forms of FVa and FVIIla (FVi and FVIlli respectively) have no cofactor activity anymore and are subsequently rapidly cleared from the circulation. The protein $\mathrm{C}$ pathway will be discussed in more detail below. The physiological importance of the protein $\mathrm{C}$ pathway is illustrated by the observation that deficiencies of protein $\mathrm{C}$ or protein $\mathrm{S}$ result in an increased risk for venous thrombosis $[43,44]$.
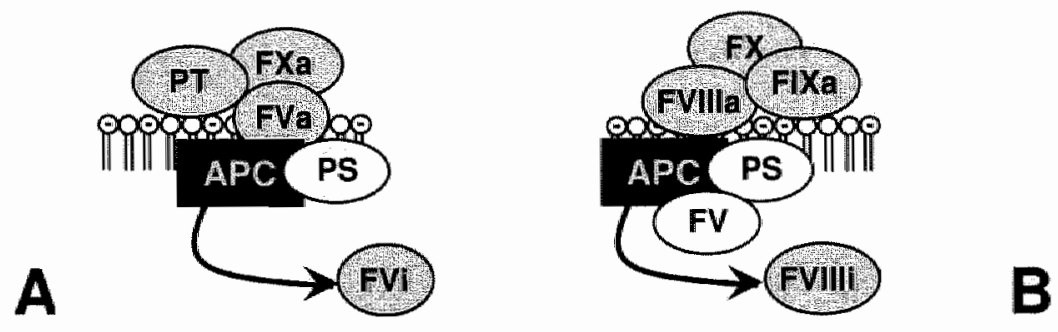

\section{Fiqure 3: The protein $C$ pathway.}

A) Inactivation of activated factor $V$, the cofactor of the prothrombinase complex, by APC and its cofactor protein S. B) inactivation of activated factor VIII, the cofactor of the tenase complex, by $A P C$ and its cofactors protein $S$ and factor $V$.

\section{The fibrinolytic system}

The ultimate goal of the coagulation system is to convert fibrinogen into fibrin, thereby stabilizing the primary platelet thrombus. However, once the bleeding has stopped and the vascular injury has been repaired, the thrombus should be dissolved. This process, known as fibrinolysis, is accomplished by the fibrinolytic system. This requires binding of the circulating zymogen plasminogen to the clot, conversion of plasminogen to the active protease plasmin by tissue-type plasminogen activator ( $t$-PA) released by the endothelial cells, proteolysis of the clot, and finally inactivation of plasmin by $\alpha 2$-antiplasmin 
[45] Of course fibrinolysis also has to be strictly regulated, which is achieved with feedback loops and specific inhibitors.

Initially, a weak ternary complex with minimal catalytic activity is formed between $t-P A$, fibrin and plasminogen. Both $t-P A$ and plasminogen bind to fibrin via interaction with the carboxyl-terminal lysine residues of fibrin. The plasmin that is formed at the fibrin surface will then cleave fibrin, thereby exposing new binding sites, enabling more t-PA and plasminogen to bind to the fibrin surface. This positive feedback mechanism ensures that active plasmin is initially generated at a slow pace, increases as more fibrin is cleaved and limits the process to the surface of the clot [46].

In order to prevent early clot lysis, fibrinolysis is inhibited by a variety of specific inhibitors. $\alpha 2$-antiplasmin ( $\alpha 2$-AP) reacts with and inactivates plasmin very rapidly, but it also interferes with plasminogen binding to fibrin [47, 48]. Therefore, it is considered to be the primary negative regulator of the fibrinolysis. Other inhibitors include thrombin activatable fibrinolysis inhibitor (TAFI), which prevents plasmin from binding to fibrin and plasminogen activator inhibitor (PAI), which controls the action of t-PA and therefore the amount of plasmin formed.

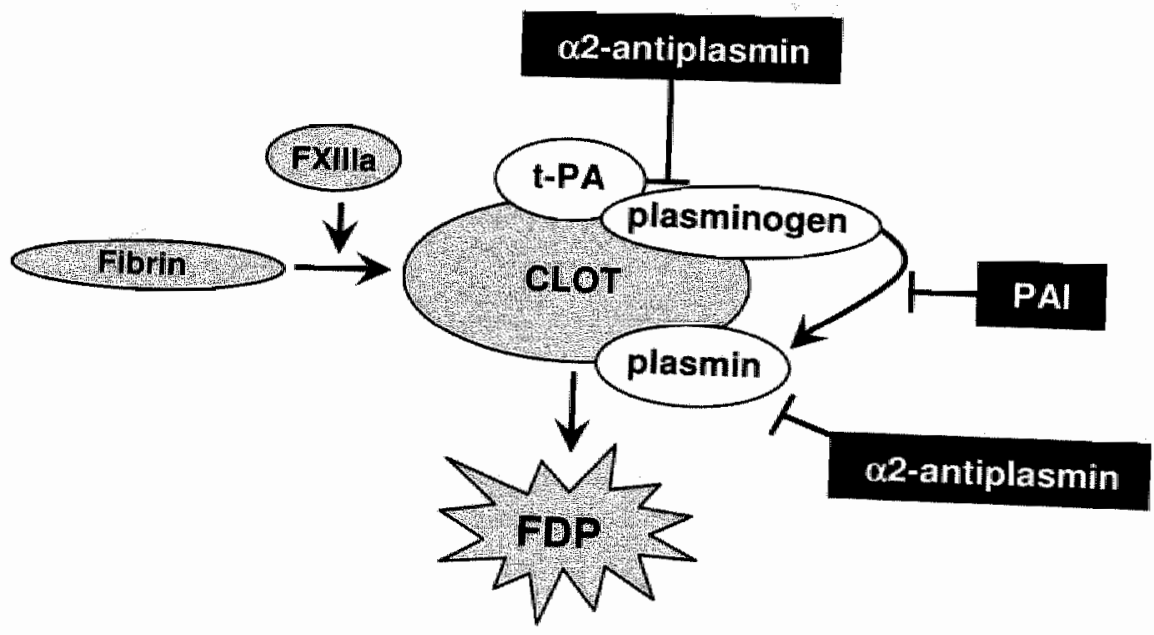

Fiqure 4: Schematic overview of the fibinolytic system.

Fibrinolysis is important to dissolve the thrombus after the tissue damage has been specific inhibitors (black squares). FDP, Fibrin 


\subsection{Components of the protein $\mathrm{C}$ pathway}

\section{Proteîn C}

Protein $C(P C)$ is the key player in the protein $C$ pathway. It is a vitamin$\mathrm{K}$-dependent protein, synthesized by the liver as a $62 \mathrm{kDa}$ glycoprotein and circulates in plasma as an inactive zymogen at a concentration of approximately $65 \mathrm{nM}[49]$.

Protein $\mathrm{C}$ is converted into activated protein $\mathrm{C}$ (APC) by thrombin bound to thrombomodulin (TM), an integral membrane protein constitutively expressed by endothelial cells $[50,51]$. When thrombin binds to $\mathrm{TM}_{3}$ its substrate specificity changes and thrombin loses its procoagulant activity $[52,53]$. The activation of PC by thrombin is further stimulated by the endothelial protein $C$ receptor (EPCR), bringing $P C$ and thrombin in close proximity [54]. Since thrombin has a high affinity for $T M$, and TM is abundantly expressed in the microcirculation, low levels of thrombin will mainly have an antithrombotic function. However, when the procoagulant stimulus is large enough, high levels of thrombin are generated and the procoagulant activity of thrombin will prevail.

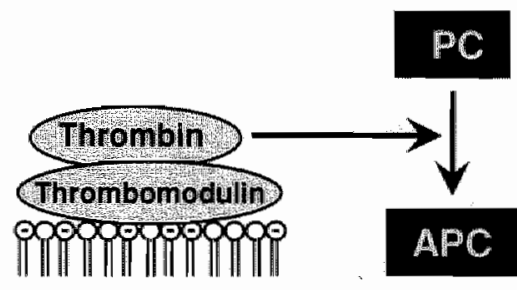

Fiqure 4: Protein $\mathrm{C}$ is activated by the thrombin-thrombomodulin complex

Activated protein C (APC) is a serine protease that expresses its anticoagulant activity by proteolysis of the cofactors of the tenase complex and the prothrombinase complex, FVIIla and FVa respectively. Furthermore, APC can also proteolytically inactivate the native form of both cofactors, FVIII and FV. These reactions are dependent on the presence of phospholipids. As FV and FVIII show strong homology [18], especially concerning the APC-cleavage sites, both inactivation reactions are quite similar, and will be discussed later in more detail. Briefly, both activated cofactors are inactivated by two cleavages in the heavy chain (at Arg306 and Arg506 in FVa, and at Arg336 and Arg562 in FVIlla), resulting in the dissociation of the $A 2$ domain in both cases $[39,40]$. Since the A2-domain of FVIIla contains most of the interaction sites for FIXa and the A2-domain of FVa contains the only PT-binding site and a few 
interaction sites for $\mathrm{FXa}_{\text {, }}$ it is understandable that dissociation of the $\mathrm{A2}$ domains in both molecules results in a complete loss of cofactor activity.

The inactivations of both FVIIla and FVa by APC are stimulated by protein $S$, a non-enzymatic cofactor of APC in the protein C pathway $[41,42,55]$. In addition, FV serves as a cofactor for APC in the inactivating of FVIIla [56-58].

\section{Protein S}

Protein S (PS) is another vitamin K-dependent protein that plays an important role in the protein $C$ pathway. It is mainly synthesized by the liver, but is also expressed in the lungs and by endothelial cells [59-61]. PS circulates in plasma as a $75 \mathrm{kDa}$ glycoprotein at a total concentration of $350 \mathrm{nM}$. Approximately $60 \%$ of all PS is complexed in a $1: 1$ ratio with $\mathrm{C} 4 \mathrm{~b}$ binding protein (C4bBP), a protein from the complement system, leaving only about $40 \%$ free PS in circulation [62].

Protein $S$ itself has no catalytic domain and functions as a cofactor for APC in the inactivation of FVa and FVIIla $[41,42,55]$. PS exhibits this cofactor function by enhancing the binding of APC to phospholipids [63]. It was shown that PS also causes a relocation of the active site of APC [64]. This may explain the PS specific stimulation of one of the APC-cleavage sites in FVa, located closer to the membrane. How PS stimulates the inactivation of FVIIla by APC is not known yet, but as FV and FVIII show strong homology, this may occur via similar mechanisms.

It has been shown that PS can be cleaved by thrombin and factor $\mathrm{Xa}$ in a specific region, called the thrombin sensitive region [65-67]. About 10-20\% of all PS in plasma is present in the cleaved form. This cleaved PS is no longer a cofactor for APC [68]. In addition, it has been shown that only free PS and not $P S$ in complex with C4bBP functions as a cofactor for APC $[69,70]$.

Under certain circumstances cofactor for APC $[69,70]$ independent anticoagulant activity [71] protein $S$ also exhibits an APCthat PS binds to FVa and FXa, leading It was shown by Heeb and coworkers by the prothrombinase complex and direct inhibition of thrombin formation prothrombin for binding sites on FVa [72-74]. PS competes with FXa and also inhibit the intrinsic activation $[75,76]$. For PS to express its APC-ind $X$ via a specific interaction with FVIII essential that PS can bind to a phospholipidendent anticoagulant activity it is the inhibition of the prothrombinase and the surface. According to van Wijnen, consequence of the accupation of the tenase complex by PS is a direct [77]. 


\section{Coagulation Factor $\mathrm{V}$}

\section{General characteristics}

Human factor $V(F V)$ is primarily synthesized in the liver but also by megakaryocytes $[11,78,79]$. The $80-\mathrm{kb} F V$ gene is located on chromosome 1 at q21-25 and consists of 25 exons and 24 introns [80-82]. Following transcription it gives rise to a $6.8-\mathrm{kb}$ mature mRNA and after translation of the mRNA and translocation of the translation product to the endoplasmatic reticulum, a 330 $\mathrm{kDa}$ single chain glycoprotein is formed, containing 2196 amino acids. FV circulates in blood at a concentration of approximately $20 \mathrm{nM}(\sim 8 \mu \mathrm{g} / \mathrm{ml})$. About $20-25 \%$ of total human FV is found in the $\alpha$-granules of platelets [11].

Full length FV has a typical domain structure that is identical to that of FVIII $[18,83]$. They both consist of three homologous A-domains, two smaller homologous C-domains and a highly glycosylated B-domain. The A-domains show homology with those of ceruloplasmin [84], the C-domains are homologous to the phospholipid binding domains present in discoidins and milk fat globule proteins. FV and FVIII share $\sim 40 \%$ amino acid homology in their A and $C$ domains $[18,81]$. However, the B-domains of FV and FVIII show little homology to each other and are also poorly conserved among species $[81,85]$. Whereas the $\mathrm{A}$ and $\mathrm{C}$-domains of $\mathrm{FV}$ extend over several exons, the $\mathrm{B}$-domain of $F V$ is encoded by a single unusually large exon, exon 13 [82].

Factor $V$ contains 19 cysteine residues, 14 of which are involved in disulfide bridges forming several loops, while the other 5 are present as free $\mathrm{SH}$-groups $[86,87]$. Before being secreted, the FV molecule undergoes several posttranslational modifications, including sulfation, phosphorylation and glycosylation [88-90]. One of the consequences of these posttransiational modifications is that there is heterogeneity in the plasma FV molecules [91-93]. This heterogeneity is due to partial glycosylation of the asparagine residue at position 2181 in the $\mathrm{C} 2$-domain of factor $V$, resulting in two structurally and functionally different $F V$ isoforms, FV1 and FV2 $[94,95]$.

\section{Activation of factor $V$}

Factor $V$ circulates in plasma as a single chain protein which by itself has little or no cofactor function in the generation of thrombin by FXa. Therefore FV has to be activated to express full procoagulant activity [96]. This activation is achieved by limited proteolysis by several proteases, the most important ones in vivo being thrombin $[29,92,97,98]$ and $\mathrm{FXa}[25,99]$. A FV activator important 
because of its use in research and in clinical laboratories is RVV-V [29,98], a serine protease present in the venom from Russell's viper.
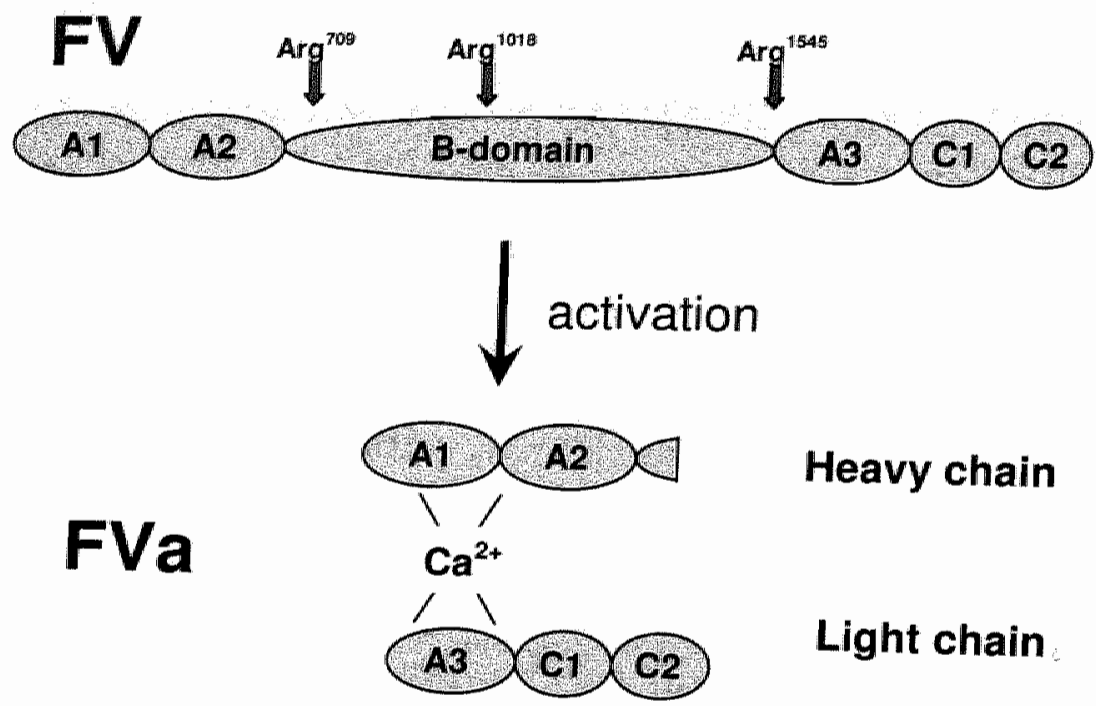

\section{Fiqure 5: Activation of factor $V$ by thrombin}

Full length FV is activated by thrombin through cleavage of 3 peptide bonds at $\mathrm{Arg}^{709}$, $\mathrm{Arg}^{1018}$ and $\mathrm{Arg}^{1545}$. This results in the release of the B-domain and the formation of a heterodimer, consisting of a heavy chain (domains A1, A2 and a small part of the $B$ domain) and a light chain (domains $A 3, C 1$ and $C 2$ ), non-covalently bound by a calcium
ion.

$\operatorname{Arg}^{1018}$ and $\operatorname{Arg}^{1545}$ activates $\mathrm{FV}$ by sequential cleavage at positions $\operatorname{Arg}^{709}$ $\mathrm{Arg}^{1018}$ are kinetically the B-domain. The cleavages at positions $\mathrm{Arg}^{709}$ and first two cleavages only cleavage is essential for full factorially active cofactor ( $30 \%)$, while the $\operatorname{Arg}^{1545}$ cleavages do however factility $[100,101]$. The first two the B-domain is released and final cleavage at $\operatorname{Arg}^{1545}$ [102]. As a result, consisting of a heavy chain (residues heterodimeric FVa molecule is formed, (residues 1546-2196, Mr=74,0sidues 1-709, Mr=105,000) and a light chain by a single calcium ion $[103,104]$. 71,000$)[29,92,97,98]$, non-covalently linked indicated initial cleavage at $\mathrm{Arg}^{1018}$ followed borts about activation of FV by FXa Later however, Thorelli and collowed by a second cleavage at $\mathrm{Arg}^{709}$ [25]. $\mathrm{Arg}^{1545}$ and that there is an additioners showed that FXa also cleaves FV at A single cleavage at $\mathrm{Arg}^{1545}$ by the a $\mathrm{FXa-specific} \mathrm{cleavage} \mathrm{site} \mathrm{at} \operatorname{Arg}^{1765}$ [26]. sufficient to elicit complete FVa cofactor actor present in Russell's viper venom is 
thrombin is, in contrast to activation by FXa, independent of a negatively charged phospholipid surface [25].

\section{The procoagulant activity of factor Va: the prothrombinase complex}

Activated FV functions as a non-enzymatic cofactor of FXa in the conversion of prothrombin to thrombin $[96,105,106]$. This reaction takes place in a macromolecular enzyme complex, called the prothrombinase complex, which consists of the enzyme FXa and its cofactor FVa assembled on a negatively charged phospholipid surface provided in vivo by the activated platelets in the presence of $\mathrm{Ca}^{2+}$-ions. These $\mathrm{Ca}^{2+}$-ions are essential for the binding of the vitamin K-dependent proteins to the membrane.

The assembly of the prothrombinase complex is mostly driven by the non-enzymatic components, FVa and phospholipids. Activation of prothrombin by FXa in free solution, in the absence of phospholipids and FVa, is a very slow process. Addition of a negatively charged phospholipids surface alone increases the (apparent) affinity of the enzyme for its substrate several orders of magnitude $[105,107,108]$, resulting in a decrease of the $\mathrm{Km}$. Addition of the cofactor FVa alone causes a dramatic increase of the turnover number (kcat) of the enzyme, FXa $[105,106,109,110]$.

\begin{tabular}{l|l|c|c}
$\begin{array}{c}\text { Activating } \\
\text { component }\end{array}$ & $\begin{array}{c}\mathbf{K m} \\
(\mu \mathrm{M})\end{array}$ & $\begin{array}{c}\text { Vmax } \\
\left(\mathbf{m o l}^{-1} \mathbf{s}^{-1}\right)\end{array}$ & $\begin{array}{c}\text { Catalytic efficiency } \\
\mathbf{k c a t} / \mathbf{K m}\left(\mathbf{M}^{-1} \mathbf{s}^{-1}\right)\end{array}$ \\
\hline FXa & 84 & 0.011 & 131 \\
FXa, PL & 0.06 & 0.038 & $6.3 * 10^{5}$ \\
FXa, FVa & 34 & 6.22 & $1.8 * 10^{5}$ \\
FXa, FVa, PL & 0.21 & 32 & $1.5 * 10^{8}$
\end{tabular}

The addition of both phospholipids and FVa combines the stimulatory effect of both components by simultaneously lowering the $\mathrm{Km}$ for prothrombin and increasing the maximum turnover number of the enzyme complex. This results in an overall increase of the catalytic efficiency by at least five orders of magnitude.

\section{Inactivation of factor $V$ and factor Va}

Activated $F V$ is effectively inactivated via limited proteolysis by the protein $\mathrm{C}$ system (see above). Activated protein C (APC) cleaves FVa in the 
heavy chain at $\mathrm{Arg}^{308}, \mathrm{Arg}^{506}$ and $\mathrm{Arg}^{679}[39,111]$, leading to the dissociation of the A2-domain [112] and subsequent complete loss of procoagulant activity [113-116]. This reaction is strongly dependent on the presence of negatively charged phospholipids and calcium ions [117]. The inactivation of $\mathrm{FVa}$ is a biphasic process, consisting of a rapid phase, in which approximately 50 to $60 \%$ of the cofactor activity is lost, followed by a slow phase resulting in complete loss of cofactor activity. The rapid phase corresponds with the cleavage at $\operatorname{Arg}^{506}$, while the slow phase is consistent with the $\operatorname{Arg}^{306}$ cleavage $[114,116]$. The cleavage at these two sites is random, although kinetic data show a 20 -fold difference in rate constants, favoring the $\mathrm{Arg}^{506}$ cleavage in the presence of phospholipids [114]. The cleavage at $\mathrm{Arg}^{679}$ only occurs upon prolonged incubation of FVa with APC and only contributes to the loss of cofactor activity in the absence of phospholipids. Intact FV is cleaved by APC at the same positions as FVa, and has an additional cleavage site at position Lys ${ }^{994}$ in the Bdomain [39].

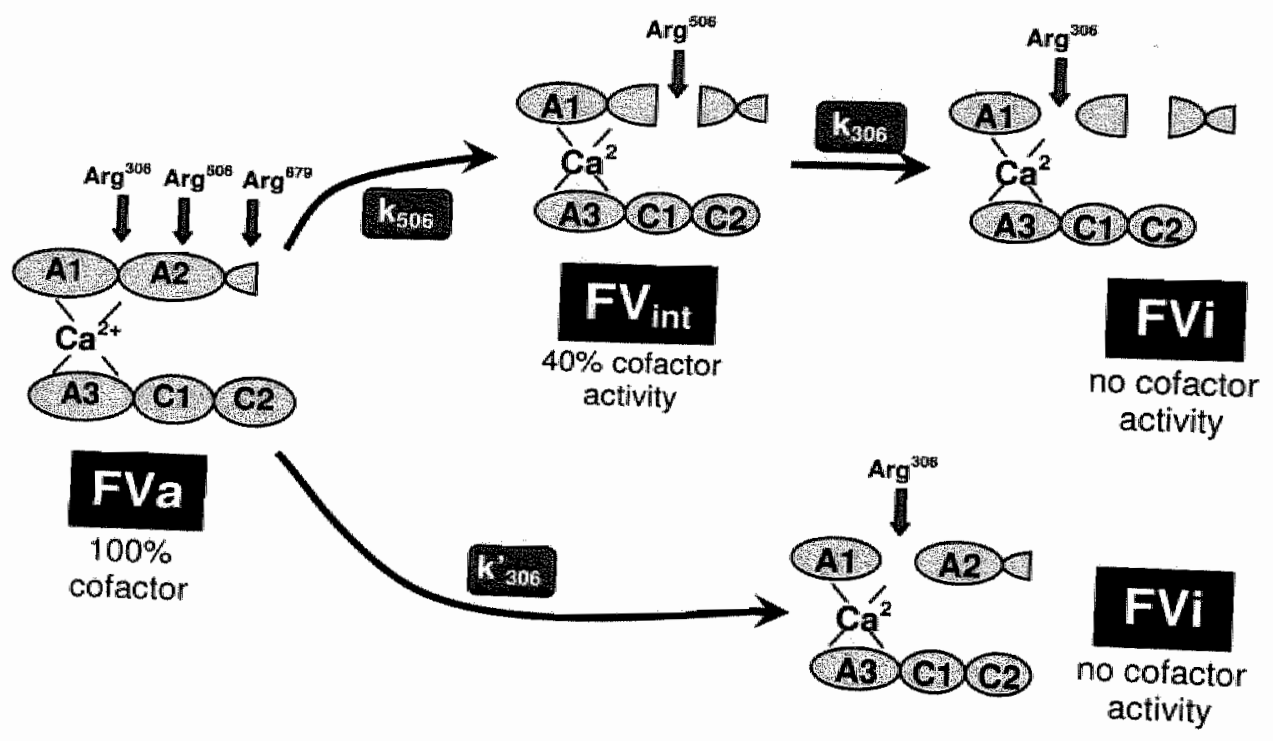

\section{Fiqure 6: Inactivation of activated factor $V$ by $A P C$}

FVa is inactivated by $\mathrm{APC}$ by cleavage of $\mathrm{Arg}^{306}, \mathrm{Arg}^{506}$ and $\mathrm{Arg}^{679}$. After initial cleavage subsequent cleavage at $\mathrm{Arg}^{306}$. FV that still has procoagulant activity and only after immediately results in the complete loses all cofactor activity. Cleavage at Arg $^{306}$ relevant under physiological conditions. 
The inactivation of FVa by APC is greatly stimulated by protein $S$ and inhibited by FXa $[41,117-119]$. For a long time proteins $S$ was thought to increase the rate of $\mathrm{Arg}^{306}$ cleavage about 20-fold, while no effect on the cleavage at $\operatorname{Arg}^{506}$ was observed [119]. However, Norstrom and coworkers have recently shown that protein $S$ does stimulate both cleavages at $\mathrm{Arg}^{506}$ and $\mathrm{Arg}^{306}$ in a phospholipid-dependent manner (5-fold and 27-fold respectively) [120]. Differences in experimental conditions may account for part of this discrepancy: Within the prothrombinase complex $\mathrm{FXa}$ has been shown to selectively inhibit the APC-catalysed cleavage at $\mathrm{Arg}^{506}$, while protein $\mathrm{S}$ was able to counteract this effect $[118,121]$, indicating the possibility that $\mathrm{FXa}$ and protein $S$ have overlapping binding sites on FVa [121].

\section{The anti-coagulant function of factor $V$}

The idea that FV possesses anticoagulant activity by acting as a cofactor of APC in the inactivation of FVIIla was first put forward by Dahlbäck and Hildebrand in 1994 [58]. They observed that the addition of normal plasma to APC-resistant plasma, was able to normalize the clotting time in a dosedependent manner. They concluded that the APC-resistant plasma was missing an important, so far unknown cofactor of APC that was present in normal plasma. They were able to purify this cofactor and found that it was indistinguishable from FV. Further investigations evaluating the ability of factor $V$ to stimulate the inactivation of FVIII and FVIIla revealed that FV and protein $S$ act as synergistic cofactors to APC while FVa does not $[56,57]$.

The reason why FV loses its anti-coagulant activity after activation by thrombin was investigated using site-directed mutagenesis of the thrombin cleavage-sites in FV. These studies showed that thrombin-mediated cleavage at Arg709 and/or Arg1018 yielded FV molecules that were still able to function as APC cofactors, whereas cleavage at Arg1545 led to complete loss of the APC-cofactor function [122]. Moreover, B-domain deleted FV has no APCcofactor activity. This and additional experiments led to the conclusion that the anti-coagulant activity of FV probably resides in the C-terminal region of the $\mathrm{B}$ domain of $F V$, residues $1477-1545$ being essential.

It has been proposed that FV has to be cleaved by APC at $\mathrm{Arg}^{506}$ to express its anticoagulant function [123]. This hypothesis was confirmed by the observation that $\mathrm{FV}^{\mathrm{A} 506 \mathrm{Q}}$, a naturally occurring mutation in one of the APC cleavage sites, had a 10 -fold reduced cofactor activity in the APC dependent FVIlla inactivation as compared to normal FV [56]. Thorelli and coworkers showed, using recombinant FV molecules mutated at different APC cleavage sites, that all mutants in which the APC cleavage site at position $\mathrm{Arg}^{506}$ had 
been removed, expressed very poor anti-coagulant cofactor activity, whereas the other APC-cleavage site mutants expressed APC cofactor activity comparable to that of normal FV. Therefore they concluded that cleavage at $\mathrm{Arg}^{506}$ by $\mathrm{APC}$ is essential for the expression of full anti-coagulant activity of $\mathrm{FV}$, whereas Arg to Gin substitutions in the other APC cleavage sites (Arg ${ }^{306}$ and $\mathrm{Arg}^{679}$ ) did not affect the APC-cofactor function [124].

\section{Platelet factor $V$}

About $20 \%$ of the total FV pool resides in platelets $[11,125]$. The origin of this platelet FV has been a matter of debate for a long time, as megakaryocytes have been shown to express $F V$ in vitro $[79,126]$ and $F V$ MRNA has been found in both megakaryocytes and platelets [127]. However, it is now believed that the majority of the platelet FV is derived from endocytosis of plasma FV by bone-morrow megakaryocytes [128-131].

Platelet FV is stored in the $\alpha$-granules of the platelets $[132,133]$. It is non-covalently associated with a $155-\mathrm{kD}$ membrane-associated glycoprotein, multimerin [134]. Upon activation of the platelets, FV dissociates from multimerin and is secreted from the $\alpha$-granules and become exposed on the platelet surface where it takes part in the coagulation cascade as a cofactor of $\mathrm{FXa}$ in the prothrombinase complex. It is thought that platelet FV plays a crucial role in the initiation of thrombin formation at the site of injury. A platelet FV deficiency, known as FV Quebec [135], is associated with a severe bleeding disorder due to the absence of functional platelet FV (even in the presence of normal plasma antigen levels). The absence of platelet FV activity is associated with a quantitative deficiency of multimerin [136].

Although platelet FV derives from plasma by endocytosis, there are differences between both FV pools. It has been shown that platelet $\mathrm{FV}$ is composed of fragments with apparent $\mathrm{Mr}$ ranging between $115 \mathrm{kD}$ and $330 \mathrm{kD}$, which are different from the intermediates and end products obtained during activation of plasma FV by thrombin [137]. These partially proteolysed molecules already possess significant cofactor activity that can only be increased 2 to 3 -fold by treatment with factor $X a$ or thrombin $[138,139]$. However, the end products of thrombin activated platelet FV and plasma FV activated protein $\mathrm{C}$ is unable to completely inactivate platelet-derived $\mathrm{FVa}$, as it 


\section{Coagulation Factor VIII}

Activated factor $\mathrm{V}$ III is an important cofactor for $\mathrm{F} \| \mathrm{Xa}$ in the activation of FX by the tenase complex [142]. The FX-generating capacity of this tenase complex is tightly regulated for instance by the protein $\mathrm{C}$ pathway, as FVIlla is inactivated by APC and its cofactors, protein $S$ and FV. Therefore factor FVIII will be briefly discussed in this chapter.

Factor VIII (FVIII) is primarily synthesized by the liver, but also by a variety of other organs, such as kidney and spleen [143]. Although it is synthesized as a large single chain protein with the same domain structure as FV (A1-A2-B-A3-C1-C2) [144], FVIII circulates in plasma as a variety of heterodimers, non-covalently bound by a metal ion [145]. This heterogeneity is due to proteolysis in the B-A3-junction and additional cleavages at several sites in the B-domain, resulting in a heavy chain with a B-domain with variable size. The plasma concentration of FVIII is about 20 times lower then that FV, approximately $1 \mathrm{nM}$. In contrast to FV, FVIII circulates in plasma in a tight, noncovalent complex with von Willebrand Factor (WWF) [146], a large multimeric protein functioning as a carrier protein. Binding of VWF to FVIII stabilizes the FVIII molecule and prevents premature association of FVIII with thrombogenic surfaces and also binding of FVIII to FIXa.

Factor VIII can be proteolytically activated by thrombin and FXa, although thrombin is physiologically the most important activator (see review) [147]. Thrombin cleaves FVIII at three sites in both heavy and light chain: Arg372, Arg740 and Arg1689. The heavy chain is initially cleaved at the A2-B Junction (Arg740) resulting in the release of the B-domain, followed by the cleavage at the A1-A2 junction (Arg372) separating both domains in the heavy chain. This latter cleavage is required to achieve FVIlla activity. The main purpose of the Arg1689 cleavage is to dissociate the cofactor from its carrier protein WWF. So, FVIIla is a heterotrimer consisting of $A 1, A 2$ and $A 3-C 1-C 2$ subunit [148]. The interaction between the $A 1$ and $A 3-C 1-C 2$ subunits is dependent on a metall ion, while the association of the A2 subunit with the dimer (A1/A3-C1-C2) is mediated by electrostatic interactions.

This tree FVIlla is unstable and undergoes spontaneous decay, due to the spontaneous dissociation of the A2-subunit [148]. However, when FVIlla is incorporated in the tenase complex, the rate of spontaneous decay is reduced by about 10-fold [149]. Apart from this spontaneous loss of FVIIla activity, APC also inactivates FVIIla by cleavage at Arg336 and Arg562 [40]. Initial cleavage occurs at Arg562, resulting in the abolishment of a critical FIXa binding site. This cleavage site for APC is protected by FIXa, but this protective effect is counteracted by protein S [150]. The second cleavage at Arg336 leads to the dissociation of the A2-domain. A third cleavage site has been proposed at 
Arg 740, resulting in the release of the B-domain fragments, but this cleavage does probably not contribute to inactivation. Of course this third APC cleavage site is only relevant when FVIII is proteolysed by APC, as FVIlla has already been cleaved at Arg 740 during activation by thrombin.

\subsection{APC-resistance}

\section{First observation}

The term APC-resistance was first introduced by Dahlbäck and coworkers in 1993 [151]. They described one patient with venous thrombosis, who had a poor anticoagulant response when exogenous APC was added to his/her plasma (measured as a poorly prolonged clotting time after the addition of APC). It was hypothesized that in this patient a cofactor of the APC anticoagulant pathways was missing. One year later, Dahlback and Hildebrand demonstrated that the APC-resistant phenotype in these patients could be corrected for by the addition of purified FV to the APC-resistant plasma [58]. Therefore they concluded that FV was the missing cofactor for APC.

Several studies have shown that APC-resistance is an important risk factor for thrombosis, with a prevalence of $20-30 \%$ in unselected thrombotic patients and even up to $50 \%$ in patients with a family history of thrombosis. In fact, it is the most common inherited risk factor for thrombosis identified so far $[152,153]$.

\section{The factor $V_{\text {Leiden }}$ mutation}

One year after the original publication of Dahlback et al, the molecular mechanism underlying APC-resistance was elucidated [154-158]. A single point mutation in the FV gene (a G to A transition at nucleotide 1691) leads to an amino acid substitution at position 506, where an arginine is replaced by a glutamine. This amino acid substitution results in the loss of one of the important cleavage sites for APC in FV [39]. Indeed, extensive analysis of inactivation patterns and kinetic data from the inactivations of normal $\mathrm{FVa}$ and FVa Leiden by APC revealed that an initial cleavage at position $\mathrm{Arg}^{506}$ is essential for rapid inactivation of activated $F V$ and this cleavage is not occurring in $F V a_{\text {Leiden }}[114,119,124,159,160]$. Thus, the general idea at that time was that the most important reason why the $F V_{\text {Leiden }}$ mutation caused APC-resistance 
was because it affected an important APC cleavage site, thereby rendering FVa Leiden less susceptible to the inactivation by APC. This appeared to be a satisfactory explanation, and therefore "the missing cofactor theory" from Dahlback was somewhat forgotten. However, some groups did not give up on the APC-cofactor theory of FV. Already in 1994, Shen et al. showed that in a purified system FV stimulated the inactivation of FVIIla in a dose-dependent manner when protein $S$ was present. They therefore concluded that $F V$ and protein S act as synergistic cofactors in the APC-mediated inactivation of FVIIla [57]. This was later confirmed by Varadi et al. who also demonstrated that FV Leiden was a poor cofactor [56]. Furthermore, Thorelli and coworkers demonstrated that the anticoagulant function of FV is dependent on APCmediated cleavage of intact FV at $\mathrm{Arg}^{506}$ [124]. Together this provides a good explanation for the decreased sensitivity towards APC of a plasma containing $F V_{\text {Leiden, }}$, because 1) the inactivation of $F V_{\text {Leiden }}$ by APC is impaired and 2) FV $V_{\text {Leiden }}$ does not function as a cofactor of APC in the inactivation of FVIlla.

The $\mathrm{FV}_{\text {Leiden }}$ mutation is found exclusively in the Caucasian population with a frequency of approximately $5 \%[154,161]$ and about $90-95 \%$ of all cases of APC-resistance are attributable to this mutation [162]. Several epidemiological studies have estimated that the risk for thrombosis, associated with the $F V_{\text {Leiden }}$ mutation, is increased 7 -fold in heterozygous carriers of the mutation and as much as 80 -fold in homozygous carriers as compared to normal individuals [162-165].

\section{Other mutations in factor $\mathrm{V}$ causing $\mathrm{APC}$ resistance}

Besides the $F V_{\text {Leiden }}$ mutation, which affects the $\mathrm{Arg}^{506}$ cleavage site of APC, two other mutations have been described affecting the APC cleavage site at $\mathrm{Arg}^{306}$. A mutation at nucleotide 1091, causing a $\mathrm{G}$ to $\mathrm{C}$ transition results in the substitution of $\mathrm{Arg}^{306}$ by a Thr, and was first described in a British patient suffering from thrombosis [166]. This patient and his mother, who also carried the mutation, were found to be APC-resistant. However, the Arg to Thr substitution at position 306, now known as FV Cambridge, was not found in a group of 585 patients with thrombotic complications, nor was it found in a group of 226 healthy individuals [166]. Unfortunately due to the rare occurrence of this mutation, good epidemiological studies are not available.

The second mutation at $\mathrm{Arg}^{306}$ is caused by an $A$ to $G$ transition at position 1090, resulting in an Arg to Gly substitution. This mutation, now known as FV Hong Kong, was first described in Chinese patients from Hong Kong, and 
was shown to be quite frequent among the Hong Kong Chinese population (4.5\% prevalence) [167,168]. In contrast to FV Cambridge, FV Hong Kong has not been associated with APC-resistance yet. However, Norstrom et al. showed that the recombinant FV Cambridge and FV Hong Kong molecules behaved identically in in vitro assays, both causing mild APC-resistance due to a moderately impaired APC cofactor activity [169].

Apart from the mutations affecting the APC-cleavage sites described so far, another mutation in the heavy chain of FV has been found to be associated with APC-resistance. The $T$ to $C$ transition at nucleotide 1250 results in the substitution of $11 \mathrm{e}^{359}$ by a Thr (FV Liverpool), thereby introducing a new $\mathrm{N}$-linked glycosylation consensus sequence at $\mathrm{Asn}^{357}$ [170]. Steen et al. were able to show that an additional carbohydrate at this position interferes with both APCmediated inactivation of FV Liverpool and with its APC cofactor activity [171].

\section{The factor V R2-polymorphism}

The R2-polymorphism is a common genetic variation within the FV gene, and has been associated with mild APC-resistance and possibly with an increased risk for venous thrombosis. It was first described in 1996 by Lunghi et al. as an $A$ to $G$ transition at position 4070 , causing a His to Arg substitution at position 1299 in the B-domain of FV [172]. Further analysis revealed that this substitution is tightly linked to a number of other polymorphisms throughout the FV gene, which are collectively known as the R2-haplotype [173,174]. Based on
the geographical distribution of the R2-haplotype and its prevalence in both the Caucasian and non-Caucasian population, Bernardi et al. proposed that R2haplotype originated from ancestral mutational events dating further back than the FV Leiden mutation [173]. The overall prevalence of the R2-haplotype is estimated to be approximately $10 \%$ in the European population, but can differ
greatly between populations [173,175-177].

At the phenotypic level the R2-haplotype has been associated with slightly reduced FV levels in plasma, a shift in FV1/FV2-ratio towards the more thrombogenic FV1-isoform (42/58 vs. 30/70) and mild resistance towards APC $[174,178-180]$. Although it has been shown that reduced FV levels and shifted isoform ratio do account for part of the APC-resistance abserved in carriers of the R2-haplotype, the mechanism by which this FV variant causes APCresistance has still not been completely elucidated [181]. The most likely inactivation. 
The thrombotic risk associated with the R2-haplotype is still a matter of debate. Several epidemiological studies have been performed, but as the results of these studies were contradictory, there is inconclusive evidence whether or not the R2-haplotype on its own is associated with a relevant clinical risk for venous thrombosis [182]. However, it is generally accepted that compound heterozygous carriership of the FV Leiden and the FV-R2 is indeed associated with a higher risk for venous thrombosis than heterozygous FV Leiden alone $[180,183,184]$.

\section{Prothrombin, the G20210A mutation and APC-resistance}

In 1996 Poort and coworkers identified a mutation in the $3^{\prime}$ untranslated region of the prothrombin gene that resulted in an increased prothrombin level in plasma [185]. This mutation, a $G$ to $A$ transition at position 20210, was also associated with a 3 -fold increased risk for venous thrombosis when present in the heterozygous state. The association of the G20210A variant with elevated plasma prothrombin levels was confirmed by several independent studies as well as its importance as a risk factor for venous thrombosis [186-189]. In arterial thrombotic diseases however, it seems that the prothrombin mutation does not play an important role, though it has been suggested that it could be a genetic risk factor for the development of myocardial infarction [190-193]. The overall prevalence of the prothrombin mutation in Europe was estimated to be approximately $2 \%$, although this number seemed to differ between northern and southern Europe (1.7\% versus $3.0 \%$ respectively) [194]. Apparently the prothrombin variant appeared to be very rare in individuals from African and Asian origin. The first indications that elevated plasma prothrombin levels are associated with APC-resistance came from Tripodi et al., who showed that there was an inverse relationship between the prothrombin levels in plasma and the normalized APC sensitivity ratio, measured with the aPTT-based APCresistance assay [195]. This was confirmed by Castaman and coworkers, who demonstrated that the addition of purified prothrombin to the plasmas of 90 healthy individuals resulted in a dose dependent increase in the APC-resistance of these plasmas [196]. Nowadays it is generally accepted that elevated prothrombin levels in plasma cause APC-resistance and represent a risk factor for venous thrombosis.

The exact mechanism by which increased prothrombin levels induce APC-resistance is still not completely understood. It has been proposed that the prothrombin concentration in plasma influences the anticoagulant protein $\mathrm{C}$ system via an immediate and dose-dependent inhibition of the APC-cofactor, 
protein S [197]. Later, Smirnov et al. confirmed that prothrombin levels indeed had an influence on the anticoagulant function of APC, though their data showed that this was caused by the protective role of prothrombin towards the inactivation of factor $\mathrm{Va}$ by $\mathrm{APC}$ and that this process was independent of protein $S$ [198]. They also showed that the inactivation of FVa Leiden by APC, was much less sensitive to prothrombin inhibition and postulated that the discrepancy between his findings and the observations by Mitchell might be due to the use of plasma from a FV Leiden carrier, an unknown condition at that time. Finally, Norström and coworkers used recombinant factor $V$ molecules mutated at the APC-cleavage sites unravel the mechanism of APC-resistance caused by increased prothrombin levels. From their data they concluded that prothrombin directly impaired the activity of APC and also decreased the cofactor function of protein S [199].

\section{Scope of this thesis}

APC resistance is an important risk factor for venous thrombosis. The general objective of my thesis was to get a better insight into the mechanisms leading to APC-resistance in order to elucidate how some naturally occurring mutations in coagulation factors cause APC-resistance and thereby contribute to venous thrombosis.

The FV R2-haplotype is a common genetic variation associated with a mild APG-resistance and with reduced FV levels in plasma. Yamazaki et al. showed that the aspartate to glycine substitution at position 2194 in the $\mathrm{C} 2$ domain of FV, which is part of the FV R2-haplotype, was responsible for the impaired expression of the FV R2 allele. In chapter 2 we investigated how the D2194G mutation causes a reduction in FV levels in plasma using computational methods, which were confirmed with experimental data.

Chapter 3 focuses on the APC resistance associated with impaired APC cofactor activity of FV in carriers of the FV Leiden mutation and the R2haplotype. The data presented in this chapter indicate that the APC cofactor regulation of thrombin formation and that impairment of this function in the accounts for a large fraction of the APC impairment of this function of FV FV Leiden mutation and of the R2-haplotype.

In chapter 4 we describe and

associated with FV Leiden pseudo-homozcharacterize the APC-resistance plasmas from 7 pseudo-homozygous FV Loosity. To this end, we compared 
Leiden heterozygous and FV Leiden homozygous individuals. These FV Leiden genotypes were also mimicked in a model system. We conclude that the difference in APC-resistance between a FV Leiden heterozygous individual and a pseudo-homozygous FV Leiden individual is due to the APC-cofactor activity of the normal FV that is present in the plasma of heterozygotes but which is absent in the pseudo-homozygotes.

Finally, in chapter 5 we extended our knowledge about the APCresistance associated with increased prothrombin levels in plasma. We found that the amount of protein S present in plasma is an important modulator of the degree of APC-resistance caused by elevated prothrombin levels. 


\section{References}

1. E. J. Weiss, V.T. Turitto and H. R. Baumgartner. Effect of shear rate on platelet interaction with subendothelium in citrated and native blood. I Lab C/in Med. $1978 ; 92: 750-764$.

2. M. J. Barnes, C. G. Knight and R. W. Farndale. The collagen - platelet interaction. Current Opinion in Hematology. 1998; 5:314-320.

3. S. Beumer, H. F. Helinen, M. J. IJsseldijk, E. Orlando, P. H. de Groot and J. J. Sixma. Platelet adhesion to fibronectin in flow: the importance of von Willebrand factor and glycoprotein Ib. Blood. 1995; 86:3452-3460.

4. J. E. Sadier. Contact - How platelets touch von Willebrand factor. Science. 2002, 297:1128-1129.

5. B. Savage, E. Saldivar and Z. M. Ruggeri. Initiation of platelet adhesion by arrest onto fibrinogen or translocation on von Willebrand factor. Cell. 1996;

6. B. Savage, F. Almus-Jacobs and Z. M. Ruggeri. Specific synergy of multiple substrate-receptor interactions in platelet thrombus under flow. Cell. 1998;

7. E. M. Bevers, P. Comfurius, J. L. M. Van Rijn, H. C. Hemker and R. F. A. Zwaal. Generation of thrombin-converting activity and the exposure of phosphatidylserine at the outer surface of platelets. Eur $J$ Biochem. 1982 ;
$122: 429-436$

8. E. M. Bevers, P. Comfurius and R. F. A. Zwaal. Changes in membrane phospholipid distribution during platelet activation. Biochim Biophys Acta. 1983;

9. J. W. N. Akkerman, G. Gorter and E. Kloprogge. Kinetic analysis of alphagranule secretion by platelets: A methodological report. Thromb Res. 1982;
27:59-64.

10. H. Holmsen, K. L. Kaplan and C. A. Dangelmaier. Differential requirements for platelet responses: A simultaneous study of dense granule, alpha-granule and acid hydrolase secretion, arachidonate liberation, phosphatidylinositol turnover

11. P. B. Tracy, L. $\quad$.

factor $V$ in human plasma and platelets and K. G. Mann. Radioimmunoassay of

12. C. Giachet. Platelet activation platelets. Blood. 1982;60(1):59-63. 2000; 32:15-20.

antagonists. Ann. Med G. R. Sambrano, E. J. Weiss, Y. W. Zheng, W. Huang and S. R. Coughlin. Role
of thrombin signalling in platelets in haemostasis and thrombosis. Nature. 2001;
$413.74-78$.

14.

15.

16.

B. Savage, M. Cattaneo and Z. M. Ruggeri. Mechanism of platelet aggregation.
Current Opinion in Hematology. 2001; $8: 270-276$. R. G. MacFarland. An enzy

function as a biochemical amplifing in the blood clotting mechanism, and its E. W. Davie and O. D. Ratnoff Wature. 1964; 202:498-499.

Science. 1964; 145:1310-2. 53:505-518. and functional and E. W. Davie. Blood coagulation factors $V$ and VIII: Structural

19. E E W. Whorders. Blood 1988; 71: maintenance, and reguwa and W. Kisiel. The coagulation cascade: Initiation,

20. B. Dahlback. Blood coagulation. Biochemistry. 1991; 30:10363-10370. 
21. D. S. Fair and M. J. MacDonald. Cooperative interaction between factor VII and cell surface-expressed tissue factor. J Biol Chem. 1987; 262:11692-11698.

22. R. Bach, R. Gentry and $Y$. Nemerson. Factor FVII binding to tissue factor in reconstituted phospholipid vesicles: induction of cooperativity by phosphatidylserine. Biochemistry. 1986; 25:4007-4020.

23. $Y$. Nemerson. Tissue factor: then and now. Thromb Haemostasis. 1995; $74: 180-184$.

24. V. J. Bom, V. W. van Hinsbergh, H. H. Reinaida-Poot, R. W. Mohanlal and R. $M$. Bertina. Extrinsic activation of human coagulation factors $I X$ and $X$ on the endothelial surface. Thromb Haemost. 1991; 66:283-291.

25. D. Monkovic and P. B. Tracy. Activation of human factor V by factor Xa and thrombin. Biochemistry. 1990; 29:1118-1128.

26. E. Thorelli, R. J. Kaufmann and B. Dahlback. Cleavage requirements for activation of factor V by factor Xa. Eur J Biochem. 1997; 273:12-20.

27. S. Krishnaswamy, W. R. Church, M. E. Nesheim and K. G. Mann. Activation of human prothrombin by human prothrombinase: influence of factor $\mathrm{Va}$ on the reaction mechanism. J Biol Chem. 1987; 262:3291-3299.

28. M. E. Nesheim and K. G. Mann. The kinetics and cofactor dependence of the two cleavages inwolved in prothrombin activation. I Biol Chem. 1983; 258:53865391.

29. K. Suzuki, B. Dahiback and J. Stenflo. Thrombin-catalyzed activation of human coagulation factor V. J Biol Chem. 1982; 257:6556-6564.

30. K. Naito and K. Fujikawa. Activation of human blood coagullation factor XI independent of FXII. Factor FXI is activated by thrombin and factor Xla in the presents of negatively charged surfaces. J Biol Chem. 1991; 266:7353-7558.

31. G. S. Dufner and G. A. Marbet. Factor XIII in man: a review. Hamostaseologie. 2002; 22:11-19.

32. R. J. Baugh, G. J. Broze and S. Krishnaswamy. Regulation of extrinsic pathway factor Xa formation by tissue factor pathway inhibitor. J Biol Chem. 1998; 237:4378-4386.

33. D. J. Jordan, S. Pemberton, M. Acquila, P. G. Mori, E. G. Tuddenham and D. P. O'Brien. The kinetics of hemostatic enzyme-antithrombin interactions in the presence of low molecular weight heparin. I Biol Chem. 1980; 255:1008110090.

34. J. A. Marcum and R. D. Rosenberg. Anticoagulantly active heparin-like moleculles from vascular tissue. Biochemistry. 1984; 23:1730-1737.

35. F. C. Church, R. E. Treanor, G. B. Sherrill and H. C. Whinna Carboxylate poly anions accelerate inhibition by heparin colactor II. Biochem Blophys Res Commun. 1987; 148:362-368.

36. R. J. Barret and P. M. Starkey. The interaction of $\alpha 2$ macroglobulin with proteases. Biochem J. 1973; 133:709-715.

37. L. Sottrup-Jensen. Alpha-macroglobulins:structure, shape, and mechanism of proteases complex formation. J Biol Chem. 1989; 264:11539-11542.

38. T. Lindhout, J. Franssen and G. M. Willems. Kinetics of the inhibition of tissuefactor/factor VIla by the tissue factor pathway inhibitor. Thromb Haemost. 1995; 74:910-915.

39. M. Kalafatis, M. D. Rand and K. C. Mann. The mechanism of inactivation of human factor $V$ and human factor $V a$ by activated protein C. J Biol Chem. 1994; 169:31869-31880.

40. P. J. Fay, T. M. Smudzin and F. J. Walker. Activated protein C-catalyzed inactivation of human factor VIII and factor VIlla. Identification of cleavage sites and correlation of proteolysis with cofactor activity. J Biol Chem. 1991; 266:20139-45.

41. F. Walker. Regulation of activated protein $\mathrm{C}$ by a new protein. A possible function for bovine protein S. J Biol Chem. 1980; 255:5521-5524. 
42. F. J. Walker, S. I. Chavin and P. J. Fay. Inactivation of factor VIII by activated protein C and protein S. Arch Biochem Biophys. 1987; 252:322-8.

43. R. A. Marlar and A. Neumann. Neonatal purpura fulminans due to homozygous protein C or protein S deficiencies. Semin Thrombo Hemast. 1990; 16:299-309.

44. B. Dahiback. The protein $\mathrm{C}$ anticoagulant system: inherifed defects as basis for venous thrombosis. Thromb Res. 1995; 77:1-43.

45. B. Wiman and D. Collen. Molecular mechanism of physiological fibrinolysis. Nature. 1978 . 272:549-50.

46. N. Aiko. Fibrinolysis: Its initiation and regulation. I Protein Chem. 1986; 5:269275.

47. D. Collen. a2-antiplasmin inhibitor deficiency. Lancet. 1979;313:1039-40.

48. B. Wiman and D. Collen. On the kinetics of the reaction between human antiplasmin and plasmin. Eur J Biochem. 1978; 84:573-8.

49. W. Kisiel. Human plasma protein $\mathrm{C}$ : isolation, characterization, and mechanism of activation by alphaw thrombin. $J$ Clin Invest. $1979 ; 64: 761-9$.

50. C. T. Esmon and W. G. Owen. Identification of an endothelial cell cofactor for thrombin catalysed activation of protein C. ProC Nat/ Acad Sci USA. 1981; 78:2249-2252.

51. W. G. Owen and C. T. Esmon. Functional properties of an endothelial cell cofactor for thrombin-catalysed activation of protein C.J Biol Chem. 1981;

52. $J_{.} \mathrm{H}$. Griffin. Blood coagulation - the thrombin paradox. Nature. 1995; 378:337338.

53. C. T. Esmon, N. L. Esmon and K. W. Harris. Complex formation between thrombin and thrombomodulim inhibits both thrombin-catalysed fibrin formation

54. and factor $V$ activation. I Biol Chem. 1982; 257:7944-7947.

D. J. Stearns-Kurosawa, S. M. Kurosawa, J.S., G. L. Ferrell and C. T. Esmon. thrombin-thrombomodulin complocer augments protein $C$ activation by the 10216.

55. J. human factor VIll C. Meljers, J. J. Sixma and B. N. Bouma. Inactivation of protective effect of von willebrand protein $\mathrm{C}$. Cofactor activity of protein $\mathrm{S}$ and

56. K. Varadi, J. Rosing, Gillebrand factor. J Clin Invest. 1988; 82:1236-43 enhances the cofactor function of protein $S$. Keil and H. P. Schwarz. Factor $V$ factor VIII: influence of the Factor VR506 in the APC - mediated inactivation of $76(2): 208-214$

$L$. Shen and $B$.

activated protein $\mathrm{C}$ in . Factor $\mathrm{V}$ and protein $\mathrm{S}$ as synergistic cofactors to 269:18735-18738.

58. corrected by anticoagulant Proc Natl Acad Sci USA. 1994:91:13ctivity found to be a property of factor V.

59. D. S Fair R A. Marlar and; $191: 1396-1400$. protein S. Blood. 1986;67:1168-71. Levin. Human endothellial cells synthesize $X$. He, L. Shen, A. Bjartell and B. Dahlback. The gene encoding vitamin K-
dependent anticoagulant protein $S$ is expressed in demonstrated by northern blotting, in situ hybridization, and
immunohistochemistry. J Histochem Cytochem. 1995; $43.85-96$. Hoskins, J. Hoskins, D. K. Norman, R. J. Beckmann 1995; 43:85-96. characterization of human liver cDNA encoding and $G$. L. Long. Cloning and Acad Sci U S A. 1987; 84:349-53.

62. J. H. Griffin, A. Gruber and J. A. Fernandez. Reevaluation of total, free, and
bound protein S and C4b-binding protein levels in plasma anticoagulated with
citrate or hirudin. Blood. $1992 ; 79: 3203-11$. 
63. B. Dahlback, B. Frohm and G. Nelsestuen. High affinity interaction between $\mathrm{C} 4 \mathrm{~b}$-binding protein and vitamin $\mathrm{K}$-dependent protein $\mathrm{S}$ in the presence of calcium. Suggestion of a third component in blood regulating the interaction. J Biol Chem. 1990; 265:16082-7.

64. S. Yegneswaran, G. M. Wood, C. T. Esmon and A. E. Johnson. Protein S alters the active site location of activated protein $\mathrm{C}$ above the membrane surface. A fluorescence resonance energy transfer study of topography. J Biol Chem. 1997; 272:25013-21.

65. G. L. Long, D. Lu, R. L. Xie and M. Kalafatis. Human protein $S$ cleavage and inactivation by coagulation factor $\mathrm{Xa}$. J Biol Chem. 1998; 273:11521-6.

66. G. T. Chang, L. Aaldering, T. M. Hackeng, P. H. Reitsma, R. M. Bertina and B. N. Bouma. Construction and characterization of thrombin-resistant variants of recombinant human protein S. Thromb Haemost. 1994; 72:693-7.

67. F. Meijer-Huizinga, K. Mertens and J. A. van Mourik. Isolation and characterization of single-chain protein S. Thromb Haemost. 1994; 72:408-14.

68. K. Suzuki, J. Nishioka and S. Hashimoto. Regulation of activated protein $\mathrm{C}$ by thrombin-modified protein S. J Biochem (Tokyo). 1983; 94:699-705.

69. B. Dahlback. Inhibition of protein $\mathrm{Ca}$ cofactor function of human and bovine protein $S$ by C4b-binding protein. $J$ Biol Chem. 1986; 261:12022-7.

70. M. J. Heeb and J. H. Griffin. Activated protein C-dependent and-independent anticoagulant activities of protein $S$ have different structural requirements. Blood Cells Mol Dis. 2002; 29:190-199.

71. K. M. Sere, J. Rosing and T. M. Hackeng. Inhibition of thrombin generation by protein $S$ at low procoagulant stimuli: implications for maintenance of the hemostatic balance. Blood. 2004; 104:3624-30.

72. T. M. Hackeng, C. van 't Veer, J. C. Meijers and B. N. Bouma. Human protein S inhibits prothrombinase complex activity on endothelial cells and platelets via direct interactions with factors Va and Xa. J Biol Chem. 1994; 269:21051-8.

73. M. J. Heeb, R. M. Mesters, G. Tans, J. Rosing and J. H. Griffin. Binding of protein $S$ to factor $V a$ associated with inhibition of prothrombinase that is independent of activated protein C. J Biol Chem. 1993; 268:2872-7.

74. M. J. Heeb, J. Rosing, H. M. Bakker, J. A. Fernandez, G. Tans and J. H. Griffin. Protein $S$ binds to and inhibits factor Xa. Proc Natl Acad Sci U S A. 1994; 91:2728-32.

75. S. J. Koppelman, T. M. Hackeng, J. J. Sixma and B. N. Bouma. Inhibition of the intrinsic factor $X$ activating complex by protein $S$ : evidence for a specific binding of protein $S$ to factor VIII. Blood. 1995; 86:1062-71.

76. S. J. Koppelman, C. van't Veer, J. J. Sixma and B. N. Bouma. Synergistic inhibition of the intrinsic factor $X$ activation by protein $S$ and $C 4 b$-binding protein. Blood. 1995; 86:2653-60.

77. M. van Wijnen, J. G. Stam, C. van't Veer, J. C. Meijers, P. H. Reitsma, R. M. Bertina and B. N. Bouma. The interaction of protein $S$ with the phospholipid surface is essential for the activated protein C-independent activity of protein $\mathrm{S}$. Thromb Haemost. 1996; 76:397-403.

78. D. B. Wilson, H. H. Salem, J. S. Mruk, I. Maruyama and P. W. Majerus. Biosynthesis of coagulation factor $V$ by a human hepatocellular carcinoma cell line. I Clin Invest. 1984; 73:654-658.

79. H. C. Chiu, P. K. Schick and R. W. Colman. Biosynthesis of factor V in isolated guinea pig megakaryocytes. J Clin invest,. 1985; 75:339-346.

80. W. H. Kane, A. Ichinose, F. S. Hagen and E. W. Davie. Cloning of cDNAs coding for the heavy chain region and connecting region of human factor $\mathrm{V}$, a blood coagulation factor with four types of internal repeats. Biochemistry. 1987; 26:6508-14.

81. R. J. Jenny, D. D. Pittman and J. J. Toole. Complete CDNA and derived amino acid sequence of human factor V. Proc Natl Acad Sci USA. 1987; 84:4846-50. 
82. L. D. Cripe, K. D. Moore and W. H. Kane. Structure of the gene for human coagulation factor $V$. Blochemistry. 1992; $31: 3777-85$.

83. J. Gitschier, W. L. Wood, T. M. Goralka, K. L. Wion, E. Y. Chen, D. H. Eaton, G. A. Vehar, D. J. Capon and R. M. Lawn. Characterization of the human factor VIll gene. Nature. 1984; 312:326-30.

84. W. R. Church, R. L. Jernigan, J. Toole, R. M. Hewick, J. Knopf, G. J. Knutson, M. E. Nesheim, K. G. Mann and D. N. Fass. Coagulation factors V and VIII and ceruloplasmin constitute a family of structurally related proteins. Proc Natl Acad Sci USA. 1984; 81:6934-7.

85. E. R. Guinto, C. T. Esmon, K. G. Mann and R. T. MacGillivray. The complete cDNA sequence of bovine coagulation factor $V$. J Bio/ Chem. 1992; 267:2971-8.

86. J. Xue, M. Kalafatis and K. C. Mann. Determination of the disulfide bridges in factor Va light chain. Biochemistry. 1993; 32:5917-5923.

87. J. Xue, M. Kalafatis, J. R. Silveira, C. Kung and K. G. Mann. Determination of the disulfide bridges in factor Va heavy chain. Biochemistry. 1994; 33:13109-16.

88. G. L. Hortin. Sulfation of tyrosine residues in coagulation factor V. Blood. 1990; 76:946-952.

89. D. D. Pittman, K. N. Tomkinson and R. J. Kaufman. Post-translational requirements for functional factor $V$ and factor V:II secretion in mammalian cells. J.Biol. Chem. 1994; 269:17329-17337.

90. H. P. M. Kumar, M. J. Besman, R. L. Lundblad, N. S. Jenny and K. G. Mann. Carbohydrate analysis of plasma factor $\mathrm{V}$ and factor VIII. Tromb Haemost

91. M. E Nesheim, suppl 82

activation intermediates. Foster and R. M. Hewick. Characterization of factor $V$

92.

93 J. Rosing. H. M. Bul.

Characterization of two forms of . D. Thomassen, H. C. Hemker and G. Tans. activities. J Biol Chem. 1993;268.21 human factor Va with different cofactor L. Hoekema, G. A. F. Nicolaes, H. G. Hemker,

factor Va1 and factor Va2: properties in ther, G. Tans and $J$ Rosing. Human pathways. Biochemistry. 1997; 36:3331-5 the procoagulant and anticoagulant

94. G. A. F. Nicolaes, B. O Villoutreix and

Asn2181 in human factor $V$ as and $B$. Dahlback. Partial glycosylation of heterogeneity. Modulation of glycosylation efficiency molecular and functional consensus sequence for $\mathbb{N}$-linked glycosylation. Biochemistry. 1999; 38:13584-
91 .

95.

(1999; 38:13584-

Lentz and W. H. Krtel, M. A. Quinm-Allen, L. Yoo, L. Worfolk, X. Zhai, B. R. C-type domain of human factor $V$ s complex. Biochemistry. 1999; 38:11448-54.

96.

M. E. Nesheim, I B Taswell and K O.

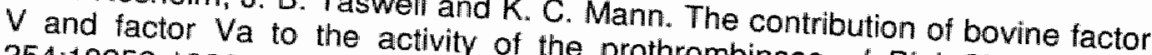
254:10952-10962.

97.

activated factor $V$, separation sture of thrombin-activated factor $V$. Isolation of

98. activity. J Biol Chem. 1979; 254:964-973. W. H. Kane and P. W. Majerus. Purifica

coagulation factor $V$. J Biol Chem. $1981 ; 256: 1002-1$ characterization of human

99.

100

101. W. B. Foster, M E Nesheim and $K$ 256:1002-1007. activation of factor V. J Biol Chem. 1983;258:13970-13977.
R. Toso and R. M. Camire Ra-catalyzed rather than specific proteolysis und of B-domain sequences from factor $V$ function is realized. Alol Chem. underlie the mechanism by which cafactor M. Kalafatis, D. O. Beck and K . 2004; 279:21643-21650. of factor $\mathrm{Va}$ activity. I Biol Chem. 2003. Structural requirements for expression 
102. K. A. Marquette, D. D. Pittman and R. J. Kaufman. The factor V B-domain provides two functions to facilitate thrombin cleavagle and release of the light chain. Blood. 1995; 86:3026-3034.

103. E. R. Guinto and C. T. Esmon. Formation of a calcium-binding site on activated bovine factor $V$ following recombination of the isolated subunits. I Biol Chem. 1982; 257:

104. K.W. Sorensen, G. A. F. Nicolaes, B. O. Villoutreix, T. Yamazaki, G. Tans, J. Rosing and $B$. Dahlback. Functional properties of recombinant factor $V$ mutated in a potential calcium-binding site. Biochemistry. 2004; 43:5803-5810.

105. J. Rosing, G. Tans, J. W. P. Govers Riemslag, R. F. A. Zwaal and H. C. Hemker. The role of phospholipids and factor $\mathrm{Va}$ in the prothrombinase complex. J Biol Chem. 1980; 255:274-283.

106. S. Krishnaswamy. Prothrombinase complex assembly contribution of proteinprotein and protein-membrane interactions toward complex formation. J Biol Chem. 1990;265:3708-3718.

107. J. L. M. L. Rijn van, J. W. P. Govers Riemslag, R. F. A. Zwaal and J. Rosing. Kinetic studies of prothrombin activation: Effect of factor $\mathrm{Va}$ and phospholipids on the formation of the enzyme-substrate complex. Biochemistry. 1984; 23:4557-4563.

108. S. Krishnaswamy, K. C. Jones and K. G. Mann. Prothrombinase complex assembly Kinetic mechanism of enzyme assembly on phospholipild vesicles. $J$ Biol Chem. 1988; 263:3823-3834.

109. M. E. Nesheim, C. Kettner, E. Shaw and K. G. Mann. Cofactor dependence of factor Xa incorporation into the prothrombinase complex. J Biol Chem. 1981; 256:6537-6540.

110. M. E. Nesheim, S. Eid and K. G. Mann. Assembly of the prothrombinase complex in the absence of prothrombin. J Biol Chem. 1981; 256:9874-988.2.

111. F. J. Walker, P. W. Sexton and C. T. Esmon. The inhibition of blood coagulation by activated protein $C$ through selective inactivation of activated factor $V$. Biochim Biophys Acta. 1979; 571:333-342.

112. K. C. Mann, M. F. Hockin, K. J. Begin and M. Kalafatis. Activated protein C cleavage of factor $\mathrm{Va}$ leads to dissociation of the A2-domain. I Biol Chem. 1997; 272:20678-20683.

113. J. Rosing and $G$. Tans. Coagulation factor $V$ : an old star shines again. Thromb Haemost. 1997; 78:427-433.

114. G. A. F. Nicolaes, G. Tans, M. C. L. G. D. Thomassen, H. C. Hemker, I. Pabinger, K. Varadi, H. P. Schwarz and J. Rosing. Peptide bond cleavage and loss of functional activity during inactivation of factor $\mathrm{Va}$ and factor VaR506Q by activated protein C. J Biol Chem. 1995; 270:21158-2\|166.

115. K. Suzuki, J. Stenflo, B. Dahlback and B. Teodorsson. Inactivation of human coagulation factor $V$ by activated protein C. J Biol Chem. 1983; 258:1914-1920.

116. M. F. Hockin, K. M. Cawthern, M. Kalatatis and K. C. Mann. A model describing the inactivation of factor Va by APC: Bond cleavage, fragment dissociation, and product inhibition. Biochemistry. 1999; 38:6918-6934.

117. H. M. Bakker, G. Tans, T. Janssen-Claesen, M. C. L. G. D. Thomassen, H. C. Hemker, J. H. Griffin and J. Rosing. The effect of phospholipids, calcium lons and protein $S$ on rate constants of human factor $V a$ inactivation by activated human protein C. Eur J Biochem. 1992; 208:171-178.

118. S. Solymoss, M. M. Tucker and P. B. Tracy. Kinetics of inactivation of membrane-bound factor $\mathrm{Va}$ by activated protein $\mathrm{C}$. Protein $\mathrm{S}$ modulates factor Xa protection. J Biol Chem. 1988; 263:14884-14890.

119. J. Rosing, L. Hoekema and G. A. F. Nicolaes. Effect of protein S and factor Xa on peptide bond cleavages during inactivation of factor $\mathrm{Va}$ and factor VaR506Q by activated protein C. J Biol Chem. 1995; 270:27852-27858. 
120. E. A. Norstrom, M. Steen, S. Tran and B. Dahlback. Importance of protein S and phospholipid for activated protein C-mediated cleavage of factor $\mathrm{Va}$. I Blol Chem. 2003; 278:24904-24911.

121. M. J. Heeb, Y. Kojima, T. M. Hackeng and J. H. Griffin. Binding sites for blood coagulation factor $X a$ and protein $S$ involving residues 493-506 in factor $\mathrm{Va}$. Protein Sci. 1996; 5:1883-9.

122. E. Thorelli, R. J. Kaufman and B. Dahlback. The C-terminal region of the factor $\checkmark$ B-domain is crucial for the anticoagulant activity of factor $V$. I Biol Chem.

$1998 ; 273: 16140-16145$

23. D. Lu, M. Kalafatis, K. G. Mann and G. L. Long. Comparison of activated protein C/protein S-mediated inactivation of human factor VIII and factor $V$. Blood.

$1996 ; 87: 4708-4717$

124. E. Thorelli, R. J. Kaufman and B. Dahlback. Cleavage of factor $V$ at Arg 506 by activated protein $\mathrm{C}$ and the expression of anticoagulant activity of factor $\mathrm{V}$.

125. Blood. 1999; 93:2552-2558. 125. W. L. Nichols, D. A. Gastineau, L. A. Solberg and K. G. Mann. Identification of
126. Auman megakaryocyte coagulation factor V. Blood. 1985; 65:1396-1406.

126. A. M. Gewirtz, M. Keefer, K. Doshi, A. E. Annamalai, H. C. Chiu and R. W. 1648.

127. A. M. Gewirtz, C. Shapiro, Y. M. Shen, R. Boyd and R. W. Colman. Cellular and molecular regulation of factor $\mathrm{V}$ expression in human megakaryocytes. J Cell

128. B. A Boucha; $153: 277-287$.

Endocytosis of plasma-derived, N. T. Meisler, M. W. Long and P. B. Tracy. clathrin-dependent, specific membrane $V$ by megakaryocytes occurs via a

2005; 3:541-551.
129. W. R. Gould, P. Simioni, J R Silvirame binding event. J Thromb Haemost.

Tracy. Megakaryocytes endocytose and vivo to form the entire pool of a unique platently modify human factor $V$ in Haemost. $2005 ; 3: 450-456$.

130.

M. C. L. G. D. Thomassen, E.. Castoldi, E. J. Magdeleyns, C. Delaunoit, L. Debusscher, K. J. Van Assche and J.Rosing. Endogenous factor $\mathrm{V}$ synthesis in
megakaryocytes contributes negligibly to the

Haematologica. 2003; 88:1150-1156.
131. R. M. Camire, E. S. Pollak K. Kaubly to the platelet factor $V$ pool.

R. M. Camire, E. S. Pollak, K. Kaushansky and P. B. Tracy. Secretable human

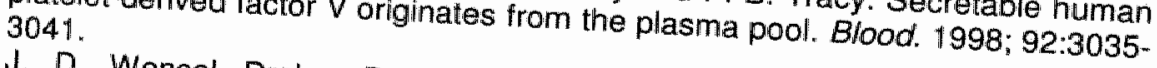

132. J. D. Wencel Drake, B. Dahlbäck, J. G. White and M. H. Ginsberg.

Ultrastructural localization of coagulation factor $V$ in human platelets. Blood.
$1986 ; 68: 244-249$.

133.

secretion of factor $V$. Pifer and R. W. Colman. Subcellular localization and 78:5180-5184.

134. C. P. M. Hayward, E. Furmaniak-Kazmierczak, A. M. Cieutat, J. C. Moore, D. F.
Bainton, M. E. Nesheim and J. G. Kelton. Factor $V$ is complexed with multimerin
in resting platelet lysates and colocalizes with multimerin in platelet a-ganus
J Biol Chem. 1995. $\checkmark$ Biol Chem. 1995; 270:19217-19224.

135.

P. B. Tracy, A. R. Giles, K. G. Mann, L. L. Eide, H. Hoogendoorn and G. E.
Rivard. Factor V (Quebec): a Bleeding diathesis

136. C. C. P. M. Haymardiefiency. J Clin invest, 1984; 74:1221-1228. Moore and

associated with Kelton. An autosomal dominant, qualitative L. Zheng, J. C. associated with multimerin deficiency, abnormalities in platelet disorder 
thrombospondin, von willebrand factor, and fibrinogen and an epinephrine aggregation defect. Blood. 1996; 87:4967-4978.

137. R. W. Viskup, P. B. Tracy and K. G. Mann. The isolation of human platelet factor V. Blood. 1987; 69:1188-1195.

138. D. D. Monkovic and P. B. Tracy. Functional characterization of human plateletreleased factor $V$ and its activation by factor $\mathrm{Xa}$ and thrombin. J Biol Chem. $1990 ; 265: 17132-17140$.

139. W. R. Gould, J. R. Silveira and P. B. Tracy. Unique in vivo modifications of coagulation factor $V$ produce a physically and functionally distinct plateletderived cofactor: characterization of purified platelet-derived factor VNa. J Biol Chem. 2004; 279:2383-2393.

140. R. M. Camire, M. Kalafatis, P. Simioni, A. Girolami and P. B. Tracy. Plateletderived factor $\mathrm{Va} / \mathrm{VaLeiden}$ cofactor activities are sustained on the surface of activated platelets despite the presence of activated protein C. Blood. 1998; 91:2818-2829.

141. R. M. Camire, M. Kalafatis, M. Cushman, R. P. Tracy, K. G. Mann and P. B. Tracy. The mechanism of inactivation of human platelet factor Va from normal and activated protein C-resistant individuals. I Biol Chem. 1995; 270:2079420800.

142. P. J. Lenting, J. A. van Mourik and K. Mertens. The life cycle of coagulation factor V VII in view of its structure and function. Blood. 1998; 92:3983-96.

143. K. L. Wion, D. Kelly, J. A. Summertield, E. G. Tuddenham and R. M. Lawn. Distribution of factor VIII mRNA and antigen in human liver and other tissues. Nature. 1985; 317:726-9.

144. J. J. Toole, J. L. Knopf, J. M. Wozney, L. A. Sultzman, J. L. Buecker, D. D. Pittman, R. J. Kaufman, E. Brown, C. Shoemaker, E. C. Orr and et al. Molecular cloning of a cDNA encoding human antihaemophilic factor. Nature. 1984; 312:342-7.

145. L. O. Andersson, N. Forsman, K. Huang, K. Larsen, A. Lundin, B. Pavlu, H. Sandberg, K. Sewerin and J. Smart. Isolation and characterization of human factor VIII: molecular forms in commercial factor VIII concentrate, cryoprecipitate, and plasma. Proc Natl Acad Sci U S A. 1986; 83:2979-83.

146. R. J. Hamer, J. A. Koedam, N. H. Beeser-Visiser, R. M. Bertina, J. A. Van Mourik and J. J. Sixma. Factor VIII binds to von Willebrand factor via its Mr80,000 light chain. Eur J Biochem. 1987; 166:37-43.

147. P. J. Fay. Activation of factor VIII and mechanisms of cofactor action. Blood Rev. 2004; 18:1-15.

148. P. J. Fay, P. J. Haidaris and T. M. Smudzin. Human factor Villa subunit structure. Reconstruction of factor Villa from the isolated $\mathrm{A} 1 / \mathrm{A3}-\mathrm{C} 1-\mathrm{C} 2$ dimer and A2 subunit. J Biol Chem. 1991; 266:8957-62.

149. P. J. Fay, T. L. Beattie, L. M. Regan, L. M. O'Brien and A. J. Kaufman. Model for the factor VIIla-dependent decay of the intrinsic factor Xase. Role of subunit dissociation and factor IXa-catalyzed proteolysis. J Biol Chem. 1996; 271:6027 32.

150. L. M. Regan, B. J. Lamphear, C. F. Huggins, F. J. Walker and P. J. Fay. Factor IXa protects factor VIIla from activated protein C. Factor IXa inhibits activated protein C-catalyzed cleavage of factor VIlla at Arg562. I Biol Chem. 1994; 269:9445-52.

151. B. Dahlback, M. Carlsson and P. J. Svensson. Familial thrombophilia due to a previously unrecognized mechanism characterized by poor anticoagulant responce to activated protein $\mathrm{C}$ : prediction of a cofactor activated protein $\mathrm{C}$. Proc Natl Acad Sci USA. 1993; 90:1004-4008.

152. P. J. Svensson and B. Dahlbäck. Resistance to activated protein $\mathrm{C}$ as a basis for venous thrombosis. N Engl J Med. 1994; 330:517-522. 
153. T. Koster, F. R. Rosendaal, H. De Ronde, E. Briet, d. P. Vandenbroucke and R M. Bertina. Venous thrombosis due to a poor anticoagulant response to activated protein C: Leiden Thrombophilia Study. Lancet. 1993; 342:1503-1506.

154. R. M. Bertina, B. P. Koeleman, T. Koster, F. R. Rosendaal, R. J. Dirven, H. de Fonde. P. A. van der Velden and P. H. Reitsma. Mutation in blood coagulation factor $V$ associated with resistance to activated protein C. Nature. 1994; $369: 64-67$.

155. J. S. Greengard, X. Sun, X. Xu, J. A. Fernandez, J. H. Griffin and B. Evatt. Activated protein $C$ resistance caused by Arg506Gin mutation in factor $\mathrm{Va}$. Lancet. 1994; $343: 1361-2$.

156. X. Sun, B. Evatt and J. H. Griffin. Blood coagulation factor Va abnormality associated with resistance to activated protein $C$ in venous thrombophilia. Blood. 1994; $83: 3120-3125$.

157. J. Voorberg, J. C. Roelse, R. Koopman, H. R. Buller, F. Berends, J. W. Ten Cate, K. Mertens and J. A. Van Mourik. Association of idiopathic venous thromboembolism with single point-mutation at Arg506 of factor $V$. Lancet. 1994; 343:1535-1536.

158. B. Zoller, P. J. Svensson, $X$. He and B. Dahlbäck. Identification of the same factor $V$ gene mutation in 47 out of 50 thrombosis-prone families with inherited resistance to activated protein C. J Clin Invest. 1994; 94:2521-2524.

159. M. Kalafatis, R. M. Bertina, M. D. Rand and K. G. Mann. Characterization of the molecular defect in factor VA506Q. J Biol Chem. 1995;270:4053-7.

160. M. J. Heeb, Y. Kojima, J. S. Greengard and J. H. Griffin. Activated protein C resistance: molecular mechanisms based on studies using purified Gin506factor V. Blood 1995; 85:3405-11.

161. D. C. Rees, M. J. Cox and J. B. Clegg. World distribution of factor $V$ Leiden. Lancet. 1995; 346:1133-1134.

162. B. Dahlback. Inherited Thrombophilia: Resistance to activated protein $C$ as a pathogenic factor of venous thromboembolism. Blood. 1995; 85:607-614.

163. P. M. Ridker, C. H. Hennekens, K. Lindpaintner, M. J. Stampfer, P. R. Eisenberg and J. P. Miletich. Mutation in the gene coding for coagulation factor $V$ and the risk of myocardial infarction, stroke, and venous thrombosis in apparently healthy men. N Eng/ IMed. 1995; 332:912-917

164. F. R. Rosendaal, T. Koster, J. P. Vandenbroucke and P. H. Reitsma. High risk of thrombosis in patients homozygous for factor $V$ Leiden (activated protein $C$ resistance). Blood. 1995; 85:1504-1508.

165. B. Manten, R. G. J. Westendorp, T. Koster, P. H. Reitsma and F. R. Rosendaal Fisk factor profiles in patients with different clinical manifestations of venous thromboembolism. A focus on the factor $V$ Leiden mutation. Thromb Haemost. $1996 ; 76: 510-513$.

166. D. Williamson, K. Brown, R. Luddington, C. Baglin and T. Baglin. Factor V Cambridge: A new mutation (Arg306 to Thr) associated with resistance to activated protein C. Blood. 1998; $91: 1140-1144$.

167. R. Liang, C. K. Lee, M. S. Wat and $Y$. L. Kwong. Clinical significance of Arg306 mutations of factor $V$ gene. Blood. 1998; 92:2599-2600.

168. W. P. Chan, C. K. Lee, Y. L. Kwong, C. K. Lam and R. Liang. A of Arg306 of factor $V$ gene in Hong $K$.

E. A Norstrom, E The Blood. 1998; 91:1135-1139. recombinant FVHong Korelli and $B$. Dahlback. Functional characterization of

170. A. D Mumford, J. H. McVey, C. FV Cambridge. Blood. 2002; 100:524-530.

E. G. Tuddenham B. Morse, K. Gomez, M. Steen, E. A. Norstrom, novel mutation, Bahlback and P. H. B. Bolton-Maggs. Factor V 1359T: a C. British Journal

Haematology. 2003; 123:496-501.

M. Steen, E. A. Norstrom, A. Tholander, P. H. B. Bolton-Maggs, A. D. Mumford, J. H. MoVey, E. G. Tuddenham and B. Dahlback. Functional characterization 
factor V-lle359Thr: anovel mutation associated with thromosis. Blood. 2004; 103:3381-3387.

172. B. Lunghi, L. lacoviello, D. Gemmati, M. G. Dilasio, E. Castoldi, M. Pinotti, G. Castaman, R. Redaelli, G. Mariani, G. Marchetti and F. Bernardi. Detection of new polymorphic markers in the factor $V$ gene: association with factor $V$ levels in plasma. Thromb Haemost. 1996; 75:45-48.

173. F. Bernardi, E. M. Faioni, E. Castoldi, B. Lunghi, G. Castaman, E. Sacchi and $P$. M. Mannucci. A factor $V$ genetic component differing from factor $V R 506 Q$ contributes to the activated protein $C$ resistance phenotype. Blood. 1997; 90:1552-1557.

174. E. Castoldi, J. Rosing, D. Girelli, L. Hoekema, B. Lunghi, F. Mingozzi, P. Ferraresi, S. Friso, R. Corrocher, G. Tans and F. Bernardi. Mutations in the R2 $\mathrm{FV}$ gene affect the ratio between the two $\mathrm{FV}$ isoforms in plasma. Thromb Haemost. 2000; 83:362-365.

175. N. M. Pecheniuk, C. P. Morris, T.P. Walsh and N. A. Marsh. The factor V HR2 haplotype: prevalence and association of the $A 4070 \mathrm{G}$ and $\mathrm{A6755G}$ polymorphisms. Blood Coagul Fibrinolysis. 2001; 12:201-206.

176. H. Kostka, G. Siegert, T. Schwarz, S. Gehrisch, E. Kuhlisch, S. Schellong and W. Jaross. Frequency of polymorphisms in the B-domain of factor $\mathrm{V}$ gene in APC-resistant patients. Thromb Res. 2000; 99:539-547.

177. E. M. Faioni. Factor V HR2: an ancient haplotype out of Africa - a reason for being interested. Thromb Haemost. 2000; 83:358-359.

178. T. Yamazaki, G. A. F. Nicolaes, K. W. Sorensen and B. Dahlback. Molecular basis of quantative factor $V$ deficiency associated with the factor $V$ R2. haplotype. Blood. 2002; 100:2515-2521.

179. L. Hoekema, E. Castolli, G. Tans, D. Girelli, D. Gemmati, F. Bernardi and J. Rosing. Functional properties of factor $V$ and factor $V a$ encoded by the R2gene. Thromb Haemost. 2001; 85:75-81.

180. M. C. de Visser, J. F. Guasch, P. W. Kamphuisen, H. L. Vos, F. R. Rosendaal and R. M. Bertina. The HR2 haplotype of factor $V$ : effects on factor $V$ levels, normalized activated protein $\mathrm{C}$ sinsitivity ratios and the risk of venous thrombosis. Thromb Haemost. 2000; 83:577-5:82.

181. J. W. P. Govers-Riemslag, E. Castoldi, G. A. F. Nicolaes, G. Tans and J. Rosing. Reduced factor $V$ concentration and altered FV1/ FV2 ratio do not fully explain R2-associated APC-resistance. Thromb Haemost. 2002; 88:444-449.

182. G. Castaman, E. M. Faioni, A. Tosetto and F. Bernardi. The factor V HR2 haplotype and the risk of venous thrombosis: a meta-analysis. Haematologica. 2003; 8:8:1182-1189.

183. G. Castaman, B. Lunghi, E. Missiaglia, F. Bernardi and F. Rodeghiero. Phenotypic homozygous activated protein $C$ resistance associated with compound heterozygosity for Arg506Gin (factor $V$ Leilden) and His1299Arg substitutions in factor V. British Journal of Haematology. 1997; 99:257-261.

184. E. M. Faioni, F. Franchi, P. Bucciarelli, M. Margaglione, V. De Stefano, G. Castaman, G. Finazzi and P. M. Mannucci. Coinheritance of the HR2 haplotype in the factor $V$ gene confers an increased risk of venous thromboembolism to carriers of factor V R506Q (factor V Leiden). Blood. 1999; 94:3062-6.

185. S. R. Poort, F. R. Rosendaal, P. H. Reitsma and R. M. Bertina. A common genetic variation in the 3 -untranslated region of the prothrombin gene is associated with elevated plasma prothrombin levels and an increase in venous thrombosis. Blood. 1996; 88:3698-3703.

186. J. C. Souto, I. Coll, D. Llobet, E. del Rio, A. Oliver, J. Mateo, M. Borrell and J. Fontcuberta. The prothrombin 20210A allele is the most prevalent genetic risk factor for venous thromboembolism in the Spanish population. Thromb Haemost. 1998; 80:366-9. 
187. R. K. Kapur, L. A. Mills, S. G. Spitzer and M. B. Hultin. A prothrombin gene mutation is significantly associated with venous thrombosis. Arterioscler Thromb Vasc Biol. 1997; 17:2875-9.

188. K. Brown, R. Luddington, D. Williamson, P. Baker and T. Baglin. Risk of venous thromboembolism associated with a $G$ to $A$ transition at position 20210 in the $3^{\prime}$ untranslated region of the prothrombin gene. Br J Haematol. 1997; 98:907-9.

189. A. Hillarp, B. Zoller, P. J. Svensson and B. Dahlback. The 20210A allele of the prothrombin gene is a common risk factor among Swedish outpatients with verified deep venous thrombosis. Thromb Haemost. 1997; 78:990-992.

190. V. R. Arruda, J. M. Annichino-Bizzacchi, M. S. Goncalves and F. F. Costa. Prevalence of the prothrombin gene variant (nt20210A) in venous thrombosis and arterial disease. Thromb Haemost. 1997; 78:1430-3.

191. R. F. Franco, S. E. Santos, J. Elion, M. H. Tavella and M. A. Zago. Prevalence of the G20210A polymorphism in the 3 '-untranslated region of the prothrombin gene in different human populations. Acta Haematol. 1998; 100:9-12.

192. P. M. Ridker, C. H. Hennekens and J. P. Miletich. G20210A mutation in prothrombin gene and risk of myocardial infarction, stroke, and venous thrombosis in a large cohort of US men. Circulation. 1999; 99:999-1004.

193. P. Ferraresi, G. Marchetti, C. Legnani, E. Cavallari, E. Castoldi, F. Mascoli, D. Ardissino, G. Palareti and F. Bernardi. The heterozygous $20210 \mathrm{G} / \mathrm{A}$ prothrombin genotype is associated with early venous thrombosis in inherited thrombophilia and is not increased in frequency in arterial disease. Arterioscler Thromb Vasc Biol. 1997; 17:2418-2422.

194. F. R. Rosendaal, C. J. Doggen, A. Zivelin, V. R. Arruda, M. Aiach, D. S. Siscovick, A. Hillarp, H. H. Watzke, F. Bernardi, A. M. Cumming, F. E. Preston and P. H. Reitsma. Geographic distribution of the $20210 \mathrm{G}$ to A prothrombin
variant. Thromb Haemost. 1998; $79: 706-8$.

195. A. Tripodi, V. Chantarangkul and P. M. Mannucci. Hyperprothrombinemia may result in acquired activated protein C resistance. Blood. 2000; 96:3295-3296.

196. G. Castaman, A. Tosetto, M. Simioni, M. Ruggeri, D. Madeo and F mutation is associated with an increased risk of venous thrombosis. Thromb

197. Haemost. 2001; 86:804-808

C. A. Mitchell, S. M. Jane and H. H. Salem. Inhibition of the anticoagulant

198. M. D. Smirnov, O. Safathrombin. J Clin Invest, $1988 ; 82: 2142-2147$. protein $\mathrm{C}$ anticoagulant activity by prothrombin. T. Esmon. Inhibition of activated

199. E. A. Norstrom, S. Tran and Brothrombin. Blood. 1999; 94:3839-3846. individual activated protein C cleav. Dahlback. Prothrombin inhibition of the 


\section{CHAPTER 2}

Theoretical and experimental study of the D2194G mutation in the C2-domain of coagulation factor $V$

Miteva MA, Brugge JM, Rosing J, Nicolaes GAF, Villoutreix BO

Based on: Biophysical Journal, 2004, $86: 488-498$. 
a

a 


\section{ABSTRACT}

Coagulation factor $V(F V)$ is a large plasma glycoprotein with functions in both pro- and anticoagulant pathways. In carriers of the so-called R2-FV haplotype, the FV D2194G mutation, in the C2 membrane binding domain, is associated with low expression levels, suggesting a potential folding/stability problem. To analyze the molecular mechanisms potentially responsible for this in vitro phenotype, we used molecular dynamics (MD) and continuum electrostatic calculations. Implicit solvent simulations were performed on the $\mathrm{X}$-ray structure of the wild-type C2 domain and on a model of the D2194G mutant. Because D2194 is located next to a disulficle bond (S-S bond), MD calculations were also performed on S-S bond depleted structures. D2194 is part of a salt-bridge network and investigations of the stabilizing/destabilizing role of these ionic interactions were carried out. Five mutant FV molecules were created and the expression levels measured with the aim of assessing the tolerance to amino acid changes of this region of the molecule. Analysis of the MD trajectories indicated increased flexibility in some areas and energetic comparisons suggested overall destabilization of the structure due to the D2194G mutation.

This substitution causes electrostatic destabilization of the domain by $\sim 3$ $\mathrm{kcal} / \mathrm{mol}$. Together these effects likely explain the lowered expression levels in R2-FV carriers. 


\section{INTRODUCTION}

Coagulation factor $V(F V)$ is the precursor of an essential pro-coagulant cofactor that accelerates FXa-catalyzed prothrombin activation. It is a large glycoprotein that is structurally and functionally homologous to factor VIII (FVIII), the two proteins sharing the domain organization $\mathrm{A} 1-\mathrm{A} 2-\mathrm{B}-\mathrm{A} 3-\mathrm{C} 1-\mathrm{C} 2$. Activation of $\mathrm{FV}$ involves proteolytic removal of the large $\mathrm{B}$ domain, converting the procofactor into the fully active cofactor FVa (Nicolaes and Dahlback, 2002; Mann and Kalafatis, 2003). Interestingly, FV also has a reported anticoagulant function in the APC-mediated inactivation of FVIIla (reviewed by Nicolaes and Dahlback, 2002). FV and FVIII interact with many proteins and bind to cell surfaces, essentially via the $\mathrm{C} 2$ domain. The three-dimensional (3D) structure of the $\mathrm{C} 2$ domains of FV/FVIII was initially predicted using a combination of threading and comparative modeling based on the structure of galactose oxidase (Villoutreix et al., 1998; Pellequer et al., 1998; Baumgartner et al., 1998). Despite very low sequence identity $(\sim 10 \%)$ between the $C$ domains of FV/FVIII and galactose oxidase, the overall 3D fold of the predicted structures was correct as seen from comparison with recently reported $X$-ray structures of the isolated $\mathrm{C} 2$ domains of FV and FVIII (Macedo-Ribeiro et al., 1999; Pratt et al., 1999). These $\mathrm{C}$ domains (also called discoidin domains) exhibit a distorted jelly-roll $\beta$-barrel motif, consisting of eight major anti-parallel strands arranged in two $\beta$-sheets. The amino- and carboxy-terminal segments are clamped together by the only disulfide bond (S-S bond) present in this module (C2038-C2193). The modeled and experimental structures of the $\mathrm{C} 2$ domain of $\mathrm{FV}$ allowed for proposal of key regions involved in membrane binding (Nicolaes et al., 2000; Kim et al., 2000). This FV membrane-binding motif consists of several exposed hydrophobic side chains located essentially on loop structures (e.g., the 2060loop), surrounded by a ring of basic residues. In human plasma, FV circulates as a mixture of two isoforms, FV1 (glycosylated) and FV2 (not glycosylated) that have slightly different molecular weights because of partial $\mathrm{N}$-linked glycosylation at N2181. This leads to differences in membrane binding behavior between FV1 and FV2 (Rosing et al., 1993; Hoekema et al., 1997, Nicolaes et al., 1999). Also, glycosylation at N2181 has been proposed to modulate the FV expression levels (Nicolaes et al., 1999).

The FV R2 haplotype, firstly described in a cohort of thromboembolic patients, encompasses several genetically linked polymorphisms, that encode amino acid substitutions (of which M385T, H1299R, M1736V and D2194G are most likely linked to the haplotype) in different domains of the molecule (Lunghi et al., 1996; Bernardi et al., 1997; Castoldi et al., 2000). There is no consensus from epidemiogical studies if these polymorphisms are associated with venous 
or arterial thrombosis. Yet, in vitro studies have demonstrated that at least; the D2194G substitution in the FV C2 domain induces a substantially impaired expression due to retention of the mutant protein in the endoplasmic reticulum (ER), a place where mistolded proteins tend to be trapped and degraded (Yamazaki et al., 2002). Thus the D2194G substitution appears to affect the folding/structure/stability of the C2 domains (Yamazaki et al., 2002; Van Der Neut Kolfschoten et al., 2003) via mechanisms that are not fully understood.

It is a major challenge to establish the links between point mutations, $3 \mathrm{D}$ structures and disease states (Villoutreix, 2002; Bross et al., 1999; Wickner et al., 1999; Sinha and Nussinov, 2001, Hilser et al., 1998; Taverna et Goldstein, 2002). Potentiall impacts of mutations on protein stability, folding and function can be investigated theoretically using a single 3D conformation of the folded native protein as starting point (Wang and Moult, 2001) or via (short/long) molecular dynamics (MD) simulations (Cregut and Serrano, 1999; Schiffer and van Gunsteren, 1996; Kazmirski et al., 1995; Rizzuti et al., 2001). When a mutation involves a charged residue that has ionic interactions with surrounding groups, some specific electrostatic computations can also be performed to investigate the stabilizing or destabilizing roles of salt bridges on protein stability (Kumar and Nussinov, 1999; Hendsch and Tidor, 1994; Lounnas and Wade 1997; Barril et al., 1998; Dong and Zhou, 2002).

To study the potential impacts of the D2194G mutation on the C2 domain of human $\mathrm{FV}$, we used MD, electrostatic computations and site-directed mutagenesis. In the native 3D structure of the $\mathrm{C} 2$ domain, residue D2194 is partially solvent exposed, fully conserved in the FV species and located next to the C2038-C2193 disulfide bond. It is involved in electrostatic interactions with the side chains of K2101 and K2103. We hypothesized that the D2194G substitution could affect the stability of the molecule due to electrostatic destabilization and/or induce conformational/flexibility changes. Due to its position, directly juxtaposed to the disulfide bridge in the $\mathrm{C} 2$ domain, the D2194G mutation could also influence disulfide bond formation. We decided to run MD simulations with an implicit solvent model on the $\mathrm{C} 2$ domain of wild-type FV (WT-FV) and on the D2194G mutant, in the presence or the absence of the C2038-C2193 bond. Simulations without the S-S bond were carried out to examine some of the effects of this bond on the 3D structure of the domain. Electrostatic computations were also run on different $\mathrm{C} 2$ structures to further investigate the role of ionic interactions in the 2194 area. Several mutant proteins (D2194K, K2101E/K2103E, K2101E/K2103E/D2194K and C2038A/C2193A) were produced and the final expression levels characterized in order to assess the overall sensitivity of this region to amino acid changes. Taken together, our data indicate that aspartate at position 2194 is important for 
the stability of the domain and that the above amino acid substitutions affect the stability and/or the conformation of the domain.

\section{MATERIALS AND METHODS}

\section{Computational methods}

\section{Molecular Dynamics}

Molecular dynamics simulations were carried out on the high resolution X-ray structure (Macedo-Ribeiro et al., 1999) of domain C2 of WT-FV and on a model of the D2194G mutant. The X-ray structure of the human WT-FV C2 domain (Macedo-Ribeiro et al., 1999) was taken from the Protein Data Bank (Berman et al., 2000) (entry $1 \mathrm{czt}, 1.8 \AA$ resolution). There is no experimental structure for the D2194G mutant and we have built an initial 3D model for this domain on the basis of the WT-structure by simply removing the D2194 side chain. The $\mathrm{N}$-terminal group was acetylated in all initial structures to account for the fact that this residue is linked to the $C 1$ domain. MD simulations were performed for the WT-C2 domain and the mutant D2194G, with or without the disulfide bond C2038-C2193. The same protocol for energy minimization and molecular dynamics was used for all the relevant simulations. Calculations were performed using the program CHARMm (Brooks et al., 1983) using CHARMm 22 parameters on two Silicon Graphics (IRIX 6.5) Fuel V12 single 600-MHz processor workstations (Mountain View, CA). Interactive analysis of the results was performed in Insightll (running on SGI workstations) or with ICM (Malsoft) running on two Precision 530 Dell PC dual-2.4-GHz processors driven by Red Hat Linux 7.3.

The importance of correct accounting for solvation effects during MD simulations has been widely discussed. Because explicit treatment of solvent is very time-consuming and eventually not needed, several implicit methods have been proposed for calculation of solvation effects in proteins (Bashford and Case, 2000, Feig and Brooks, 2002). We have used in our MD simulations the Generalized Born (GB) method as implemented by Dominy and Brooks (1999) into the program CHARMm to account for the electrostatic contribution to the solvation energy (Brooks et al., 1983) (version 27.b1 or 28.b1, Accelrys). The $\mathrm{GB}$ approximation is based on a two-dielectric model and its mathematical form, for a molecule with arbitrary shape, has been extensively parameterized (Dominy and Brooks, 1999).

The empirical Atomic Solvation Parameter (ASP) approach as proposed by Wesson and Eisenberg (1992) with parameterization by Sharp et al. (1991) 
was also applied to account for the nonpolar solvation energy. This method assumes that the nonpolar (considered in the present article to be the solventsolvent cavity and solute-solvent van der Waals terms) solvation free energy of the solute can be decomposed into a sum of atomic free energy components that are proportional to the solvent accessible surface (SAS) of atoms of type $k$ : $G^{\text {hydrophobic }}=\Sigma \sigma_{k} S A S_{k}$. Here we used $\sigma_{k}=12.3 \mathrm{cal} / \mathrm{mol} / \AA^{2}$ for the hydrophobic carbon atoms and $\sigma_{k}=0.0 \mathrm{cal} / \mathrm{mol} / \AA^{2}$ for the other atoms as suggested by several research groups (Qiu et al., 1997; Morozov et al., 2003).

The charge-charge interactions were treated using Coulomb law with a dielectric constant $\varepsilon=1$ to be consistent with the GB parameterization. The GB parameters proposed in Dominy and Brooks (1999) were used and a dielectric constant of 80 was applied to represent the highly polarizable solvent medium. For all nonbonded interactions we used a cutoff of $15 \AA$ and a switch function.

Initial hydrogen positions were calculated using the HBUILD utility of CHARMm. Definition of the charged state for the titratable groups in the X-ray structure of WT-FV and the mutant D2194G before the MD simulations was decided after electrostatic computations of the mean proton occupancy (see below for computational details). The results indicated that all Lys, Arg, Glu, Asp, and the C-terminal group are charged while the remaining residues including His residues were found to be neutral. Only K2148 was found not to be completely charged (calculated mean proton occupancy $q=0.4$ ) at $\mathrm{pH}=7$.

The initial 3D structures were energy minimized (1500 steps steepest descent method or a tolerance of energy gradient of $0.15 \mathrm{kcal} / \mathrm{mol} / \mathrm{A})$ and $\mathrm{MD}$ simulations were then performed on the minimized structures. The temperature of the system was raised gradually from 240 to $300 \mathrm{~K}$ in 20-ps followed by equilibration at $300 \mathrm{~K}$ for 50 -ps. This was further continued by a 900-ps production run of NVT-MD at 300K with the Berendsen algorithm (Berendsen et al., 1984) and the protein conformations were recorded every 1-ps. The time step was 1 -ts and the SHAKE algorithm was used to eliminate the high frequency thydrogen/heavy atom bond vibrations.

\section{Electrostatic Calculations}

All electrostatic calculations ( $\mathrm{pKa}$, electrostatic free energies of stabilization) were performed for the WT and mutants but only on the structures possessing the S-S bond. Thus, the $X$-ray structure of the WT, the structures with the D2194G, D2194K, K2101E/K2103E, K2101E/K2103E/D2194K substitutions (without simulations) were selected for computations. The same calculations were also carried out on the last conformations of the MD simulations for the WT and the D2194G mutant, as well as on 30 structures 
sampled from the MD trajectories from 670 to 970 ps of the production run (one structure selected every $10 \mathrm{ps}$ ).

\section{Finite difference Poisson-Boltzmann energy calculations}

For computation of electrostatic energies used in protonation states and electrostatic stabilization calculations, we used the program UHBD (Davis et al., 1991) that solves the Poisson-Boltzmann equation numerically on a grid by the finite difference method (Warwicker and Watson, 1982; Sharp and Honig, 1990; Yang et al., 1993). It has been previously proposed (Antosiewicz et al., 1994) that a better agreement between calculated and experimental $p K_{a}$ values of titratable groups can be obtained using a higher protein dielectric constant (e.g., $\varepsilon_{\text {in }}=20$ ). However, in this work we use $\varepsilon_{i n}=4$, because accurate results for evaluation of salt-bridge energetic were obtained earlier with this value (Hendsch \& Tidor, 1994; Lounnas and Wade, 1997; Barril et al., 1998). The protein atomic radii and charges were based on the CHARMm 22 parameter set. The dielectric boundary between the protein and solvent was defined using the solvent accessibility surface with probe sphere of radius $1.4 \AA$ and 500 dots per atom for generation of the surface. Initial boundary conditions were determined by calculating the potential at each boundary point using the DebyeHuckel approximation. A salt concentration of $0.15 \mathrm{M}$ and salt exclusion radius of $2.0 \AA$ were used in the finite difference Poisson-Boltzmann calculations.

In the calculation of protonation states, first the protein structures were included into a grid of $45 \times 45 \times 45$ points with a resolution of $2.5 \AA$. A focusing scheme proposed previously (Yang et al., 1993; Antosiewicz et al., 1994) using four successive lattices with increasing grid resolution was applied for calculation of electrostatic potentials created by every ionized group. The last focusing run was done in a $3 \mathrm{D}$ grid of dimension of 20 nodes and a resolution of $0.25 \AA$ centered at the titration site. A procedure with two focusing runs in boxes of dimension of 65 with resolution of $1.5 \AA$, followed by a box of dimension of 70 with a $0.3 \AA$ resolution, was applied to calculate the electrostatic energies involved in the calculation of electrostatic stabilization of the charged triads (see below).

\section{Protonation states}

The FDPB method has been widely used for calculation of protein protonation states (Bashford and Karplus, 1990; Yang et al., 1993; Antosiewicz et al., 1994). To calculate intrinsic $p K a$ value $\left(p K^{\text {int }}\right)$ of a given titratable group (Tanford and Kirkwood, 1957), (the $p K^{\mathrm{int}}$ is defined as the pKa that the group would have if all other titratable groups were neutral) one unit charge at the protonation site of this group and all permanent partial charges of the protein 
were taken into account.

The protonation state $n$ of a protein with $N$ titratable residues is characterized by the protonation state vector $\delta_{n}(i), i=1$ to $N$, where $\delta_{n}(i)=1$ when the $i t h$ group is charged and 0 when it is neutral. The free energy of the nth protonation state $\Delta G^{n}$ is given by:

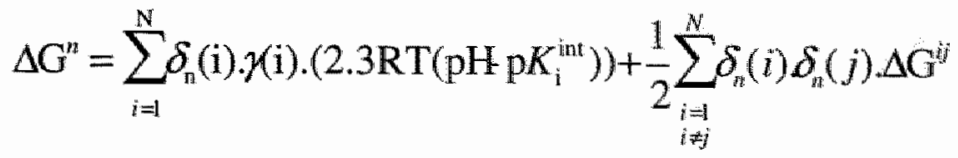

where $\gamma(i)=-1$ or 1 for an acidic or basic group $i$, respectively, $\mathrm{p} K_{i}^{\mathrm{int}}$ is the intrinsic $\mathrm{p} K_{\mathrm{a}}$ value of the group $i$, and $\Delta \mathrm{G}^{i}$ is the electrostatic interaction energy between groups $i$ and $j$ in their charged states defined by $\delta(i)$ and $\delta(j)$. In this work the protonation states of all studied structures were obtained at $\mathrm{pH} 7.0$ (Antosiewicz et al., 1994).

In the computation of electrostatic potentials $\phi_{i j}$ due to the charge $j$ at the location of the charged site $i$, involved in pairwise interactions calculation $\left(\Delta G^{i j}=\gamma_{i} \phi_{i j}\right)$, only a unit charge at the protonation site was included. The protonation sites were set to the atoms: $C^{\gamma}$ of $A s p, C^{\delta}$ of Glu, $C^{\zeta}$ of $A r g, N^{\zeta}$ of Lys, $\mathrm{N}^{\mathrm{e} 2}$ of His, $\mathrm{OH}$ of Tyr, $\mathrm{C}$ atom of main-chain $\mathrm{C}$-terminus. The mean proton occupancies $q$ of titratable groups at $\mathrm{pH} 7$ are computed by averaging over the protonation states sampled by the Monte Carlo method based on the $\Delta G^{n}$ calculations (Antosiewicz and Porschke, 1989).

Electrostatic free energy contributions to the protein stability for salt-link triads The electrostatic free energy, $\Delta \Delta \mathrm{G}^{\text {tot }}$, contributing to protein stability due to a triad of charged amino acid residues in a protein (WT- or mutants) was calculated relative to a reference protein hydrophobic isosteres (an isostere is defined as a residue with the same conformation and position in the protein as the original residue but neutral). The term $\Delta \Delta G^{\text {tot }}$ was calculated following the procedure proposed by Hendsch and Tidor 1994:

$$
\Delta \Delta G^{\text {tot }}=\Delta \Delta G^{\text {sol }}+\Delta \Delta G^{\text {triad }}+\Delta \Delta G^{p r}
$$

The three terms $\Delta \Delta G^{s o l}, \Delta \Delta G^{\text {triad }}, \Delta \Delta G^{\text {pr }}$ were computed as differences between the energies of the protein and the protein with appropriate amino acids involved into the ionic triad replaced to their respective hydrophobic isosteres. The desolvation electrostatic energy $\Delta G^{\text {soll }}$ of the triad in a protein was calculated as: 


$$
\Delta \mathrm{G}^{\mathrm{sol}}=\Delta \mathrm{G}_{\mathrm{A}}^{\mathrm{sol}}+\Delta \mathrm{G}_{\mathrm{B}}^{\mathrm{sol}}+\Delta \mathrm{G}_{\mathrm{C}}^{\mathrm{sol}}
$$

and $\Delta \mathrm{G}^{\mathrm{sol}}{ }_{\mathrm{A}}, \Delta \mathrm{G}_{\mathrm{B}}^{\mathrm{sol}}$, and $\Delta \mathrm{G}^{\mathrm{sol}}{ }_{\mathrm{C}}$ are the electrostatic desolvation free energies of each residue of the triad $A, B, C$, respectively. The electrostatic desolvation energy $\Delta G^{\text {solv }}$ for taking a residue from solvent to protein environment is given following Gilson and Honig (1988).

The electrostatic energy of internal interactions in the triad $\Delta G^{\text {triad }}$ was presented as:

$$
\Delta G^{\text {triad }}=\Delta G_{A B C}-\Delta G_{A}-\Delta G_{B}-\Delta G_{C}
$$

where. $\Delta G_{A B C}$ is the electrostatic free energy of the protein involving only the charges of the triad; $\Delta G_{A}, \Delta G_{B}, \Delta G_{C}$ are the electrostatic free energies of the protein involving the charges of only one of the triad residues $A, B$, or $C$, respectively.

The electrostatic free energy of interactions between the triad and the rest of the protein $\Delta \mathrm{G}^{\text {pr }}$ is calculated by:

$$
\Delta G^{p r}=\Delta G_{\text {prot, triad }}-\Delta G_{A B C}-\Delta G_{\text {prot }}
$$

The three terms in Eq.5 correspond to electrostatic tree energy of the protein when all protein charges are present ( $\Delta G_{\text {prot,triad }}$; all charges are present excluding the charges of the triad $\left(\Delta \mathrm{G}_{\mathrm{prot}}\right)$, and only the charges of the triad are present $\left(\Delta \mathrm{G}_{\mathrm{ABC}}\right)$.

These calculations were performed for investigation of the WT triad (D2194, K2101, K2103 versus the mutant G2194, K2101, K2103). In the calculation of these electrostatic energies of stabilization, the atomic partial charges corresponding to CHARMm22 parameters were used (such charged state of the groups is in agreement with our calculated mean proton occupancies $q$ at $\mathrm{pH} 7$ for the WT and D2194G mutant). In the modeled MD structures of WT- and mutant D2194G all Lys, Arg, Glu, Asp and C-term residues were calculated to be charged and the others groups, including the His residues were computed to be neutral.

For other C2 mutant structures (D2194K, K2101E/K2103E, K2101E/K2103E/D2194K), residue E2103 in mutants K2101E/K2103E and $\mathrm{K} 2101 \mathrm{E} / \mathrm{K} 2103 \mathrm{E} / \mathrm{D} 2194 \mathrm{~K}$, as well as residue K2101 in mutant D2194K were taken non-charged in the calculation of triad electrostatic stabilization, as computed from the mean proton occupancies. 


\section{Experimental procedures}

\section{Site-directed Mutagenesis}

Site-directed mutagenesis was performed using the Quick Change SiteDirected Mutagenesis Kit (Stratagene, USA) according to the manufacturer's instructions in order to generate new variant $F V$ recombinant molecules: D2194K, K2101E/K2103E, C2038A/C2193A. As a template we used the fulllength cDNA of human FV, coding for the FV2 isoform (WT-N2181Q) described previously (Nicolaes et al., 1999). A fourth mutant was constructed by mutagenesis of D2194 into $\mathrm{K}$, using the $\mathrm{K} 2101 \mathrm{E} / \mathrm{K} 2103 \mathrm{E}$ plasmid as a template. The construction of an expression vector for recombinant FV containing the R2associated D2194G mutation has previously been described (Yamazaki et al., 2002). Two complementary oligonucleotides (DNA Technology, Denmark) were used as mutagenic primers for each construct, the sense oligo being:

\section{5'-GAACTCTTTGGCTGTAAGATTTACTAGAATTG-3' (D2194K), 5'-TTGATCTACTCGAGATCGAGAAGATAACGGC-3' (K2101E/K2103E), 5'-TGAGGTAAATGGAGCTTCCACACCCCTG-3' (C2038A) and 5'-CTGGAACTCTTTGGCGCTGATATTTACTAG-3' (C2193A).}

To ensure that during the mutagenesis no additional mutations were introduced, a small polymerase chain reaction ( $P C R$ ) fragment containing the desired mutation(s) was cut out of the PCR-product by restriction endonucleases and ligated into a new template that had been cleaved by the same restriction enzymes. The presence of only the desired mutations in each of the plasmids was checked by DNA sequencing.

\section{Transient expression of Factor $V$}

Recombinant Factor $\mathrm{V}$ plasmids were transiently co-expressed with a Green Fluorescent Protein-lamin construct (GFP-lamin) in COS-1 cells using Fugene 6 Transfection Reagent (Roche Molecular Biochemicals, Indianapolis, IN). A transfection mixture was made by mixing $100 \mu$ l of Optimem serum-free medium (Optimem with Glutamax I; Gibco, Life Technologies, Gaithersburg, MD) with $7.5 \mu$ l Fugene 6 Transfection Reagent, $2 \mu \mathrm{g}$ of mutated pMT2-FV and $0.5 \mu \mathrm{g}$ pEGFP-lamin plasmid. This mixture was incubated at room temperature for 20 minutes, before adding it to $\sim 80 \%$ confluent monolayer of COS1 cells in 2 ml Dulbecco modified Eagle medium (DMEM), supplemented with L-glutamine. Transfection was allowed to proceed for 16 hours before replacing the transfection medium with fresh DMEM, supplemented with L-glutamine, 10\% fetal calf serum, $100 \mathrm{IU} / \mathrm{ml}$ penicillin and $100 \mu \mathrm{g} / \mathrm{ml}$ streptomycin. After $48 \mathrm{~h}$ 
posttransfection, cells were washed with phosphate-buffered saline and after trypsinisation, $25 \%$ of the cells were harvested to quantitate the transfection efficiency by flow cytometry. The remainder of the cells was cultured for an additional $28 \mathrm{~h}$ in $3 \mathrm{ml}$ serum-free medium supplemented with $0.1 \mathrm{mg} / \mathrm{ml}$ Albumax I (Gibco BRL, Life Technologies) and $2.5 \mathrm{mM} \mathrm{CaCl}_{2}$.

\section{FV antigen measurements in media}

Conditioned media were collected in prechilled tubes and centrifuged for 10 minutes at $200 \mathrm{~g}$ to remove cells and cell debris. The supernatant was aliquoted and stored at $-80^{\circ} \mathrm{C}$. The Factor $\mathrm{V}$ antigen levels in the media were determined by a FV ELISA kit (Kordia, The Netherlands). ELISA standard curves were constructed with normal pooled plasma from 81 healthy individuals. 


\section{RESULTS}

\section{Overall characteristics of the MD simulations}

MD simulations were performed on the $\mathrm{C}_{2}$ domain of the WT and of the D2194G mutant with or without the $\mathrm{C} 2038-\mathrm{C} 2193 \mathrm{~S}-\mathrm{S}$ bond. The minimization procedure that was applied to relax the structures yielded conformations with root-mean-square deviations (RMSD) for heavy atoms between the initial WT $x$ ray structure and the minimized structure of $0.2 \AA$. With regard to $M D$, for all studied structures, the potential energy decreased during the first $150 \mathrm{ps}$ of the simulation and then stabilized. Therefore, the entire production time interval (900 ps) was considered for the MD analysis. For the wild-type, the average RMS deviations for the $C \alpha$ atoms relative to the $x$-ray structure over the last 900 ps are $1.67 \AA$ and $1.75 \AA$, in the presence or absence of the S-S bridge, respectively. For the mutant D2194G with or without the disulfide bond, RMSD were $1.86 \AA$ and $1.76 \AA$, respectively. Similar RMSD for the simulated structures indicate that the mutation D2194G and the removal of the disulfide bridge do not result in large structural rearrangements (see below).

Figure $1 \mathrm{~A}$ shows plots of the potential energy calculated over the trajectories. The higher potential energy observed for both mutant forms (irrespective of the presence of the S-S bond) suggests that the D2194G mutation has destabilizing effects (see below). Figs.1B and $1 \mathrm{C}$ show the Coulombic and GB solvation energies of both WT forms (WT with or without S$S$ bond) calculated during the MD trajectories. It was previously proposed by Spassov et al. (1994), that proteins containing no disulfide bonds are optimized electrostatically as compared to molecules possessing disulfide bridges. It is interesting to note that breaking the S-S-bond in the FV C2 domain leads to lower Coulombic energies during the MD indicating optimization of electrostatic interactions. The lack of S-S bond apparently facilitates reorientation of charged residues and formation of stronger favorable charge-charge interactions. In contrast, more favorable Coulombic interactions lead to less-favorable solvation energies. This can be seen from the GB energies, which are higher for the WT when the structure does not have the S-S bond. The van der Waals interactions (not shown) were similar for all trajectories and remained stable during the MD simulations. 

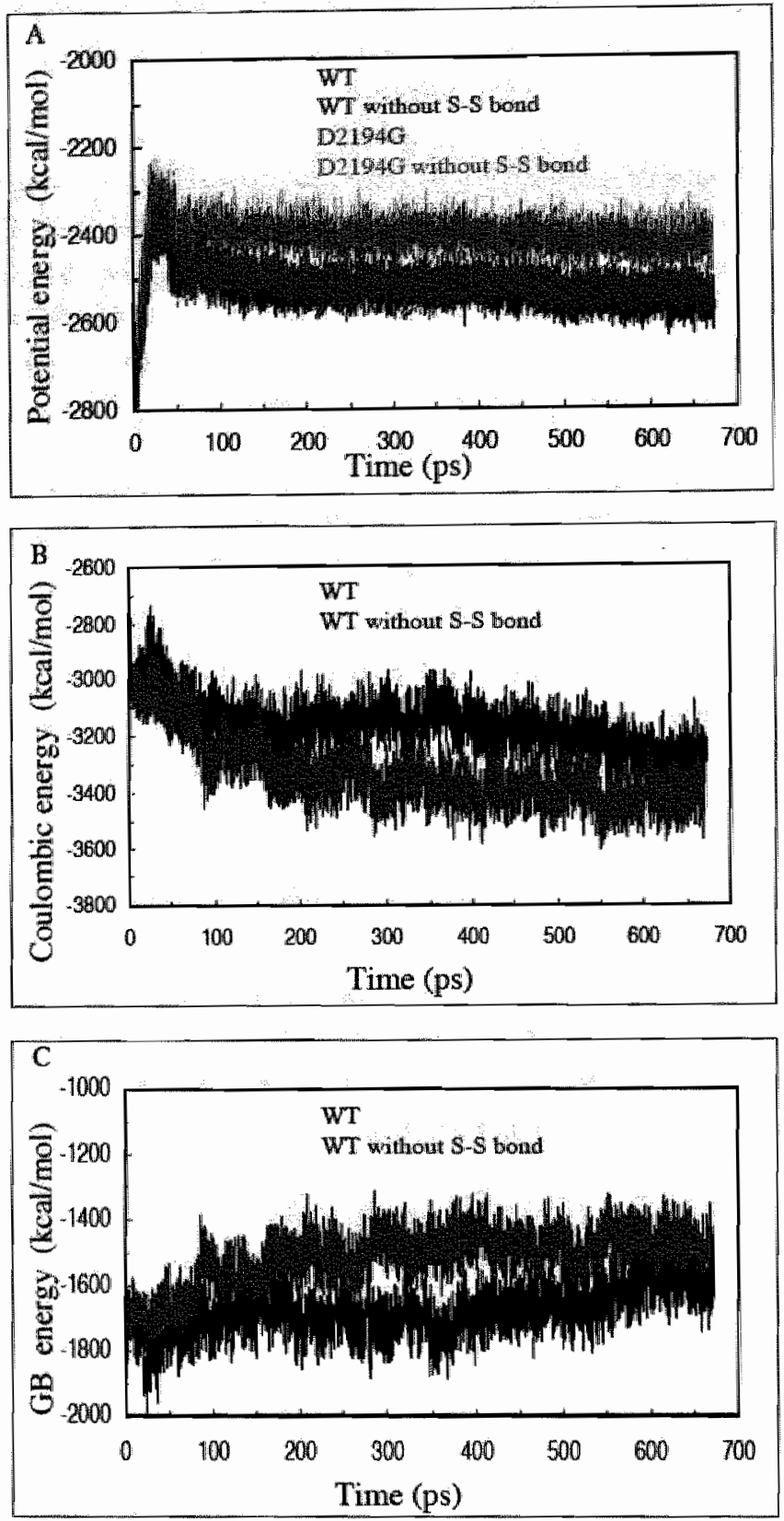

FIGURE 1: Energetic values obtained during the MD trajectories.

(A) Potential energy versus the time. The WT C2 domain is shown in black; WT without S-S bond, blue; D2194 mutant, red; and D2194G mutant without S-S bond, magenta. (B) Coulombic energy versus the time. The WT C2 domain is shown in black; WT without S$S$ bond, blue. (C) GB solvation energy versus the time. The WT C2 domain is shown in black; WT without S-S bond, blue. 


\section{Structural and flexibility differences between $x$-ray and silmulated WT}

The root mean square fluctuations (RMSF) for the $\mathrm{C}^{\alpha}$ atoms of the $\mathrm{C} 2$ domain per residue (sampled over 900 structures) were calculated. In Fig. $2 \mathrm{~A}$ the fluctuations of the simulation WT structures with and without S-S bond and the $B$ factors $\left(C^{\alpha}\right.$ atoms) of the $C 2 x$-ray structure are presented.

The calculated fluctuations of simulated WT (with S-S bond) are in good agreement with the B factors. The zones of greatest flexibility in the simulated and crystal structures tend to be similar but some differences are also noted. The loop $2140-2150$ is very flexible in the WT-simulated and crystal structures. The membrane binding loop (residues 2060 to 2067 including two key Trp residues 2063 and 2064) and residues 2130-2139 appear to be more flexible in the crystal than in the WT-simulated structure. Some differences between the B-factors of the crystal and calculated RMSF for the WT-simulated structures are also seen for the region 2152-2162 that is found to be more rigid in the $x$-ray structure.

No significant structural differences are present between the $x$-ray and averaged simulation structure of the WT C2 domain (not shown). Important changes occur only for the loop 2060-2067 involved in membrane binding, which appears to be flexible (i.e., it adopts two different conformations in the crystal structures) (Macedo-Ribeiro et al., 1999). Some conformational changes also take place at the level of the 2074-2080-loop, which is very flexible in both, the $x$-ray and simulated WT structures.

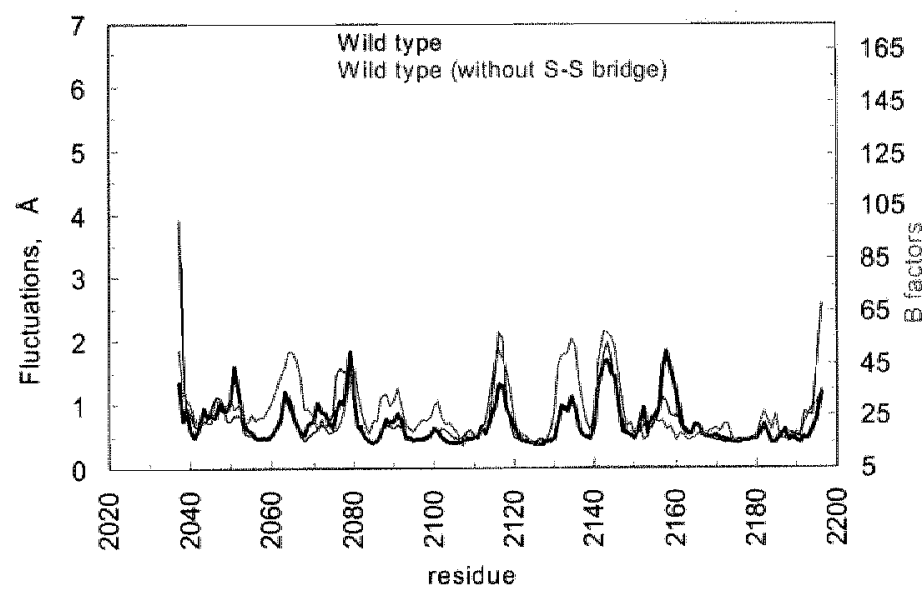

A 


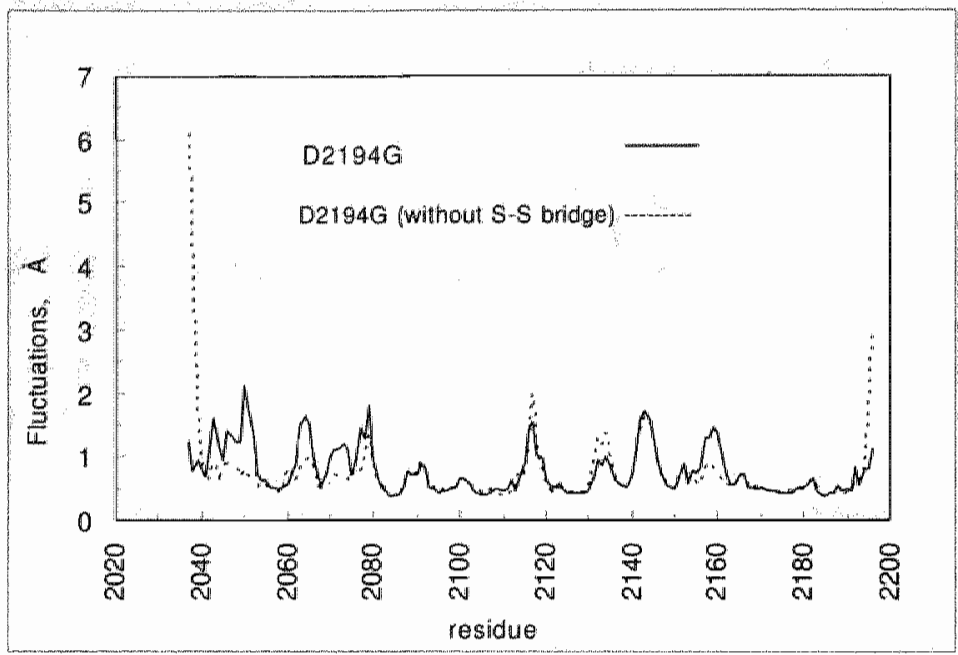

B

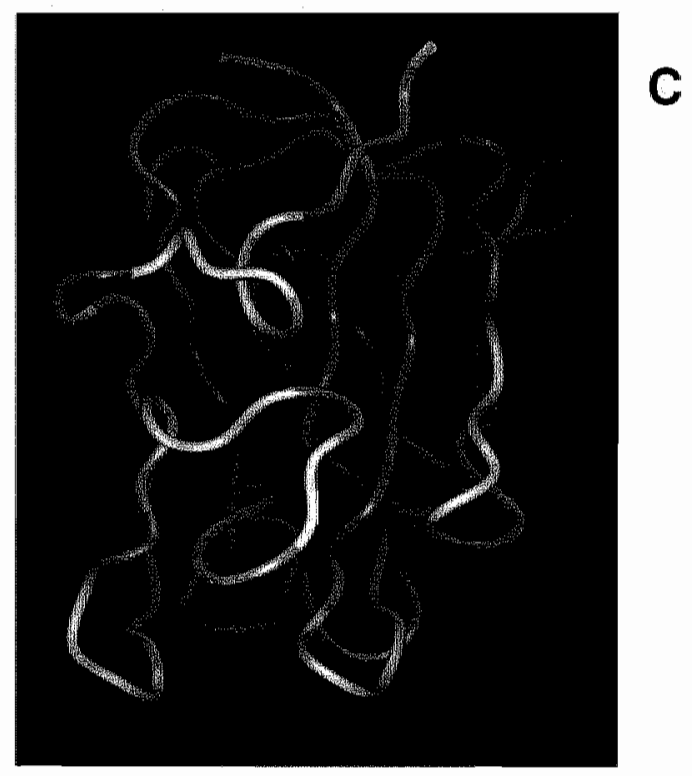

FIGURE 2: Root mean square fluctuations (RMSF) computed over the last 900 ps of the MD simulations. (A) RMSF of the simulated WT structures with (black) and without (blue) S-S bond and the B factors $\left(C^{\alpha}\right.$ atoms) of the C2 $x$-ray structure (red). (B) RMSF of the simulated mutant D2194G structures with (black) and without (dotted line) S-S bond. (C) Ribbon diagram for the averaged modeled structure of the D2194G mutant over the last 900 ps of the MD simulations color coded according to the calculated RMSF. 


\section{Structural and flexibility differences between WT and mutant D2194 with S-S bond}

Fig. 2B shows the fluctuations of modeled mutant D2194G with or without the disulfide bridge. In Fig. $2 \mathrm{C}$ the averaged modeled structure for the D2194G mutant over the last 900 ps of the MD simulations is given color coded according to the calculated RMSF. Comparisons of the flexibilities in the modeled WT and the mutant indicate that the regions 2075-2085 and 21402150 are flexible in both WT and D2194G mutant (Fig. 2). The loop 2042-2053, situated nearby the mutated residue, is more flexible in the mutant structure. The 2060-2067 loop also becomes more flexible in the D2194G mutant. This is possibly caused by the increased mobility of the loop 2042-2053.

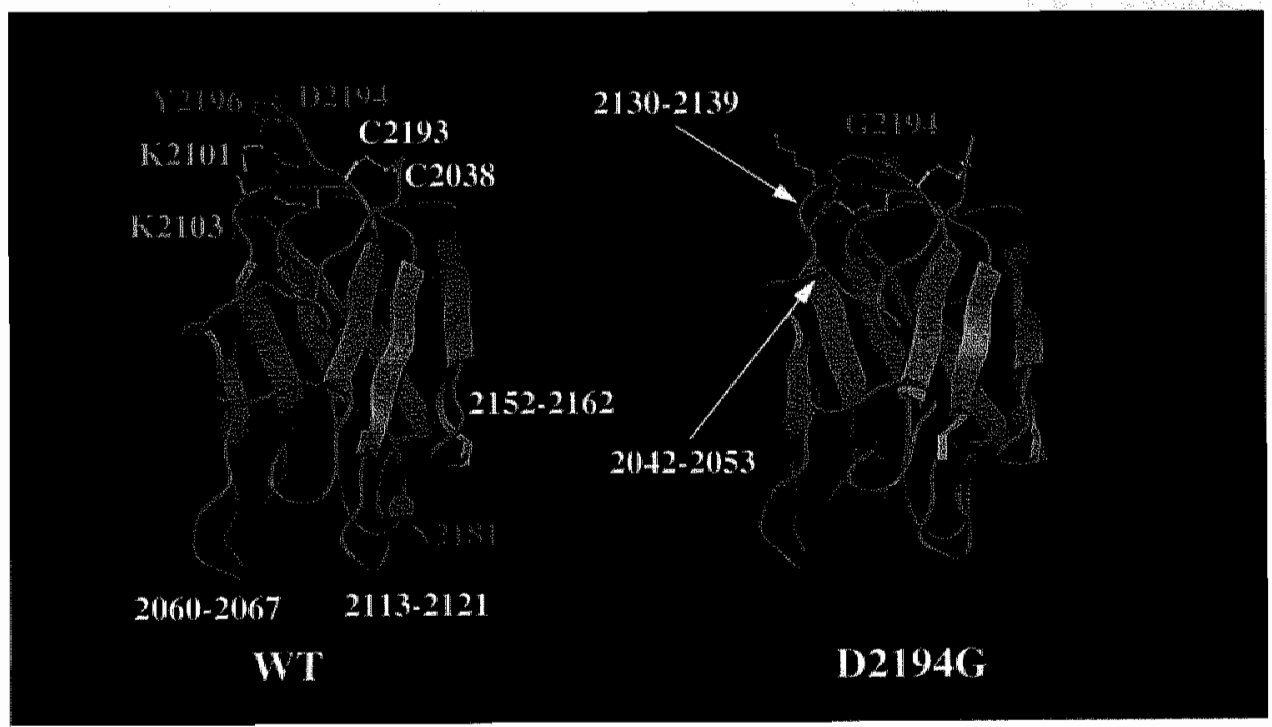

FIGURE 3: Ribbon diagram of the WT and D2194G C2 domain. The last structures obtained in the simulations (with $\mathrm{S}-\mathrm{S}$ bond) are shown and key regions are labeled (see text).

Fig. 3 shows the last structure obtained from the simulation for the WT protein domain and the $\mathrm{D} 2194 \mathrm{G}$ mutant ( $\mathrm{S}-\mathrm{S}$ bond present). These structures can be considered as representative of the MD simulations in the area of residue 2194 since the calculated electrostatic stabilization energies of a set of sampled MD conformations (see below) are similar to those calculated for the last MD structure. The regions showing structural changes upon the D2194G substitution (in the presence of S-S bond) involve the loop 2130-2139 and the $\mathrm{C}$-terminal residues (the $\mathrm{N}$-term residues remain essentially unchanged). The 
D2194G mutation does not affect the dynamical properties of these two regions, which do not appear flexible in the simulated WT and D2194G mutant structures (Fig. 2), but the mutation rather causes conformational changes. In the last simulation structures (with S-S bond, Fig. 3), the loop 2130-2139 is opened in the mutant as compared to the WT, the $C^{\alpha}$ of N2132 shifts by about 3 A.

We also noted that upon mutation of D2194, the nonflexible C-terminus (Tyr2196) inserts into the structure of the domain, attempting to fill the hole created by the D2194 to $G$ substitution, probably also trying to compensate for the missing negative charge of this mutant. These events could lead to enhanced flexibility of the loop 2042-2053 and to conformational changes of the 2130-2139 region.

\section{Structural and flexibility differences between structures with or without disulfide bond}

It is evident from Figs. $2 \mathrm{~A}$ and $2 \mathrm{~B}$ that the $\mathrm{N}$-terminal (not charged in the simulation since it is in vivo connected to the $\mathrm{C} 1$ domain) and C-terminal regions of the WT- and mutant D2194G modeled structures become extremely mobile in the absence of the disulfide bond. As a result, important conformational changes occur at both termini. Also, the flexibility of the 20872093 and 2113-2121 loops in the WT is enhanced upon removal of the S-S bridge. Loss of the S-S bond also results in a decreased mobility and in structural changes of regions 2152-2162 in both the simulated WT and D2194G mutant. The observed changes in the dynamical properties of $\mathrm{C} 2$ domain occurring upon S-S bond disruption could influence the folding process.

\section{Electrostatic contribution to the stability of the triad K2101-K2103- D2194/K2101-K2103-G2194}

The electrostatic free energies $\Delta \Delta \mathrm{G}^{\text {tot }}$ of the triads $\mathrm{K} 2101, \mathrm{~K} 2103$, D2194 in the WT and K2101, K2103, G2194 in the mutant, relative to their corresponding hydrophobic isoesters were computed only for the structures possessing the S-S bond. The electrostatic stabilization of the triad, taking into account the mean proton occupancies at $\mathrm{pH} \mathrm{7,} \mathrm{calculated} \mathrm{first} \mathrm{on} \mathrm{the} x$-ray structure and on the $x$-ray structure with simple D2194G substitution without simulations are given in Table 1 . The same calculations were also carried out on the last conformations of the MD simulations for the WT and the D2194G mutant, as well as on 30 structures sampled from the MD trajectories from 670 to $970 \mathrm{ps}$ of the production run (one structure selected every $10 \mathrm{ps}$ ). The averaged energies for the $30 \mathrm{MD}$ conformations and the term contributing to $\Delta \Delta G^{\text {tot }}$ with standard deviations are reported in Table 1. 


\begin{tabular}{|c|c|c|c|c|c|}
\hline & \multicolumn{2}{|c|}{$\Delta \Delta G^{\text {tot }}$} & \multicolumn{2}{|c|}{$\Delta \Delta \mathrm{C}^{\mathrm{sol}}$} & \multirow[t]{2}{*}{ 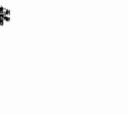 } \\
\hline & WT & mutant & WT & mutant & \\
\hline$x-1 a y$ & -2.13 & +0.93 & +1.85 & +0.72 & \\
\hline MD: last conformation & -6.34 & 4.46 & +9.41 & +5.48 & \\
\hline \multirow[t]{6}{*}{ MD: 30conformations } & $-6.81+-0.7$ & $-4.64+1.0$ & $+9.83+-1.1$ & $+4.56+0.4$ & \\
\hline & $*$ & \multicolumn{2}{|c|}{$\Delta \Delta \mathrm{G}^{\operatorname{tr} a A}$} & \multicolumn{2}{|c|}{$\Delta \Delta G^{p r}$} \\
\hline & & WT & mutant & $\mathrm{WT}$ & mutant \\
\hline & & -3.38 & +1.23 & -0.60 & -1.02 \\
\hline & & -10.62 & -0.91 & -5.13 & -9.03 \\
\hline & & $-11.46+-1.2$ & $-0.68+-0.5$ & $-5.1 .7+-0.95$ & $-8.52+-0.9$ \\
\hline
\end{tabular}

TABLE 1: Electrostatic free energy contributions of the triad to the protein stability (Kcal/mol): K2101/K2103/D2194 versus K2101/K2103/G2194

Additional computations of the electrostatic stabilization of the triad $2101,2103,2194$ and the pKa values of titratable groups were carried out for the mutants D2194K, K2101E/K2103E and K2101E/K2103E/D2194K. The stabilization contributions and mean charges at $\mathrm{pH} 7$ of the triad residues are given in Table 2.

\section{Mean charge at $\mathrm{pH}$ 7of the triad:}

\begin{tabular}{lllll} 
Mutant & 2101 & 2103 & 2194 & $\Delta \Delta G^{\text {tot }}$ \\
\hline D2194K & 0.00 & 0.98 & 1.00 & +3.46 \\
K2101E/K2103E/D2194K & -0.99 & 0.00 & 1.00 & -0.31 \\
K2101E/K2103E & -0.68 & 0.00 & -0.86 & +1.97
\end{tabular}

\section{TABLE 2: Mutants D2194K, K2101E/K2103E/D2194K and K2101E/K2103E}

The $\Delta \Delta G$ energies are well optimized for the structures sampled from the MD simulations, relative to the $x$-ray structure. The electrostatic energies obtained from averaging over 30 conformations were similar to those for the final simulations structures of the WT and the mutant and the relatively small 
standard deviations confirm that the structures in the region of the mutation are very similar in the last 300 ps of the simulations.

In the simulated structures ( 30 conformations) strong favorable chargecharge interactions for the triad ( $\left.\Delta \Delta G^{\text {triad }}\right)$ were obtained for the WT $(-11.46$ $\mathrm{kcal} / \mathrm{mol}$ ), whereas in the mutant no significant electrostatic interactions were calculated. In all structures no large differences between the simulated WT and the mutant were found for electrostatic interactions of the triad with the rest of the protein $\Delta \Delta \mathrm{G}^{\mathrm{pr}}$. The averaged electrostatic stabilization due to the interactions between the triad and the protein varies between -5.14 and -8.52 $\mathrm{kcal} / \mathrm{mol}$ in the WT and mutant, respectively. As can be expected, the presence of three partially buried ionized amino acid residues causes larger unfavorable desolvation energy $\Delta \Delta G^{\text {sol }}$ in the WT $(+9.83 \mathrm{kcal} / \mathrm{mol})$ compared to the mutant $(+4.56 \mathrm{kcal} / \mathrm{mol})$.

The electrostatic stabilization values calculated for the triad 2101, 2103, 2194 in the mutants D2194K, K2101E/K2103E, K2101E/K2103E/D2194K demonstrate the destabilizing effect of these mutations in comparison to electrostatic stabilization energy of the triad in WT computed on the $x$-ray structure.

\section{Mutagenesis}

To investigate the importance of the charged triad K2101, K2103 and D2194 and of the S-S bond, several mutant FV molecules were created. These mutagenesis experiments were also performed to probe the tolerance of this region of $\mathrm{FV}$ to amino acid substitution. To ensure that any effects observed on expression levels of the recombinant proteins were not due to altered glycosylation of the C2 domain, which per se is a modulator of FV expression levels (Nicolaes et al., 1999), all triad mutations were constructed using a template that resulted in the production of only the FV2 isoform (lacking a glycan structure at position N2181). This construct will subsequently be called WT*. The effect of the presently studied FV mutations on the final levels of FV expression in COS-1 cells, which do not express endogenous FV, were quantitated by FV-ELISA. Results were corrected for variations in transfection efficiency by cotransfecting the pMT2-FV with a pEGFP-C1-lamin vector as described in the Materials and Methods section. 


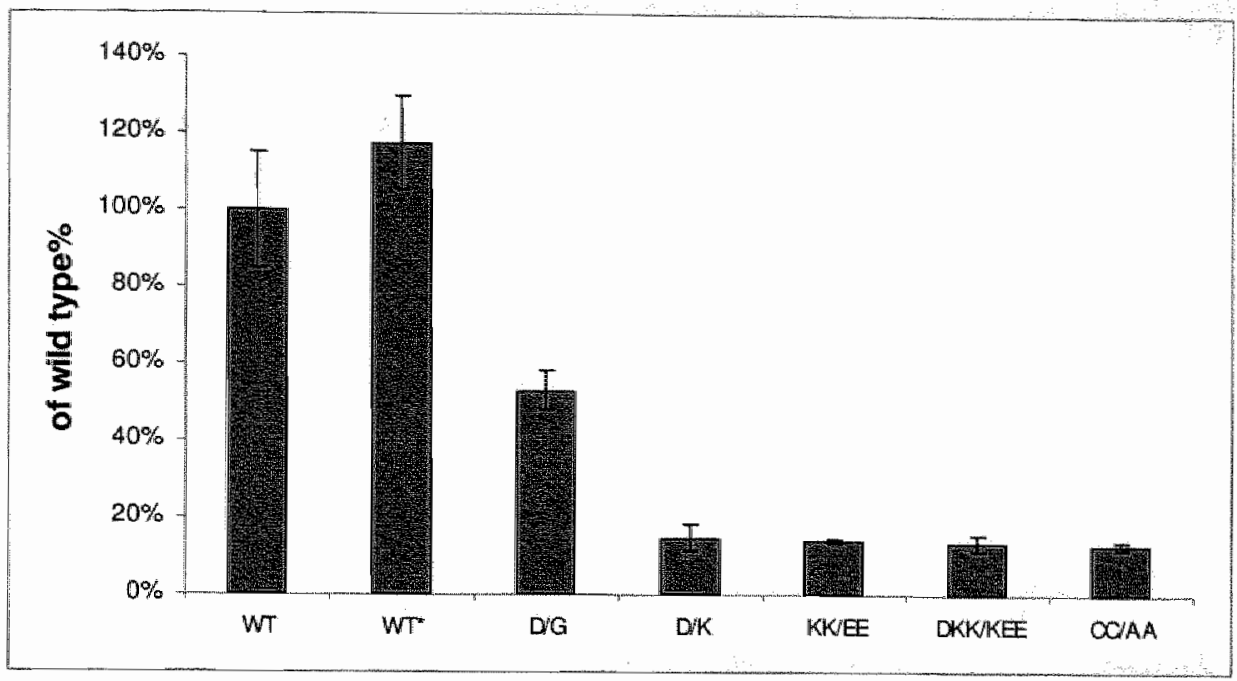

FIGURE 4: Transient expression of FV proteins in serum-free culture medium. COS- 1 cells were transiently transfected to express WT-FV or the FV mutants. FV antigen levels were measured in the culture media by ELISA. Bars represent the means \pm standard deviations $(n=6)$. The mean value of WT-FV was $23.8 \mathrm{ng} / 35 \mathrm{~mm}$ well and is assigned to be $100 \%$ in this figure. This WT-FV construct was used as a template for the $D / G$ mutation and to construct the WT* plasmid (which only expresses the FV2 isoform). There was no significant difference between the expression levels of the WT FV-plasmid and the $W T^{*}$ plasmid, the $W T^{*}$ plasmid serving as a template for the other FV-mutants (nomenclature: D2194G (D/G), D2194K (D/K), K2101E/K2103E (KK/EE), K2101E/K2103E/D2194K (DKK/KEE), and C2038A/C2193A (CC/AA)).

FV antigen level in serum-free media, conditioned for 28 hours in cells expressing the WT FV-plasmid, ranged from $17.6 \mathrm{ng}$ to $26.9 \mathrm{ng} / 35 \mathrm{~mm}$ well $(n=6)$. In conditioned media of cells transfected with the pMT2/FV-D2194G plasmid, the FV antigen level was $53 \%$ as compared to WT (Fig. 4). This is in line with previous observations by Yamazaki et al. (2002), who found that the D2194G mutation is the major determinant of low expression levels within the R2-polymorphism (Yamazaki et al., 2002). Compared to WT, a seven- to eightfold reduction in FV expression levels was observed for the mutants D2194K, K2101E/K2103E, K2101E/K2103E/D2194K and C2038A/C2193A (Fig. 4). Together these data indicate that mutations in the C2-domain of FV that interfere with the charged triad D2194, K2101 and K2103 lower the amount of FV secreted by the cells. Mutation of the $S-S$ bridge results in decreased final FV expression. However, expression of the mutants studied was not completely inhibited by these mutations as expression levels $>13 \%$ were achieved for all constructs. 


\section{DISCUSSION}

Recently, it has been proposed that $\sim 80 \%$ of missense mutations associated with disease states are amino acid substitutions that affect the stability of the proteins by about $\sim 1-3 \mathrm{kcal} / \mathrm{mol}$ (Wang and Moult., 2001). Stability problems can be due to loss of hydrogen bonds, of S-S bonds, overpacking, backbone strain and/or burial of charged residues. In silico strategies can be used to investigate the potential roles of a mutation on, for instance, protein stability.

In the present study, MD simulations (970 ps) were executed on the $\mathrm{C} 2$ domain of WT FV and the D2194G mutant that is present in carriers of the FVR2 gene. Because this mutation could potentially act on the formation of the nearby C2038-C2193 S-S bond and/or the conformation of the $\mathrm{N}$-term/C-term residues, simulations of the WT and D2194G S-S bondless structures were compared. Electrostatic computations were performed to investigate the energetics of the WT K2101-K2103-D2194 triad and of several mutants. Mutagenesis experiments and secretion levels were also used to probe further the 2194 region of the FV C2 domain (mutants were: D2194G, D2194K, K2101E/K2103E, K2101E/K2103E/D2194K, C2038A/C2193A) because observed secretion efficiencies often relate to mutant stability in vitro. These experimental data were correlated with theoretical work while trying to include in our reasoning the fact that protein engineering methods usually probe several physical contributions at the same time (e.g., electrostatic, steric and entropic) (Lounnas and Wade, 1997) while theoretical investigations may not.

A key step after MD computations is to evaluate the accuracy of the calculations, through for instance evaluation of RMSD, potential energy versus time and others (Figs. 1 and 2). Yet, while MD simulations with implicit solvation models have been found of reasonable accuracy, some authors suggest that despite low RMSD between the simulated structures and the starting $x$-ray model, the conformations of the simulated molecules are of poor quality (Simonson T., 2001). We thus investigated several structures of the simulated WT with the energy strain utility included in the ICM package (Molsoft) (Maiorov and Abagyan, 1998). The simulated WT and mutant C2 domains had similar structural features as the starting high resolution $x$-ray structure. Secondary structure contents in the starting $x$-ray and simulated structures (WT or mutant) computed using the method of Kabsch and Sander (1983) were similar. Furthermore, the protein core of the WT or mutant $\mathrm{C} 2$ domain remained stable during the simulations performed on structures in the absence of the S-S bond, despite increased flexibility/conformational changes in some regions of the modeled structures (Figs. 2 and 3). These results as well as the low RMSD 
calculated between the $x$-ray and modeled structures together with the ICM evaluations confirm that the implicit solvation method and simulation protocol used here are appropriate.

It has been shown that physical energy functions similar to the one used in this study can identify native-like structure from misfolded protein models and that low quality $3 \mathrm{D}$ structures tend to unfold during a simulation (Dominy and Brooks, 2002; Feig and Brooks, 2002). Although we did not observe unfolding of the D2194G mutant we noted that its total potential energy (with or without S-S bond) is significantly higher that the one of the WT (Fig. 1). Thus, in this specific case, investigation of the potentiall energy suggests overall destabilization of the protein due to the mutation.

We then analyzed trajectories obtained for the WT C2 structure (with or without $\mathrm{S}-\mathrm{S}$ bond). It is known that disulfide bonds in proteins can influence the stability as well as the folding pathway and the efficiency of folding (Kowalski et al., 1998; Omura et al., 1992; Parodi 2000). Generally, loss of a native disulfide bond reduces stability and such mutant proteins may not be able to fold, secretion can be impeded or delayed. Yet, in some situations, removal of S-S bonds does not seem to affect the $3 \mathrm{D}$ structure of a protein nor its function. In the simulation of the WT C2 domain with or without S-S-bond, the protein core remained stable. However, the increased mobility of the two termini, in the absence of S-S bond could impair correct folding/stability of the domain and damage interaction with the $\mathrm{C} 1$ domain. The WT protein without S-S bond does not express well, suggesting folding/stability problems. Similar folding/stability/expression problems were also noticed when removing S-S bond(s) in retinoschisin, a discoidin-domain containing protein (Wu and Molday, 2003).

The potential energies of the WT C2 domain (with or without S-S bond) are similar and one would not expect folding/stability problems, but S.S bond depleted 3D structures have to be analyzed with special care. It appears that removing the disulfide bond in the $\mathrm{FV} \mathrm{C} 2$ domain facilitates optimization of some energy terms (thus lower the total potential energy). This hypothesis is supported by the observation that electrostatic interactions are optimized in proteins that do not contain S-S bond as compared to molecules containing S-S bonds (Spassov et al., 1994). Thus, potential energies for the WT C2 domain with or without $\mathrm{S}$-S bond can not be directly correlated with expression levels. In addition, it can be noticed in the WT and D2194G simulations that the region $2152-2162$ is less flexible in the structure without the S-S bond. This is consistent with previous MD simulations showing that removal of an S-S bond can decrease the flexibility of large portions of a protein (Rizzuti et al., 2001). 
The protein core of the D2194G mutant with or without the S-S bond remained also stable during the simulation. However, some regions become more rigid or more flexible due to the mutation (Fig. 2). For the mutant protein without the S-S bond we observe significantly higher flexibilities within the $\mathrm{N}$ term residues as compared to the WT (simulation without S-S bond). This suggests potential folding/stability problems and/or damaged interaction with the $\mathrm{C} 1$ domain. Also it is probable that the increased flexibility of the $\mathrm{N}$-term residues due to the D2194G mutation affects the formation of the nearby $S-S$ bond. A possible in vivo scenario could be that mutant molecules (either D2194G or S-S bond free structure) could be marginally stable and could equilibrate between the folded state and an ensemble of unfolded conformations. This latter population could then be recognized inside the ER, be partially retained and degraded. This hypothesis would be in fact in good agreement with the observed low expression levels of these mutants.

\begin{tabular}{|c|c|c|c|}
\hline & & 21012103 (buried) & 2194 \\
\hline & & $\star *$ & * \\
\hline $\mathrm{hFV} \_\mathrm{C} 2$ & : & . . ANNNKQWLE IDLLKIKKITAIIT. & . LELEGCDIY \\
\hline bFV_C2 & : & . . ANNNNQWLQIDLLKIKKITAIVT. & . LELFGCDMY \\
\hline pigFV_C2 & : & . . ANNNNNQWLQIDLLKIKKITAITT. & . LELEGCDIY \\
\hline hFVIII_C2 & : & . . VNNDEKEWLQVDFQKTMKVTGVTT. & MEVLGCEAQ \\
\hline mouseFVIII_C2 & : & . . VNDPKQWLQVDLQKTMKVTGIIT. & . LEI LGCEAQ \\
\hline pigFVIII_C2 & : & . .VSSAEEWLQVDLQKTVKVTGITT & . LEVLGCEAQ \\
\hline
\end{tabular}

TABLE 3: Multiple sequence alignment in the area of FV residue 2194 and surrounding area

FV C2 domain residue D2194 is involved in electrostatic interactions with the side chains of K2101 and K2103. Conservation (full or partial) of ionic interaction in this region of FV or FVIII suggests that these salt-bridges could be important for the stability/structure of the $\mathrm{C} 2$ domain (Table 3). It has been noted that conserved salt bridges important for the stability of proteins are often buried (Schueler and Margalit, 1995) whereas in the C2 domain, the 21012103-2194 triad is partially exposed. However, surface salt bridges can also be important for protein stability (Strop and Mayo, 2000; Dong and Zhou, 2002). In fact, salt bridges can be stabilizing or destabilizing depending on their environment (Kumar and Nussinov, 2001; Kumar and Nussinov, 1999; Schutz and Warshel, 2001). In the present study, we assumed that the D2194G 
mutation could alter the stability of the FV C2 domain. Comparison of the electrostatic free energies $\left(\Delta \Lambda G^{\text {tot }}\right.$ ) of the 2101-2103-2194 triad between the WT FV C2 domain and the D2194G mutant shows electrostatic destabilization due to the mutation by $\sim 3 \mathrm{kcal} / \mathrm{mol}$. This value is in the range of what has been observed by Wang and Moult (2001). Therefore, we suggest that the D2194G mutation destabilizes the domain and that this modified structure could be detected by the proofreading apparatus inside the cells.

To understand better the reactions taking place at the level of residue 2194 , other mutants were created in vitro and in silico. Changing the distribution of charged groups in the 2194 area could underline the importance of the saltbridge network and could provide information about tolerance to amino acid substitutions. Computations of electrostatic energies of the 2101-2103-2194 triad in the mutants $\mathrm{D} 2194 \mathrm{~K}$ ( $\mathrm{D} / \mathrm{K}$, thus 3 expected positive charges), K2101E/K2103E (KK/EE, thus 3 expected negative charges), K2101E/K2103E/D2194K (DKK/KEE, modification of the distribution of charges) calculated on the rigid structures (see Table 2) also show destabilization effects in comparison to the WT (x-ray structure). The D2194K, K2101E/K2103E, K2101E/K21D3E/D2194K mutants show lower expression levels than the D2194G mutant. These experimental data correlate well with the calculated electrostatic destabilizations excluding the K2101E/K2103E/D2194K (DKK/KEE) mutant. Generally, it is expected that mutations leading to the positioning of three negatively or positively charged groups close in space will be destabilizing, as observed here in the case of the $D 2194 \mathrm{~K}(\mathrm{D} / \mathrm{K})$ and K2101E/K2103E (KK/EE) substitutions (Table 2). These mutants are thus predicted to be less stable than the D2194G mutant and this correlates well with the experimental expression levels. On the other hand, we initially hypothesized that the mutant $\mathrm{K} 2101 \mathrm{E} / \mathrm{K} 2103 \mathrm{E} / \mathrm{D} 2194 \mathrm{~K}$ (DKK/KEE) would form a stabilizing salt-bridge triad that could mimic the WT protein. However, the calculated proton occupancies at $\mathrm{pH} 7$ show that 2103 is not charged while in the WT the three triad residues are ionized. This indicates that the distribution of charges in the K2101E/K2103E/D2194K mutant is not favorable as compared to the one of the WT. Although $\Delta \Delta \mathrm{G}^{\text {tot }}$ suggests that the mutated triad is slightly stabilizing, apparently, in this case, additional structural features have to be integrated in the analysis.

In summary, the D2194G substitution in the C2 domain seems to electrostatically destabilize the structure, as shown by computer calculations. Low expression levels were observed for this mutant "suggesting also potential stability and/or folding problems. Our experimental and MD/electrostatic data shows that the right distribution of charges in the 2194 region of the $F V C_{2}$ 
domain is essential to the stability and the presence of a $\mathrm{S}-\mathrm{S}$ bond is required for the stability/folding of this essential coagulation protein.

\section{Acknowledgments}

This work was supported by the Dutch Organization for Scientific Research (NWO, GN) (grant no. 902-26-227); the Netherlands Heart Foundation (grant no. 2000-021 to J.B.); and a MW-NWO/INSERM travel grant (no.0408-023(GN and BV). A grant from the Inserm Institute "poste-vert" is also greatly appreciated. 


\section{REFERENCES}

Antosiewicz, J. J.A. McCammon, and M. Gilson. 1994. Prediction of pH-dependent properties of proteins. J. Mol. Biol. 238: 415-436

Antosiewicz, J., and D. Porschke. 1989. The nature of protein dipole moments: experimental and calculated permanent dipole of a-chymotrypsin. Biochemistry 28:10072-10078

Barril, X., C. Aleman, M. Orozco, and F.J. Luque. 1998. Salt bridge interactions: stability of the ionic and neutral complexes in the gas phase, in solution, and in proteins. Proteins $32: 67-79$

Bashford D., and D.A. Case. 2000. Generalized born models of macromolecular solvation effects. Annu. Rev. Phys. Chem. 51:129-152

Bashford, D., and M. Karplus. 1990. The pKa's of ionizable groups in proteins: atomic detail from a continuum electrostatic model. Biochemistry $29: 10219-10225$

Baumgartner, $S_{n}$, K. Hofmann, R. Chiquet-Ehrismann, and P. Bucher 1998. The discoidin domain family revisited: new members from prokaryotes and a homollogy-based fold prediction. Protein Sci. 7:1626-1631

Berman, H.M., J. Westbrook, Z. Feng, G. Gilliland, T.N. Bhat, H. Weissig, I.N. Shindyalow, and P.E. Bourne. 2000. The Protein Data Bank. Nucleic Acid's Res. 28: $235-242$

Bernardi, F., E.M. Falloni, E. Castoldi, B. Lunghi, G. Castaman, E. Sacchi, and P.M. Mannucci. 1997. A factor $V$ genetic component differing from factor $V R 506 Q$ contributes to the activated protein $C$ resistance phenotype. Blood 90:1552-1557

Brooks, B.R., R.E. Bruccoleri, B.D. Olafson, D.J. States, S. Swaminathan, and M. Karplus. 1983. CHARMM: A program for macromolecular energy, minimization and dynamics calculations. J. Comp. Chem. 4:187-217

Bross, P., T.J. Corydon, B.S. Andresen, M.M. Jørgensen, L. Bolund, and N. Gregersen. 1999. Protein misfolding and degradation in genetic diseases. Hum. Mutat. $14: 186-198$

Castoldi, E., J. Rosing, D. Girelli, L. Hoekema, B. Lunghi, F. Mingozzi, P. Ferraresi, S. Friso, R. Corrocher, G. Tans, and F. Bernardi. 2000. Mutations in the R2 FV gene affect the ratio between the two $\mathrm{FV}$ isoforms in plasma. Thromb. Haemost. $83: 362-365$

Cregut D., and L. Serrano. 1999. Molecular dynamics as a tool to detect protein foldability. A mutant of domain B1 of protein $G$ with non-native secondary structure propensities. Protein Sci. $8: 271-282$

Davis, M.E., J.D. Madura, B.A. Luty, and J.A. McCammon. 1991. Electrostatics and diffusion of molecules in solution: Simulations with the University of Houston Brownian Dynamics program. Comput. Phys. Commun. 62:187-197

Dominy, B., and C. Brooks. 1999. Development of a generalized born model parametrization for proteins and nucleic acids. J. Phys. Chem. B 103:3765-3773

Dominy, B., and C. Brooks. 2002. Identifying native-like protein structures using physicsbased potentials. J. Comput. Chem. 23:147-160

Dong, $F_{n}$, and $H_{.}-X$. Zhou. 2002. Electrostatic contributions to T4 lysozyme stability: solvent-exposed charges versus semi-buried salt bridges. Biophysical J. 83:11341- 


\section{7}

Feig, M., and C. Brooks. 2002. Evaluating CASP4 predictions with physical energy evaluations. Proteins $49: 232-245$

Gilson, M.s and B. Honig. 1988. Calculation of the total electrostatic energy of a macromalecular system: solvation energies, binding energies, and conformational analysis. Protens $4: 7-18$

Hendsch, Z.S., and B. Tidor. 1994. Do salt bridges stabilize proteins? A continuum electrostatic analysis. Protein Sci. 3:211-226

Hilser, V.J., D. Dowdy, T.G. Oas, and E. Freire. 1998. The structural distribution of cooperative interactions in proteins: analysis of the native state ensemble. Proc. Nath. Acad. Sci. USA 95:9903-9908

Hoekema, L., G.A.F. Nicolaes, H.C. Hemker, G. Tans, and J. Rosing. 1997. Human Factor $\mathrm{Va}_{1}$ and Factor Va: Properties in the Procoagulant- and Anticoagulant Pathways. Biochemistry 36:3331-3335

Kabsch, W., and C. Sander. 1983. Dictionary of protein secondary structure: pattem recognition of hydrogen-bonded and geometrical features. Biopolymers 22:25772637

Kazmirski, S.L., D.O. Alanso, F.E. Cohen, S.B. Prusiner, and V. Daggett. 1995. Theoretical studies of sequence effects on the conformational properties of a fragment of the prion protein: implications for scrapie formation. Chem. Biol. 2:305-315

Kim, S.W., M.A. Quinn-Allen, J.T. Camp, S. Macedo-Ribeiro, P. Fuentes-Prior, W. Bode, and W.H. Kane. 2000. Identification of functionally important amino acid residues within the $\mathrm{C} 2$-domain of human factor $V$ using alanine-scanning mutagenesis. Biochemistry 39:1951-1958

Kowalski, J.M., R. Parekh, and K.D. Wittrup. 1998. Secretion efficiency in Saccharomyces cerevisiae of Bovine Pancreatic Trypsin Inhibitor mutants lacking disulfide bonds is correlated with thermodynamic stability. Biochemistry 37:12641273

Kumar, S., and R. Nussinov. 1999. Salt bridge stability in monomeric proteins. J. Mol. Biol. 293:1241-1255

Kumar, S., and R. Nussinov. 2001. Fluctuations in ion pairs and their stabilities in proteins. Proteins 43:433-454

Lounnas, V., and R.C. Wade. 1997. Exceptionally stable salt bridges in cytochrome P450cam have functional roles. Biochemistry 36:5402-5417

Lunghi, B., L. lacoviello, D. Gemmati, M.G. Dilasio, E. Castoldi, M. Pinotti, G. Castaman, R. Redaelli, G. Mariani, G. Marchetti, and F. Bernardi. 1996. Detection of new polymorphic markers in the factor $V$ gene: association with factor $V$ levels in plasma. Thromb. Haemost. 75:45-48

Macedo-Ribeiro, S., W. Bode, R. Huber, A. Quinn-Allen, W. Kim, G.P. Bourenkov, H. Bartunik, M.T. Stubbs, W.H. Kane, and P. Fuentes-Prior. 1999. Crystal Structures of the Membrane-Binding C2 Domain of Coagulation Factor V. Nature 402:434439

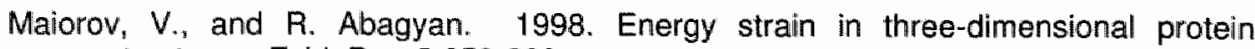
structures. Fold. Des. 3:259-269 
Mann, K.G., and M. Kalafatis. 2003. Factor V: a combination of Dr Jekyll and Mr Hyde. Blood 101:20-30

Nicolaes, G.A., and B. Dahlback. 2002. Factor $V$ and thrombotic disease: description of a janus-faced protein. Arterioscler. Thromb. Vasc. Biol. 22:530-538

Nicolaes, G.A.F., B.O. Villoutreix, and B. Dahlbäck. 1999. Partial glycosylation of $\mathrm{Asn}^{2181}$ in human factor $\mathrm{V}$ as a cause of molecular and functional heterogeneity. Modulation of glycosylation efficiency by mutagenesis of the consensus sequence for N-linked glycosylation. Biochemistry 38:13584-13591

Nicolaes, G.A., B.O. Villoutreix, and B. Dahlback. 2000. Mutations in a potential phospholipid binding loop in the $\mathrm{C} 2$ domain of factor $\mathrm{V}$ affecting the assembly of the prothrombinase complex. Blood Coagul. Fibrinolysis 11:89-100

Omura, F., M. Otsu, and M. Kikuchi. 1992. Accelerated secretion of human lysozyme with a disulfide bond mutation. Eur. J. Biochem. 205:551-559

Parodi, A.J. 2000. Role of $\mathrm{N}$-olligosaccharide endoplasmic reticulum processing reactions in glycoprotein folding and degradation. Biochem. J. 348:1-13

Pellequer, J.L., A.J. Gale, J.H. Griffin, and E.D. Getzoff. 1998. Homology models of the $\mathrm{C}$ domains of blood coagulation factors $\mathrm{V}$ and VIII: a proposed membrane binding mode for FV and FVIII C2 domains. Blood Cells Mol. Dis. 24:448-461

Pratt, K.P., B.W. Shen, K. Takeshima, E.W. Davie, K. Fujikawa, and B.L. Stoddard. 1999. Structure of the C2 domain of human factor VIII at 1.5 A resolution. Nature 402:439-442

Rizzuti, B., L. Sportelli, and R. Guzzi. 2001. Evidence of reduced flexibility in disulfide bridge-depleted azurin: a molecular dynamics simulation study. Biophys. Chem. 94:107-120

Rosing, J., H.M. Bakker, M.C. Thomassen, H.C. Hemker, and G. Tans. 1993. Characterization of two forms of human factor Va with different cofactor activities. J. Biol. Chem. 268:21130-21136

Schiffer, C.A., and W.F. van Gunsteren. 1996, Structural stability of disulfide mutants of basic pancreatic trypsin inhibitor: a molecular dynamics study. Proteins 26:66-71

Schueler, $\mathrm{O}$., and $\mathbb{H}$. Margalit. 1995. Conservation of salt bridges in protein families. $J$. Mol. Biol. 248:125-135

Schutz, C.N., and A. Warshel. 2001. What are the dielectric "constants" of proteins and how to validate electrostatic models? Proteins 44:400-417

Sharp, K.A., and B. Honig. 1990. Electrostatic interactions in macromolecules: theory and applications. Annu. Rev. Biophys. Biophys. Chem. 19:301-332

Sharp, K., A. Nicholls, R. Friedman, and B. Honig. 1991. Extracting hydrophobic free energies from experimental data: Relationship to protein folding and theoretical models. Biachemistry 30:9686-9697

Simonson, T. 2001. Macromolecular electrostatics: continuum models and their growing pains. Curr. Opin. Struct. Biol. 11:243-252

Sinha, N., and R. Nussinov. 2001. Point mutations and sequence variability in proteins: redistributions of preexisting populations. Proc. Natl. Acad. Sci. USA 98:31393144

Spassov, V.Z., A.D. Karshikoff, and R. Ladenstein. 1994. Optimization of the electrostatic interactions in proteins of different functional and folding type. 
Protein Sci. 3:1556-1569

Strop, P., and S.L. Mayo. 2000. Contribution of surface salt bridges to protein stability. Biochemistry 39:1251-1255

Tanford, C. and J.G. Kirkwood. 1957. Theory of protein titration curves. I. General equations for impenetrable spheres. J. Am. Chem. Soc. 79:5333-5339

Taverna, D.M., and A.A. Goldstein. 2002. Why are proteins so robust to site mutations? J. Mol. Biol. 315:479-484

Van Der Neut Kolfschoten, M. R.u. Dirven, H.L. Vos, and R.M. Bertina. 2003. The R2haplotype associated Asp2194Gly mutation in the light chain of human factor $V$ results in lower expression levels of $\mathrm{FV}$, but has no influence on the glycosylation of Asn2181. Thromb. Haemost. 89:429:437

Villoutreix BO, Bucher P, Hofmann K, Baumgartner S, Dahlbäck B. 1998. Molecular models for the two discoidin domains of human blood coagulation factor V. J. Mol. Model. 4:268-275

Villoutreix, B.0. 2002. Structural bioinformatics: methods, concepts and applications to blood coagulation proteins. Curr. Protein Pept. Sci. 3:341-364.

Wang, Z., and J. Moult. 2001. SNPS, Protein Structure, and Disease. Hum. Mutat. 17:263-270

Warwicker, J., and H.C. Watson. 1982. Calculation of the electric potential in the active site cleft due to a helix dipoles. J. Mol. Biol. 157:671-679

Wesson, L., and D. Eisenberg. 1992. Atomic solvation parameters applied to molecular dynamics of proteins in solution. Protein Sci. 1:227-235

Wickner, S., M.R. Maurizi, and S. Gottesman. 1999. Posttranslational quality control: Folding, refolding and degrading proteins. Science 286:1888-1893

Wu, W.W., and R.S. Molday. 2003. Defective discoidin domain structure, subunit assembly and ER processing of retinoschisin are primary mechanisms responsible for X-linked retinoschisis. J. Biol. Chem. In press.

Yamazaki, T., G.A.F. Nicolaes, K.W. Sørensen, and B. Dahlbäck. 2002. Molecular basis of quantitative factor $V$ deficiency associated with factor V R2 haplotype. Blood 100:2515-2521

Yang, A.-S., M. Gunner, R. Sampogna, K. Sharp, and B. Honig. 1993. On the calculation of pKas in proteins. Proteins 15:252-265 


\section{CHAPTER 3}

Impaired APC cofactor activity of factor V plays a major role in the APC resistance associated with the factor V Leiden (R506Q) and R2 (H1299R) mutations

Castoldi E, Brugge JM, Nicolaes GA, Girelli D, Tans G, Rosing J.

Based on: Blood, 2004, Jun 1; 103(11): 4173-4179. 


\section{SUMMARY}

APC resistance is a major risk factor for venous thrombosis. Factor $V$ (FV) gene mutations like $F V_{\text {Leiden }}(\mathrm{R} 506 \mathrm{Q})$ and $F V_{\mathrm{R} 2}(\mathrm{H} 1299 \mathrm{R})$ may cause APC resistance either by reducing the susceptibility of $F V a$ to $A P C$-mediated inactivation or by interfering with the cofactor activity of FV in APC-catalysed FVIIla inactivation. We quantified the APC-cofactor activity expressed by $F V_{\text {Leiden }}$ and $F V_{R 2}$, and determined the relative contributions of reduced susceptibility and impaired APC-cofactor activity to the APC resistance associated with these mutations. Plasmas containing varying concentrations of normal $F V, F V_{\text {Leiden }}$ or $F V_{R_{2} 2}$ were assayed with the Immunochrom APC Response test, which specifically measures the APC-cofactor activity of $\mathrm{FV}$, and with the Coatest ${ }^{\circledast 2} \mathrm{APC}^{\mathrm{rm}}$ Resistance assay, which probes both the susceptibility and APC-cofactor components. $\mathrm{FV}_{\mathrm{R} 2}$ expressed $73 \%$ of the APC-cofactor activity of normal FV, whereas $F V_{\text {Leiden }}$ exhibited no cofactor activity in FVIIla inactivation. Poor susceptibility to APC and impaired APC-cofactor activity contributed equally to FV Leiden-associated APC resistance, while $\mathrm{FV}_{\mathrm{A2}}$-associated APC resistance was entirely due to the reduced $A P C$-cofactor activity of $\mathrm{FV}_{\mathrm{R2}}$. Thrombin generation assays confirmed the importance of the anticoagulant activity of FV and indicated that $F V_{\text {Leiden }}$ homozygotes are exposed to a higher thrombotic risk than heterozygotes because their plasma lacks normal FV acting as an anticoagulant protein. 


\section{INTRODUCTION}

The protein $C$ pathway is a major anticoagulant mechanism that downregulates the prothrombin- and intrinsic factor $X(F X)$-activating complexes via inactivation of their respective cofactors activated factors $\mathrm{V}(\mathrm{FVa})$ and VIII (FVIlla) 1 . Cofactor inactivation occurs by limited proteolysis at amino acid positions 306, 506 and 679 in $\mathrm{FVa}^{2}$, and 336, 562 and 740 in FVIIla ${ }^{3}$. These reactions are catalysed by the serine protease activated protein $C$ (APC) and stimulated by the APC-cofactor protein S. In vitro experiments using purified proteins have shown that $\mathrm{FV}$ also stimulates the APC-mediated inactivation of FVIIla ${ }^{4-6}$. In order to express full APC-cofactor activity, FV must retain (part of) the $B$ domain ${ }^{4,6,7}$ and be cleaved by $A P C$ at $\operatorname{Arg}^{506}$. Although this anticoagulant function of $\mathrm{FV}$ is still poorly characterized, a recent report suggests that it plays a critical anti-thrombotic role in vivo ${ }^{9}$.

Functional defects of the protein $C$ pathway, due to inherited or acquired conditions, determine a plasma phenotype known as APC resistance ${ }^{10}$, which is a prevalent and important risk factor for venous thrombosis ${ }^{11-13}$. A plasma is termed APC resistant when the addition of exogenous APC fails to prolong its clotting time in an aPTT assay ${ }^{10}$. Since the discovery of APC resistance, several other methods have been developed to detect this condition and to study the underlying molecular mechanism.

To date, a few FV gene mutations have been identified in association with APC resistance. In principle, these mutations may cause APC resistance either by reducing the susceptibility of $\mathrm{FVa}$ to $\mathrm{APC}$-mediated inactivation (susceptibility component) or by interfering with the APC-cofactor activity of FV in FVIIla inactivation (APC-cofactor activity component). The FV R506Q mutation ( $F V_{\text {Leiden }}{ }^{14}$ ) is the major cause of hereditary APC resistance in the Caucasian population. Due to the loss of the APC-cleavage site at $\mathrm{Arg}^{506}$, $\mathrm{FV}(\mathrm{a})_{\text {Leiden }}$ is less susceptible to inactivation by $A P C{ }^{15,16}$ and expresses reduced APC-cofactor activity in FVIIla inactivation ${ }^{8,17}$. The common FV gene haplotype marked by the H1299R (R2) polymorphism ${ }^{18,19}$ has also been reported to cause mild APC resistance, particularly in the homozygous condition ${ }^{19,20}$. Although the underlying molecular mechanism remains unknown, it has been shown that $\mathrm{FV}(\mathrm{a})_{\mathrm{F} 2}$ is inactivated by $\mathrm{APC}$ at the same rate as normal $\mathrm{FVa}$, whereas its cofactor activity in APC-mediated FVIlla inactivation is impaired ${ }^{20}$. The FV R306T (FV Cambridge ${ }^{21}$ ) and FV R306G ( $\mathrm{FV}_{\text {Hong Kong }}{ }^{22}$ ) mutations, which affect the APC-cleavage site at $\mathrm{Arg}^{306}$, are rather rare and confer only mild APC resistance ${ }^{23,24}$. Among all these mutations, only $\mathrm{FV}_{\text {Leiden }}$ has been conclusively associated with an increased risk of venous thrombosis ${ }^{25}$, while $\mathrm{FV}_{\mathrm{R} 2}$ has been 
reported to increase $F V_{\text {Leiden }}$-related thrombosis risk in doubly heterozygous individuals ${ }^{26,27}$.

Although the relative weight of the susceptibility and APC-cofactor activity components in FV Leiden-associated APG resistance has never been quantified ${ }^{28}$, it is generally believed that resistance of FVateiden to APCmediated inactivation is the predominant underlying defect ${ }^{29}$ In the present study we have dissected the relative contributions of the susceptibility and APCcofactor activity components to the APC resistance associated with the FV Leiden and $F V_{R 2}$ mutations. Our findings not only indicate that poor $A P G$-cofactor activity of $\mathrm{FV}$ is a major component of APC resistance, but they also provide evidence for an important role of the anticoagulant function of $F V$ in the in vivo regulation of thrombin formation.

\section{MATERIALS AND METHODS}

\section{Plasma samples}

Venous blood was drawn in $129 \mathrm{mM}$ sodium citrate $(9: 1 \mathrm{vol} / \mathrm{vol})$. Platelet-poor plasma was obtained by centrifugation at $3,000 \mathrm{~g}$ (25 minutes at room temperature) followed by a second centrifugation at $20,000 \mathrm{~g}$ ( 30 minutes at $4{ }^{\circ} \mathrm{C}$ ), after which samples were aliquoted, snap-frozen in liquid nitrogen and stored at $-80^{\circ} \mathrm{C}$ until use.

A normal plasma pool was prepared by pooling the plasma of 74 healthy blood donors. Moreover, plasma was obtained from two $F_{\mathrm{A} 2}$ homozygotes and two $\mathrm{FV}_{\text {Leiden }}$ homozygotes. All blood samples were collected from consenting individuals in accordance to the Helsinki protocol. FV genotypes were ascertained by PCR amplification of genomic DNA followed by restriction analysis (R506Q and $\mathrm{H} 1299 \mathrm{R}$ mutations). The $\mathrm{FV}_{\mathrm{R2}}$-homozygous individuals were homozygous for the whole HR2 haplotype, as determined by direct sequencing of $F V$ exons $8,13,16$ and 25 . The demographic characteristics of the subjects who donated blood, as well as the FV, FVIII and protein $S$ levels of all plasmas, are shown in Table 1. Congenitally FV-deficient plasma was purchased from George King Bio-Medical Inc., Overland Park, KS.

\section{APC resistance assays}

Measurement of APC resistance with the Immunochrom $A P C$ Response assay

Normal pooled plasma and individual plasmas from subjects with different $\mathrm{FV}$ genotypes (two $\mathrm{FV}_{\mathrm{R} 2}$ homozygotes and two $\mathrm{FV}_{\text {Leiden }}$ homozygotes, see Table 1), respectively, were mixed with $\mathrm{FV}$-deficient plasma in various 
proportions, ranging from $2.5 \%$ to $100 \%$ sample plasma, and assayed with the Immunochrom APC Response kit (Progen Biotechnik GmbH, Heidelberg, Germany). This test ${ }^{30}$ specifically quantifies the ability of APC and its cofactors protein $S$ and $F V$ to inhibit FXa generation by the intrinsic FX-activating complex via inactivation of FVIlla. Phospholipids, $\mathrm{CaCl}_{2}$ and all relevant proteins ( $\mathrm{FIXa}$, FX and APC) are exogenously added, except for FVIII, protein S and FV, which are contributed by the plasma. The assay was performed as previously described $^{31}$ and the APC-sensitivity ratio (APCsr) was expressed as the ratio of the amounts of FXa generated in the absence and in the presence of APC. A low APCsr indicates a defect in the inactivation of FVIIla and consequent APC resistance. APCsr's were measured four times in duplicate for normal plasma, two times in duplicate for $\mathrm{FV}_{\mathrm{R} 2}$-homozygous plasma and three times in duplicate for $\mathrm{FV}_{\text {Leiden }}$-homozygous plasma.

\section{Measurement of $A P C$ resistance with the Coatest $A P C^{2 M}$ Resistance assay}

Dilutions of sample plasmas in FV-deficient plasma were also assayed with the Coatest ${ }^{\text {APC }}{ }^{\text {TM }}$ Resistance kit (Chromogenix, Mölndal, Sweden), i.e. the classical aPTT-based APC resistance test that reflects the effect of APC on both FVa and FVIlla inactivation. The test was performed according to the manufacturer's instructions in an ACL 300 Research coagulometer (Automated Coagulation Laboratory). The APC-sensitivity ratio (APCsr) was expressed as the ratio of the clotting times determined in the presence and absence of APC. Also in this assay a low APCsr indicates APC resistance. APCsr's were measured six times in duplicate for normall plasma, four times in duplicate for $\mathrm{FV}_{\mathrm{R} 2}$-homozygous plasma and three times in duplicate for $\mathrm{FV}_{\text {Leiden }}$-homozygous plasma.

\section{Statistics}

Regression lines in Figs. 1 and 2 were calculated according to the least squares method. After performing an analysis of variance (ANOVA) on the regression, the slopes of the normal $F V$ and $F V_{\mathrm{R} 2}$ lines were compared using the t-test for parallelism of regression lines.

\section{Measurement of FV, FVIII and protein S levels in plasma}

The FV concentration in plasma was measured via a prothrombinasebased chromogenic assay. ${ }^{32}$ Plasma was diluted 1:1000 in a buffer containing $25 \mathrm{mM}$ Hepes ( $\mathrm{pH} 7.7$ at room temperature), $175 \mathrm{mM} \mathrm{NaCl}, 0.5 \%$ BSA, $3 \mathrm{mM}$ $\mathrm{CaCl}_{2}$ and $10 \mu \mathrm{M}$ phospholipid vesicles (DOPS/DOPC $20 / 80 \mathrm{~mol} / \mathrm{mol}$ ), and activated with $1 \mathrm{nM}$ thrombin at $37^{\circ} \mathrm{C}$ for 10 minutes. Prothrombin activation was started by the addition of $5 \mathrm{nM} F X a$ and $1 \mu \mathrm{M}$ prothrombin (finall 
concentrations) and stopped after 2 minutes by the addition of (ice-cold) buffer containing EDTA ( $19.6 \mathrm{mM}$ final). The amount of thrombin formed, which is a measure of the FVa present in the reaction mixture, was quantitated using the chromogenic substrate $\mathrm{S} 2238$. The FV concentration was calculated from a calibration curve constructed with known amounts of purified plasma FV.

FVIII levels were calculated from the data obtained with the Immunochrom ${ }^{\circledast 2}$ APC Response assay. Since FVIII is the limiting factor under the assay conditions, the FXa generation rate is directly proportional to the FVIII concentration in plasma. Therefore, the measurement obtained in the absence of APC reflects the amount of FVIII present in a given plasma, which was expressed as percentage of the FVIII present in pooled normal plasma determined in the same experiment.

Protein $S$ levels were measured with an enzyme-linked immunosorbent assay $(E L I S A)^{33}$ in plasma samples diluted $1: 800$ or $1: 1600$ in a buffer containing $25 \mathrm{mM}$ Hepes ( $\mathrm{pH} 7.7$ at room temperature), $175 \mathrm{mM} \mathrm{NaCl}$ and $0.5 \%$ BSA. Serial dilutions of normall plasma were used as a reference.

\section{Reconstitution experiments}

Human FV was purified from pooled normal plasma and from the plasma of a $\mathrm{FV}_{\text {Leiden }}$-homozygous individual, as described. ${ }^{34}$ Purified $\mathrm{FV}$ was desalted on a PD-10 column (Pharmacia Biotech, Uppsala, Sweden) and the FV concentration was measured as described above. Congenitally FV-deficient plasma (George King Bio-Medical Inc., Overland Park, KS) was supplemented with purified $\mathrm{FV}$ to various final concentrations, ranging from $0.6 \mathrm{nM}(2.5 \%)$ to $23 \mathrm{nM}(100 \%)$, and the APCsr of the reconstituted plasmas was determined with the Coatest ${ }^{(1)} \mathrm{APC}^{\text {IN }}$ Resistance assay kit (Chromogenix, Mölndal, Sweden).

\section{Measurement of thrombin generation}

The plasma concentration of FV was varied between $10 \%$ and $120 \%$ of the normal level by adding a variable amount of purified normal $F V$ or $F V_{\text {Leiden }}$ to congenitally FV-deficient plasma (George King Bio-Medical Inc., Overland Park, $\mathrm{KS}$ ). In a similar way, FV-deficient plasma was reconstituted with normal FV and/or $F V_{\text {Leiden }}$ to simulate normal plasma $(100 \%$ normal $F V)$, $F V_{\text {Leiden }}{ }^{-}$ heterozygous plasma ( $50 \%$ normal $\mathrm{FV}$ and $50 \% \mathrm{FV}_{\text {Leiden }}$ ), $\mathrm{FV}_{\text {Leiden }}$-homozygous plasma (100\% $\mathrm{FV}_{\text {Leiden }}$ ) and $\mathrm{FV}_{\text {Leiden }}$ pseudo-homozygous ${ }^{35}$ plasma (50\% $F V_{\text {Leiden }}$ only). Plasma doubly heterozygous for $F V_{\text {Leiden }}$ and $F V_{R 2}$ was obtained

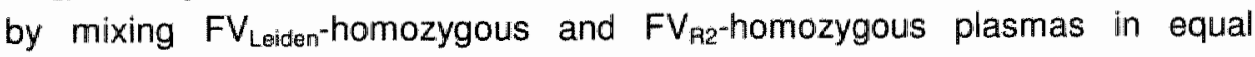
proportions.

Thrombin generation was measured essentially as described ${ }^{36}$. Plasma was mixed with a low-affinity fluorogenic substrate for thrombin (Z-Gly-Gly-Arg- 
AMC, BACHEM AG, Bubendorf, Switzerland, $300 \mu \mathrm{M}$ final) and coagulation was: initiated with a mixture containing recombinant tissue factor (TF, Dade Innovin ${ }^{6}$ ), synthetic phospholipid vesicles (DOPS/DOPC/DOPE 20/60/20 $\mathrm{mol} / \mathrm{mol} / \mathrm{mol}$ ) and $\mathrm{CaCl}_{2}$ (final concentrations in plasma: $\sim 320 \mathrm{pg} / \mathrm{ml}$ TF $(\sim 6.8$ $\mathrm{pM}), 15 \mu \mathrm{M}$ phospholipids and $16 \mathrm{mM}$ added $\mathrm{CaCl}_{2}$ ), in the absence or presence of APC $(5,10$ or $20 \mathrm{mM}$, as specified below). The formation of

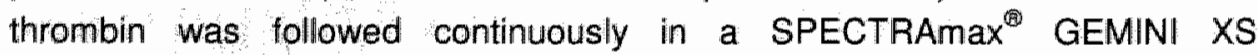
fluorometer (Molecular Devices Corporation, Sunnyvale, CA), using $368 \mathrm{~nm}$ (excitation) and $460 \mathrm{~nm}$ (emission) filters. A thrombin standard (Synapse b.v., Maastricht, The Netherlands; was used to correct the raw fluorescence data for inner-filter effect and substrate consumption and to convert relative fluorescence units (RFUs) into $n M$ thrombin. After subtraction of the signal attributable to the $\alpha_{2} M$-thrombin complex, the first derivative of the data was calculated to obtain the fully corrected thrombin generation curve, and the underlying area (endogenous thrombin potential, ETP) was determined according to Hemker et al. ${ }^{37}$. Each time-course of thrombin generation was measured in duplicate. 


\section{RESULTS}

\section{APC-cofactor activity of $F V_{\text {Leiden }}$ and $F V_{R 2}$}

The concentration of normal $F V, F V_{\text {Leiden }}$ and $F V_{R 2}$ in plasma was varied between $2.5 \%$ and $100 \%$ by mixing normal plasma, $\mathrm{FV}_{\text {Leiden }}$-homozygous plasma and $F V_{\mathrm{R}^{2}}$-homozygous plasma, respectively, with $\mathrm{FV}$-deficient plasma. The APCsr of the plasma mixtures was determined with the Immunochrom APC Response test, which specifically probes the APC resistance resulting from poor APC-cofactor activity of FV in FVIIla inactivation ${ }^{30}$. As shown in Fig. 1, the APCsr increased linearly with increasing concentrations of normal FV and $\mathrm{FV}_{\mathrm{R} 2}$, while it remained virtually constant and independent of the $\mathrm{FV}$

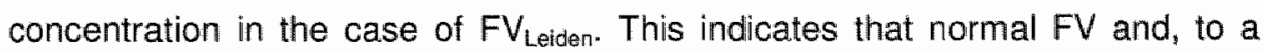
lesser extent, $F V_{R 2}$ act as cofactors in APC-catalysed FVIlla inactivation, whereas $\mathrm{FV}_{\text {Leiden }}$ lacks APC-cofactor activity in FVIlla inactivation.

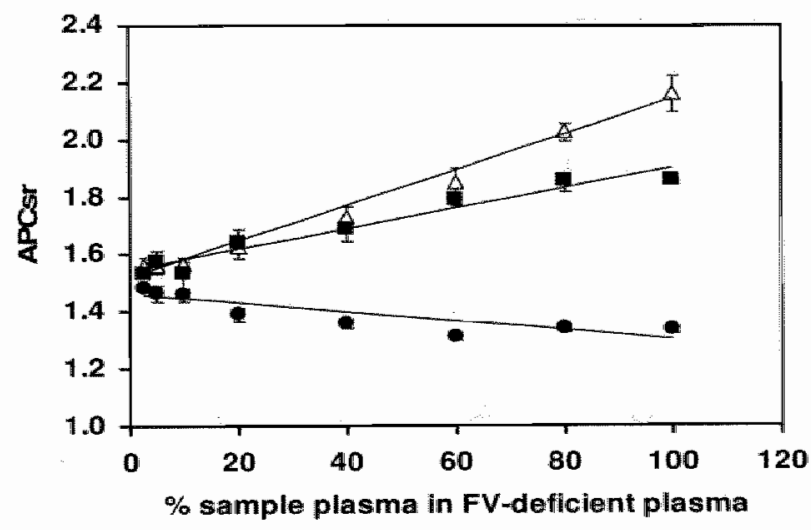

FIGURE 1: Effect of FV level on the APCsr determined with the Immunochrom APC Response test. The FV level was varied by mixing sample plasma with FVdeficient plasma in different proportions and the APCsr was determined as described under Methods. Each point is the average of two or more duplicate experiments, with error bars representing one standard error above and below the mean. $\Delta$, normal plasma; $\mathbf{E}, \mathrm{FV}_{\mathrm{A2}-\text {-homozygous plasma; }}-\mathrm{FV}_{\text {Leiden }}$-homozygous plasma.

Taking into account the actual amount of FV present in the different plasmas (Table 1), we calculated the slopes of the lines ( $\triangle \mathrm{APCsr} / \mathrm{UU}$ FV), which are a measure of the APC-cofactor activity of the FV contained in the respective plasma samples. The slopes obtained with $\mathrm{FV}_{\mathrm{R} 2}(\triangle \mathrm{APCsr}=0.45 / \mathrm{IU} \mathrm{FV}, 95 \% \mathrm{Cl}$ $0.35-0.56$ ) and normal FV ( $\triangle \mathrm{APCsr}=0.62 / \mathrm{UU} \mathrm{FV}, 95 \% \mathrm{Cl} 0.55-0.69$ ) were significantly different $(P<0.005)$ and indicated that $F V_{A 2}$ expresses $73 \%$ of the 
APC-cofactor activity of normal FV. FV Leiden $(\triangle \mathrm{APCsr}=-0.14 / \mathrm{UU} \mathrm{FV}, 95 \% \mathrm{Cl}$ $0.23-0.06$ ) expresses no APC-cofactor activity and might even slightly inhibit APC-catalysed FVIIla inactivation.

\section{Effect of FV concentration on the APCsr determined with the Coatest APC $^{\text {Tim }}$ Resistance assay}

We also determined the effect of FV concentration on the APCsr measured with the Coatest ${ }^{(1)}$ APC $^{\text {M }}$ Resistance assay (Fig. 2A). Since in this test clotting is initiated via the intrinsic pathway, both FVIIla and FVa inactivation by APC contribute to the test result (APCsr). Consequently, variation of the FV concentration in plasma can affect the APCsr by modifying the rates of both FVIlla inactivation, in which FV acts as a cofactor of APC, and FVa inactivation, in which FVa is the substrate of APC.

As shown in Fig. 2A, the dependence of the APCsr on the FV concentration in plasma was different for $F V_{\text {Leiden }}$ (closed circles) and normal $F V$ (open triangles). Variation of the concentration of $\mathrm{FV}_{\text {Leiden }}$ between $2.5 \%$ and $100 \%$ did not significantly affect the APCsr, which remained constant at about 1.5. This not only confirms that $F V_{\text {Leiden }}$ does not express APC-cofactor activity, but also shows that, under the assay conditions, the susceptibility of FVa to APC is independent of the FV concentration. In contrast, variation of the amount of normal FV from $2.5 \%$ to $100 \%$ caused the APCsr to increase from 2.3 to 3.3 . Since the susceptibility of FVa is independent of the FV concentration, this increase in APCsr is attributable to an increase in the APC-cofactor activity at increasing FV concentration. At very low FV levels, where the APC-cofactor activity is negligible, the difference between the APCsr of plasmas containing normal $F V$ and $F V_{\text {Leiden }}$ is entirely due to the difference in the susceptibility of normal and mutant FVa for APC, which does not change when the FV concentration is increased. Thus, the difference in APCsr between plasmas containing normal FV and $F V_{\text {Leiden }}$ at any given FV concentration can be resolved in a susceptibility component, which is constant and independent of the FV concentration, and an APC-cofactor activity component, which progressively increases at increasing FV (Fig. 2B). At $100 \%$ FV, i.e. in full plasma, the difference between the APCsr of normal plasma and FV Leidenhomozygous plasma ( $\triangle \mathrm{APCsr}=1.81, \mathrm{Fig} .2 \mathrm{~A}$ ) is due for $49 \%$ to the fact that $\mathrm{FVa}_{\text {Leiden }}$ is less susceptible to APC-mediated inactivation than normal $\mathrm{FVa}$, and for $51 \%$ to the fact that $\mathrm{FV}_{\text {Leiden }}$ expresses no APC-cofactor activity in the inactivation of FVIIla (Fig. 2B). 

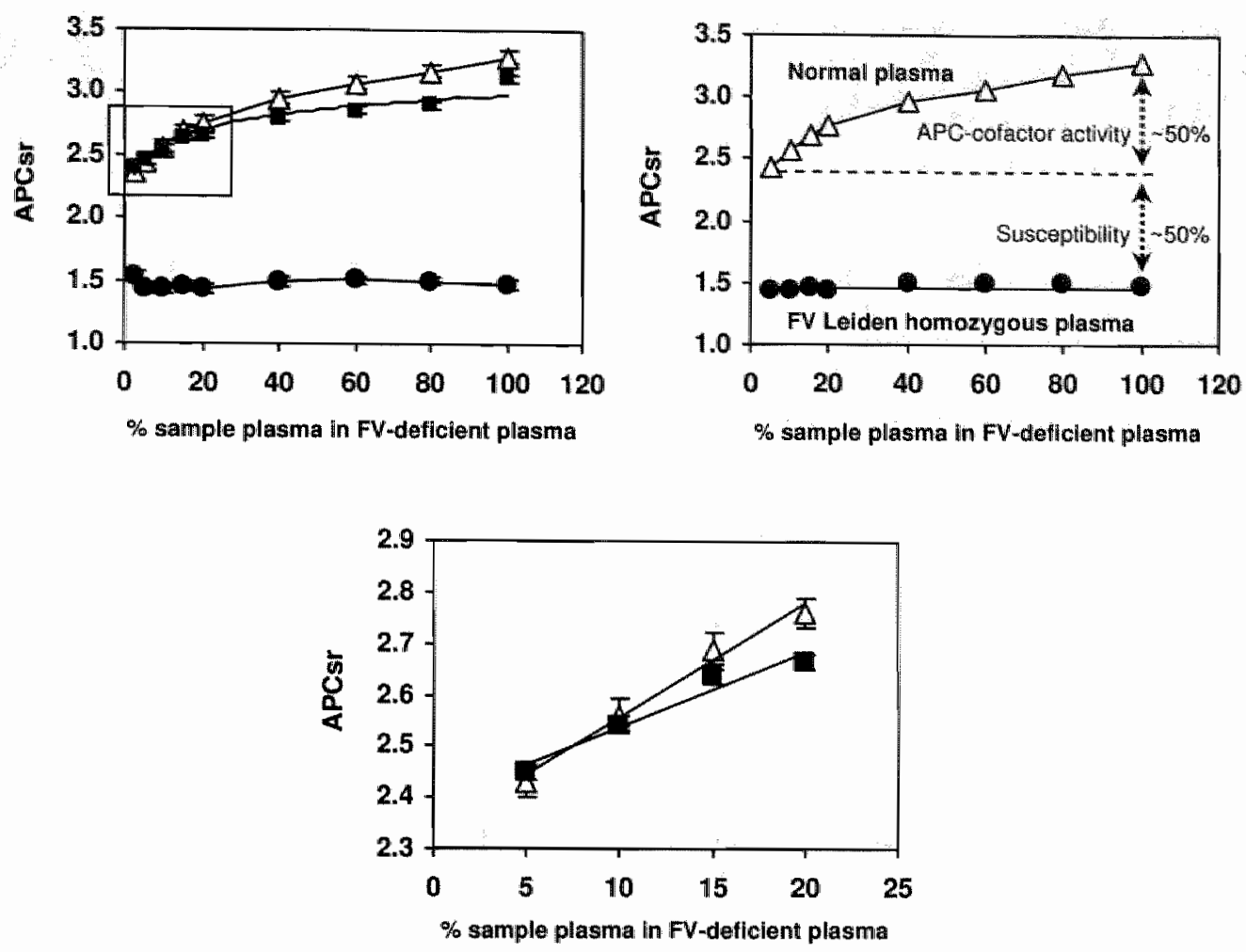

FIGURE 2: Effect of FV level on the APCsr determined with the Coatest 8 APCTM Resistance assay. A) Plot of the APCsr as a function of FV concentration. The FV level was varied by mixing sample plasma with FV-deficient plasma in different proportions and the APCsr was determined as described under Methods. B) The difference in APCsr

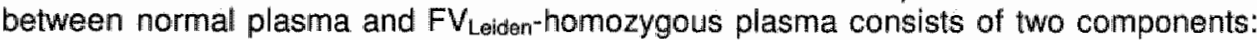
a) poor susceptibility of $F V a_{\text {Leiden }}$ to $A P C$, quantified by the difference between the $Y$-axis intercepts of the APCsr plots of normal and FV Leiden-homozygous plasma, and b) impaired APC-cofactor activity of $F V_{\text {Leiden }}$ in FVIIIla inactivation, whose contribution to the APCsr is deduced by subtracting the susceptibility component from the total APCsr difference between normal and $\mathrm{FV}_{\text {Leiden }}$-homozygous plasma measured in full plasma. $\mathrm{C}$ ) Blow-up of the inset in panel A. Each point is the average of three or more duplicate experiments, with error bars representing one standard error above and below the mean. $\triangle$, normal plasma; $\mathbf{D V}_{\text {, }}$-homozygous plasma" $\bullet, \mathrm{FV}_{\text {Leiden }}$-homozygous plasma.

It should be emphasized that the FV-deficient plasma used to dilute sample plasmas, in contrast to many other commercially available FV-deficient plasmas ${ }^{38}$, had a normal protein $\mathrm{S}$ level (Table 1). This congenitally FVdeficient plasma was chosen to avoid varying the protein $S$ levels (and thereby affect the APCsr) when mixing sample plasma and FV-deficient plasma in different proportions. 


\begin{tabular}{|c|c|c|c|c|c|c|}
\hline Plasma & Source & $A g(y r)$ & Sex & $\%$ FV & s. FIII & \% prateins \\
\hline Normal pool & Healthy blood fonorw $(N=7.4)$ & $400( \pm 8 \mathrm{SD})$ & $\mathrm{M} / \mathrm{F}(45 / 29)$ & $100 \%$ & $100 \%$ & $100 \%$ \\
\hline FVis homozygoti & Healthy blood donor & 55 & $\mathrm{M}$ & $77 \%$ & $150 \%$ & $132 \%$ \\
\hline FVar horiorygote & Cononaropathic patient & 49 & $\mathrm{M}$ & $80 \%$ & $82 \%$ & $104 \%$ \\
\hline FVIAtuet homozygote & Healthy blood donor & $28:$ & $\mathrm{F}$ & $91 \%$ & $76 \%$ & 740 \\
\hline 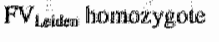 & Thrombotic patient & 79 & M & $121 \%$ & $155 \%$ & $116 \%$ \\
\hline Fvodeficient plasmei & Commerela (George King) & - & $\ldots$ & $<1 \%$ & $118 \%$ & 1130 \\
\hline
\end{tabular}

\section{TABLE 1: Definition of sample pllasmas}

The variation of the APCsr with the concentration of $F_{\mathrm{R} 2}$ (Fig. 2A, closed squares) was similar to that observed with normal FV (Fig. 2A, open triangles). This is in line with the report that $\mathrm{FV}_{\mathrm{R2}}$ has a minor effect on the APCsir determined with the aPTT-based APC resistance test ${ }^{20}$.

Since the increase in APCs.r with the FV concentration is due to APCcofactor activity, the initial slopes of the lines in Fig. $2 \mathrm{~A}$ can be taken as a measure of the APC-cofactor activity expressed by the FV contained in the respective plasma. Fig. $2 \mathrm{C}$ shows that the initial slope of the APCsr plot as a function of the $F V$ concentration was actually lower for $F V_{R 2}(\triangle A P C s r=1.86 / 1 U$ $\mathrm{FV}, 95 \% \mathrm{Cl} 0.65-3.08)$ than for normal $\mathrm{FV}(\triangle \mathrm{APCsr}=2.24 / \mathrm{UU} \mathrm{FV}, 95 \% \mathrm{Cl} 1.36-$ 3.13), suggesting that $F V_{R 2}$ expresses reduced $A P C$-cofactor activity, but confidence intervals largely overlapped and the difference did not reach significance.

Since the plasma from the two $\mathrm{FV}_{\text {Leiden }}$-homozygous donors might not have been representative for all $F V_{\text {Leiden }}$ homozygotes, we repeated the Coatest experiment using FV-deficient plasma reconstituted with varying amounts of purified normal FV or FV Leiden. Plasma reconstituted with normal FV exhibited a similar dependence of the APCsr on the FV concentration as normal pooled plasma, while plasma reconstituted with $F V_{\text {Leiden }}$ behaved the same as the plasma from the $F V_{\text {Leiden }}$-homozygous individual, showing a constant APCsr of 1.5 (data not shown). Therefore, our results can be generalized to any homozygous carrier of $F V_{\text {Leiden. }}$.

\section{Effect of the APC-cofactor activity of FV on TF-initiated thrombin generation}

The experiments described above indicate that impaired APC-cofactor activity of $F V$ is an important component of $F V_{\text {Leiden }}$-associated APC resistance as measured with the Coatest assay. To evaluate the role of the anticoagulant 
function of FV within a more physiological setting, we used a thrombin generation assay in which coagulation was initiated via the extrinsic pathway at a low TF concentration (6.8 pM). Control experiments performed in FVIIIdeficient plasma with and without added FVIII demonstrated that the intrinsic FX-activating complex significantly contributes to $\mathrm{FXa}$ (and thus thrombin) generation under these experimental conditions, both in the absence and presence of APC (data not shown).

First of all, we performed a FV titration of thrombin generation in FV. deficient plasma reconstituted with purified normal $F V$ or $F V_{\text {Laiden. }}$ In the absence of APC (Fg. 3A,B), increasing the concentration of normal FV or $F V_{\text {Leiden }}$ up to about $60 \%$ of the normal plasma concentration resulted in a gradual increase of the amount of thrombin formed and in a decrease of the time of onset of thrombin generation. At higher FV concentrations both the time of onset of thrombin generation and the total amount of thrombin formed did not further change. In the presence of $A P C(10 \mathrm{nM})$, increasing the concentration of normal FV caused an initial increase of thrombin generation (up to $60 \% \mathrm{FV}$ ), which was followed by a progressive decrease of thrombin generation (Fig. 3C). This decrease is presumably attributable to the increasing anticoagulant activity expressed by increasing amounts of normal FV. Conversely, when the same experiment was performed with $F V_{\text {Leiden, }}$ which expresses no APC-cofactor activity, thrombin generation in the presence of APC steadily increased towards a maximum and hardly any decrease at the highest FV concentrations was observed (Fig. 3D).
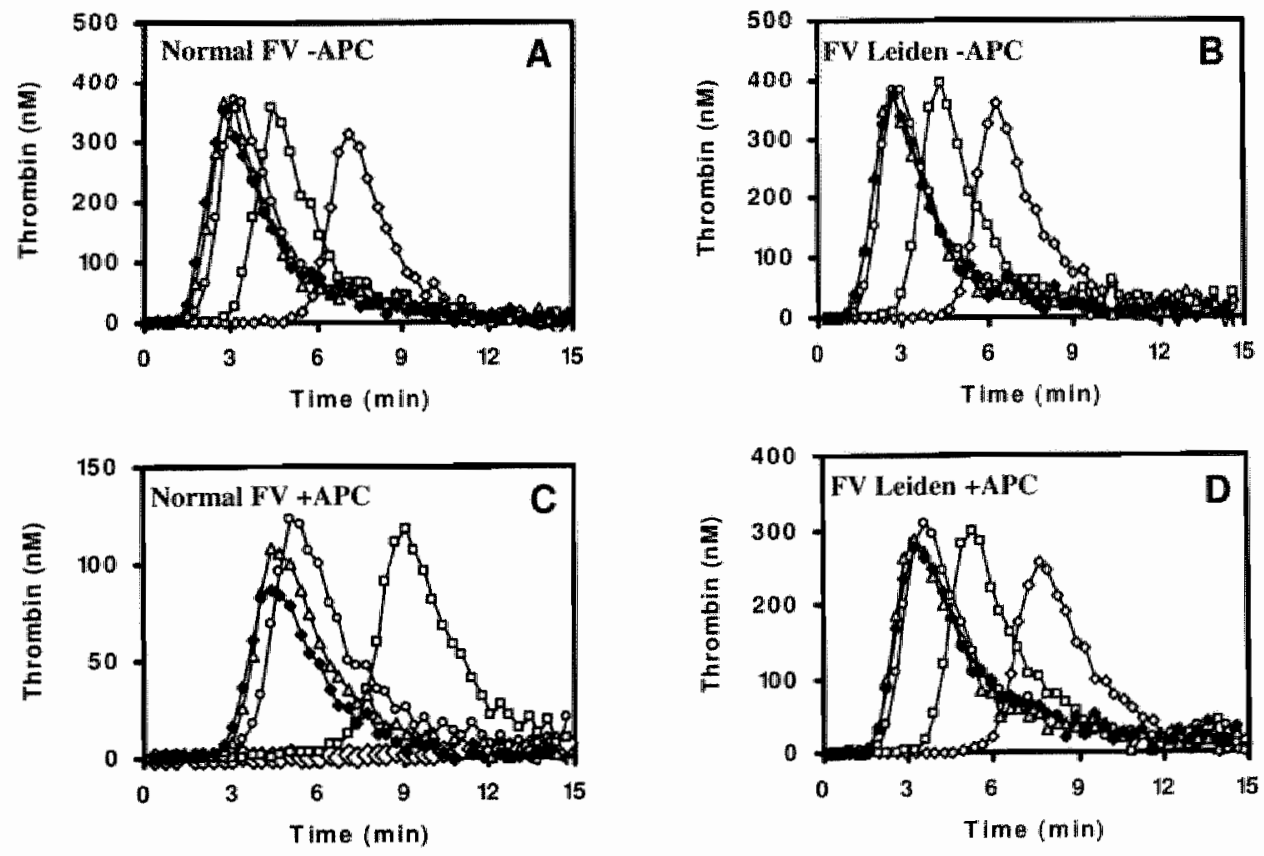
FIGURE 3: Effect of FV concentration on thrombin generation. Congenitally FVdeficient plasma was reconstituted with varying amounts of purified normal $F V(A, C)$ or FV Leiden $(B, D)$. Thrombin generation after extrinsic activation of plasma in the absence $(A, B)$ or presence $(C, D)$ of 10 nM APC was measured as described under Methods. $O$, $10 \% \mathrm{FV} ; \mathrm{D}, 20 \% \mathrm{FV} ; \mathrm{O}, 60 \% \mathrm{FV} ; \triangle 100 \% \mathrm{FV} ; 1,120 \% \mathrm{FV}$.

We also simulated normal, $F V_{\text {Leiden-heterozygous, } F V_{\text {Leiden }} \text {-homozygous }}$ and $F V_{\text {Leiclen }}$ pseudo-homozygous plasmas by reconstituting $F V$-deficient plasma with the appropriate amount of purified normal $F V$ and/or $F V_{\text {Leiden. }}$ Following initiation of coagulation with TF in the absence of APC (Fig. 4A), all plasmas ylelded superimposable thrombin generation curves, except for $F V_{\text {Leiden }}$ pseudohomozygous plasma which showed a slightly longer lag phase due to its lower (50\%) FV concentration. In the presence of $20 \mathrm{nM} \mathrm{APC} \mathrm{(Fig.} \mathrm{4B),} \mathrm{strong}$ inhibition of thrombin generation was observed in FV-deficient plasma reconstituted with normal $F V$ (open triangles). In contrast, simulated $F V_{\text {Leiden- }}$ homozygous (100\% $\mathrm{FV}_{\text {Leiden, }}$ closed circles) and pseudo-homozygous (50\% FV Leiden, open diamonds) plasmas were fully resistant to APC, with identical ETPs in the presence and absence of APC. In FV $\mathrm{F}_{\text {Leiden }}$-heterozygous plasma (open circles), which differs from pseudo-homozygous plasma by the additional presence of $50 \%$ normal $F V$, about half as much thrombin was formed as in pseudo-homozygous plasma. This reduction in thrombin generation is likely due to the anticoagulant activity expressed by normal FV in the presence of APC.
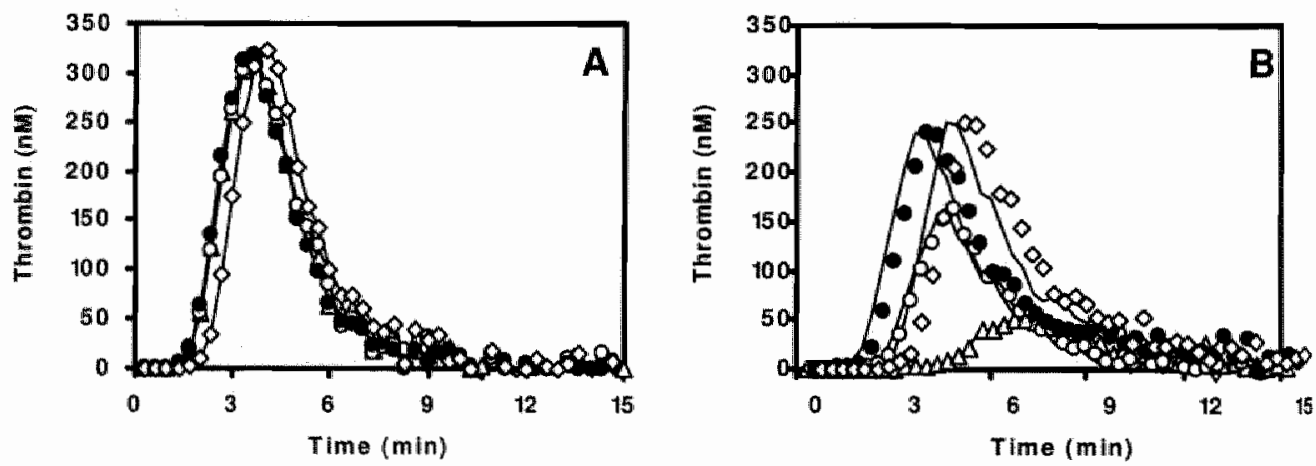

FIGURE 4: Thrombin generation in FV-deficient plasma reconstituted with normal FV and/or FV Lelden. Congenitally FV-deficient plasma was reconstituted with purified normal $F V$ and/or $F V_{L \text { Liden }}$ in order to simulate normal plasma $(\triangle), F V_{\text {Leiden }}$-heterozygous plasma (O), FV Leiden-homozygous plasma (O) and $F V_{\text {Leiden }}$ pseudo-homozygous plasma $(\diamond)$. Thrombin generation after extrinsic activation of plasma in the absence $(\mathrm{A})$ and presence (B) of $20 \mathrm{nM}$ APC was measured as described under Methods. 
Since $\mathrm{FV}_{\mathrm{R} 2}$ expresses reduced APC-cofactor activity in FVIII(a) inactivation (Figs. 1 and $2 \mathrm{C}$ ), we expected that more thrombin would be generated in $\mathrm{FV}_{\mathrm{R}}$-homozygous plasma than in normal plasma following activation in the presence of APC. As a matter of fact, the amount of thrombin formed in the plasma from a $\mathrm{FV}_{\mathrm{F} 2}$-homozygous individual in the presence of APC $(5 \mathrm{nM}$ ) was $23 \%$ of that in the absence of APC (Fig. 5B), as compared to a residual thrombin generation of $13 \%$ in normal pooled plasma ( $\mathrm{Fig} .5 \mathrm{~A}$ ). In other words, while virtually equal amounts of thrombin were formed in the absence of APC, in the presence of APC the plasma from the FV F2 $_{\text {homozygote generated }}$ 1.8 times more thrombin than normal pooled plasma. To exclude the possibility that increased thrombin generation in $\mathrm{FV}_{\mathrm{R} 2}$-homozygous plasma in the presence of APC was due to plasma components other than $F V$, we repeated the experiment after a 5 -fold dilution of both plasmas in FV-deficient plasma and verified that the difference persisted (data not shown).
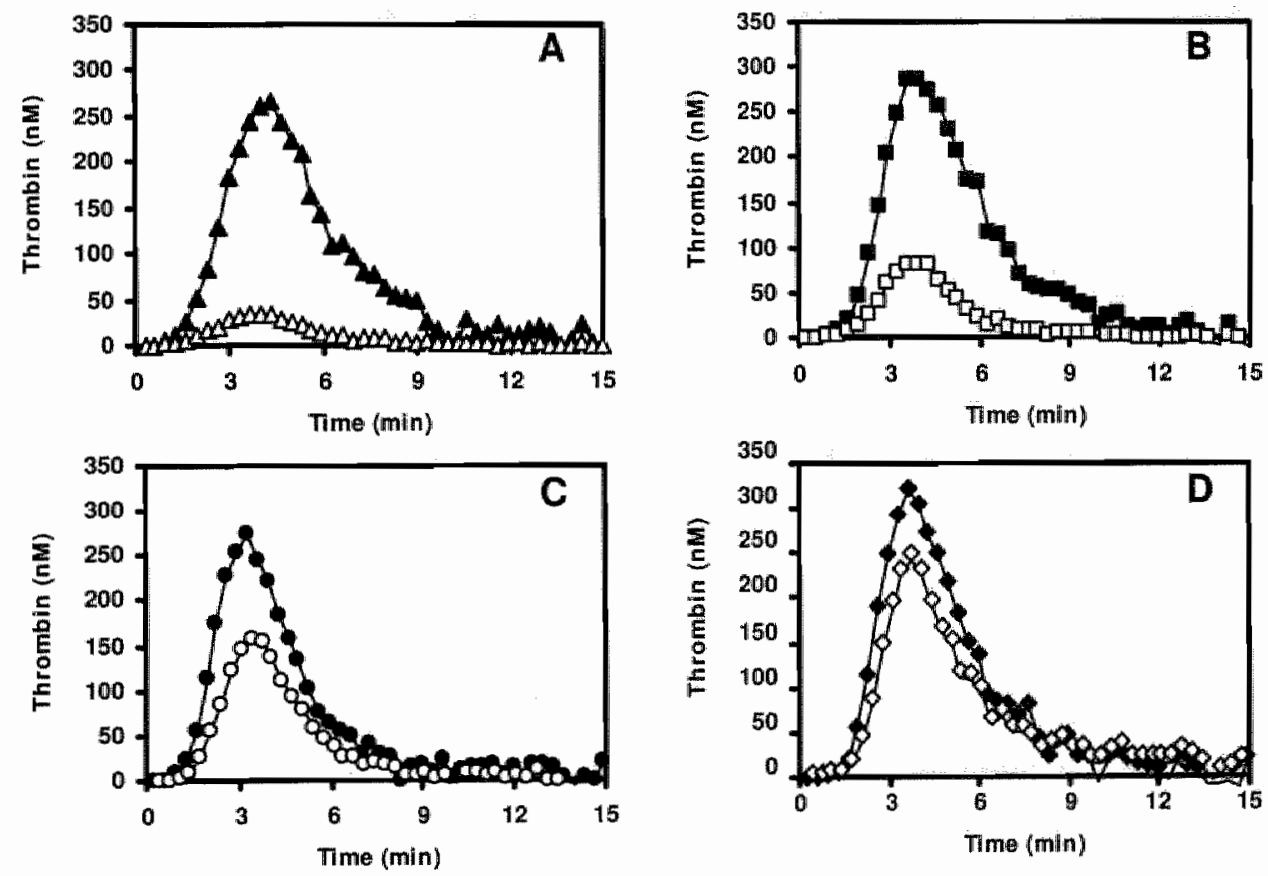

FIGURE 5: Thrombin generation in plasmas containing $F V_{A 2}$ and/or $F V_{\text {Leiden. }}$ Thrombin generation after extrinsic activation of plasma in the absence (closed symbols) and presence (open symbols) of $5 \mathrm{nM}$ APC was measured as described under Methods. (A) normal pooled plasma; (B) plasma of a $F V_{R 2}$-homozygous individual; (C) $F V_{\text {Leidem- }}$ heterozygous plasma obtained by pooling plasma from two unrelated $F V_{\text {Leiden }}$ heterozygous individuals; (D) simulated $\mathrm{FV}_{\text {Leiden }} / \mathrm{FV}_{\mathrm{Rz}}$-doubly heterozygous plasma obtained by mixing plasma from a FV Leiden-homozygous individual and from a FV Fa* homozygous individual in equal proportions. 
Since it has been reported that co-inheritance of $F V_{R 2}$ enhances the $A P C$ resistance ${ }^{19,39}$ and the thrombotic risk ${ }^{26,27}$ associated with $F V_{\text {Leiden, we }}$ also investigated the combined effect of $\mathrm{FV}_{\mathrm{P} 2}$ and $\mathrm{FV}_{\text {Leiden }}$ on thrombin generation in the presence and absence of APC. To this end, a simulated $F V_{\text {Leiden }} / F V_{P_{2}}$-doubly heterozygous plasma, prepared by mixing $F V_{\text {Leiden- }}$ homozygous and $\mathrm{FV}_{\mathrm{R2}}$-homozygous plasmas in equal proportions, was compared to pooled plasma from two $F V_{\text {Leiden }}$ heterozygous individuals. In the presence of $5 \mathrm{nM} \mathrm{APC}$ residual thrombin generation (relative to thrombin generation in the same plasma triggered in the absence of APC) was $55 \%$ in FV Leiden -heterozygous plasma (Fig. $5 \mathrm{C}$ ) and $79 \%$ in $\mathrm{FV}_{\text {Leiden }} / \mathrm{FV}_{\mathrm{R2}}$-doubly heterozygous plasma (Fig. 5D). 


\section{DISCUSSION}

In the original report on APC resistance, Dahlbäck and coworkers observed that the addition of normal plasma to APC-resistant plasma corrected the abnormal phenotype and they concluded that APC resistance was due to the defect of a new APC-cofactor ${ }^{10}$, which later turned out to be FV ${ }^{40}$. Subsequently, the ability of FV to stimulate APC-mediated inactivation of FVIlla was proven directly in model systems containing purified proteins ${ }^{4-6}$. However, after the $F V_{\text {Leiden }}$ mutation was discovered as the main cause of APC resistance ${ }^{14}$, little attention was paid to the role of FV as an APC-cofactor. The abolition of the APC-cleavage site at $\mathrm{Arg}^{506}$, which impaired the inactivation of $\mathrm{FVa}_{\text {Leiden }}$ in in vitro studies 15,16,29,44, appeared a satisfactory explanation for the APC resistance associated with the mutation. Only when it was reported that $F V_{\text {Leiden }}$ is a poor cofactor in APC-catalysed FVIIla inactivation ${ }^{8.17}$, was it realized that reduced $A P C$-cofactor activity may also contribute to $\mathrm{FV}_{\text {Leiden }}$-associated APC resistance.

Here we demonstrate that FV plays a crucial role in the APC-mediated inactivation of FVIlla in plasma and that this anticoagulant activity of FV is lost in $F V_{\text {Leiden }}$ (Fig. 1). This result extends to the plasma milieu previous reports on the APC-cofactor activities of purified and recombinant $\mathrm{FV}$ and $F V_{\text {Leiden }}$ determined in model systems of FVIlla inactivation ${ }^{4-6,8}$. Furthermore we show that, although reduced susceptibility of $\mathrm{FVa}_{\text {Leiden }}$ to APC-catalysed inactivation remains an important determinant of $F V_{\text {Leiden-associated } A P C \text { resistance, }}$ impaired APC-cofactor activity of FV Leiden in FVIIla inactivation accounts for about half of the difference between the APCsr of normal individuals and $\mathrm{FV}_{\text {Leiden }}$ homozygotes, as measured with the Coatest ${ }^{\text {APC resistance assay }}$ (Fig. 2B).

In order to gain an insight into the physiological role of the anticoagulant activity of FV, we measured thrombin generation in plasma after initiation of coagulation via the extrinsic pathway. This assay allows the evaluation of the overall efficiency of the coagulation system under conditions that are close to the in vivo situation ${ }^{42}$. To ensure that $\mathrm{FXa}$ formed via the intrinsic $\mathrm{FX}$-activating complex contributes to thrombin generation, coagulation was initiated with a low TF concentration. As illustrated in Fig. 3C, increasing the concentration of normal FV in plasma triggered in the presence of APC led to an initial increase of thrombin generation, followed by a gradual decrease at FV concentrations higher than $60 \%$. This remarkable pattern is likely explained by the dual function of $\mathrm{FV}$ in coagulation. At low FV concentrations the procoagulant activity of FV prevails over the anticoagulant activity, leading to progressively higher thrombin generation at increasing FV concentration. However, at a FV level of $60 \%$, the 
procoagulant activity of $F V$ is saturated (Fig. 3A), and a further increase of the FV concentration results in increased anticoagulant activity and consequently decreased thrombin generation. This interpretation is supported by the parallel experiment conducted with $F V_{\text {Leiden }}$ (Fig. 3D), which showed hardly any inhibition of thrombin generation in the presence of APC at high FV concentrations, thus confirming that $F V_{\text {Leiden }}$ expresses no anticoagulant activity.

The physio-pathological relevance of the APC-cofactor activity of FV is well illustrated by the comparison of heterozygosity, homozygosity and pseudohomozygosity ${ }^{35}$ for the $F V_{\text {Leiden }}$ mutation as shown in Fig. 4. FV-deficient plasma reconstituted with $50 \%$ purified $\mathrm{FV}_{\text {Leiden }}$ (which corresponds to the plasma of a $F V_{\text {Leiden }}$ Pseudo-homozygous individual) was fully resistant to APC in the thrombin generation test. However, when $50 \%$ normal FV was added to this plasma, thrombin generation in the presence of APC was reduced by half (Fig. 4B), due to the anticoagulant activity expressed by the normal FV. Conversely, the addition to $\mathrm{FV}_{\text {Leiden }}$ pseudo-homozygous plasma of $50 \% \mathrm{FV}_{\text {Leiden }}$ (which does not express APC-cofactor activity) was ineffective in decreasing thrombin generation in the presence of APC (Fig. 4B). These findings may explain the respective thrombotic risks associated with heterozygosity, homozygosity and pseudo-homozygosity for the $\mathrm{FV}_{\text {Leiden }}$ mutation. Moreover, they suggest that the reason why $F V_{\text {Leiden }}$ homozygotes are exposed to a higher thrombotic risk than heterozygotes is not the presence of twice as much $F V_{\text {Leiden }}$ in their plasma, but the absence of normal FV capable of expressing anticoagulant activity. This is in line with the recent in vivo observation that the thrombotic lethality of $F V_{\text {Leiden }}$ pseudo-homozygous mice with heterozygous TFPI deficiency ( $\mathrm{FV}^{\mathrm{Q}-} \mathrm{TFPI}^{+/-}$genotype) can be corrected by transgene expression of wila'type $\mathrm{FV}^{\prime \prime}$.

In contrast to $F V_{\text {Leiden, }}$ the APC-cofactor activity of $F V_{R 2}$ is reduced to $73 \%$ of that of normal FV (Figs. 1 and $2 \mathrm{C}$ ). However, since $F V_{R 2}$ is expressed at a lower level than normal FV ${ }^{18,20,39}$, the overall APC-cofactor activity contained in the plasma of a typical $\mathrm{FV}_{\mathrm{R} 2}$ homozygote with a FV level of $\sim 75 \%$ is actually about half of that present in normal plasma. Since it has been reported that $\mathrm{FVa}_{\mathrm{R} 2}$ and normal $\mathrm{FVa}$ are inactivated at equal rates by $\mathrm{APC}$, both in the presence and in the absence of protein $S^{20}$, reduced APC-cofactor activity in FVIIla inactivation appears to be the only determinant of the mild APC resistance observed in carriers of the $\mathrm{FV}_{\mathrm{R2}}$ haplotype. The patho-physiological consequences of the decreased anticoagulant activity of $F V_{R 2}$ are apparent in the thrombin generation assay, which shows that $\mathrm{FV}_{\mathrm{R} 2}$-homozygous plasma forms almost twice as much thrombin as normal plasma in the presence of $5 \mathrm{nM}$ $\mathrm{APC}$ (Fig. 5A,B). Although the plasma of only a single $\mathrm{FV}_{\mathrm{R} 2}$-homozygous individual was used in the thrombin generation experiments, increased thrombin 
formation in the presence of APC was still observed after 1:5 dilution in FVdeficient plasma, which strongly reduces the interference by plasma components other than FV. Therefore, in spite of the inconclusive results of epidemiological studies (see ref. ${ }^{43}$ and references therein), our experiments provide evidence for the mild prothrombotic character of $\mathrm{FV}_{\mathrm{R} 2}$, both per se (Fig. 5A,B) and in combination with $\mathrm{FV}_{\text {Leiden }}$ (Fig. 5C,D).

In conclusion, our study shows 1) that the impaired APC-cofactor activity of $F V_{\text {Leiden }}$ and $F V_{\mathrm{R} 2}$ in FVllla inactivation contributes prominently to the APC resistance associated with carriership of these mutations; and 2) that the anticoagulant activity of $\mathrm{FV}$ plays a pivotal role in the regulation of thrombin formation.

\section{ACKNOWLEDGEMENTS}

We are grateful to Dr. K. Hamulyák and R. van Oerle from the Haematology Department of Maastricht Academic Hospital for providing the plasmas from a $\mathrm{FV}_{\mathrm{R} 2^{-}}$and a $\mathrm{FV}_{\text {Leiden }}$-homozygous individuals, as well as the normal plasma pool. We also thank M.C.L.G.D. Thomassen and E.J.P. Magdeleyns for technical assistance. Prof. C. Scapolil from the Department of Biology of the University of Ferrara (Italy) is gratefully acknowledged for assistance with the statistical analysis. 


\section{REFERENCES}

1. Walker FJ, Fay PJ. Regulation of blood coagulation by the protein $C$ system. Faseb J. 1992;6:2561-2567.

2. Kalatatis M, Rand MD, Mann KG. The mechanism of inactivation of human factor $V$ and human factor $V a$ by activated protein $C$. J Biol Chem. $1994 ; 269.31869-31880$.

3. Fay PJ, Smudzin TM, Walker FJ. Activated protein C-catalyzed inactivation of human factor VIII and factor VIIIa. Identification of cleavage sites and correlation of proteolysis with cofactor activity. J Biol Chem. 1991;266:20139. 20145.

4. Shen $L$, Dahlbäck B. Factor $V$ and protein $S$ as synergistic cofactors to activated protein $C$ in degradation of factor VIlla. J Biol Chem. 1994;269:1873518738.

5. Váradi K, Rosing J, Tans $G$, Schwarz HP. Influence of factor $V$ and factor $V a$ on APC-induced cleavage of human factor VIII. Thromb Haemost. 1995;73:730731.

6. Lu D, Kalafatis $M$, Mann KG, Long GL. Comparison of activated protein $\mathrm{C} /$ protein S-rmediated inactivation of human factor VIII and factor $\mathrm{V}$. Blood. $1996 ; 87: 4708-4717$.

7. Thorelli E, Kaufman RJ, Dahlbäck B. The C-terminal region of the factor $V$ Bdomain is crucial for the anticoagulant activity of factor $V . J$ Biol Chem. $1998 ; 273: 16140-16145$.

8. Thorelli $E$, Kaufiman RJ, Dahlbäck B. Cleavage of factor $V$ at Arg 506 by activated protein $\mathrm{C}$ and the expression of anticoagulant activity of factor $\mathrm{V}$. Blood. 1999;93:2552-2558.

9. Westrick RJ, Sun $H$, Eitzman DT, et al. The factor $V$ Leiden mutation results in the in vivo loss of a critical FV anticoagulant function [abstract]. Blood. 2002;100:127a.

10. Dahlbäck $B$, Carlsson M, Svensson PJ. Familial thrombophilia due to a previoustly unrecognized mechanism characterized by poor anticoagulant response to actiwated protein $\mathrm{C}$ : prediction of a cofactor to activated protein $\mathrm{C}$. Proc Natl Acad Sci U S A. 1993;90:1004-1008.

11. Koster $T$, Rosendaal FR, de Ronde $H$, Briët $E$, Vandenbroucke JP, Bertina RM. Venous thrombosis due to poor anticoagulant response to activated protein $\mathrm{C}$. Leiden Thrombophilia Study. Lancet. 1993;342:1503-1506.

12. Svensson PJ, Dahlbäck $B$. Resistance to activated protein $C$ as a basis for venous thrombosis. N Engl J Med. 1994;330:517-522.

13. de Visser MC, Rosendaal FR, Bertina RM. A reduced sensitivity for activated protein $C$ in the absence of factor $V$ Leiden increases the risk of venous thrombosis. Blood. 1999;93:1271-1276.

14. Bertina RM, Koeleman BP, Koster T, et al. Mutation in blood coagulation factor $V$ associated with resistance to activated protein C. Nature. 1994;369:64-67.

15. Nicolaes GA, Tans G, Thomassen MC, et al. Peptide bond cleavages and loss of functional activity during inactivation of factor $\mathrm{Va}$ and factor $\mathrm{Va}{ }^{\mathrm{R5060}}$ by activated protein C. J Biol Chem. 1995;270:21158-21166. 
16. Kalafatis M, Bertina RM, Rand MD, Mann KG. Characterization of the molecular defect in factor $V^{R 506 Q}$. J Biol Chem. 1995;270:4053-4057.

17. Váradi $K$, Rosing J, Tans G, Pabinger I, Keil B, Schwarz HP. Factor $V$ enhances the cofactor function of protein $S$ in the APC- mediated inactivation of factor VIII: influence of the factor $V^{\mathrm{A5060}}$ mutation. Thromb Haemost. 1996;76:208-214.

18. Lunghi $B$, lacoviello L, Gemmati $D$, et al. Detection of new polymorphic markers in the factor $V$ gene: association with factor $V$ levels in plasma. Thromb Haemost. 1996;75:45-48.

19. Bernardi $F$, Faioni EM, Castoldi $E$, et al. A factor $V$ genetic component differing from factor $V R 506 Q$ contributes to the activated protein $C$ resistance phenotype. Blood. 1997;90:1552-1557.

20. Hoekema L, Castoldi E, Tans G, et al. Functional properties of factor $V$ and factor Va encoded by the R2-gene. Thromb Haemost. 2001;85:75-81.

21. Williamson D, Brown K, Luddington R, Baglin $C$, Baglin T. Factor V Cambridge: a new mutation $\left(\mathrm{Arg}^{306} \rightarrow-\rightarrow \mathrm{Thr}\right.$ ) associated with resistance to activated protein $\mathrm{C}$. Blood. 1998;91:1140-1144.

22. Chan WP, Lee CK, Kwong YL, Lam CK, Liang R. A novel mutation of Arg306 of factor $V$ gene in Hong Kong Chinese. Blood. 1998;91:1135-1139.

23. van der Neut Kolfschoten M, Diven RJ, Tans G, Rosing J, Vos HL, Bertina RM. The activated protein C (APC)-resistant phenotype of APC cleavage site mutants of recombinant factor $V$ in a reconstituted plasma model. Blood Coagul Fibrinolysis. 2002;13:207-215.

24. Norstrem E, Thorelli E, Dahlbäck B. Functional characterization of recombinant FV Hong Kong and FV Cambridge. Blood. 2002;100:524-530.

25. Nicolaes GA, Dahlbäck B. Factor $V$ and thrombotic disease: description of a janus-faced protein. Arterioscler Thromb Vasc Biol. 2002;22:530-538.

26. Faioni EM, Franchi $F$, Bucciarelli $P$, et al. Coinheritance of the HR2 haplotype in the factor $V$ gene confers an increased risk of venous thromboembolism to carriers of factor V R506Q (factor V Leiden). Blood. 1999:94:3062-3066.

27. Folsom AR, Cushman $M$, Tsai $M Y$, et al. A prospective study of venous thromboembolism in relation to factor $V$ Leiden and related factors. Blood. 2002;99:2720-2725.

28. Dahibäck B. The discovery of activated protein $C$ resistance. J Thromb Haemost. 2003;1:206-213.

29. Heeb MJ, Kojima $Y$, Greengard JS, Griffin JH. Activated protein C resistance: molecular mechanisms based on studies using purified $\mathrm{Glin}{ }^{506}$-factor $\mathrm{V}$. Blood. 1995;85:3405-3411.

30. Váradi $\mathrm{K}$, Moritz $\mathrm{B}$, Lang $\mathrm{H}$, et al. A chromogenic assay for activated protein $\mathrm{C}$ resistance. Br J Haematol. 1995;90:884-891.

31. Govers-Riemslag JW, Castoldi $E_{*}$ Nicolaes GA, Tans G, Rosing J. Reduced factor $V$ concentration and altered $F V_{1} / F_{2}$ ratio do not fully explain R2associated APC-resistance. Thromb Haemost. 2002;88:444-449.

32. Hoekema $\mathrm{L}$, Rosing $\mathrm{J}$, Tans $\mathrm{G}$. An assay to quantify the two plasma isotorms of factor $V$. Thromb Haemost. 2000;84:1066-1071. 
33. Seré KM, Janssen MP, Willems GM, Tans G, Rosing J, Hackeng TM. Purified protein $S$ contains multimeric forms with increased APC- independent anticoagulant activity. Biochemistry. 2001;40:8852-8860.

34. Rosing J, Bakker HM, Thomassen MC, Hemker HC, Tans G. Characterization of two forms of human factor Va with different cofactor activities. J Biol Chem. 1993;268:21130-21136.

35. Simioni $P$, Scudeller $A$, Radossi $P$, et al. "Pseudo homozygous" activated protein $C$ resistance due to double heterozygous factor $V$ defects (factor $V$ Leiden mutation and type I quantitative factor $V$ defect) associated with thrombosis: report of two cases belonging to two luinrelated kindreds. Thromb Haemost. 1996;75:422-426.

36. Castoldi $E$, Govers-Riemslag JW, Pinotti $M$, et al. Co-inheritance of FV Leiden enhances thrombin formation and is associated with a mild bleeding phenotype in patients homozygous for the FVII 9726+5G>A (FVII Lazio) mutation. Blood. 2003;102:4014-4020.

37. Hemker HC, Wielders $S$, Kessels $H$, Béguin $S$. Continuous registration of thrombin generation in plasma, its use for the determination of the thrombin potential. Thromb Haemost. 1993;70:617-624.

38. Samama MS, Gouin-Thibault I, Trossaërt $M$, et al. Low levels of protein $S$ activity in factor $V$ depleted plasma used in APC resistance test. Thromb Haemost. 1998;80:715-7»6.

39. de Visser MCH, Guasch JF, Kamphuisen PW, Vos HL, Rosendaal FR, Bertina RM. The HR2 haplotype of factor V: Effects on factor $V$ levels, normalized activated protein $\mathrm{C}$ sensitivity ratios and the risk of venous thrombosis. Thromb Haemost. 2000;83:577-582.

40. Dahllbäck B, Hildebrand B. Inherited resistance to activated protein $C$ is corrected by anticoagulant cofactor activity found to be a property of factor $\mathrm{V}$. Proc Natl Acad Sci U S A. 1994;91:1396-1400.

41. Aparicio $\mathrm{C}$, Dahlbäck B. Molecular mechanisms of activated protein $\mathrm{C}$ resistance. Properties of factor $V$ isolated from an individual with homozygosity for the Arg506 to Gln mutation in the factor V gene. Blochem J. 1996;313:467472.

42. Hemker $H C$, Béguin S. Phenotyping the clotting system. Thromb Haemost. 2000;84:747-751.

43. Castaman G, Faioni EM, Tosetto A, Bernardi $F$. The factor $V$ HR2 haplotype and the risk of venous thrombosis: a meta-analysis. Haematologica. 2003;88:1182-1189. 


\section{CHAPTER 4}

Expression of the normal factor $V$ allele modulates the APC resistance phenotype in heterozygous carriers of the factor $\mathrm{V}$ Leiden mutation.

JM Brugge, P Simioni, F Bernardi, D Tormene, B Lunghi, G Tans, A Pagnan, J Rosing, E Castoldi

Based on: Journal of Thrombosis and Haemostasis, $3(\mathrm{dec})$ : p. $2695-2702$ 



\section{ABSTRACT}

Background: Functional defects of the protein $C$ pathway, detectable in plasma as activated protein $C$ (APC) resistance, are a prevalent risk factor for venous thrombosis. The factor $V$ (FV) Leiden mutation causes APC resistance by interfering with the APC-mediated inactivation of both FVa and FVIIla. Coinheritance of FV Leiden and quantitative FV deficiency on different alleles, a rare condition known as pseudo-homozygous APC resistance, is associated with pronounced APC resistance and $50 \%$ reduced FV levels, due to nonexpression of the non-Leiden FV allele.

Objectives: The role of normal FV in modulating the APC resistance phenotype in carriers of FV Leiden was investigated in patients with pseudo-homozygous APC resistance and in model systems.

Patients/Methods: Four functional plasma assays probing both components of APC resistance (susceptibility of FVa to APC and cofactor activity of FV in FVIlla inactivation) were employed to compare 7 clinically and genetically characterised FV Leiden pseudo-homozygotes to 30 relatives with different FV genotypes (including $12 \mathrm{FV}$ Leiden heterozygotes and 7 carriers of FV deficiency) and to 32 unrelated FV Leiden homozygotes.

Results and Conclusions: All assays consistently indicated that FV Leiden pseudo-homozygotes are significantly more APC-resistant than heterozygotes and indistinguishable from homozygotes. Thrombin generation measurements in FV-deficient plasma reconstituted with purified normal FV and FV Leiden confirmed these observations and showed that the expression of the normal FV allele is an important modulator of APC resistance in FV Leiden heterozygotes. These findings provide an explanation for the higher thrombotic risk of FV Leiden pseudo-homozygotes as compared to heterozygotes. 


\section{INTRODUCTION}

The protein $\mathrm{C}$ pathway plays a major role in the down-regulation of coagulation by proteolytically inactivating the non-enzymatic cofactors $\mathrm{Va}$ (FVa) and VIIla (FVIIla). Functional defects of this pathway result in a plasma phenotype known as activated protein C (APC) resistance, which is characterised by a relative inability of exogenous APC to prolong the clotting time in an aPTT-based assay [1]. APC resistance is the most common risk factor for venous thromboembolism.

Most cases of inherited APC resistance in the Caucasian population are due to the $\mathrm{Arg}^{506} \rightarrow \mathrm{Gin}$ mutation in the factor $\mathrm{V}$ gene (FV Leiden) [2]. This mutation decreases the susceptibility of FVa to inactivation by APC $[3,4]$ and impairs the ability of FV to stimulate the APC-mediated inactivation of FVIlla $[5,6]$. As a consequence, FV Leiden heterozygotes experience a 7 -fold increased risk of venous thrombosis and homozygotes an 80 -fold increased risk as compared to non-carriers [7].

Pseudo-homozygous APC resistance is a rare condition characterised by the co-inheritance of the FV Leiden mutation and a FV null mutation on different alleles [8]. Despite genotypic heterozygosity for FV Leiden, pseudohomozygous individuals show an APC resistance phenotype that resembles that of homozygotes. This discrepancy is due to the fact that the non-Leiden FV allele is not expressed, resulting in the exclusive presence of FV Leiden molecules in plasma $[9,10]$.

Although most cases of pseudo-homozygous APC resistance reported in the literature are thrombotic patients [8-18], the thrombotic risk associated with this condition has been difficult to establish in epidemiological studies [19], because of its rare occurrence in the general population [9]. Based on the comparison of Kaplan-Meier thrombosis-free survival curves of probands with different FV Leiden genotypes, we have recently shown that FV Leiden pseudohomozygotes experience the same thrombotic risk as FV Leiden homozygotes [20].

To account for this finding and to get more insight into the role of the non-Leiden allele in FV Leiden carriers, we now report a full characterisation of the APC resistance phenotype in seven pseudo-homozygous individuals and in a plasma model system. 


\section{MATERIALS AND METHODS}

\section{Patients}

Seven FV Leiden pseudo-homozygous individuals (Table 1), belonging to six unrelated families, and 33 family members were recruited. Among the pseudo-homozygotes, six were consecutive thrombotic patients, while the seventh was the asymptomatic brother of one of them. Family members were normal $(n=12)$, heterozygous for the FV Leiden mutation $(n=13)$ or carriers of quantitative FV deficiency $(n=8)$. Three of them (one for each genotype) were excluded from the study due to ongoing oral anticoagulant treatment following a thrombotic event. None of the remaining 30 relatives had experienced venous thrombosis. Five of the six probands [20] and three families $[8-10,17]$ have been previousily reported.

An unrelated group of $32 \mathrm{FV}$ Leiden homozygotes belonging to 25 different families was also investigated. Of these, 12 were thrombotic patients $(6$ had deep vein thrombosis, 5 superficial vein thrombosis and 1 a transient ischaemic attack) and 20 were asymptomatic members of thrombophilic famillies. None of the patients included in the study was on oral anticoagulants at the time of blood collection.

Blood was drawn by venipuncture in $3.8 \%$ sodium citrate $(1.9 \mathrm{vol} / \mathrm{vol})$. Platelet-poor plasma was obtained by two centrifugation steps at $2000 \times \mathrm{g}$ for 15 min, snap-frozen and stored at $-80^{\circ} \mathrm{C}$. The study was conducted in accordance with the Helsinki protocol and informed consent was obtained from all participants.

\section{DNA analysis}

Genomic DNA was extracted from peripheral blood leukocytes. Carriership of the FV Leiden mutation was ascertained by Mnl I-restriction analysis of amplified exon 10. Screening for the mutations responsible for $F V$ deficiency was performed by direct sequencing of FV gene exons and splicing junctions, as described [21].

\section{aPTT-based APC resistance test}

The aPTT-based APC resistance test was performed in undiluted plasma as described [22].

\section{Thrombin generation assay (ETP-based APC resistance test)}

The thrombin generation assay was performed essentially as reported [23]. Conversion of the fluorogenic substrate by the thrombin formed in plasma. was followed in a Fluoroskan Ascent ${ }^{(1)}$ reader (Thermo Labsystems, Helsinki, 
Finland). Thrombin generation curves and the area-under-the-curve (endogenous thrombin potential, ETP) were calculated using the Thrombinoscoperm software (Synapse B.V., Maastricht, The Netherlands). All thrombin generation curves were determined at least in duplo.

For each plasma, the ratio of the ETPS obtained in the presence and absence of APC was calculated and normalised against the ratio of normal pooled plasma (normalised APC sensitivity ratio, nAPCsr) [24]. A high nAPCsr indicates APC resistance. The APC concentration in the assay $(\sim 5 \mathrm{nM})$ was aimed at reducing the ETP of normal plasma to $10 \%$ of its value without APC. In the experiment in which FV Leiden pseudo-homozygotes and homozygotes were compared (Fig. 3B), a higher APC concentration was used to enthance a possible difference between the two groups.

Data presented in Figs. 4 and 5 were obtained by performing the ETPbased assay in congenitally FV-deficient plasma (George King Bio-Medical Inc., Overland Park, KS) reconstituted with purified normal FV and/or FV Leiden. Single-chain FV was purified as previously described [4] and migrated as a single band of $\sim 330 \mathrm{kD}$ on an SDS-gel.

\section{Assay for the measurement of FVa susceptibility to APC}

The susceptibility of FVa to APC-mediated inactivation was determined with a previously described prothrombinase-based assay [25], with minor modifications. Plasma was diluted $1 / 1000$ in a buffer containing $25 \mathrm{mM}$ Hepes (pH 7.7 at room temperature), $175 \mathrm{mM} \mathrm{NaCl}, 3 \mathrm{mM} \mathrm{CaCl}, 5 \mathrm{mg} / \mathrm{ml} \mathrm{BSA}$ and $21.6 \mu \mathrm{M}$ phospholipids (DOPS/DOPC, $10 / 90 \mathrm{~mol} / \mathrm{mol}$ ), and $\mathrm{FV}$ was activated with $2.7 \mathrm{nM}$ lla in the presence or absence of $0.26 \mathrm{nM}$ APC. After 8 minutes, the FVa present in the activation/inactivation mixtures was quantified via a prothrombinase-based assay in a reaction mixture containing $0.3 \mathrm{nM}$ factor $\mathrm{Xa}$ (FXa), $1 \mu \mathrm{M}$ prothrombin, $19.8 \mu \mathrm{M}$ phospholipids (DOPS/DOPC, $10 / 90 \mathrm{~mol} / \mathrm{mol}$ ) and $2.6 \mathrm{mM} \mathrm{CaCl}_{2}$ (final concentrations). The ratio of the $\mathrm{FVa}$ activities determined in the presence and absence of APC was expressed as the percentage FVa left after APC treatment (\%rest). The higher the \%rest, the more resistant $\mathrm{FVa}$ is to $\mathrm{APC}$-mediated inactivation. Each sample was measured in duplo.

This assay was also used to determine the residual expression of the non-Leiden FV allele in plasma from the FV Leiden pseudo-homozygotes. FVdeficient plasma reconstituted with a fixed amount of purified FV Leiden (11.5 $\mathrm{nM})$ and increasing amounts of purified normal FV $(0-11.5 \mathrm{nM})$ was diluted $1 / 1000$ in buffer to simulate dilutions of plasma from FV Leiden-heterozygous individuals with variable expression of the counterpart FV allele. Based on the $\%$ rest of these reconstituted plasmas in the prothrombinase-based APC 
resistance test, a calibration curve was constructed and used to determine the normal FV/FV Leiden ratio in plasma from the pseudo-homozygotes. Each point was measured three times in duplo.

\section{Assay for the measurement of the APC-cofactor activity of FV}

The ability of FV to stimulate APC-mediated FVIlla inactivation was measured with a home-made assay based on a test kit for the measurement of FVIII levels in plasma (Ilmmunochrom FVIII:C, Progen Biotechnik GmbH, Heidelberg, Germany). Plasma was diluted 1:21 in the buffer provided with the kit and incubated with either buffer or APC (Kordia, Leiden, The Netherlands, $\sim 30 \mathrm{nM}$ final concentration) in the presence of phospholipids (Reagent A) for 2 min. Subsequently, the residual FVIII was activated and quantified by adding Reagent $\mathrm{B}$ (thrombin, factor $\mathrm{IXa}, \mathrm{FX}$ and $\mathrm{Ca}^{2+}$ ), and $\mathrm{FXa}$ generation was stopped after 5 min with EDTA-containing buffer. The amount of FXa generated was subsequently quantified using the chromogenic substrate S2765, and the ratio between the amidolytic activities obtained in the absence and in the presence of APC was calculated (APCsr). This method yields APCsr's comparable to those obtained with the Immunochrom ${ }^{\mathbb{1}}$ APC Response assay [26]. All samples were measured in duplo.

\section{Measurement of coagulation factor concentrations in plasma}

FV antigen was measured by a home-made ELISA [8]. FV activity levels were obtained from the prothrombinase-based assay (measurement without APC). FVIII activity levels were derived from the FVIII-based APC resistance test (measurement without APC). Prothrombin levels were measured with an amidolytic assay after activation of prothrombin with Ecarin (Pentapharm, Basel, Switzerland). Free protein S levels were determined by ELISA [27].

\section{Statistics}

For statistical purposes individuals were grouped according to their FV genotypes, irrespective of patient/control status. Plasma levels of coagulation factors and APC resistance values were compared between genotype groups using the Mann-Whitney-Wilcoxon test. 


\section{RESULTS}

\section{Characterisation of FV Leiden pseudo-homozygous individuals}

Seven FV Leiden pseudo-homozygotes were enrolled in the study. Their demographic, genetic and clinical features are summarised in Table 1.

Diagnosis of pseudo-homozygous APC resistance was based on heterozygous carriership of the FV Leiden mutation, reduction of FV antigen and activity levels in plasma (Table 1) and pronounced APC resistance in the aPTT-based assay. Absence of normal FV in plasma was subsequently verified via the prothrombinase-based APC resistance assay, whose outcome (\%rest) is a sensitive marker of the ratio between normal FV and FV Leiden present in plasma. Comparison of the \%rest obtained in the plasmas of the pseudohomozygotes with a calibration curve constructed with FV-deficient plasma reconstituted with $50 \%$ purified $\mathrm{FV}$ Leiden and varying amounts of purified normal FV (Fig. 1A) indicated that the non-Leiden allele expressed between $1.5 \%$ and $3.6 \% \mathrm{FVa}$ activity in the different pseudo-homozygous individuals (Fig. 1B).
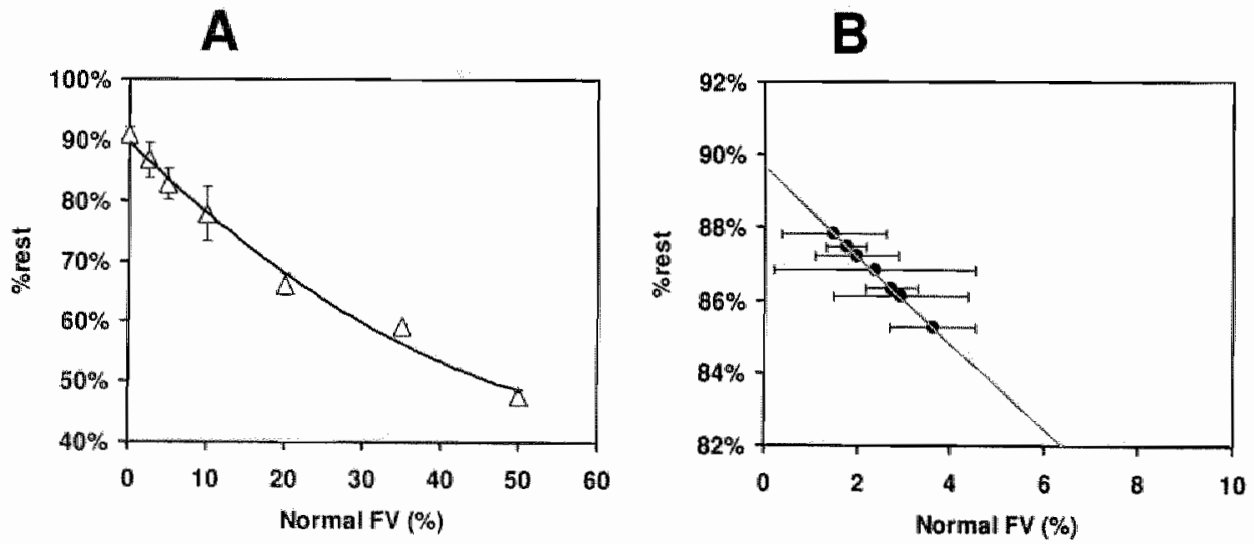

FIGURE 1: Determination of normal FV expression in plasma from FV Leiden pseudo-homozygotes. FV present in 1/1000-diluted plasma was activated with thrombin and subsequently inactivated with $\mathrm{APC}$, and $\mathrm{FVa}$ activity was determined via a prothrombinase-based assay. The outcome of the test was expressed as residual FVa activity (\%rest) after APC treatment. Each data point is the average of three duplo measurements and error bars represent the standard error of the mean. A) Calibration curve determined in FV-deficient plasma reconstituted with a fixed amount $(50 \%)$ of purified FV Leiden and a variable amount $(0-50 \%)$ of purified normal FV. B) Percentage expression of the non-Leiden FV allele in the FV Leiden pseudo-homozygous individuals as estimated from the \%rest in the prothrombinase-based APC resistance assay. 
FV deficiency was caused by frame-shift or nonsense mutations in four pseudo-homozygous individuals and by missense mutations in the other three (Table 1). After screening all family members for carriership of the FV defect identified in the respective propositus, complete co-segregation between FV gene mutation and reduced FV levels was observed in all families.

\section{APC resistance in FV Leiden pseudo-homozygotes and their relatives with different FV genotypes}

APC resistance was measured in the seven FV Leiden pseudohomozygotes and in 30 family members, among which 12 FV Leiden heterozygotes, 7 carriers of quantitative FV deficiency and 11 normal subjects (Fig. 2). Both in the aPTT-based assay (Fig. 2A) and in the ETP-based assay (Fig. 2B), plasma from FV Leiden pseudo-homozygotes was significantly more APC-resistant than that from FV Leiden heterozygotes, which in turn was more APC-resistant than plasma from non-carriers of the FV Leiden mutation. No significant difference was detected in either assay between individuals with partial FV deficiency (in the absence of FV Leiden) and their relatives with a normal FV genotype. Although the mean plasma levels of the major determinants of the APC resistance tests (FVIII, protein S and prothrombin) did not differ significantly between any of the genotype groups (data not shown), multiple regression analysis was performed to dissect the net effect of FV genotype on APC resistance. Correction for demographic parameters (age, sex and patient/control status) and plasma variables (FV, FVIII, protein $S$ and prothrombin levels) hardly affected the observed differences in APC resistance between genotype groups, and FV genotype remained the main determinant of these differences.

To further characterise the APC resistance phenotype in FV Leiden pseudo-homozygous plasma, we also determined APC resistance with the prothrombinase-based assay (Fig. $2 \mathrm{C}$ ), which probes the susceptibility of $\mathrm{FVa}$ for APC, and with the FVIII-based test, which specifically quantifies the APCcofactor activity of FV in FVIIla inactivation (Fig. 2D). In both tests, FV Leiden pseudo-homozygotes proved significantly more APC-resistant than heterozygotes, indicating that the higher APC resistance in FV Leiden pseudohomozygous plasma is due both to decreased APC-susceptibility of FVa and to impaired APC-cofactor activity of FV in FVIlla inactivation.

Interestingly, a significant difference in APC-cofactor activity was observed between normal individuals and subjects with partial FV-deficiency in the FVIII-based APC resistance test (Fig. 2D). 

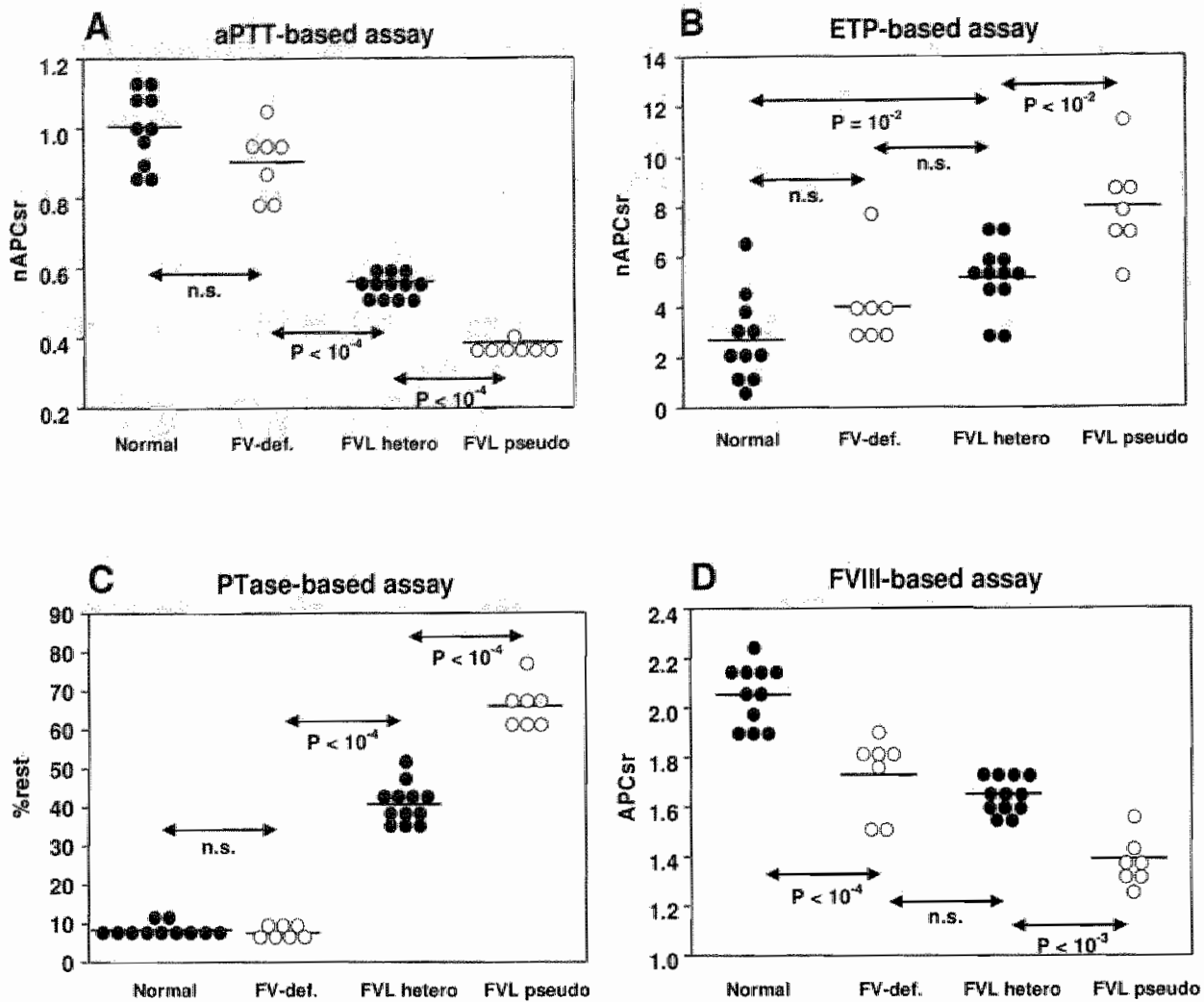

FIGURE 2: APC resistance in FV Leiden pseudo-homozygotes and their family members with different FV genotypes. APC resistance was determined with the aPTT-based (A), ETP-based (B), prothrombinase-based (C) and FVIII-based (D) assays as described under Methods. FVL, FV Leiden. The horizontal lines represent the means of each genotype group.

\section{APC resistance in FV Leiden pseudo-homozygotes versus FV Leiden homozygotes}

The FV Leiden pseudo-homozygous individuals were also compared to an unrelated group of 32 FV Leiden homozygotes (Fig. 3). Although the latter included both thrombotic patients $(n=12)$ and asymptomatic relatives $(n=20)$, all FV Leiden homozygotes were treated as a single group since APC resistance, FV, FVIII, protein $S$ and prothrombin levels were not significantly associated with the disease status (data not shown). FV Leiden pseudo-homozygotes and homozygotes appeared virtually indistinguishable in the aPTT-based (Fig. 3A), ETP-based (Fig. 3B) and prothrombinase-based (Fig. 3C) APC resistance assays. Only in the FVIII-based test (Fig. 3D), plasma from FV Leiden pseudo- 
homozygotes was significantly more APC-resistant than plasma from FV Leiden homozygotes. However, multiple regression analysis showed that $60 \%$ of this difference was attributable to small differences in demographic and plasma parameters between the two genotype groups, and after correction for these variables the APC resistance difference between FV Leiden homozygotes and pseudo-homozygotes was not significant anymore.
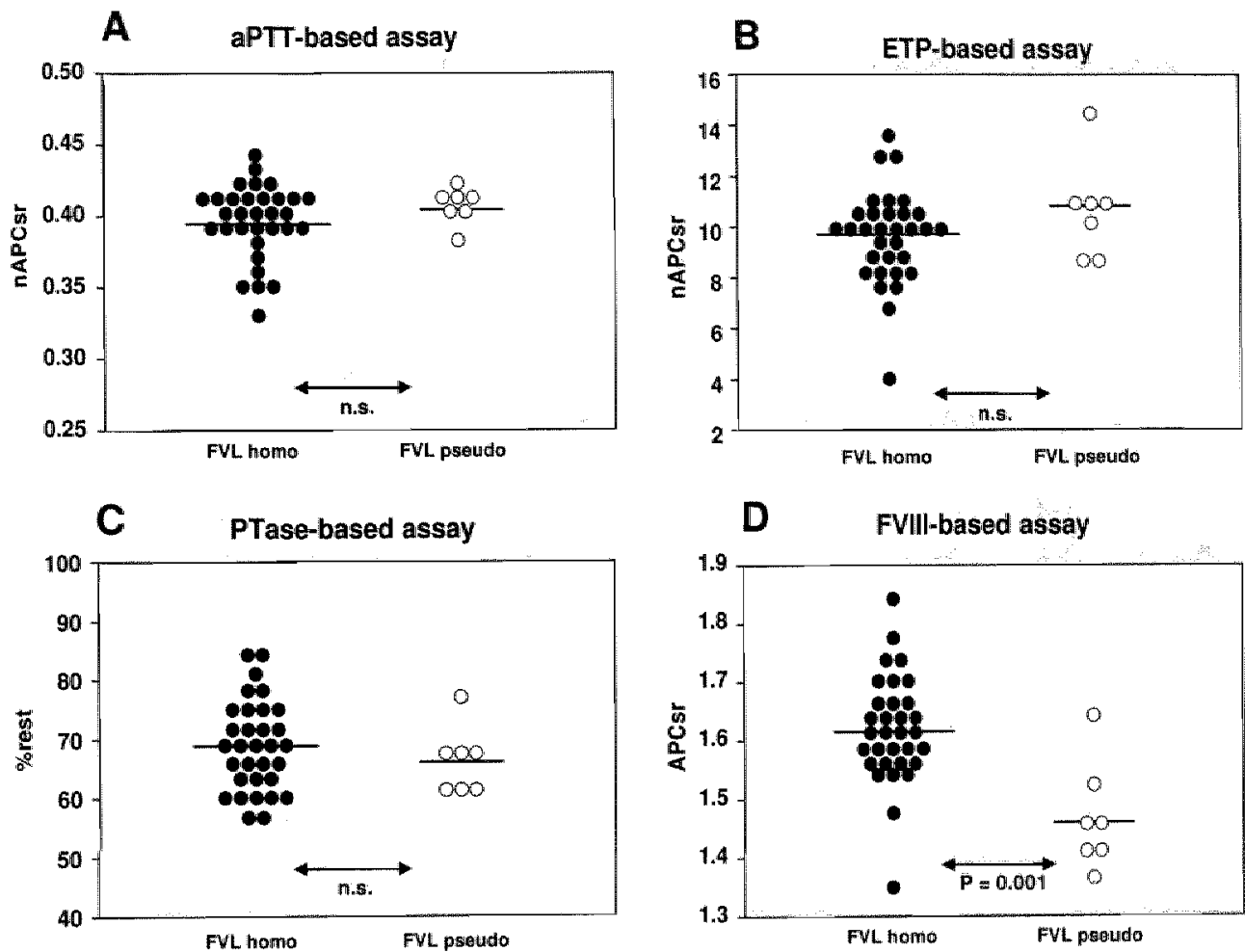

FIGURE 3: APC resistance in FV Leiden pseudo-homozygotes and in unrelated FV Leiden homozygotes. APC resistance was determined with the aPTT-based (A), ETPbased (B), prothrombinase-based (C) and FVIII-based (D) assays as described under Methods. FVL, FV Leiden. The horizontal lines represent the means of each genotype group.

ETP-based APC resistance test in simulated FV Leiden pseudohomozygous plasma

To exclude the possibility that differences in plasma variables other than FVIII, protein $S$ and prothrombin among the FV genotype groups could have influenced our results, we also performed a "proof-of-principle" experiment 
in a plasma model. FV Leiden-heterozygous, homozygous and pseudohomozygous plasmas as well as normal plasma were simulated by reconstituting FV-deficient plasma with purified normal FV and/or FV Leiden, and the nAPCsr of the reconstituted plasmas was determined with the ETPbased APC resistance test. While in the absence of APC all plasmas yielded virtually identical ETPS, in the presence of APC FV Leiden homozygous and pseudo-homozygous plasma generated twice as much thrombin as FV Leidenheterozygous plasma (Fig. 4A). Consequently, after normalisation against simulated normal plasma, FV Leiden pseudo-homozygous plasma (nAPCsr 9.1) proved significantly more APC-resistant than heterozygous plasma (nAPCsr 4.6) and was actually indistinguishable from homozygous plasma (nAPCsr 9.2) (Fig. 4B).

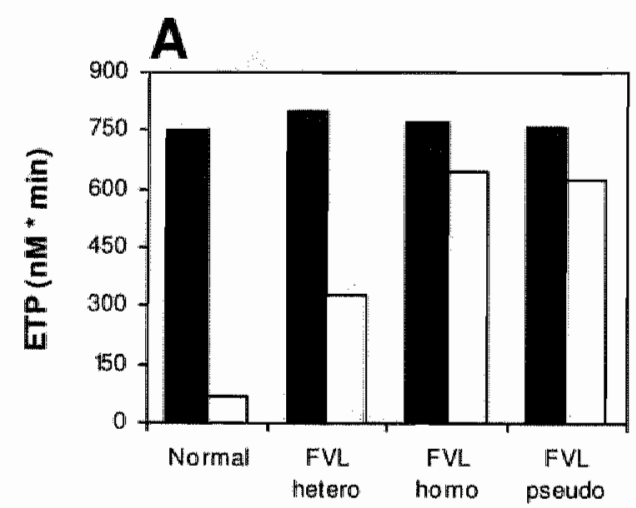

FV genotype

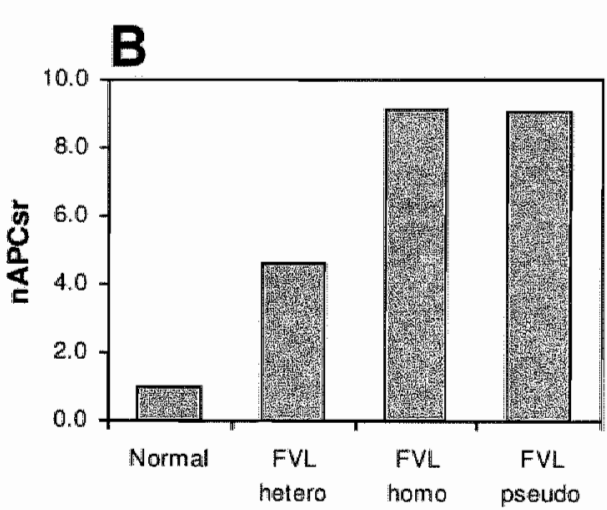

FV genotype

FIGURE 4: ETP-based APC resistance assay in simulated plasmas from individuals with different FV genotypes. FV-deficient plasma was reconstituted with purified FV to mimic normal plasma ( $100 \%$ normal FV), FV Leiden-heterozygous plasma ( $50 \%$ FV Leiden and 50\% normal FV). FV Leiden-homozygous plasma (100\% FV Leiden) and FV Leiden pseudo-homozygous plasma (50\% FV Leiden only). Thrombin generation was measured after extrinsic activitation of plasma in the absence and presence of APC. A) ETP of the different plasmas in the absence (black) and presence (white) of APC; B) nAPCsr as a function of the FV genotype.

\section{APC resistance in FV Leiden heterozygotes: effect of the counterpart FV allele}

The data presented above indicate that, in heterozygous carriers of FV Leiden, complete non-expression of the counterpart FV allele significantly increases APC resistance. To further evaluate the role of the non-Leiden FV allele as a possible modulator of the APC resistance phenotype in FV Leiden heterozygotes, we simulated plasmas from FV Leiden heterozygotes with 
variable expression of the counterpart FV allele and measured thrombin generation in the absence and presence of APC. When the concentration of normal FV complementing the $50 \% \mathrm{FV}$ Leiden was varied in plasma from $0 \%$ (true pseudo-homozygosity) to $50 \%$ (perfect heterozygosity) and further increased to $60 \%$ (to mimic a slight over-expression of the normal $\mathrm{FV}$ allele), the ETP in the absence of APC remained constant, while the ETP in the presence of APC progressively decreased with increasing normal FV (Fig. 5A). Consequently, the nAPCsr decreased linearly (plasma became less APCresistant) with the proportion of normal FV present in plasma (Fig. 5B).
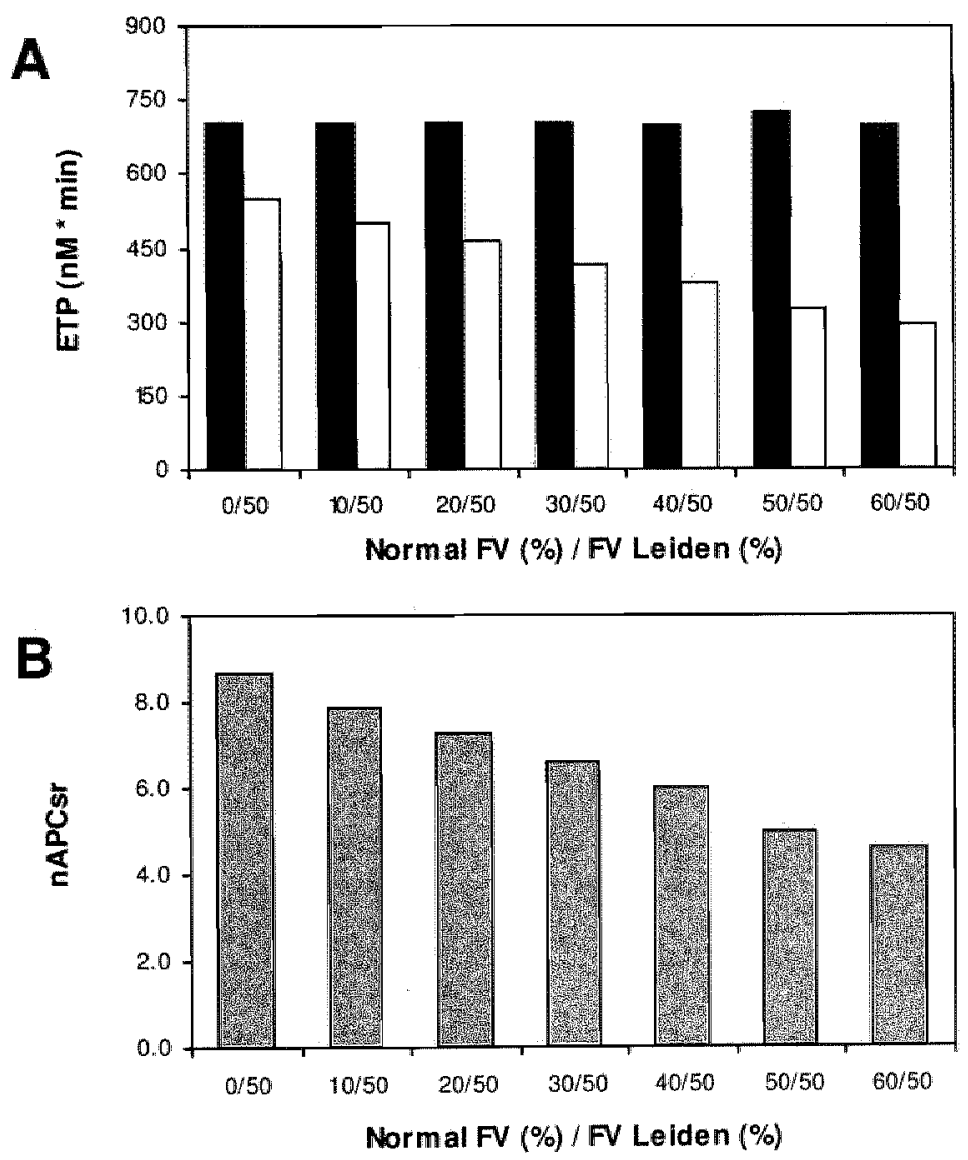

FIGURE 5: ETP-based assay in simulated plasmas from FV Leiden heterozygotes with variable expression of the counterpart FV allele. FV-deficient plasma was reconstituted with a fixed amount $(50 \%)$ of purified FV Leiden and a variable amount $(0$ $60 \%$ ) of purified normal $\mathrm{FV}$, and thrombin generation was measured after extrinsic activitation of plasma in the absence and presence of APC. A) ETP of the different plasmas in the absence (black) and presence (white) of APC; B) nAPCsr as a function of the relative amount of normal FV in plasma. 


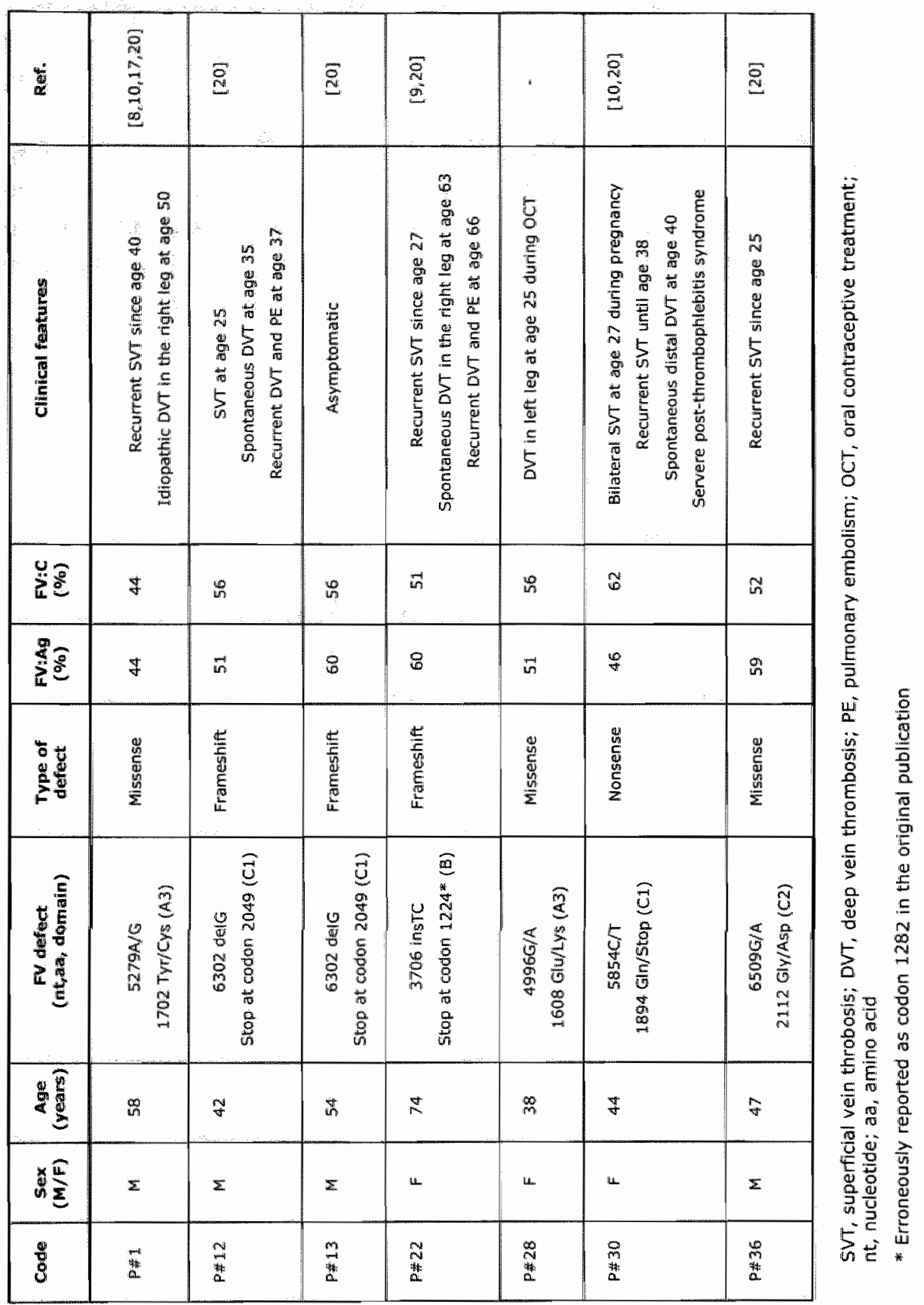




\section{DISCUSSION}

Several case reports describing pseudo-homozygous APC resistance; i.e. double heterozygosity for FV Leiden and a FV null mutation, have appeared in the literature during the last 10 years [8-18]. Pseudo-homozygous APCresistant individuals are characterised by a discrepancy between $\mathrm{FV}$ Leiden genotype (heterozygous) and APC resistance phenotype (similar to that of homozygotes), accompanied by a $50 \%$ reduction of $\mathrm{FV}$ levels in plasma. Although most known cases are thrombotic patients, the severity of the hypercoagulable state and of the thrombotic risk associated with pseudohomozygous APC resistance has been difficult to establish due to the rarity of the condition and a possible referral bias.

In this paper we present a detaled characterisation of the APC resistance phenotype associated with pseudo-homozygous APC resistance, based on the study of seven FV Leiden pseudo-homozygotes (Table 1) and on simulation of this condition in a plasma model. All pseudo-homozygotes included in the study were characterised by virtual absence of normal FV in plasma, as demonstrated by a) the $50 \%$ reduction of plasma $\mathrm{FV}$ antigen and activity levels, and b) the very low $(<4 \%)$ residual expression of the non-Leiden FV allele as estimated in the prothrombinase-based APC resistance test (Fig. 1B). Quantitative FV deficiency in the seven pseudo-homozygotes was caused by a wide spectrum of molecular defects including frameshift, nonsense and missense mutations (Table 1). While the frameshift and nonsense mutations are definitely null defects $[9,10]$, the missense mutations are compatible with normal mRNA expression [15,17] and might theoretically lead to (residual) expression of the mutated protein. However, the 1702 Tyr/Cys and 2112 Gly/Asp mutations have been reported in the homozygous state in patients with undetectable FV levels and severe bleeding $[28,29]$, and shown to yield no protein by Western blot analysis (1702 TyriCys [17]) and by expression of the recombinant molecule (2112 Gly/Asp [29]), respectively. Although the 1608 Glu/Lys mutation was shown to produce appreciable FVa activity in the conditioned medium of transfected cells [30], its expression in patient $P$ \#28 was extremely low (2.9\%) and indistinguishable from that of the truly null FV defects as estimated by the prothrombinase-based APC resistance test (Fig. 1B).

Four functional plasma tests that measure different aspects of APC resistance were used to compare the 7 pseudo-homozygous individuals to 30 family members with different FV genotypes (including $12 \mathrm{FV}$ Leiden heterozygotes) and to 32 unrelated FV Leiden homozygotes. All assays consistently showed that FV Leiden pseudo-homozygotes are significantly more APC-resistant than FV Leiden heterozygotes (Fig. 2) and indistinguishable from 
homozygotes (Fig. 3). Since the aPTT-based and ETP-based APC resistance tests, which were performed in full plasma, are sensitive to plasma FVIII, protein $S$ and prothrombin levels [31], inter-individual differences in the levels of these proteins may account for the variation in nAPCsr observed within each FV genotype group. However, since the average levels of FVIII, protein S and prothrombin did not differ significantly between any of the FV genotype groups, the observed differences in APC resistance between FV Leiden pseudohomozygous and heterozygous individuals are largely attributable to the FV genotype, as confirmed by multiple regression analysis. The same applies to the FVIII-based APC resistance test which is sensitive to FVIIII and protein S levels as well as FV levels [32]. These conclusions are confirmed by ETP measurements in simulated plasmas (Fig. 4), where the influence of plasma components other than FV is excluded by reconstitution of one and the same FV-deficient plasma with purified FV. As shown in Fig. 4B, the ETP-based nAPCsr's of FV Leiden pseudo-homozygous and homozygous plasmas are identical and twice as high as that of heterozygous plasma when potential modulators of the APC resistance phenotype are kept constant.

In plasma, the difference between FV Leiden pseudo-homozygotes and heterozygotes lies in the absence or presence of the $50 \%$ normal FV produced by the counterpart (mon-Leiden) allele. This normal FV not only ensures APCcofactor activity in FVIlla inactivation (Fig. 2D), but it also increases the overall susceptibility of plasma FVa to APC-mediated inactivation (Fig. 2C). This explains why a progressive reduction of the relative amount of normal FV in plasma from $\mathrm{FV}$ Leiden heterozygotes results in increasing APC resistance (Fig. 5B). Differently, the 50\% extra FV Leiden that distinguishes FV Leidenhomozygous from pseudo-homozygous plasma does not affect $\mathrm{FVa}$ susceptibility to APC-catalysed inactivation (Fig. $3 \mathrm{C}$ ) nor the inactivation of FVIIla. In fact, the difference in FVIII-based APCsr between FV Leiden homozygotes and pseudo-homozygotes (Fig. 3D) largely disappeared after correction for demographic and plasma variables, in accordance with the notion that FV Leiden does not express APC-cofactor activity in FVIIla inactivation [23].

By comparing the thrombosis-free survival of probands with different FV genotypes, we have recently shown that FV Leiden pseudo-homozygous and homozygous individuals experience a higher thrombotic risk than heterozygotes [20]. Since APC resistance is an excellent indicator of thrombotic risk $[33,34]$, the present data offer a functional explanation for these epidemiological observations.

In conclusion, our findings indicate that the hypercoagulable state associated with pseudo-homozygous APC resistance is indistinguishable from 
that found in FV Leiden homozygotes and that APC resistance in FV Leiden carriers does not depend on the absolute amount of FV Leiden in plasma, but rather on the relative amount of normal FV.

ACKNOWLEDGEMENTS: The authors wish to thank Ms. Ute Becker and Ms. Ina Kleen from Progen Biotechnik $\mathrm{GmbH}$, Heidelberg, Germany, for kindly providing the Immunochrom FVIII:C reagent kits. Ms. M.C.L.G.D. Thomassen and Ms. E.J.P. Magdeleyns are gratefully acknowledged for their excellent technical assistance. P.S. wishes to thank Sabrina Gavasso, Patrizia Zerbinati and Mariangela Fadin for the laboratory work-up of thrombophilic patients. 


\section{REFERENCES}

1 Dahlback $B$, Carlsson $M$, Svensison PJ. Familial thrombophilia due to a prewiously unrecognized mechanism characterized by poor anticoagulant response to activated protein C: prediction of a colactor to activated protein C. Proc Natl Acad Sci USA $1993 ; 90: 1004-8$.

2. Bertina RM, Koeleman BP, Koster $T$, Rosendaal FR, Dirven $\mathrm{RJ}$, de Ronde $\mathrm{H}_{\text {, van }}$ der Veiden PA, Reitsma PH. Mutation in blood coagulation factor $V$ associated with resistance to activated protein C. Nature $1994 ; 369: 64-7$.

3 Kalafatis M, Bertina $\mathrm{AM}$, Rand MD, Mann KG. Characterization of the molecular defect in factor VR506Q. J Biol Chem 1995; 270: 4053-7.

4 Nicolaes $\mathrm{GA}_{\text {, Tans }} \mathrm{G}$, Thomassen MC, Hemker HC, Pabinger I, Văradi K, Schwarz HP, Rosing J. Peptide bond cleavages and loss of functional activity during inactivation of factor $\mathrm{Va}$ and factor $\mathrm{VaR} 506 \mathrm{Q}$ by activated protein $\mathrm{C}$. I Biol Chem 1995; 270: 21158-66.

5 Váradi $K$, Rosing J, Tans G, Pabinger $\|$, Keil B, Schwarz HP. Factor $V$ enhances the cofactor function of protein $S$ in the APC- mediated inactivation of factor VII: influence of the factor VR506Q mutation. Thromb Haemost 1996; 76: 208-14.

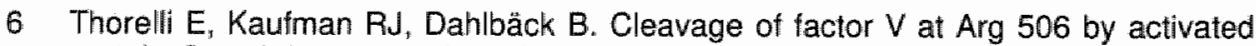
protein $C$ and the expression of anticoagulant activity of factor $V$. Blood 1999; 93: 2552-8.

7 Rosendaal FR, Koster $T$, Vandenbroucke JP, Reitsma $\mathrm{PH}$. High risk of thrombosis in patients homozygous for factor $V$ Leiden (activated protein $C$ resistance). Blood 1995; 85: 1504-8.

8 Simioni P, Scudeller A, Radossi P, Gavasso S, Girolami B, Tormene D, Girolami A. "Pseudo homozygous" activated protein $C$ resistance due to double heterozygous factor $V$ defects (factor $V$ Leiden mutation and type I quantitative factor $V$ defect) associated with thrombosis: report of two cases belonging to two unrelated kindreds. Thromb Haemost 1996; 75: 422-6.

9 Castaldi E, Kalafatis M, Lunghi B, Simioni P, loannou PA, Petio M, Girolami A, Mann $K G$, Bernardi F. Molecular bases of pseudo-homozygous APC resistance: the compound heterozygosity for $F V$ R506Q and a FV null mutation results in the exclusive presence of FV Leiden molecules in plasma. Thromb Haemost 1998; 80 : $403-6$.

10 Kalafatis M, Bernardi F, Simioni P, Lunghi B, Girolami A Mann KG. Phenotype and genotype expression in pseudohomozygous factor $V^{L E D E N}$ : the need for phenotype analysis. Arterioscler Thromb Vasc Biol 1999; 19: 336-42.

11 Zehnder $\mathrm{JL}$, Jain $\mathrm{M}$. Recurrent thrombosis due to compound heterozygosity for factor V Leiden and factor V deficiency. Blood Coagul Fibrinolysis 1996; 7: 361-2.

12 Guasch JF, Lensen RP, Bertina RM. Molecular characterization of a type I quantitative factor $V$ deficiency in a thrombosis patient that is "pseudo homozygous" for activated protein $C$ resistance. Thromb Haemost $1997 ; 77: 252-7$.

13 Castaman G, Lunghi B, Missiaglia E, Bernardi F, Rodeghiero F. Phenotypic homozygous activated protein $C$ resistance associated with compound heterozygosity for Arg506Gln (factor $V$ Leiden) and His1299Arg substitutions in factor V. Br J Haematol 1997; 99: 257-61. 
14 Delahousse $B$, lochmann $S$, Pouplard $C_{*}$ Fimbel $B$, Charbonnier $B$, Guvel $Y$, Pseudo-homozygous activated protein $C$ resistance due to coinheritance of heterozygous factor $V$ Leiden mutation and type $\|$ factor $V$ deficiency. Variable expression when analyzed by different activated protein $\mathrm{C}$ resistance functional assays. Blood Coagul Fibrinolysis 1997; $8: 503-9$.

15 Lunghi B, Castoldi E, Mingozzi F, Bernardi F, Castaman G. A novel factor $V$ null mutation detected in a thrombophilic patient with pseudo-homozygous APC resistance and in an asymptomatic unrelated subject. Blood 1998; 92: 1463-4.

16 Standen G, Marse C, Aslam S, Bowron A. Recurrent thrombosis in a patient with pseudohomozygous activated protein $C$ resistance and homozygosity for MTHFR gene polymorphism C677T. Thromb Haemost 1999; 81: 663-4.

17 Castoldi $E$, Simioni $P$, Kalafatis $M$, Lunghi $B$, Tormene $D$, Girelli $D$, Girolami $A$, Bernardi F. Combinations of 4 mutations (FV R506Q, FV H1299R, FV Y1702C, PT $20210 \mathrm{G} / \mathrm{A}$ ) affecting the prothrombinase complex in a thrombophilic family. Blood $2000 ; 96: 1443-8$.

18 Dargaud $\mathrm{Y}$, Trzeciak $M C$, Meunier $S$, Angei $C$, Pellechia D, Negrier $C$, Vinciguerra $C$. Two novel factor $V$ null mutations associated with activated protein $C$ resistance phenotype/genotype discrepancy. Br J Haematol 2003; 123: 342-5.

19 Castaman G, Tosetto A, Ruggeri M, Rodeghiero F. Pseudohomozygosity for activated protein $\mathrm{C}$ resistance is a risk factor for venous thrombosis. $\mathrm{Br} J$ Haematol 1999; 106: 232-6.

20 Simioni $\mathrm{P}$, Castoldi $\mathrm{E}$, Lunghi $\mathrm{B}$, Tormene $\mathrm{D}$. Rosing J, Bernardi F. An underestimated combination of opposites resulting in enhanced thrombotic tendency. Blood. 2005; 106(7): 2363-5.

21 Scanavini $D_{*}$ Girelli $D$, Lunghi $B_{*}$ Martinelli $N$, Legnani $C$, Pinotti $M$, Palareti $G$, Bernardi $F$. Modulation of factor $V$ levels in plasma by polymorphisms in the $\mathrm{C}_{2}$ domain. Arterioscler Thromb Vasc Biol 2004; 24: 200-6.

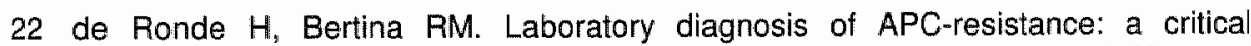
evaluation of the test and the development of diagnostic criteria. Thromb Haemost 1994; 72: 880-6.

23 Castoldi E, Brugge JM, Nicolaes GA, Gireili D, Tans G, Rosing J. Impaired APC cofactor activity of factor $V$ plays a major role in the APC resistance associated with the factor V Leiden (R506Q) and R2 (H1299R) mutations. Blood 2004; 103: 4173-9.

24 Nicolaes GA, Thomassen MC, Tans G, Rosing J, Hemker HC. Effect of activated protein $C$ on thrombin generation and on the thrombin potential in plasma of normal and APC-resistant individuals. Blood Coagul Fibrinolysis 1 997; 8: 28-38.

25 Nicolaes GA, Thomassen MC, van Oerle $R$, Hamulyák $K$, Hemker HC, Tans $G$, Rosing J. A prothrombinase-based assay for detection of resistance to activated protein C. Thromb Haemost 1996; 76: 404-10.

26 Váradi K, Moritz $B_{*}$ Lang $H$, Bauer K, Preston $E$, Peake I, Rivard GE, Kell $B$. Schwarz HP. A chromogenic assay for activated protein $\mathrm{C}$ resistance. $\mathrm{Br} J$ Haematol 1995; 90: 884-91.

27 Koenen RR, Thomassen MC, Tans G, Rosing J, Hackeng TM. Effect of oral contraceptives on the anticoagulant activity of protein $S$ in plasma. Thromb Haemost 2005; $93: 853-9$. 
28 Castoldi $E$, Lunghi $B$, Mingozzi $F$, Muleo $G$, Redaelli $R$, Mariani $G$, Bernardi $F$. A missense mutation $(Y 1702 C$ ) in the coagulation factor $V$ gene is a frequent cause of factor $V$ deficiency in the Italian population. Haematologica $2001 ; 86: 629-33$.

29 Olds $R$, Simioni $P$, Thompson $E$, Morgan $T$, Girolami $A$, Lane DA. Factor $V$ Gly2112Asp, a C2-domain variant, is associlated with severe deficiency and bleeding tendency. 4 Thromb Haemost 2003; 1 (Suppl. 1): P1206.

30. Lunghi B, Scanavimi D, Castoldi E, Gemmati D, Tognazzo S, Redaelli R, Ghirarduzzi A, leran $M$, Pinoti $M$, Bernardi $F$. The factor $V$ Glu1608Lys mutation is recurrent in famillal thrombophilia. I Thromb Haemost 2005; 3: 2032-8.

31 de Visser MC, van Hylckama Vlieg A, Tans $G$, Rosing $J_{\text {"Dahm }}$ AE, Sandset PM, Rosendaal FA, Bertina RM. Determinants of the APTT-based and ETP-based APC sensitivity tests. J Thromb Haemost $2005 ; 3: 1488-94$.

32 Govers-Rlemslag JW, Castoldi E, Nicolaes GA, Tans G, Rosing J. Reduced factor V concentration and altered $F V_{1} / F V_{2}$ ratio do not fully explain $R 2$-associated $A P C$ resistance. Thromb Haemost 2002; 88: 444-9.

33 de Visser MC, Rosendaal FR, Bertina RM. A reduced sensitivity for activated protein $C$ in the absence of factor $V$ Leiden increases the risk of venous thrombosis. Blood 1999; 93:1271-6.

34 Rodeghiero $F$, Tosetto $A$. Activated protein $C$ resistance and factor $V$ Leiden mutation are independent risk factors for venous thromboembolism. Ann Intern Med 1999; 130: 643-50. 


\section{CHAPTER 5}

Protein S levels modulate the activated protein $C$ resistance phenotype induced by elevated prothrombin levels

JM Brugge, G. Tans, J Rosing, E Castoldi

Based on: Thrombosis and Haemostasis, 2005, in press 


\section{SUMMARY}

Elevated plasma prothrombin levels, due to the prothrombin 20210 G/A mutation or to acquired causes, are a risk factor for venous thrombosis, partly because of prothrombin-mediated inhibition of the protein $\mathrm{C}$ anticoagulant pathway and consequent activated protein $C$ (APC) resistance. We have determined the effect of plasma prothrombin concentration on the APC resistance phenotype and evaluated the role of protein $S$ levels as a modulating variable. The effect of prothrombin and protein $S$ levels on APC resistance was investigated in reconstituted plasma systems and in a population of healthy individuals using both the aPTT-based and the thrombin generation-based APC resistance tests. In reconstituted plasma APC resistance increased at increasing prothrombin concentration in both assays. Enhanced APC resistance was caused by the effect of prothrombin on the clotting time in the absence of APC in the aPTT-based test, and on thrombin formation in the presence of APC in the thrombin generation-based test. In plasma from healthy individuals prothrombin levels were highly correlated to protein $S$ levels. Since prothrombin and protein $S$ had opposite effects on the APC resistance phenotype, the prothrombin/protein $S$ ratio was a better predictor of APC resistance than the levels of either protein alone. Prothrombin titrations in plasmas containing different amounts of protein $S$ confirmed that protein $S$ levels modulate the ability of prothrombin to induce APC resistance. These findings suggest that carriers of the prothrombin $20210 \mathrm{G} / \mathrm{A}$ mutation, who have a high prothrombin/protein $S$ ratio, may experience a higher thrombosis risk than noncarriers with comparable prothrombin levels. 


\section{INTRODUCTION}

Prothrombin is a $72-\mathrm{kDa}$ vitamin $\mathrm{K}$-dependent glycoprotein synthesised in the liver and circulating in plasma at a concentration of $1.5-2.0 \mu \mathrm{M}$. Structurally, it comprises a Gla domain, responsible for $\mathrm{Ca}^{2+}$-dependent binding to phospholipid membranes, two kringle domains and a serine-protease domain. Prothrombin is the inactive precursor of thrombin, which plays a pivotal role in thrombus formation by converting fibrinogen to fibrin and activating coagulation factors (F) XIII, XI, VIII and $\mathrm{V}$ as well as platelets (1). After binding to thrombomodulin on the surface of endothelial cells, thrombin loses its affinity for these substrates and activates protein $C$, thereby initiating the anticoagulant pathway. Activated protein $\mathrm{C}$ (APC) proteolytically inactivates coagulation $\mathrm{FVa}$ and FVIlla. The vitamin K-dependent APC-cofactor protein S stimulates APCmediated FVa- and FVIIla-inactivation (2), but also expresses anticoagulant activity in the absence of APC $(3,4)$. Functional defects of the protein $C$ pathway, e.g. associated with the FV Leiden mutation (5), determine a typical plasma phenotype known as APC resistance (6), which is a common risk factor for venous thrombosis. The hallmark of APC-resistant plasma is the impaired ability of exogenous APC to prolong the clotting time of plasma in an aPTTbased assay (6).

The $20210 \mathrm{G} / \mathrm{A}$ mutation in the 3'-untranslated region of the prothrombin gene causes a $\sim 30 \%$ increase in plasma prothrombin levels in the heterozygous state (7). Elevated plasma levels of prothrombin, due to this mutation or to acquired conditions, are a prevalent risk factor for venous thrombosis (7). Although the molecular basis for the association between increased risk of venous thrombosis and elevated prothrombin levels is unclear, several possible explanations have been put forward (8-12). Evidence has also been provided that prothrombin interferes with the protein $C$ anticoagulant pathway (FVa inactivation) by inhibiting APC (13) and/or protein S (14) function. This effect is already observed at physiological prothrombin concentrations and is not explained by simple competition between prothrombin and the APC/protein $S$ complex for binding to the phospholipid surface $(13,15)$. Accordingly, elevated plasma prothrombin levels were shown to cause APC resistance both in unselected individuals (16) and in carriers of the prothrombin $20210 \mathrm{G} / \mathrm{A}$ mutation (17).

In order to get more insight into prothrombin-induced APC resistance, we have investigated the effect of plasma prothrombin levels on the APC resistance phenotype in reconstituted plasma systems and in a population of healthy individuals using two functional APC resistance assays. 


\section{MATERIALS AND METHODS}

\section{Plasmas}

Prothrombin-deficient plasma. Congenitally prothrombin-deficient plasma (FII:C 2\%) was purchased from George King Bio-Medicals Inc. (Overland Park, KS).

Individual plasmas. Blood was collected in $3.8 \%$ sodium citrate from 77 fasting healthy individuals ( 49 males and 28 females; mean age 41.0 years) free of medication and not using oral contraceptives. Platelet-poor plasma was prepared by centrifuging twice at $3000 \mathrm{~g}$ for $15 \mathrm{~min}$ at room temperature, aliquoted and snap-frozen at $-80^{\circ} \mathrm{C}$. All donors were genotyped for the FV Leiden and prothrombin $20210 \mathrm{G} / \mathrm{A}$ mutations, and FV Leiden carriers ( $n=3$ ) were excluded from subsequent analyses while carriers of the prothrombin mutation ( $n=2)$ were not.

Protein S-depleted plasma. Blood was drawn in $3.2 \%$ sodium citrate from 7 fasting healthy volunteers ( 6 males and 1 female; mean age 38.4 years) and platelet-poor plasma was obtained as described above. After pooling the plasma, protein S-immunodepletion was performed according to Koenen et al. (10). This procedure simultaneously removes C4b-binding protein, a complement protein that complexes $\sim 60 \%$ of plasma protein $\mathrm{S}$. The residual protein $\mathrm{S}$ level in protein S-depleted plasma was $10 \%$ of normal pooled plasma as determined by a total protein S ELISA (18). The prothrombin concentration was $96 \%$ of that of normal pooled plasma.

\section{Variation of the prothrombin and protein $\mathbf{S}$ concentrations in plasma}

Prothrombin and prothrombin fragment $1+2$ titrations (Figs. 1 and 2). Human prothrombin and prothrombin fragment $1+2$ (comprising the Gla domain and the two kringle domains) were purified from normal pooled plasma as reported $(19,20)$. The prothrombin concentration in plasma was varied between $10 \%$ and $175 \%$ by reconstituting prothrombin-deficient plasma with increasing amounts of purified prothrombin. The normal plasma prothrombin concentration $(100 \%)$ was assumed to be $2.0 \mu \mathrm{M}$. The titrations in Fig. 2 were performed by adding increasing amounts of purified prothrombin or prothrombin fragment $1+2$, ranging from 0 to $1.2 \mu \mathrm{M}$ (i.e. $0-60 \%$ of the normal plasma concentration of prothrombin), to normal pooled plasma.

Protein $S$ titrations (Fig. 5). Human protein $S$ was purified from normal pooled plasma as reported (18). The concentration of free protein $S$ in plasma was varied between $10 \%$ and $175 \%$ by supplementing protein S-depleted 
plasma with increasing amounts of purified protein $\mathrm{S}$. The normal plasma concentration of free protein S $(100 \%)$ was assumed to be $200 \mathrm{nM}$.

Prothrombin titrations at different protein $S$ concentrations (Fig. 6). Plasma containing $50 \%$ protein $S$ was prepared by mixing protein $S$-depleted plasma with normal plasma. Plasma containing $100 \%$ protein $\mathrm{S}$ was normal pooled plasma. Plasma containing $150 \%$ protein $S$ was obtained by supplementing normal pooled plasma with $50 \%(100 \mathrm{nM})$ purified protein $\mathrm{S}$. The prothrombin concentration in these plasmas was varied between $100 \%$ and $175 \%$ by adding increasing amounts of purified prothrombin. For the double titration (Fig. 6B), normal pooled plasma was supplemented with both purified prothrombin and purified protein $S$ in a constant molar ratio.

\section{Measurement of APC resistance}

aPTT-based APC resistance assay. The aPTT-based APC resistance test was performed in undiluted plasma using the Coatest ${ }^{\oplus}$ APC Resistance kit (Chromogenix, Mölndal, Sweden) in an $\mathrm{ACL} 300$ Research coagulometer (Automated Coagulation Laboratory). All clotting times were measured in duplicate ( $n=2$, unless otherwise stated in the figure legend) and results were expressed as normalised APC-sensitivity ratios (nAPCsr). A low nAPCsr indicates APC resistance.

Thrombin generation-based APC resistance assay. The thrombin generation assay was performed essentially as reported (21), with minor modifications. The tissue factor (TF) and phospholipid concentrations in the trigger were doubled, yielding final concentrations of $13.6 \mathrm{pM}$ TF (Innovin ${ }^{\mathbb{4}}$, DADE-Behring, Marburg, Germany) and $30 \mu \mathrm{M}$ synthetic phospholipid vesicles (DOPS/DOPC/DOPE, $20 / 60 / 20 \mathrm{~mol} / \mathrm{mol} / \mathrm{mol}$ ) in the reaction mixture. Conversion of the fluorogenic substrate (Z-Gly-Gly-Arg-AMC, BACHEM AG, Bubendorf, Switzerland) by the thrombin formed in plasma was followed in a Fluoroskan Ascent reader (Thermo Labsystems, Helsinki, Finland). Thrombin generation curves and the endogenous thrombin potential (ETP) (22) were calculated using the Thrombinoscope ${ }^{\mathrm{TM}}$ software (Synapse B.V., Maastricht, The Netherlands). All thrombin generation curves were determined in duplicate $(n=2$, unless otherwise stated in the figure legend).

For each plasma a normalised APC sensitivity ratio (nAPCsr) was calculated by dividing the ratio of the ETPS obtained in the presence of APC $\left(E P_{+A P C}\right)$ and in its absence $\left(E T_{{ }_{A A P C}}\right)$ by the ratio of the ETP ${ }_{+A P C}$ and ETP.APC determined in normal pooled plasma in the same experiment. A high nAPCsr indicates APC resistance. In each experiment, the APC concentration was such as to reduce the ETP of normal pooled plasma to $10 \%$ of the ETP determined in 
the absence of APC. In titration experiments, reconstituted plasma containing $100 \%$ prothrombin or protein $S$ was used as a reference instead of normal pooled plasma.

\section{Measurement of factor levels in plasma}

Plasma prothrombin levels were measured by complete activation of prothrombin with Ecarin (Pentapharm, Basel, Switzerland) in 1500-fold diluted plasma and subsequent determination of the amidolytic activity of thrombin/meizothrombin with the chromogenic substrate S2238 (Chromogenix, Mölndal, Sweden). Free protein $S$ levels were determined by ELISA (23) and FV levels by a prothrombinase-based assay (21). FVIII levels were measured using the Coatest ${ }^{\oplus}$ FVIII kit (Chromogenix, Mölndal, Sweden). Normal pooled plasma was used as a reference in all measurements.

\section{Statistics}

Multiple regression analysis was used to dissect the effect of prothrombin and free protein $S$ levels on the aPTT-based and ETP-based nAPCsr in the healthy population. Prothrombin, free protein $S, F V$ and FVIII levels were included as independent variables.

The slopes of the regression lines in Fig. 6 were compared using the ttest for parallelism of regression lines. 


\section{RESULTS}

\section{Effect of prothrombin levels on APC resistance in a reconstituted plasma system}

To determine the effect of prothrombin concentration on APC resistance, we reconstituted prothrombin-deficient plasma with varying amounts of purified prothrombin (ranging from $10 \%$ to $175 \%$ of the normal plasma concentration) and measured the nAPCsr with the aPTT- and the ETP-based $A P C$ resistance tests.

In the aPTT-based assay, the nAPCsr progressively decreased (i.e. plasma became more APC-resistant) at increasing prothrombin concentration (Fig. 1A). Between $75 \%$ and $175 \%$ prothrombin, the graph was linear with a slope of $-0.010 \mathrm{nAPCs}$ units $/ 10 \%$ prothrombin $(p=0.001)$. Interestingly, the effect of increasing prothrombin concentration on the nAPCsr was not due to a shortening of the clotting time measured in the presence of APC, which was virtually constant at prothrombin concentrations $\geq 100 \% \quad(-0.17 \mathrm{sec} / 10 \%$ prothrombin, clotting time at $100 \%$ prothrombin $=106.2 \mathrm{sec}$ ), but rather to a prolongation of the clotting time measured in the absence of APC $(+0.29$ sec/10\% prothrombin, clotting time at $100 \%$ prothrombin $=33.7 \mathrm{sec}$ ) (Fig. 1B). This unexpected observation was confirmed by a similar experiment in which the prothrombin concentration was varied by mixing prothrombin-deficient plasma with normal plasma (data not shown), thus excluding an artefact due to a possible contaminant in the prothrombin preparation used to reconstitute prothrombin-deficient plasma.

In the ETP-based APC resistance assay, the nAPCsr increased linearly with increasing prothrombin concentration (slope 0.146 nAPCsr units/10\% prothrombin, $p<10^{-5}$ ), again indicating that elevated prothrombin levels cause APC resistance (Fig. 1C). In this case, however, the effect of prothrombin concentration on the nAPCsr was driven by the ETP ${ }_{+A P C}$. In fact, although both the ETP.APC and the ETP + APC increased at increasing prothrombin concentration (Fig. 1D), the ETP.APC was a linear function of the prothrombin concentration, while the ETP + APC was a quadratic function of this concentration (Fig. 1D, inset), resulting in a linear dependence of the nAPCsr on the prothrombin level. 

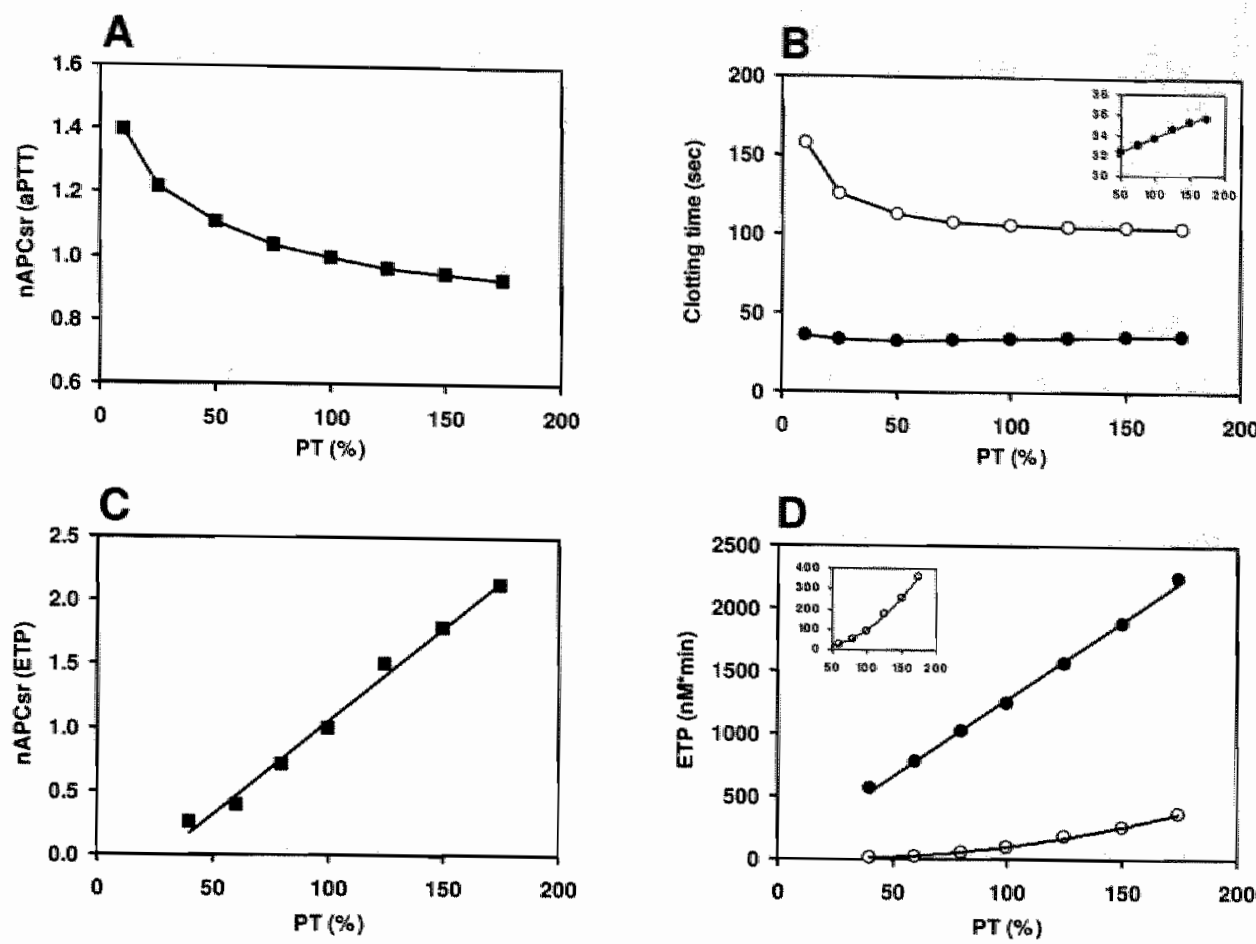

FIGURE 1: Effect of the prothrombin concentration on APC resistance (reconstituted plasma). Prothrombin-deficient plasma was reconstituted with increasing amounts of purified prothrombin and APC resistance was determined with the aPTT. based $(n=4)$ and ETP-based $(n=2)$ assays. The graphs illustrate the effect of the prothrombin (PT) concentration on: A) the aPTT-based nAPCsr; B) the clotting times measured in the absence (O) and in the presence (O) of APC; C) the ETP-based nAPCsr; and D) the ETP measured in the absence (-) and in the presence (O) of APC. Plasmas containing less than $40 \%$ prothrombin have been omitted from panels $C$ and $D$ because they yielded unmeasurably low ETPs in the presence of APC.

To verify whether the effect of prothrombin on the ETP was due to a specific protein-protein interaction or to mere competition for the phospholipid surface, an additional titration was performed with prothrombin fragment $1+2$, which binds to phospholipids with approximately the same affinity as prothrombin. Normal pooled plasma was supplemented with increasing amounts of either prothrombin or prothrombin fragment $1+2$, and thrombin generation was measured in the absence and presence of APC. While prothrombin brought about the expected increase of both the ETP.APC and the ETP $_{+A P C}$ (Fig. 2A,B), prothrombin fragment $1+2$ hardly affected either ETP (Fig. $2 C, D)$. The effect of the prothrombin fragment $1+2$ concentration on the ETP. 
based nAPCsr $(0.033$ nAPCsr units $/ 10 \%$ prothrombin fragment $1+2, p=0.038)$ was only $\sim 20 \%$ of that of prothrombin $(0.164$ nAPCsr units $10 \%$ prothrombin, $\left.p<10^{-4}\right)$ ( $t$-test for parallelism of regression lines: $p<10^{-5}$ ).
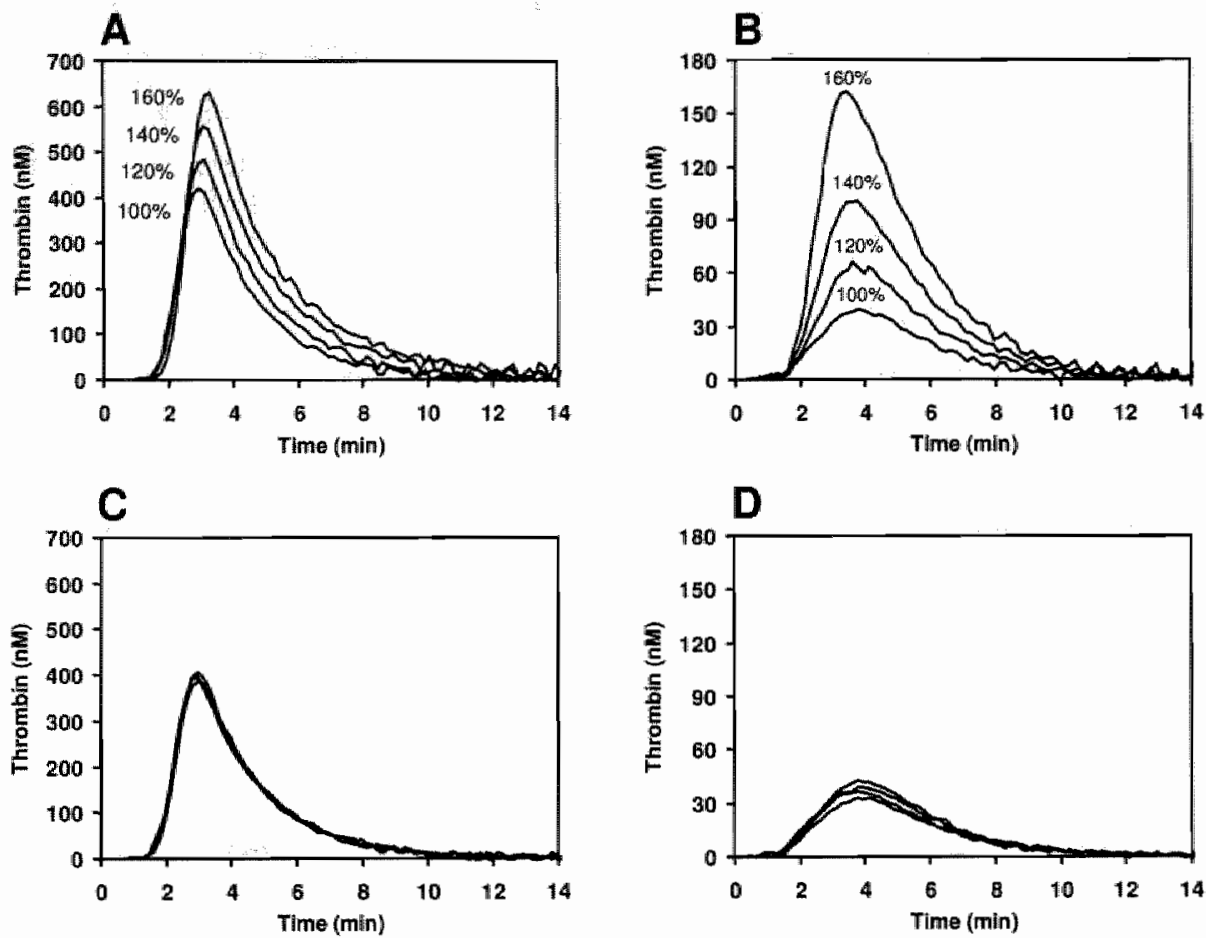

FIGURE 2: Comparison of the effects of prothrombin and prothrombin fragiment $1+2$ on thrombin generation measured in the absence and presence of APC. Normal pooled plasma containing $\sim 2 \mu \mathrm{M}$ prothrombin $(100 \%)$ was supplemented with $0.4 \mu \mathrm{M}(20 \%), 0.8 \mu \mathrm{M}(40 \%)$ and $1.2 \mu \mathrm{M}(60 \%)$ purified prothrombin $(\mathrm{A}, \mathrm{B})$ or prothrombin fragment $1+2(C, D)$, and thrombin generation was measured in the absence $(A, C)$ and presence $(B, D)$ of APC two times in duplicate $(n=4)$.

Relationship between prothrombin levels and APC resistance in plasma from healthy individuals

The relationship between APC resistance and the plasma prothrombin level was also investigated in a population of 74 healthy blood donors, including two carriers of the prothrombin $20210 \mathrm{G} / \mathrm{A}$ mutation. Prothrombin levels in this population ranged between $79 \%$ and $171 \%$. 
In accordance with the model experiment, a negative correlation was observed between plasma prothrombin levels and the nAPCsr determined with the aPTT-based APC resistance assay (Fig. 3A). Although the correlation did not reach significance, probably due to the small sample size, the slope of the regression line $(-0.011 \mathrm{nAPCsr}$ units $/ 10 \%$ prothrombin, $\mathrm{p}=0.216)$ was similar to that obtained in the model system and did not change after correction for free protein S, FV and FVIII levels (-0.011 nAPCsr units $/ 10 \%$ prothrombin, $\mathrm{p}=0.296$ ). Like in the model experiment, the clotting time measured in the absence of APC was prolonged at high prothrombin levels $(+0.27 \mathrm{sec} / 10 \%$ prothrombin, mean clotting time $=32.1 \mathrm{sec}$ ), while the clotting time measured in the presence of APC was virtually independent of the plasma prothrombin level $(-0.16 \mathrm{sec} / 10 \%$ prothrombin , mean clotting time $=113.6 \mathrm{sec}$ ) (Fig. $3 \mathrm{~B})$.
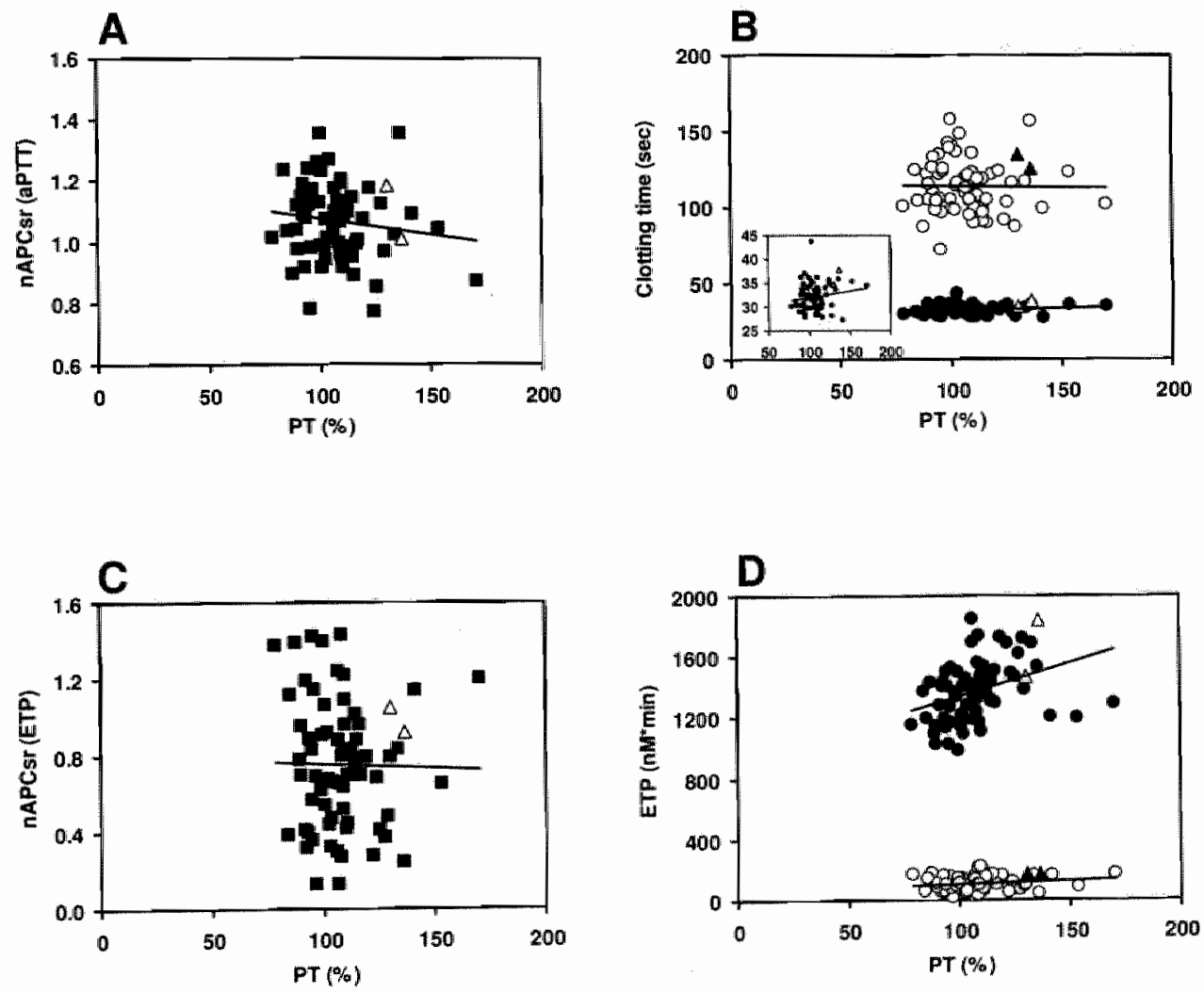


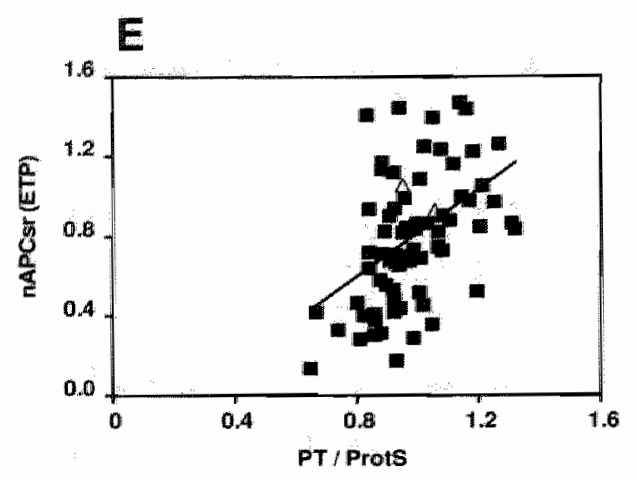

FIGURE 3: Effect of the prothrombin concentration on APC resistance (population of healthy individuals). The prothrombin level and APC resistance in the aPTT-based and ETP-based assays were determined in the plasma from 74 healthy blood donors $(n=2)$. The graphs illustrate the correlation between the plasma prothrombin (PT) level and: A) the aPTT-based nAPCsr; B) the clotting times measured in the absence (O) and in the presence (O) of APC; C) the ETP-based nAPCsr; and D) the ETP measured in the absence (O) and in the presence (O) of APC. Panel E shows the dependence of the ETP-based nAPCsr on the prothrombin/protein $S$ ratio. The two carriers of the prothrombin $20210 \mathrm{G} / \mathrm{A}$ mutation are indicated in triangles.

APC resistance in the plasma from the 74 donors was also determined with the ETP-based test. In sharp contrast to the model experiment, there was hardly any correlation between the ETP-based nAPCsr and plasma prothrombin levels (Fig. 3C), although both the ETP.APC and the ETP ${ }_{+A P C}$ showed a tendency to increase with the plasma prothrombin level (Fig. 3D), as in the model system. This discrepancy is likely due to the fact that the individuals of the population differ not only in prothrombin levels but also in numerous other plasma variables that may affect the APC resistance phenotype. In fact, after correcting for free protein $S, F V$ and FVIII levels, a positive correlation was found between the ETP-based nAPCsr and plasma prothrombin levels in the population, although the slope $(0.074$ nAPCsr units $/ 10 \%$ prothrombin, $p=0.012)$ was about half of that observed in the model experiment. According to the multiple regression analysis, the major confounder of the effect of prothrombin on the ETP-based nAPCsr was protein $S$, which had a strong negative effect on the ETP-based nAPCsr $\left(-0.113\right.$ nAPCsr units $/ 10 \%$ free protein $\left.S, p<10^{-5}\right)$. Accordingly, when the prothrombin level of each plasma was "corrected" for the corresponding protein S level by taking the prothrombin/protein S ratio, the ETP-based nAPCsr showed a much better correlation with this parameter $\left(r=0.460, p<10^{-4}\right.$, Fig. 3E) than with the prothrombin level alone ( $r=-0.024$, n.s., Fig. 3C). Further analysis revealed that the plasma levels of prothrombin and protein $S$ were significantly correlated $(r=0.605, p<0.01)$ in the donor population (Fig. 4). 


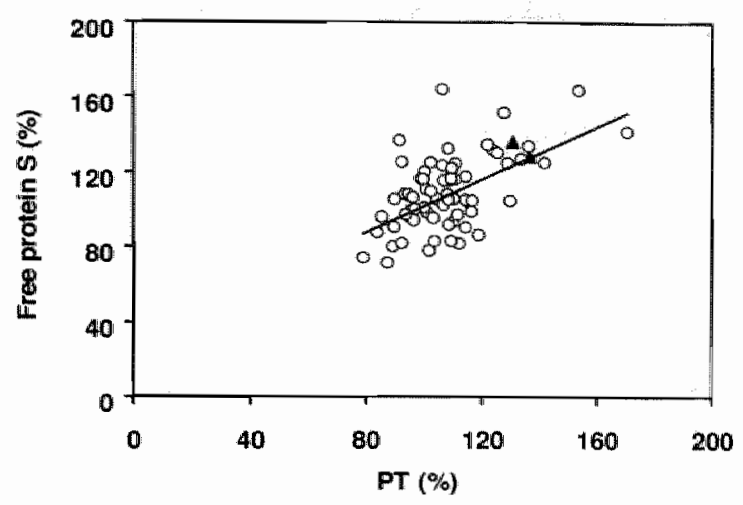

FIGURE 4: Correlation between plasma prothrombin and protein $S$ levels in a population of healthy individuals. Prothrombin and free protein $S$ levels were determined in plasma from 74 healthy blood donors as described under Methods. The two carriers of the prothrombin $20210 \mathrm{G} / \mathrm{A}$ mutation are indicated in triangles.

\section{Effect of protein S levels on APC resistance}

To verify the effect of protein S levels on APC resistance, we varied the concentration of free protein $S$ in protein $S$-depleted plasma between $10 \%$ and $175 \%$ of its normal plasma concentration and determined the nAPCsr with the aPTT- and ETP-based APC resistance tests.

In the aPTT-based assay, the nAPCsr increased (plasma became less APC-resistant) at increasing protein $S$ concentrations (Fig. 5A). At protein $S$ concentrations $\geq 75 \%$ a plateau was reached with a mild slope of 0.001 nAPCsr units $/ 10 \%$ free protein $S(p=0.410)$. As shown in Fig. 5B, the effect of protein $S$ concentration on the aPTT-based nAPCsr was entirely driven by the clotting time measured in the presence of APC, while the clotting time measured in the absence of APC was independent of the protein S concentration. 

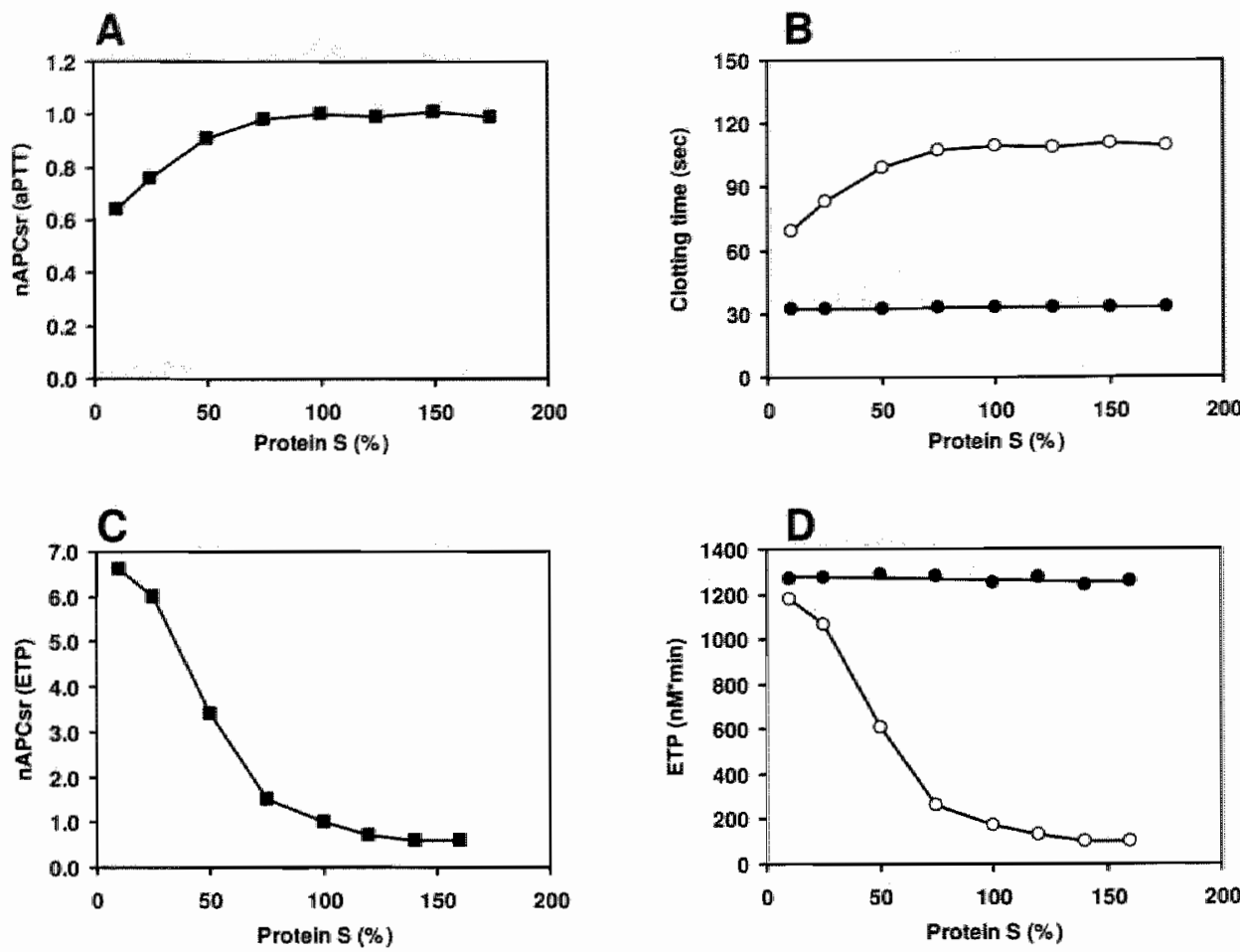

FIGURE 5: Effect of protein S concentration on APC resistance (reconstituted plasma). Protein S-depleted plasma was reconstituted with increasing amounts of purified protein S and APC resistance was determined with the aPTT-based and ETPbased assays $(n=2)$. The graphs illustrate the effect of protein $S$ concentration on: A) the aPTT-based nAPCsr; B) the clotting times measured in the absence (-) and in the presence (O) of APC; C) the ETP-based nAPCsr; and D) the ETP measured in the absence (O) and in the presence (O) of APC.

Similarly, the ETP-based nAPCsr sharply decreased (APC resistance decreased) with increasing protein $S$ concentration (Fig. 5C). For protein $S$ levels $\geq 75 \%$ the graph was linear and the slope $(-0.104$ nAPCsr units $/ 10 \%$ protein $S, p=0.015$ ) was similar to that obtained in the population after multiple regression analysis. Like in the aPTT-based assay, the effect of protein $S$ concentration on the ETP-based nAPCsr was entirely attributable to the measurement in the presence of APC, while the ETP.APC was not affected by the protein $S$ concentration at the TF concentration used (Fig. 5D). Interestingly, in the absence of protein S, APC was totally ineffective in controlling thrombin generation (Fig. 5D). 


\section{Modulation of prothrombin-induced APC resistance by protein S}

The data presented above indicate that prothrombin and protein $\mathrm{S}$ have antagonistic effects on the APC resistance measured with the ETP-based assay. To investigate the combined effects of both proteins on the ETP-based nAPCsr, we performed prothrombin titrations in plasmas containing $50 \%, 100 \%$ and $150 \%$ protein $\mathrm{S}$, respectively (Fig. $6 \mathrm{~A}$ ). In all three cases, APC resistance increased linearly with increasing prothrombin concentration, but the slopes of the lines were significantly different (t-test for parallelism of regression lines: $\left.p<10^{-4}\right)$. The effect of prothrombin concentration on the ETP-based nAPCsr was maximal at $50 \%$ protein $S\left(0.193\right.$ nAPCsr units $/ 10 \%$ prothrombin, $\left.\mathrm{p}<10^{-6}\right)$ and gradually decreased when the protein $S$ concentration was increased to $100 \%$ $\left(0.154\right.$ nAPCsr units $/ 10 \%$ prothrombin, $\left.p<10^{-6}\right)$ and $150 \%(0.113 \mathrm{nAPCsr}$ units $/ 10 \%$ prothrombin, $p<10^{-4}$ ).
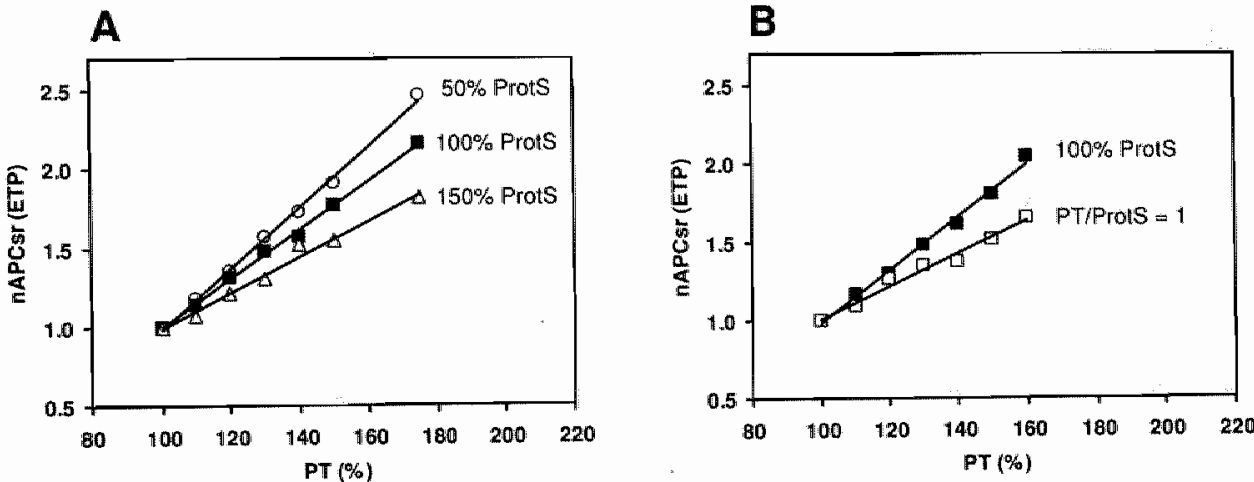

FIGURE 6: Antagonistic effects of prothrombin and protein S levels on plasma APC resistance. A) Effect of the prothrombin (PT) concentration on the ETP-based nAPCsir of plasmas containing $50 \%(O), 100 \%(\square)$ and $150 \%(\triangle)$ protein $S$ (ProtS). Plasmas containing different protein $S$ concentrations were prepared as described under Methods and the prothrombin concentration was increased by the addition of purified prothrombin. To enable quantitative comparison of the effects of prothrombin on the nAPCsr, residual thrombin formation in the presence of APC was set at $10 \%$ in plasmas containing $50 \%, 100 \%$ and $150 \%$ protein $S$ by using different APC concentrations. The slopes of the regression lines were significantly different $\left(p<10^{-4}\right)$. B) Normal pooled plasma was supplemented either with prothrombin only (a) or with prothrombin and protein $S$ in a constant molar ratio $(\square)$ and APC resistance was measured with the ETP. based assay. The slopes of the regression lines were significantly different $\left(p<10^{-5}\right)$. All nAPCsr were determined in duplicate $(n=2)$.

The correlation between prothrombin and protein $\mathrm{S}$ levels in the plasma from the healthy donors (Fig. 4) suggests that, in most individuals with high prothrombin levels, APC resistance will be counteracted by concomitantly high protein $S$ levels. This predicts that carriers of the prothrombin $20210 \mathrm{G} / \mathrm{A}$ 
mutation, in whom the higher prothrombin level is unopposed by protein $\mathrm{S}$, will have higher APC resistance than non-carriers with comparable prothrombin levels. To test this hypothesis in a model experiment, we compared two series of plasmas containing increasing concentrations of prothrombin, ranging from $100 \%$ to $160 \%$, in which the protein $S$ level was either kept constant or increased proportionally to the prothrombin level. As shown in Fig. $6 \mathrm{~B}$, in both cases the ETP-based nAPCsr increased linearly at increasing prothrombin concentrations, but the effect of prothrombin on APC resistance was significantly $\left(p<10^{-5}\right)$ more pronounced in plasma in which only the prothrombin level was increased $\left(0.169\right.$ nAPCsr units $/ 10 \%$ prothrombin, $\left.p<10^{-5}\right)$ than in plasma in which prothrombin and protein $S$ levels were increased in parallel $\left(0.105\right.$ nAPCsr units $/ 10 \%$ prothrombin, $\left.p<10^{-4}\right)$. 


\section{DISCUSSION}

The molecular mechanism underlying the association between high plasma levels of prothrombin and increased risk of venous thrombosis is still a matter of debate. Since the normal plasma concentration of prothrombin (1.5$2.0 \mu \mathrm{M}$ ) largely exceeds the $K_{m}$ for prothrombin activation by the prothrombinase complex (210 $\mathrm{nM})$ determined in model systems (24), the procoagulant advantage conferred by an increase of the plasma prothrombin concentration is not straightforward. Recently, evidence has been provided that at least part of the prothrombotic effect of high prothrombin llevels might be due to inhibition of APC-mediated FVa inactivation (13-15) and consequent APC resistance $(16,17)$. Since hyperprothrombinemia is a prevalent condition in the general population (7), it may represent a major cause of APC resistance not associated with the FV Leiden mutation (25).

In this study, we have investigated the influence of plasma prothrombin concentration on the APC resistance phenotype using both the aPTT-based and the ETP-based APC resistance tests. Since these assays are sensitive to different plasma variables (26), they provide complementary information on the molecular basis of APC resistance. Both assays indicated that APC resistance increases at increasing prothrombin levels in plasma (Fig. 1A,C), but the underlying mechanism was different in the two cases.

In the aPTT-based test, the effect of prothrombin levels on APC resistance was mainly mediated by the measurement in the absence of APC, at least for prothrombin concentrations $\geq 100 \%$. In fact, since in this range the relative effect of prothrombin concentration on the clotting time determined in the absence of APC $(+0.27 \mathrm{sec} / 10 \%$ prothrombin relative to a mean clotting time of $32.1 \mathrm{sec}$ ) was 6 times larger than that on the clotting time determined in the presence of $\mathrm{APC}(-0.16 \mathrm{sec} / 10 \%$ prothrombin relative to a mean clotting time of $113.6 \mathrm{sec}), \sim 86 \%$ of the effect of prothrombin on the aPTT-based nAPCsr is attributable to prolongation of the clotting time in the absence of APC.

Differently, in the ETP-based APC resistance test, the effect of prothrombin on the nAPCsr was driven by the measurement in the presence of APC. Our findings in reconstituted plasma confirm and extend earlier reports that thrombin generation in the absence of APC (8) and the ETP-based nAPCsr (27) are significantly higher in carriers of the prothrombin $20210 \mathrm{G} / \mathrm{A}$ mutation than in normal controls. Moreover, the inability of prothrombin fragment $1+2$ to enhance the ETP + APC (Fig. 2D) indicates that the inhibitory effect of prothrombin on the protein $C$ pathway is not merely due to competition for the phospholipid surface, but mediated by specific protein-protein interactions. 
In the aPTT-based assay no difference was observed between the results obtained in the plasma model (Fig. 1A,B) and in the population (Fig. $3 A, B)$. In the physiological range of prothrombin levels $(75 \%-175 \%)$, the dependence of the nAPCsr on the prothrombin concentration in plasma reconstituted with purified prothrombin was linear and yielded the same slope (0.010 nAPCsr units $/ 10 \%$ prothrombin) as in the population $(-0.011 / 10 \%$ prothrombin). Correction for free protein S, FV and FVIII levels did not alter the slope $(-0.011 / 10 \%$ prothrombin).

In contrast, a marked difference between the experiments conducted in reconstituted plasma (Fig. $1 C, D$ ) and in the population (Fig. $3 C, D$ ) was observed in the ETP-based APC resistance assay. The experiments performed in reconstituted plasma indicated a linear increase of the ETP-based nAPCsr at increasing prothrombin levels (Fig. 1C) with a slope of 0.146 nAPCsr units $/ 10 \%$ prothrombin. Differently, the population experiment (Fig. $3 C$ ) showed no correlation between the ETP-based nAPCsr and prothrombin levels. This discrepancy turned out to be due to the confounding effect of protein $\mathrm{S}$, whose plasma levels were highly correlated to those of prothrombin in the population (Fig. 4). Correction for free protein $S$ levels restored the expected positive correlation between ETP-based nAPCsr and prothrombin concentration (Fig. $3 E)$, although the slope $(0.074$ nAPCsr units $/ 10 \%$ prothrombin) was not the same as in the model experiment, probably because not all assay determinants (26) were included in the multiple regression analysis. While free protein $S$ levels in the physiological range hardly affected the aPTT-based nAPCsr (Fig. $5 A)$, they showed a strong inverse correlation with the ETP-based nAPCsr, with comparable slopes in the model system $(-0.104 \mathrm{nAPCsr}$ units $/ 10 \%$ free protein S) and in the population ( $-0.113 \mathrm{nAPCs}$ units $/ 10 \%$ free protein $S)$. The relative protein S-insensitivity of aPTT-based APC resistance tests has already been observed both in vitro (28) and in protein S-deficient patients (29). The superior sensitivity of the ETP-based assay to protein $S$ and prothrombin levels might derive from the different coagulation trigger (TF instead of kaolin) and/or assay end-point (ETP instead of clotting). The trigger determines the relative contributions of the extrinsic and intrinsic coagulation pathways, and hence of APC-dependent FVa and FVIIla inactivation, to the assay end-point. Thus, possible differences in protein $S$ requirements between $\mathrm{FVa}$ and FVIIla inactivation may result in differential effects of protein $S$ and prothrombin (which presumably exerts its action via protein S) on the nAPCsr determined with the two assays. With respect to the assay end-point, it should be noted that clotting occurs long before most of the thrombin is generated and therefore only probes the initiation phase of thrombin generation, while the ETP is mainly determined by the propagation and termination phases. The ability to probe the termination 
phase of thrombin generation likely accounts for the higher sensitivity of the ETP-based test to defects of the anticoagulant systems (antithrombin and the protein C pathway).

Taken together, our data indicate that prothrombin and protein $S$ have antagonistic effects on the APC resistance phenotype. This makes the ratio of their levels in plasma a more accurate predictor of APC resistance than prothrombin or protein S levels alone (Fig. $3 E$ and Fig. 6). Since prothrombin and protein $\mathrm{S}$ are both vitamin $\mathrm{K}$-dependent proteins mainly synthesised in the liver and probably share the same biosynthetic machinery within the hepatocyte, their levels show a high degree of correlation in the general population $(30,31)$. Therefore, most individuals with a high prothrombin level will also have a relatively high protein $S$ level, which will mitigate prothrombininduced APC resistance. However, in carriers of the prothrombin $20210 \mathrm{G} / \mathrm{A}$ mutation, which selectively affects prothrombin levels (7), the prothrombin/protein $S$ ratio will be shifted in favour of prothrombin and result in enhanced APC resistance. Based on these considerations, we expect prothrombin $20210 \mathrm{G} / \mathrm{A}$ carriers to have higher APC resistance (and possibly a higher thrombosis risk) than non-carriers with comparable prothrombin levels. Of course, this prediction will have to be verified in epidemiological studies.

In conclusion, protein S levels modulate the APC resistance phenotype induced by high prothrombin levels. This phenomen may account for the increased thrombosis risk associated with genetic and acquired conditions which perturb the prothrombin/protein $S$ ratio in plasma, such as carriership of the prothrombin $20210 \mathrm{G} / \mathrm{A}$ mutation and oral contraceptive use.

\section{ACKNOWLEDGEMENTS}

The authors are grateful to René van Oerle for providing the plasma collection of normal healthy individuals. 


\section{REFERENCES}

1. Dahlbäck B. Blood coagulation. Lancet $2000 ; 355: 1627-32$.

2. Walker $F J$ "Fay PJ. Regulation of blood coagulation by the protein $C$ system. Faseb J $1992 ; 6: 2561-7$.

3. Heeb MJ, Mesters RM, Tans $G$, et al. Binding of protein $S$ to factor $V a$ associated with inhibition of prothrombinase that is independent of activated protein $\mathrm{C}$. J Biol Chem 1993; 268: 2872-7.

4. Hackeng TM, van 't Veer $C$, Meijers $J C$, et al. Human protein $S$ inhibits prothrombinase complex activity on endothelial cells and platelets via direct interactions with factors Va and Xa. J Biol Chem 1994; 269: 21051-8.

5. Bertina RM, Koeleman BP, Koster $T$, et al. Mutation in blood coagulation factor $V$ associated with resistance to activated protein C. Nature 1994; 369: 64-7.

6. Dahibäck B, Carlsson M, Svensson PJ. Familial thrombophilia due to a previously unrecognized mechanism characterized by poor anticoagulant response to activated protein $\mathrm{C}$ : prediction of a cofactor to activated protein $\mathrm{C}$. Proc Nat Acad Sci U SA 1993; 90: 1004-8.

7. Poort SR, Rosendaal FR, Reitsma PH, et al. A common genetic variation in the 3'untranslated region of the prothrombin gene is associated with elevated plasma prothrombin levels and an increase in venous thrombosis. Blood 1996; 88: 3698703.

8. Kyrle PA, Mannhalter $C$, Béguin $S$, et al. Clinical studies and thrombin generation in patients homozygous or heterozygous for the G20210A mutation in the prothrombin gene. Arterioscler Thromb Vasc Biol 1998; 18: 1287-91.

9. Wolberg AS, Monroe DM, Roberts HR, et al. Elevated prothrombin results in clots with an altered fiber structure: a possible mechanism of the increased thrombotic risk. Blood 2003; 101: 3008-13.

10. Koenen $R$, Tans $G$, van Oerle $R$, et al. The APC-independent anticoagulant activity of protein $S$ in plasma is decreased by elevated prothrombin levels due to the prothrombin G20210A mutation. Blood 2003; 102: 1686-92.

11. Seré KM, Rosing J, Hackeng TM. Inhibition of thrombin generation by protein $\mathrm{S}$ at low procoagulant stimuli: implications for maintenance of the hemostatic balance. Blood 2004; 104: 3624-30.

12. Colucci $M$, Binetti $B M$, Tripodi $A$, et all. Hyperprothrombinemia associated with prothrombin G20210A mutation inhibits plasma librinolysis through a TAFImediated mechanism. Blood 2004; 103: 2157-61.

13. Smirnov MD, Safa $O$, Esmon $N L$, et al. Inhibition of activated protein $C$ anticoagulant activity by prothrombin. Blood 1999; 94 : 3839-46.

14. Mitchell CA, Jane SM, Salem HH. Inhibition of the anticoagulant activity of protein $S$ by prothrombin. J Clin Invest 1988; 82: 2142-7.

15. Norstrom EA Tran S, Dahlbäck B. Prothrombin inhibition of the individual activated protein $\mathrm{C}$ cleavage sites in factor $\mathrm{Va}$. PhD thesis University of Lund (Sweden); 2004.

16. Tripodi A, Chantarangkul V, Mannucci PM. Hyperprothrombinemia may result in acquired activated protein $C$ reistance. Blood 2000; 96: 3295-6. 
17. Castaman G, Tosetto A, Simioni M, et al. Phenotypic APC resistance in carriers of the A20210 prothrombin mutation is associated with an increased risk of venous thrombosis. Thromb Haemost 2001; 86: 804-8.

18. Seré KM, Janssen MP, Willems $G M$, et al. Purified protein $S$ contains multimeric forms with increased APC-independent anticoagulant activity. Biochemistry 2001; 40: $8852-60$.

19. Di Scipio RG, Hermodson MA, Yates $S G$, et al. A comparison of human prothrombin, factor $\mathrm{X}$ (Christmas factor), factor $X$ (Stuart factor), and protein $S$. Biochemistry 1977; 16: 698-706.

20. Govers-Riemslag JW, Speijer $H$, Zwaal RF, et al. The effects of bovine prothrombin fragment 1 and fragment 1.2 on prothrombin activation. Thromb Res 1985; 38 : 375-88.

21. Ciastoldi $E$, Brugge JM, Nicolaes GA, et al. Impaired APC cofactor activity of factor $\checkmark$ plays a major role in the APC resistance associated with the factor $V$ Leiden (R506Q) and R2 (H1299R) mutations. Blood 2004; 103: 4173-9.

22. Hemker $H C$, Wielders $S$, Kessels $H$, et al. Continuous registration of thrombin generation in plasma, its use for the determination of the thrombin potential. Thromb Haemost 1993; 70: 617-24.

23. Koenen RR, Thomassen $M C$, Tans $G$, et al. Effect of oral contraceptives on the anticoagulant activity of protein $S$ in plasma. Thromb Haemost 2005; 93: 853-9.

24. Rosing J, Tans $\mathbf{G}$, Govers-Riemslag JW, et al. The role of phospholipids and factor Va in the prothrombinase complex. J Biol Chem 1980; 255: 27-4-83.

25. Taralunga $C$, Gueguen $R$, Visvikis $S$, et al. Phenotypic sensitivity to activated protein $\mathrm{C}$ in healthy families: importance of genetic components and environmental factors. Br J Haematol 2004; 126: 392-7.

26. de Visser $M C$, van Hylckama Vlieg $A$, Tans $G$, et al. Determinants of the APTTbased and ETP-based APC sensitivity tests. J Thromb Haemost 2005; 3: 1488-94.

27. Curvers J, Thomassen MC, Rimmer J, et al. Effects of hereditary and acquired risk factors of venous thrombosis on a thrombin generation-based APC resistance test. Thromb Haemost 2002; 88: 5-11.

28. De Ronde $H$, Bertina RM. Laboratory diagnosis of APC-resistance: A critical evaluation of the test and the development of diagnostic criteria. Thromb Haemostas 1994; 72: 880-6.

29. Grand'Maison A, Bates SM, Johnston $M$ et al. "ProC Global": a functional screening test that predicts recurrent venous thromboembolism. Thromb Haemost 2005; 93: 600-4.

30. Souto $\sqrt{ } \mathrm{C}$, Almasy $L$, Blangero $J$, et al. Genetic regulation of plasma levels of vitamin K-dependent protelns involved in hematostatis: results from the GAIT Project. Genetic Analysis of Idiopathic Thrombophilia. Thromb Haemost 2001; 85 : 88-92.

31. van Hylckama Vlieg $A_{*}$ Callas PW, Cushman $M$, et al. Inter-relation of coagulation factors and $d$-dimer levels in healthy individuals. J Thromb Haemost $2003 ; 1 ; 516-$ 22. 


\title{
CHAPTER 6
}

\author{
General Discussion
}


The protein $\mathrm{C}$ anticoagulant pathway plays an important role in the regulation of thrombin formation and in the maintenance of the haemostatic balance [1]. Activated protein $\mathrm{C}$, the key player in this regulatory system, is a serine protease that proteolytically inactivates the cofactors of the intrinsic and extrinsic coagulation pathways, FVIIla and FVa, respectively. In these inactivation reactions, protein S serves as a cofactor for APC. FV that has been cleaved by APC at $\mathrm{Arg}^{506}$ acts as an additional cofactor of APC in the inactivation of FVIIla [2, 3], while FVa has no APC-cofactor activity. The addition of APC to plasma in vitro causes a prolongation of the clotting time. In some cases, however, plasma is resistant towards this regulatory function of $A P C$, a phenotype known as APC-resistance [4] which is associated with an increased risk for venous thrombosis.

APC-resistance is most often caused by a single point mutation in the FV gene, resulting in the substitution of $\mathrm{Arg}^{506}$ by a Gln (FV Leiden) [5]. Since $\mathrm{Arg}^{506}$ marks one of the APC-cleavage sites on $\mathrm{FV}(\mathrm{a})[6], \mathrm{FV}$ Leiden is less susceptible to inactivation by APC $[7,8]$. As FV needs to be cleaved at $\mathrm{Arg}^{506}$ in order to stimulate the inactivation of FVIII(a) by APC [3], FV Leiden also expresses reduced anticoagulant activity in the inactivation of FVIII(a) [9]. Other mutations in the FV gene can also cause APC-resistance, e.g. the R2-haplotype [10-12]. In this case, however, the susceptibility of FVa-R2 to APC is not affected and only the APC-cofactor activity of FV-R2 is reduced [13].

Since FV (a) is both a substrate and a cofactor of APC [14], mutations in the FV gene can cause APC-resistance by reducing the susceptibility of FVa to APC-mediated inactivation and/or by interfering with the APC-cofactor activity of FV in FVIIla inactivation. Although APC-resistance was originally defined as a deficiency in the APC-cofactor function of FV, the discovery that the main underlying defect, il.e. FV Leiden, causes the loss of a cleavage site for APC, led researchers to mainly focus on the mechanism of APC-mediated inactivation of FVa, which is now well-characterized $[7,8,15-17]$.

In this thesis we have focused on the less well characterised APCcofactor activity of FV by investigating 1) the role of impaired APC-cofactor activity in the APC-resistance phenotype assaciated with $F V_{\text {Leiden; }}$ 2) the physiological role of the APC-cofactor activity of FV in the regulation of thrombin formation; 3) the consequences of the deficiency of this activity on thrombin generation and thrombosis risk, as illustrated by two examples: a) the rare condition known as $F V_{\text {Leiden }}$ pseudo-homozygosity, and b) the FV R2-haplotype. Finally, we have also looked at the effect of prothrombin levels on APCresistance. 


\section{Quantification of the anticoagulant activity of $F V$ and $F V_{\text {Leiden }}$}

Our first objective was to quantify the contribution of APC-cofactor activity of normal $F V$ and $F V_{\text {Leiden }}$ to the APC-resistance phenotype in plasma. Using an assay that specifically measures the anticoagulant activity of FV we found that normal FV stimulated the inactivation of FVIII(a) by APC in a dosedependent manner, while $F V_{\text {Leiden }}$ had no such stimulatory effect. Thus, normal FV possesses APC-cofactor activity that increases linearly with increasing FV concentration, whereas $F V_{\text {Leiden }}$ completely lacks anticoagulant activity. This is not in complete agreement with earlier publications about the APC-cofactor activity of $F V[2,9]$, because Varadi et al. reported that it was only in the absence of protein $S$ that $F V_{\text {Leiden }}$ had no APC-cofactor activity, while in the presence of protein $S \mathrm{FV}_{\text {Leiden }}$ still had a detectable anticoagulant cofactor activity [9]. This discrepancy between the data presented by Váradi et al. and our observations can be caused by differences in the assays used to measure the APC-cofactor activity of $F V_{\text {Leiden, }}$ or by the fact that Varadi et al. used purified proteins ( $F V I I I$, protein $S$ and $F V_{\text {Leiden }}$ ), while we used homozygous FV Leiden plasma mixed with FV deficient plasma as protein source. However, despite these differences, it is clear that normal $F V$, in synergy with protein $S$, functions as a cofactor for APC in the inactivation of FVIII(a), while $F V_{\text {Leiden }}$ is severely deprived of this anticoagulant function and probably has no APCcofactor activity at all in plasma.

To verify to what extent the impaired (or complete loss of) APC-cofactor activity of $F V_{\text {Leiden }}$ contributes to APC-resistance, we set out to dissect the relative contribution of the susceptibility and the APC-cofactor components to APC-resistance associated with the $F V_{\text {Leiden }}$ mutation. To this end we used the classical aPTT-based APC-resistance assay, whose outcome (the APCsr) depends on both APC-mediated FVa inactivation (susceptibility component) as well as FVIIla inactivation (APC-cofactor activity component). Since $F V_{\text {Leiden }}$ has no APC-cofactor activity, the APCsr of a FV Leiden plasma will only reflect the susceptibility of $F \mathrm{a}_{\text {Leiden }}$ to APC. Using this assay we found that increasing concentrations of $F V_{\text {Leiden }}$ in FV-deficient plasma did not change the APCsr which led us to the conclusion that the susceptibility component is independent of the FV level. In contrast, when we varied the concentration of normal FV in plasma, the APCsr increased with increasing FV levels. As the susceptibility component is independent of the FV concentration, this increase must be due to an increase in the APC-cofactor activity of normal FV with increasing FV concentrations. Assuming that at very low FV concentrations the APC-cofactor activity of normal FV is negligible, the difference between the APCsr's of normal $F V$ and $F V_{\text {Leiden }}$ when the FV level is close to zero represents the difference in susceptibility between both FV molecules. From these experiments we 
conclude that the difference in APCsr between plasmas containing normal FV or FV Leiden at any given FV concentration is composed of a susceptibility component, which is independent of the FV concentration, and an APC-cofactor activity component, which increases with increasing FV. In full plasma containing $100 \% \mathrm{FV}$, the difference in APC-resistance observed between normal plasma and plasma from $\mathrm{FV}_{\text {Leiden }}$ homozygous carrier is for $\sim 50 \%$ attributable to the fact that $F a_{\text {Leiden }}$ is less susceptible to inactivation by APC and for $\sim 50 \%$ due to the fact that $\mathrm{FV}_{\text {Leiden }}$ does not express any APC-colactor activity in the inactivation of FVIIla.

It is still generally believed that the reduced susceptibility of $\mathrm{FVa}_{\text {Leiden }}$ towards APC is the main reason why $F V_{\text {Leiden }}$ causes APC-resistance. However, our data show that reduced susceptibility of $\mathrm{FVa}_{\text {Leiden }}$ accounts for only half of the APC-resistance measured in the aPTT-based assay while the other half is in fact caused by the impaired APC-cofactor activity of $\mathrm{FV}_{\text {Leiden }}$ in the downregulation of FVIII(a). These findings imply that impairment of the anticoagulant activity of FV should be taken into account when interpreting results obtained with the classical aPTT-based APC-resistance assay, which is still often used in clinical settings. It should be stressed that, depending on the setup and reaction conditions, other APC-resistance assays may show different contributions of susceptibility and cofactor component to the APC-resistant phenotype and therefore, care should be taken in extrapolating our results to other clinical APC-resistance assays.

\section{The physiological relevance of the APC-cofactor activity of FV}

In the aPTT-based assay coagulation is initiated in a non-physiological way, by exposing plasma to a contact activator (kaolin). Therefore, the fact that impaired APC-cofactor activity accounts for $50 \%$ of the APC-resistance associated with $F V_{\text {Leiden }}$ as measured with the aPTT-based assay does not necessary mean that the anticoagulant activity of FV plays a role in vivo. To gain more insight in this, we evaluated the importance of the APC-cofactor activity of FV in a more physiological setting by using the thrombin generation assay [18]. The amount of thrombin formed after extrinsic activation with low TF concentrations was measured in plasmas with varying $F V$ or $F V_{\text {Leiden }}$ concentrations, both in the absence and presence of APC. In the absence of APC the amount of thrombin formed increased with increasing FV concentrations and reached a maximum at $\sim 60 \% \mathrm{FV}$, after which it remained constant. There were no differences between normal $F V$ and $F V_{\text {Leidien }}$ in the amount of thrombin formed at any $F V$ concentration. As the measurement without $A P C$ reflects the procoagulant activity of $F V$, these data indicate that there is no difference between the procoagulant activity of FV and FV Leiden. 
In the presence of APC however, titrating normal FV above $60 \%$ caused a decrease in amount of thrombin formed, while increasing the $F V_{\text {Leiden }}$ concentrations beyond $60 \%$ had no further effect on the amount of thrombin generated. In fact, in the presence of APC plasma containing $100 \% \mathrm{FV}_{\text {Leiden }}$ produced three times more thrombin than plasma with $100 \%$ normal FV. As the reaction conditions (triggering with low TF) were chosen in such a way that the FVilla activity was the rate limiting step, this difference originates from the fact that normal FV has APC-cofactor activity in the inactivation of FVIII(a) whereas FV Laiden does not. Furthermore, the fact that under these conditions the amount of thrombin formed was dependent on the FVIII concentration also indicates that thrombin generation in the presence of APC is indeed affected by FVIII(a) inactivation. So, at low FV concentrations the procoagulant activity of FV prevails, leading to a gradual increase of the amount of thrombin formed. However, at a concentration of approximately $50 \%$ to $60 \% \mathrm{FV}$, the procoagulant activity of $\mathrm{FV}$ is saturated and a further increase in $\mathrm{FV}$ concentration causes an increase in anticoagulant activity, leading to a decrease in the thrombin generation. These findings further suggest that carriership of FV deficiency ( $\sim 50 \%$ FV levels) might be associated with a hypercoagulable state, because FV procoagulant activity is already maximal, while FV anticoagulant activity is only half-maximal.

These experiments illustrate that the APC-cofactor activity of FV plays an important role in the regulation of thrombin formation under physiological conditions. There appears to be a difference between the inactivation reactions of normal $F V$ and $F V_{L e i d e n}$ in a purified system and in plasma. Kinetic analysis in model systems has revealed that normal FVa is inactivated 20-times more efficiently by $A P C$ as compared to $F a_{\text {Leiden, due to the difference in }}$ susceptibility between both FV molecules $[7,8]$. However, Rosing et al. showed that the presence of protein $S$ and $F X a$ during the inactivation of $F V a$ or

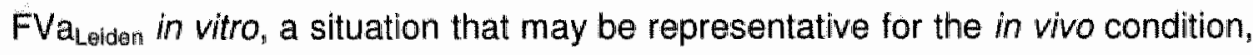
greatly reduces the differences between the inactivation rates of normal $\mathrm{FVa}$ and $F \mathrm{Fl}_{\text {Leiden }}$ [16]. This is due to the fact that $\mathrm{FXa}$ can protect $\mathrm{FVa}$ from cleavage at $\mathrm{Arg}^{506}$ by $\mathrm{APC}$, leaving only the $\mathrm{Arg}^{306}$ cleavage site available for $A P C$, just like in the case of FV Leiden. Therefore, one might expect that the protection of FVa by FXa and the stimulation of APC-cleavage at $\mathrm{Arg}^{306}$ by protein $S$, will result in only a small difference between inactivation of normal $\mathrm{FVa}$ and FValeiden by APC in vivo. However, in plasma there still is a considerable difference between the inactivations of both FV molecules. These differences can be explained by the importance of the APC-cofactor activity of $\mathrm{FV}$, of which $\mathrm{FV}_{\text {Leiden }}$ has been deprived. It might be possible that the Arg506GIn mutation has little clinical relevance for the regulation of FVa activity by APC in 
vivo, and that the absence of APC-cofactor activity of FV is the major cause for the APC-resistance associated with FV Leiden. Of course in should be emphasized that FXa only protects the 506-cleavage site when the FXa concentrations exceeds the FVa concentration, a situation which is not necessarily true under physiological conditions.

\section{FV Leiden pseudo-homozygosity and APC-resistance}

The patho-physiological relevance of the anticoagulant activity of FV is well illustrated by comparison of APC-resistance (and thrombotic risk) of pseudo-homozygous, homozygous and heterozygous $F V_{\text {Leiden }}$ carriers with normal individuals. FV Leiden pseudo-homozygosity is a plasma phenotype that arises from coinheritance of the $\mathrm{FV}_{\text {Leiden }}$ mutation and a null mutation on different $\mathrm{FV}$ alleles, resulting in $50 \% \mathrm{FV}_{\text {Leiden }}$ (and no normal FV) in plasma. It has been associated with APC-resistance and it is considered a risk factor for thrombosis, although it has not been well characterized due to its rare occurrence in the population.

We have characterized plasmas from individuals, who were heterozygous, homozygous or pseudo-homozygous for the $F V_{\text {Leiden }}$ mutation, using 4 different APC-resistance assays, also providing a detailed characterization of the APC-resistant phenotype associated with $F V_{\text {Leiden }}$ pseudo-homozygosity. In all APC-resistance assays used, the pseudohomozygous individuals were significantly more resistant towards APC than heterozygous $F V_{\text {Leiden }}$ carriers. In fact, they were found to be indistinguishable from the homozygous individuals, indicating that the extra $F V_{\text {Leiden }}$ molecules present in true homozygous plasma do not affect the susceptibility of the plasma to APC, nor do they affect the inactivation of FVIlla by APC. The difference in APC-resistance between the pseudo-homozygotes and the heterozygotes can therefore be fully attributed to the $50 \%$ normal FV that distinguishes heterozygotes from pseudo-homozygous $F V_{\text {Leiden }}$ carriers. This normal FV increases the overall susceptibility of FVa in plasma, as shown in the prothrombinase-based assay, and also serves as a cofactor in the inactivation of FVIIla by APC as shown in the FVIII-based assay. In other words, the difference in APC-resistance between the various $F V_{\text {Leiden }}$ genotypes is not determined by the amount of $F V_{\text {Leiden }}$ molecules in their plasma, but by the presence or absence of normal FV that possesses anticoagulant activity in the inactivation of FVIII(a). It is not the poor susceptibility of $\mathrm{FVa}_{\text {Leiden }}$ that causes problems in carriers of the $\mathrm{FV}_{\text {Leiden }}$ mutation, but the impaired APC-cofactor activity.

To exclude the possibility that plasma components other than the ones we measured (PT, FVIII, FV, PS) contributed to the observed differences 
between the $F V_{\text {Leiden }}$ genotypes, we repeated the ETP-based assay in a plasma model system. FV-deficient plasma was reconstituted with purified normal FV and/or $\mathrm{FV}_{\text {Leiden }}$ to mimic the various $\mathrm{FV}_{\text {Leiden }}$ genotypes, and thrombin generation was measured in the absence and presence of APC. In the absence of APC all simulated plasmas gave the same thrombin generation curves, indicating that the $F V_{\text {Leiden }}$ genotype had no effect on the amount of thrombin generated in the absence of APC. However, in the presence of APC the pseudo-homozygous $\mathrm{FV}_{\text {Leiden }}$ plasma, containing only $50 \%$ purified $\mathrm{FV}_{\text {Leiden, was very resistant to }}$ APC; it generated 9 times more thrombin than plasma reconstituted with $100 \%$ normal FV. When an additional $50 \%$ purified $\mathrm{FV}_{\mathrm{Leiden}}$ was added to this plasma, now simulating a homozygous plasma with $100 \% \mathrm{FV}_{\text {Leidens }}$ there was no change in the amount of thrombin generated in the presence of APC. This indicates that the $50 \%$ extra $\mathrm{FV}_{\text {Leiden }}$ molecules present in a homozygous $\mathrm{FV}_{\text {Leiden }}$ plasma, have no additional effect on the APC-resistance observed for the pseudohomozygous $\mathrm{FV}_{\text {Leiden }}$ plasma. On the other hand, when $50 \%$ normal $\mathrm{FV}$ was added to the pseudo-homozygous $F V_{\text {Leiden }}$ plasma, to mimic plasma from a heterozygous $F V_{\text {Leiden }}$ carrier, the amount of thrombin formed was reduced by half. This clearly demonstrates the presence of anticoagulant activity in the $50 \%$ normal FV that we added and its function as a cofactor for APC. This also shows that the anticoagulant activity of FV determines how much thrombin is formed. These results might help explain the differences in thrombotic risk observed between the various $F V_{\text {Leiden }}$ genotypes [19].

Pseudo-homozygosity for $\mathrm{FV}_{\text {Leiden }}$ can be seen as an extreme form of FV Leiden heterozygosity, where the normal FV allele is not expressed. To evaluate the importance of the expression level of the normal FV allele in $\mathrm{FV}_{\text {Lelden }}$ heterozygotes, we performed a thrombin generation experiment in $\mathrm{FV}$ deficient plasma reconstituted with $50 \% \mathrm{FV}_{\text {Leiden }}$ to which increasing amounts of purified normal FV were added. So, starting from the simulated pseudohomozygous $\mathrm{FV}_{\text {Leldan }}$ plasma, we gradually increased the amount of normal FV finally reaching a plasma resembling a $F V_{\text {Leiden }}$ heterozygote. The more normal $F V$ we added to the $F V_{\text {Leiden }}$ pseudo-homozygous plasma, the lless thrombin was generated in the presence of APC and thus the less APC-resistant the plasma became. This implies that the expression level of the non-Leiden allele in $F V_{\text {Leiden }}$ heterozygous individuals has an important influence on the APCresistance of their plasma. Furthermore it shows that $F V_{\text {Leiden }}$ pseudohomozygous individuals are more resistant to APC than $F V_{\text {Leiden }}$ heterozygous individuals.

Since APC-resistance is an indicator of thrombotic risk, our APCresistance data suggest that $F V_{\text {Leiden }}$ pseudo-homozygotes have a high thrombosis risk, higher that heterozygous $\mathrm{FV}_{\text {Leiden }}$ carriers and comparable to 
that of homozygotes. However, until recently little was known about the APCresistance phenotype and the thrombotic risk associated with $F V_{\text {Leiden }}$ pseudohomozygosity. There are several case reports available about thrombotic patients characterized as being pseudo-homozygous for the $F V_{\text {Leiden }}$ mutation [20-28], but epidemiological studies assessing the thrombotic risk associated with $\mathrm{FV}_{\text {Leiden }}$ Pseudo-homozygosity are lacking, due to the rare occurrence of this condition in the population. The case reports present in literature tend to estimate the thrombotic risk to be comparable to that of homozygous $F V_{\text {Leiden }}$ carriers, based on the early age of onset of thrombosis and the severity of their condition. In contrast to this and also in contrast with our results obtained in the plasma model system, the only epidemiological study available until recently estimated the thrombotic risk associated with $F V_{\text {Leiden }}$ pseudo-homozygosity to be comparable to that of heterozygous $F V_{L \text { Liden }}$ carriers [29]. Recently however, comparison of thrombosis-free survival curves for the different $F V_{\text {Leiden }}$ genotypes showed that $F V_{\text {Leiden }}$ pseudo-homozygotes are exposed to the same thrombotic risk as homozygous $F V_{\text {Leiden }}$ carriers [30].

\section{FV-R2 and APC-resistance}

The R2-haplotype is a set of genetically linked polymorphisms in the FV-gene that also has been associated with moderate APC-resistance [10-12, 31]. Since none of the polymorphisms affect an APC-cleavage site or a known functional region of the FV molecule, the mechanism of R2-associated APCresistance is unclear. Hoekema et al. showed that R2-FVa is equally well inactivated by APC as normal FVa, both in the absence and presence of protein $\mathrm{S}$, and that plasma of FV R2-homozygous individuals contains reduced APCcofactor activity [13]. This means that the APC-resistance associated with the R2-haplotype is not caused by a reduced susceptibility of R2-FVa towards APC, but is due to the reduced anticoagulant activity of R2-FV. There are three possible explanations for the reduced APC-cofactor activity measured in FV-R2 plasma: 1) reduced $\mathrm{FV}$ levels, associated with the $\mathrm{R} 2$-haplotype, result in less $F V$ to function as a cofactor, 2) the relative increase in the $F V_{1}$ isoform, which expresses less cofactor activity, and 3) a possible role of the mutations themselves in reducing the APC-cofactor activity of R2-FV. Since the reduced levels and shifted isoform ratio only account for part of R2-associated APCresistance [32], R2-FV itself must be a poor cofactor due to the mutations. We have quantified the specific APC-cofactor activity of FV-R2 to be $73 \%$ of that of normal FV. After taking into account that the FV leveis are reduced in $R 2$ plasmas, the APC-cofactor activity present in plasma from FV R2 homozygotes is about half of that present in normal plasma. As a consequence, plasma from a homozygous R2-carrier forms almost twice as much thrombin in the presence 
of APC as compared to normal plasma. Also, in combination with FV Leidens simulated $F V_{\text {Leiden }} / \mathrm{FV}_{R 2}$-double heterozygous plasma produced more thrombin in the presence of $\mathrm{APC}$ as compared to simulated $F V_{\text {Leiden }}$ heterozygous plasma, confirming the reports that coinheritance of these mutations enhances the APC-resistant phenotype associated with $F V_{\text {Leiden }}$ heterozygosity [10, 12].

Whether or not the R2-haplotype is associated with a relevant clinical risk for venous thrombosis is still a matter of debate. As APC-resistance per se is a risk factor for thrombosis [33] and we and other investigators have clearly shown that the R2-haplotype causes APC-resistance, one would conclude that the R2-haplotype is a risk factor for thrombosis. However, the results from epidemiological studies are contradictory and there is inconclusive evidence to prove whether or not the R2-haplotype is a risk factor for venous thrombosis [31]. Nevertheless, it is generally accepted that compound heterozygous carriership of the $\mathrm{FV}_{\text {Leiden }}$ and the FV-R2 is indeed associated with a higher risk for venous thrombosis than heterozygosity for $F V_{\text {Leiden }}$ alone [34-36]. This can be explained by several facts that have been presented in this thesis. Our observations 1) that the expression level of the non-Leiden allele in heterozygous $F V_{\text {Leiden }}$ carriers is an important determinant in the associated APC-resistance, 2) that the R2-haplotype indeed causes a reduction in the FV levels, and furthermore, 3) that R2-FV itself has reduced anticoagulant cofactor activity towards APC provide a good explanation why compound heterozygosity for $F V_{L e i d e n}$ and $F V-R 2$ is associated with a higher risk for venous thrombosis than heterozygosity for $\mathbb{F} V_{\text {Leiden }}$ alone.

Already when Lunghi et al. first described the R2-haplotype, they found that it was associated with a reduction of the FV levels in plasma [37]. Reduced FV concentration in plasma accounts for part of the APC-resistance caused by the R2-haplotype [32]. However, the molecular mechanism underlying the FV reduction in plasma has been unclear for a long time. Recently, Yamazaki et al. tackled this problem using an in vitro expression system to study the expression of recombinant FV molecules mimicking the R2-haplotype [38]. They found that the Asp2194Gly mutation was the major determinant of the low expression levels observed in the FV-R2 carriers. Further analysis revealed that the Asp2194Gly mutant had an impaired transport within the cell, from the endoplasmatic reticulum (ER) to the Golgi complex. As misfolded proteins are retained and trapped in the ER by the quality control system, eventually leading to the intracellular degradation of these proteins [39], Yamazaki et al. proposed that this was the reason for the reduced expression level associated with the Asp2194Gly mutation. These conclusions were confirmed by Van Der Neut Kolfschoten and co-workers [40]. 
Based on these observations, we tried to elaborate further on the mechanism by which the Asp2194Gly mutation affects the folding/structure/stability of the C2-domain in the FV-R2 haplotype. The crystal structure of the C2-domain of human FV [41] shows that the Asp2194 is involved in electrostatic interactions with the side chains of the lysine residues at positions 2101 and 2103. We hypothesized that these electrostatic interactions could bring the Cys2038 in the $\mathrm{N}$-terminal part of the C2-domain in close proximity of the Cys2193 at the C-terminal end of the C2-domain, potentially facilitating the formation of a disulfide bridge, and thereby stabilizing the C2-domain. The Asp2194Gly mutation would abolish these electrostatic interactions, no longer facilitating the disulfide bridge formation. In other words, the Asp2194Gly mutation would affect the stability and/or induce conformational changes in the $\mathrm{C} 2$-domain, leading to the retention of the misfolded proteins in the $E R$, eventually resulting in a reduced secretion.

To study the role of Asp2194 in the stabilization of the C2-domain of FV, molecular dynamics simulations, electrostatic computations and the in vitro expression of recombinant molecules were used. The total potential energy in the Asp2194Gly mutant was significantly higher compared to the wild-type (WT), suggesting overall destabilization of the protein due to the mutation. In the simulation of the WT C2-domain with or without the disulfide bond, the protein core remained stable, but in the absence of the disulfide bond there was an increased mobility of both $\mathrm{C}$ - and $\mathrm{N}$-termini. In vitro this resulted in the reduced expression of the WT protein without the disulfide bridge, probably due to an impairment of the correct folding of the protein. The protein core of the Asp2194Giy mutant also remained stable during the simulation with or without the disulfide bond ${ }_{n}$ but the mutant protein without the disulfide bond showed significantly higher flexibilities in the $\mathrm{N}$-terminal residues compared to the simulation of the WT without the disulfide bond. This is most likely due to the absence of the electrostatic interactions between Asp2194-Lys2101-Lys2103 in the Asp2194Gly mutant. Indeed, comparison of the electrostatic free energies of this triad between the WT FV C2-domain and the Asp2194Gly variant, indicated an electrostatic destabilization due to the mutation. Together, these data suggest that the Asp2194Gly mutation in R2-FV does indeed destabilize the C2-domain. This unstable structure can be detected by the quality control system of the cell, causing retention and degradation of the protein inside the cell, eventually leading to a reduced R2-FV level in plasma.

We also expressed mutations affecting the charges in this Asp2194Lys2101-Lys2103 triad to get more insight into the importance of this salt bridge network. When all charges in the triad were made positive or negative, the finall expression levels of these mutants were even lower than for the Asp2194Gly 
mutant. Thus, these mutations, resulting in three positively or negatively charged groups in close proximity of each other destabilize the structure. These experimental data correlated well with the calculated electrostatic destabilizations. We also reversed all charges in the triad and hypothesized that this should also form a stabilizing salt bridge. However, this was not the case; the expression level of this mutant was similar to that of the mutants with repulsive charges, whereas computation of electrostatic energies suggested a slight stabilizing effect. This shows that this region is not tolerant for amino acid substitutions. Indeed, a multiple sequence alignment of FV and FVIII indicated that this area is well conserved among species, suggesting that this salt bridge triad can be important for the stability and/or the structure of the C2-domain.

\section{Prothrombin levels and APC-resistance}

An elevated prothrombin level in plasma, due to the G20210 mutation or to other causes, is a risk factor for venous thrombosis [42-46]. At least part of the risk is thought to be due to the fact that high prothrombin levels induce APCresistance [47, 48]. The exact mechanism by which high prothrombin concentrations induce APC-resistance is not understood, although several reports have shown that increased prothrombin levels interfere with the function of the anticoagulant protein $C$ pathway [49-51].

In chapter 5, we have further investigated the effect of elevated plasma prothrombin levels on APC-resistance, using two different APC-resistance assays (the aPTT-based assay and the ETP-based assay), in a plasma model system (prothrombin-deficient plasma reconstituted with purified prothrombin) as well as in a population of healthy individuals. Both assays showed that in the plasma model system, increasing prothrombin concentrations cause APCresistance in a dose-dependent manner. However, there was a striking difference between both assays in the mechanism by which APC-resistance arose, probably due to the fact that the two assays are influenced by different determinants. In the aPTT-based assay the increased APC-resistance with increasing prothrombin concentration was mainly due to the prolongation of the clotting times in the absence of APC, while the clotting times in the presence of APC remained virtually constant in the physiological range of prothrombin concentration (70-150\% PT). This has also been observed by Smirnov et al. and is most probably due to the competition between prothrombin and other coagulation factors for the phospholipid surface [50]. In the ETP-based assay on the other hand, the increased APC-resistance due to increasing prothrombin levels was mainly caused by the measurement in the presence of APC. Thrombin generation, both with and without APC increased with increasing prothrombin levels, but the ETP with APC increased to a greater extent, leading 
to an overall increase in APC-resistance. This is in line with previous findings that the amount of thrombin generated in the absence of APC and the APCresistance is significantly higher in carriers of the prothrombin mutation as compared to a control population [52, 53].

There was no difference between the results obtained with the aPTTbased assay in the plasma model system and the population. However, in the ETP-based assay there was a discrepancy between the model system and the population. Whereas in the model system APC-resistance increased with increasing PT concentrations, it appeared that in the population APC-resistance decreased with increasing prothrombin concentrations. Further analysis revealed that this was due to confounding by protein $S$. Prothrombin levels correlated very well with the protein S levels, and increasing levels of protein $S$ lead to a decrease in APC-resistance. Furthermore, a protein $S$ titration in protein S-deficient plasma showed that the APC-resistance measured with the ETP-based assay decreases at increasing protein $S$ levels. Thus, prothrombin and protein $S$ have opposite effects on the APC-resistance measured with the ETP-based assay, as was also reported by de Visser and coworkers [54]. After correction for protein S levels in the population, the APC-resistance indeed increased with increasing prothrombin levels.

Based on these observations we propose that the protein $S$ levels in plasma play an important role in modulating the severity of the APC-resistance caused by elevated prothrombin concentrations. In other words, the APCresistance observed in a plasma due to increased plasma prothrombin levels is not only dependent on the prothrombin concentration itself, but also on the protein S level in that plasma. This is strengthened by our observation that the APC-resistance in a plasma with high prothrombin and high protein $S$ was less severe than in a plasma with high prothrombin and normal or reduced protein $S$ levels. Therefore, the prothrombin/protein $S$ ratio in plasma might be a better predictor of APC-resistance associated with that plasma than the prothrombin level alone.

As prothrombin and protein $\mathrm{S}$ both are vitamin $\mathrm{K}$-dependent proteins mainly synthesized by the liver, their plasma concentrations show a high degree of correlation $[43,55]$. This led us to the hypothesis that the APC-resistance will be less severe in plasmas with high prothrombin levels in the absence of the prothrombin mutation (G20210A) than in plasmas with elevated prothrombin levels in the presence of the G20210A mutation, because in the first case the protein $S$ levels will also be elevated and to a certain degree counteract the effect of the high prothrombin, while in the latter case the protein $S$ concentrations remain normal. Of course this remains to be proven in a 
population study with carriers and non-carriers of the prothrombin G20210A mutation.

\section{Conclusions}

In conclusion, the data presented in this thesis indicate that the anticoagulant (APC-cofactor) activity of FV is a very important component in the regulation of thrombin formation. They provide evidence that the APCresistance associated with the $F V_{\text {Leidon }}$ mutation is not entirely due the reduced susceptibility of FVa $a_{\text {Leiden }}$ towards inactivation by APC, but that the loss of APCcofactor activity due to the Leiden mutation accounts for at least half of the APC-resistance observed in homozygous $F V_{\text {Leidem }}$ carriers.

We have shown that the APC-cofactor activity of FV also plays a pivotal role in the regulation of the amount of thrombin formed under physiological conditions. In fact, it is this anticoagulant activity of FV that eventually determines how much thrombin will be formed. Although the $F V_{\text {Leiden }}$ mutation affects both the inactivation of $\mathrm{FVa}_{\text {Leiden }}$ by $\mathrm{APC}$ as well as the anticoagulant function of $F V_{\text {Leiden, }}$ it is not only the poor susceptibility of $F V_{a_{\text {Leiden }}}$ that causes problems in carriers of the $\mathrm{FV}_{\text {Leiden }}$ mutation, but there is also a contribution of the impaired APC-cofactor activity. The reason why homozygous $F V_{\text {Leiden }}$ carriers have a greater thrombotic risk compared to heterozygotes is not because they have more $\mathrm{FV}_{\text {Leiden }}$ in their plasma, but because they do not have any normal FV in their plasma that expresses anticoagulant cofactor activity towards APC.

Furthermore, we have provided a detailed characterization of the APCresistance phenotype in $\mathrm{FV}_{\text {Leiden }}$ pseudo-homozygotes. In particular, we have shown that, in a plasma model system as well as in a population, plasma from $\mathrm{FV}_{\text {Leidon }}$ pseudo-homozygates is significantly more APC-resistant compared to plasma from $F V_{\text {Leiden }}$ heterozygotes but is indistinguishable from $F V_{\text {Leiden }}$ homozygous plasma. The difference in APC-resistance between the various $F V_{\text {Laiden }}$ genotypes is not determined by the amount of $F V_{\text {Leiden }}$ molecules in their plasma, but by the presence or absence of normal FV. This normal FV not only increases the overall susceptibility of FVa towards APC in plasma, but also serves as a cofactor in the inactivation of FVIIla by APC.

The importance of the APC-cofactor activity of FV is also demonstrated by the APC-resistance associated with the R2-haplotype. We have shown that the impaired anticoagulant activity of $F V$, together with the reduced plasma $F V$ levels, results in an increased thrombin generation in the presence of APC. Also, we have provided insight into the mechanism through which the Asp2194Gly mutation in the R2-haplotype destabilizes the C2-domain of FV, resulting in reduced plasma FV levels. 
Finally, we have evaluated the effect of elevated plasma prothrombin levels on APC-resistance. Protein S levels in plasma proved to be an important modulator of the APC-resistance associated with elevated plasma prothrombin levells. As prothrombin and protein S levells in plasma are highly correlated, the ratio of these two components might provide a more accurate estimation of the APC-resistance in a given plasma than the prothrombin level alone. 


\section{References}

1. B. Dahlback. Blood coagulation. Lancet. 2000; 355:1627-32.

2. L. Shen and B. Dahlback. Factor $V$ and protein $S$ as synergistic cofactors to activated protein $C$ in degradation of factor VIlla. J Biol Chem. 1994; 269:18735:8.

3. E. Thorelli, R. J. Kaufman and B. Dahlback. Cleavage of factor V at Arg 506 by activated protein $\mathrm{C}$ and the expression of anticoagulant activity of factor $\mathrm{V}$. Blood 1999; 93:2552-8.

4. B. Dahlback, M. Carlsson and P. J. Svensson. Familial thrombophilia due to a previously unrecognized mechanism characterized by poor anticoagulant response to activated protein $\mathrm{C}$ : prediction ol a cofactor to activated protein $\mathrm{C}$. Proc Natl Acad Sci US A. 1993; 90:1004-8.

5. R. M. Bertina, B. P. Koeleman, T. Koster, F. R. Rosendaal, R. J. Dirven, H. de Ronde, P. A. van der Velden and P. H. Reitsma. Mutation in blood coagulation factor $V$ associated with resistance to activated protein C. Nature. 1994; $369: 64-7$.

6. M. Kalafatis, M. D. Rand and K. G. Mann. The mechanism of inactivation of human factor $V$ and human factor Va by activated protein C. J Biol Chem. 1994; 269:31869-80.

7. G. A. Nicolaes, G. Tans, M. C. Thomassen, H. C. Hemker, I. Pabinger, K. Varadi, H. P. Schwarz and J. Rosing. Peptide bond cleavages and loss of functional activity during inactivation of factor $\mathrm{Va}$ and factor $\mathrm{VaR} 506 \mathrm{Q}$ by activated protein C. J Biol Chem. 1995; 270:21158-66.

8. M. Kalafatis, R. M. Bertina, M. D. Rand and K. G. Mann. Characterization of the molecular defect in factor VR506Q. J Biol Chem. 1995; 270:4053-7.

9. K. Varadi, U. Rosing, G. Tans, I. Pabinger, B. Keil and H. P. Schwarz. Factor V enhances the cofactor function of protein $S$ in the APC-mediated inactivation of factor VIII: influence of the factor VR506Q mutation. Thromb Haemost. 1996; 76:208-14.

10. F. Bernardi, E. M. Faioni, E. Castoldi, B. Lunghi, G. Castaman, E. Sacchi and P. M. Mannucci. A factor $V$ genetic component differing from factor $V$ R506Q contributes to the activated protein $C$ resistance phenotype. Blood. 1997; 90:1552-7.

11. M. Alhenc-Gellas, V. Nicaud, S. Gandrille, P. van Dreden, J. Amiral, M. L. Aubry, J. N. Fiessinger, J. Emmerich and M. Aiach. The factor $V$ gene A4070G mutation and the risk of venous thrombosis. Thromb Haemost. 1999; 81:193-7.

12. M. C. de Visser, J. F. Guasch, P. W. Kamphuisen, H. L. Vos, F. R. Rosendaal and $R$. M. Bertina. The HR2 haplotype of factor $V$ : effects on factor $V$ levels, 
normalized activated protein $\mathrm{C}$ sensitivity ratios and the risk of verous thrombosis. Thromb Haemost. 2000; 83:577-82.

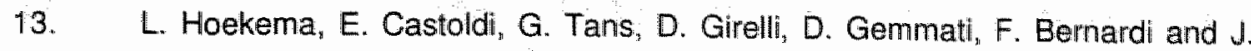
Rosing. Functional properties of factor $\mathrm{V}$ and factor $\mathrm{Va}$ encoded by the $\mathrm{R} 2$ gene. Thromb Haemost. 2001; 85:75-81.

14. G. A. Nicolaes and B. Dahiback. Factor $V$ and thrombotic disease: description of a janus-faced protein. Arterioscler Thromb Vasc Biol. 2002; 22:530-8.

15. M. J. Heeb, Y. Kojima, J. S. Greengard and J. H. Griffin. Activated protein C resistance: molecular mechanisms based on studies using purified Gin506factor V. Blood. 1995; 85:3405-11.

16. J. Rosing, L. Hoekema, G. A. Nicolaes, M. C. Thomassen, H. C. Hemker, K. Varadi, H. P. Schwarz and G. Tans. Effects of protein $S$ and factor Xa on peptide bond cleavages during inactivation of factor $\mathrm{Va}$ and factor VaR506Q by activated protein C. J Bial Chem. 1995; 270:27852-8.

17. C. Aparicio and B. Dahlback. Molecular mechanisms of activated protein $C$ resistance. Properties of factor $V$ isolated from an individual with homozygosity for the Arg506 to Gin mutation in the factor $V$ gene. Biochem J. 1996; 313 ( Pt 2):467-72.

18. H. C. Hemker, R. Al Dieri and S. Beguin. Thrombin generation assays: accruing clinical relevance. Curr Opin Hematol. 2004; 11:170-5.

19. F. R. Rosendaal, T. Koster, J. P. Vandenbroucke and P. H. Reitsma. High risk of thrombosis in patients homozygous for factor $V$ Leiden (activated protein $C$ resistance). Blood. 1995; 85:1504-8.

20. P. Simioni, A. Scudeller, P. Radossi, S. Gavasso, B. Girolami, D. Tormene and A. Girolami. "Pseudo homozygous" activated protein C resistance due to double heterozygous factor $V$ defects (factor $V$ Leiden mutation and type I quantitative factor $V$ defect) associated with thrombosis: report of two cases belonging to two unrelated kindreds. Thromb Haemost. 1996; 75:422-6.

21. J. L. Zehnder and M. Jain. Recurrent thrombosis due to compound heterozygosity for factor $\mathrm{V}$ Leiden and factor $\mathrm{V}$ deficiency. Blood Coagul Fibrinolysis. 1996; 7:361-2.

22. J. F. Guasch, R. P. Lensen and R. M. Bertina. Molecular characterization of a type I quantitative factor $V$ deficiency in a thrombosis patient that is "pseudo homozygous" for activated protein $C$ resistance. Thromb Haemost. 1997; 77:252-7.

23. B. Delahousse, S. lochmann, C. Pouplard, B. Fimbel, B. Charbonnier and Y. Gruel. Pseudo-homozygous activated protein $C$ resistance due to coinheritance of heterozygous factor $V$ Leiden mutation and type I factor $V$ deficiency. Variable expression when analyzed by different activated protein $C$ resistance functional assays. Blood Coagul Fibrinolysis. 1997; 8:503-9. 
24. G. Castaman, B. Lunghi, E. Missiaglia, F. Bernardi and F. Rodeghiero. Phenotypic homozygous activated protein $C$ resistance associated with compound heterozygosity for Arg506Gin (factor V Leiden) and His1299Arg substitutions in factor V. Br J Haematol. 1997; 99:257-61.

25. E. Castoldi, M. Kalafatis, B. Lunghi, P. Simioni, P. A. Ioannou, M. Petio, A. Girolami, K. G. Mann and F. Bernardi. Molecular bases of pseudo-homozygous APC resistance: the compound heterozygosity for FV R506Q and a FV null mutation results in the exclusive presence of $F V$ Leiden molecules in plasma. Thromb Haemost. 1998; 80:403-6.

26. B. Lunghi, E. Castoldi, F. Mingozzi, F. Bernardi and G. Castaman. A novel factor $V$ null mutation detected in a thrombophilic patient with pseudohomozygous APC resistance and in an asymptomatic unrelated subject. Blood. 1998; 92:1463-4.

27. M. Kalafatis, F. Bernardi, P. Simioni, B. Lunghi, A. Girolami and K. G. Mann. Phenotype and genotype expression in pseudohomozygous factor VLEIDEN : the need for phenotype analysis. Arterioscler Thromb Vasc Biol. 1999; 19:33642.

28. G. Standen, C. Morse, S. Aslam and A. Bowron. Recurrent thrombosis in a patient with pseudohomozygous activated protein $\mathrm{C}$ resistance and homozygosity for MTHFR gene polymorphism C677T. Thromb Haemost. 1999; 81:663-4.

29. G. Castaman, A. Tosetto, M. Ruggeri and F. Rodeghiero. Pseudohomozygosity for activated protein $\mathrm{C}$ resistance is a risk factor for venous thrombosis. $\mathrm{Br} J$ Haematol. 1999; 106:232-6.

30. P. Simioni, E. Castoldi, B. Lunghi, D. Tormene, J. Rosing and F. Bernardi. An underestimated combination of opposites resulting in enhanced thrombotic tendency. Blood. 2005; 106(7): 2363-5

31. G. Castaman, E. M. Faioni, A. Tosetto and F. Bernardi. The factor V HR2 haplotype and the risk of venous thrombosis: a meta-analysis. Haematologica. 2003; 88:1182-9.

32. J. W. Govers-Riemslag, E. Castoldi, G. A. Nicolaes, G. Tans and J. Rosing. Reduced factor $V$ concentration and altered FV1/FV2 ratio do not fully explain R2-associated APC-resistance. Thromb Haemost. 2002; 88:444-9.

33. M. C. de Visser, F. R. Rosendaal and R. M. Bertina. A reduced sensitivity for activated protein $C$ in the absence of factor $V$ Leiden increases the risk of venous thrombosis. Blood. 1999; 93:1271-6.

34. E. M. Faioni, F. Franchi, P. Bucciarelli, M. Margaglione, V. De Stefano, G. Castaman, G. Finazzi and P. M. Mannucci. Coinheritance of the HR2 haplotype in the factor $V$ gene confers an increased risk of venous thromboembolism to carriers of factor V R506Q (factor V Leiden). Blood. 1999; 94:3062-6. 
35. G. Castaman, M. Ruggeri, A. Tosetto and F. Rodeghiero. Heterogeneity of activated protein $\mathrm{C}$ resistance phenotype in subjects with compound heterozygosity for HR2 haplotype and FV Leiden mutation (R506Q) in factor $V$ gene. Thromb Haemost. 2000; 84:357-8.

36. A. R. Folsom, M. Cushman, M. Y. Tsai, N. Aleksic, S. R. Heckbert, L. L. Boland, A. W. Tsai, N. D. Yanez and W. D. Rosamond. A prospective study of venous thromboembolism in relation to factor $\mathrm{V}$ Leiden and related factors. Blood. 2002; 99:2720-5.

37. B. Lunghi, L. lacoviello, D. Gemmati, M. G. Dilasio, E. Castoldi, M. Pinotti, G. Castaman, R. Redaelli, G. Mariani, G. Marchetti and F. Bernardi. Detection of new polymorphic markers in the factor $V$ gene: association with factor $V$ levels in plasma. Thromb Haemost. 1996; 75:45-8.

38. T. Yamazaki, G. A. Nicolaes, K. W. Sorensen and B. Dahlback. Molecular basis of quantitative factor $V$ deficiency associated with factor $V$ R2 haplotype. Blood. 2002; 100:2515-21.

39. E. Chevet, P. H. Cameron, M. F. Pelletier, D. Y. Thomas and J. J. Bergeron. The endoplasmic reticulum: integration of protein folding, quality control, signaling and degradation. Curr Opin Struct Biol. 2001; 11:120-4.

40. M. van der Neut Kolfschoten, R. J. Dirven, H. L. Vos and R. M. Bertina. The R2haplotype associated Asp2194Gly mutation in the light chain of human factor $\mathrm{V}$ results in lower expression levels of $\mathrm{FV}$, but has no influence on the glycosylation of Asn2181. Thromb Haemost. 2003; 89:429-37.

41. S. Macedo-Ribeiro, W. Bode, R. Huber, M. A. Quinn-Allen, S. W. Kim, T. L. Ortel, G. P. Bourenkov, H. D. Bartunik, M. T. Stubbs, W. H. Kane and P. Fuentes-Prior. Crystal structures of the membrane-binding $\mathrm{C} 2$ domain of human coagulation factor V. Nature. 1999; 402:434-9.

42. S. R. Poort, F. R. Rosendaal, P. H. Reitsma and R. M. Bertina. A common genetic variation in the $3^{\prime}$-untranslated region of the prothrombin gene is associated with elevated plasma prothrombin levels and an increase in venous thrombosis. Blood. 1996; 88:3698-703.

43. J. C. Souto, I. Coll, D. Llobet, E. dell Rio, A. Oliver, J. Mateo, M. Borrell and J. Fontcuberta. The prothrombin 20210A allele is the most prevalent genetic risk factor for venous thromboembolism in the Spanish population. Thromb Haemost. 1998; 80:366-9.

44. R. K. Kapur, L. A. Mills, S. G. Spitzer and M. B. Hultin. A prothrombin gene mutation is significantly associated with venous thrombosis. Arterioscler Thromb Vasc Biol. 1997; 17:2875-9.

45. A. Hillarp, B. Zoller, P. J. Svensson and B. Dahlback. The $20210 \mathrm{~A}$ allele of the prothrombin gene is a common risk factor among Swedish outpatients with verified deep venous thrombosis. Thromb Haemost. 1997; 78:990-2. 
46. K. Brown, R. Luddington, D. Williamson, P. Baker and T. Baglin. Risk of venous thromboembolism associated with a $G$ to $A$ transition at position 20210 in the $3^{*}-$ untranslated region of the prothrombin gene. Br J Haematol. 1997; 98:907-9.

47. A. Tripodi, V. Chantarangkul and P. M. Mannucci. Hyperprothrombinemia may result in scquired activated protein $C$ reistance. Blood. 2000; 96:3295-6.

48. G. Castaman, A. Tosetto, M. Simioni, M. Ruggeri, D. Madeo and F. Rodeghiero. Phenotypic APC resistance in carriers of the A20210 prothrombin mutation is associated with an increased risk of venous thrombosis. Thromb Haemost. 2001; 86:804-8.

49. C. A. Mitchell, S. M. Jane and H. H. Salem. Inhibition of the anticoagulant activity of protein $S$ by prothrombin. $J$ Clin Invest. 1988; 82:2142-7.

50. M. D. Smirnov, O. Safa, N. L. Esmon and C. T. Esmon. Inhibition of activated protein $C$ anticoagulant activity by prothrombin. Blood. 1999; 94:3839-46.

51. E. Norstrom, S. Tran and B. Dahlback. Prothrombin inhibition of the individual activated protein $\mathrm{C}$ cleavage sites in factor $\mathrm{Va}$. Thesis. 2004;

52. P. A. Kyrle, C. Mannhalter, S. Beguin, A. Stumpflen, M. Hirschl, A. Weltermann, M. Stain, B. Brenner, W. Speiser, I. Pabinger, K. Lechner and S. Eichinger. Clinical studies and thrombin generation in patients homozygous or heterozygous for the G20210A mutation in the prothrombin gene. Arterioscler Thromb Vasc Biol. 1998; 18:1287-91.

53. J. Curvers, M. C. Thomassen, J. Rimmer, K. Hamulyak, J. van der Meer, G. Tans, F. E. Preston and J. Rosing. Effects of hereditary and acquired risk factors of venous thrombosis on a thrombin generation-based APC resistance test. Thromb Haemost. 2002; 88:5-11.

54. M. C. de Visser, A. Hylckama Vlieg, G. Tans, J. Rosing, A. E. Dahm, P. M. Sandset, F. R. Rosendaal and R. M. Bertina. Determinants of the APTT. and ETP-based APC sensitivity tests. J Thromb Haemost. 2005; 3:1488-94.

55. A. Van Hylckama Vlieg, P. W. Callas, M. Cushman, R. M. Bertina and F. R. Rosendaal. Inter-relation of coagulation factors and d-dimer levels in healthy individuals. I Thromb Haemost. 2003; 1:516-22. 


\section{CHAPTER 7}

Summary / Samenvatting

List of publications

Curriculum vitae

Dankwoord 


\section{Summary}

Blood coagulation proceeds through a complex series of enzymatic reactions in which protease zymogens are activated via limited proteolysis, eventually leading to the generation of thrombin, the central enzyme in coagulation. Adequate regulation of the amount of thrombin formed is necessary to prevent both bleeding and thrombotic disorders. The protein $\mathrm{C}$ pathway is a major anticoagulant mechanism that plays an important role in the regulation of thrombin formation. Activated protein $C$ (APC), a vitamin Kdependent protein, inactivates coagulation factors FVIIla and FVa. Protein S serves as a cofactor of APC during these inactivation reactions. It has been shown that FV also expresses APC-cofactor activity in the inactivation of FVIII(a). The addition of APC to plasma causes a prolongation of the clotting time, but the plasma of some individuals is insensitive to this regulatory function of APC, a phenotype known as APC-resistance. APC-resistance is associated with an increased risk for venous thrombosis.

APC-resistance is most often caused by a mutation in the FV gene which causes the substitution of an Arg by a Gln at position 506 ( $F V_{\text {Leiden }}$ ). This mutation abolishes one of the APC-cleavage sites on $F V(a)$ which makes $\mathrm{FVa}_{\text {Leiden }}$ is less susceptible to inactivation by APC. Furthermore, as FV has to be cleaved at $\mathrm{Arg}^{506}$ to serve as a cofactor for APC in the inactivation of FVIII(a), this mutation also reduces the anticoagulant activity of $\mathrm{FV}_{\text {Leiden. }}$. Apart from the $\mathrm{FV}_{\text {Leiden }}$ mutation, several other FV gene mutations also cause APCresistance, such as the $\mathrm{R} 2$-haplotype. The polymorphisms that define the $\mathrm{R} 2$ haplotype do not affect the susceptibility of FVa-R2 towards inactivation by $A P C$, but they specifically reduce the APC-cofactor activity of FV-R2.

Since FV (a) is both a substrate and a cofactor for APC, mutations in the FV gene can cause APC resistance either by reducing the susceptibility of FVa to $A P C$-mediated inactivation ( $F V_{\text {Hongkong }}$ and $F V_{\text {Cambridge }}$ ) or by interfering with the APC cofactor activity of FV in FVIlla inactivation (R2-haplotype) or by affecting both $F V$ functions at the same time ( $\left.F V_{\text {Leiden }}\right)$. This thesis mainly focuses on the cofactor activity of FV in the inactivation of FVIII(a) by APC and its role in APC-resistance.

Chapter 2 illustrates the molecular mechanism by which the amino acid substitution at position 2194 in the FV molecule, changing an aspartate into a glycine, is the main contributor to the reduced FV levels in plasma of carriers of the R2-haplotype. Molecular dynamics simulations and electrostatic computations indicated that the Asp2194Gly mutation causes an overall destabilization of the FV C2-domain by disturbing the electrostatic interactions 
within the triad Asp2194-Lys2101-Lys2103. Under normal conditions (no mutation) these electrostatic interactions facilitate the formation of the disulfide bridge between $\mathrm{Cys}^{2038}$ and $\mathrm{Cys}^{2193}$ located at the $\mathrm{N}$-terminal and the $\mathrm{C}$-terminal parts of the $\mathrm{C} 2$-domain respectively, thereby stabilizing the molecule. The replacement of the negatively charged aspartate by a neutral glycine disturbs the correct folding of the $\mathrm{C} 2$-domain, resulting in the retention and degradation of the FV molecule in the ER and therefore a reduced secretion in plasma. These in silico data were confirmed by experimental data using recombinant molecules, showing that any mutation affecting this electrostatic triad (Asp2194Lys2101-Lys2103) greatly reduces the level of secretion.

In chapter 3 we have focused on the anticoagulant activity of FV in the inactivation of FVIII(a) by APC and its role in APC-resistance. First, we have quantified the relative contributions of reduced susceptibility of FVa towards inactivation by APC and impaired APC-cofactor activity of FV to FV Leiden associated APC-resistance. We have shown that the impaired anticoagulant activity of $F V_{\text {Leiden }}$ accounts for half of the APC-resistance measured with the classical aPTT-based assay, an assay commonly used in clinical settings. Furthermore, we have demonstrated the physiological importance of the APCcofactor activity of $F V$ by means of thrombin generation measurements in plasmas with different FV concentrations triggered with tissue factor in the presence of APC. For FV levels between $60 \%$ and $120 \%$, the amount of thrombin formed in plasma decreased at increasing FV concentration, due to the anticoagulant activity expressed by normal FV. In contrast, similar increasing concentrations of $F V_{\text {Leicen }}$ (which does not express APC-cofactor activity) did not influence thrombin generation in the presence of APC. Finally, we have shown that FV-R2 expresses $~ 73 \%$ of the APC-cofactor activity of normal FV. This reduced APC-cofactor activity of FV-R2 in plasma from a homozygous R2-carrier results in the generation of twice as much thrombin in the presence of APC as compared to normal plasma.

The patho-physiological relevance of the anticoagulant activity of $F V$ is further illustrated by a rare prothrombotic condition known as pseudohomozygous APC-resistance (chapter 4). Pseudo-homozygotes are heterozygous carriers of FV Leiden whose counterpart (non-Leiden) FV allele is not expressed due to a null mutation. To characterize the APC-resistance phenotype associated with $\mathrm{FV}_{\text {Leiden }}$ pseudo-homozygosity, we have compared $\mathrm{FV}_{\text {Leiden }}$ pseudo-homozygotes, homozygotes and heterozygotes using 4 different APC-resistance assays which probe FVa inactivation, FVIlla inactivation or both. FV Leiden pseudo-homozygotes were more APC-resistant 
than heterozygotes and were comparable to homozygotes in all atstay. Thest findings can be explained by the fact that FV Liden has no APCEdactor atwity and the normal FV present in heterozygous plasma act

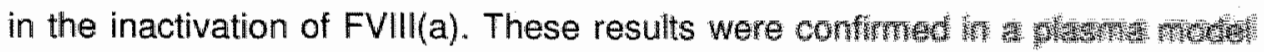
system, where the different FV genotypes were mimicked by recthothing ifydeficient plasma with purified normal FV and/or FV showed that when normal FV is titrated into pseudo-homozygow APC-resistance of this plasma progressively decreases presumbly due the the

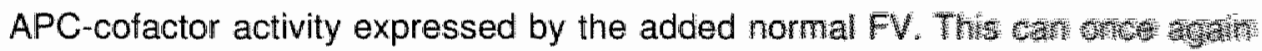

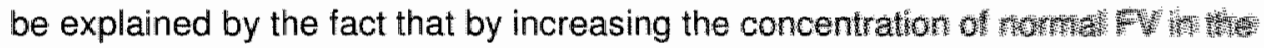

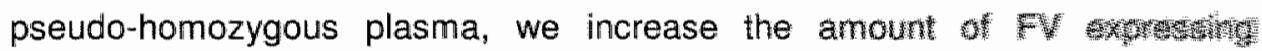
anticoagulant activity, resulting in a decrease of the APC concluded that the expression level of the non-Leiden allele in hergrosycuss:

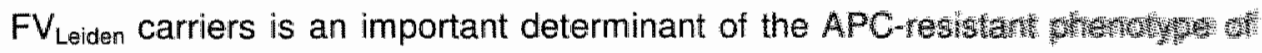
these individuals.

Finally, in chapter 5 we investigated the relationship betwest watwe prothrombin levels and APC-resistance. In prothrombirt-deffigert plistrats: reconstituted with purified prothrombin, APG-resistance horatest increasing prothrombin concentrations, both in the aPTT-based whe me thrombin generation-based APC -resistance assays. In a population al hesiby individuals the same trend was observed in the aPTT-based but wed the thrombin generation-based APC-resistance assay. This discrepanty was whe the

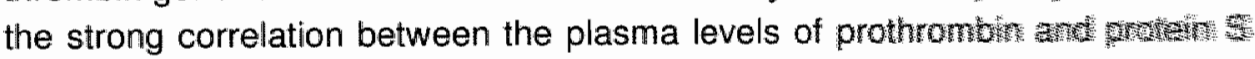
in the population. Whereas high prothrombin on the one hand increstist resistance, this is counteracted by the high protein $S$ level. Thus, the proteifi $S$ levels in plasma play an important role in modulating the severity of the APC resistance caused by elevated prothrombin levels. Prothrombin titrations in plasmas containing different amounts of protein $S$ confirmed the ability of protein $S$ to modulate the APC-resistance induced by elevated prothrombin levels. Therefore, the prothrombin/protein $S$ ratio might provide a more accurate prediction of the APC-resistance in a given plasma than the prothrombin level alone. These findings suggest that carriers of the prothrombin $20210 \mathrm{G} / \mathrm{A}$ mutation, since they have a higher prothrombin/protein $S$ ratio than noncarriers, may experience a higher thrombosis risk than non-carriers with comparable prothrombin levels. 


\section{Samenvatting}

Het stollen van bloed is een complex gebeuren, waarbij via enzymatische reacties de inactive stollingsfactoren in het bloed worden geactiveerd. De vorming van trombine is een centraal gebeuren in deze stollingscascade. Daarom is een goede regulatie van de hoeveelheid trombine dat gevormd wordt noodzakelijk voor het behoud van een hemostatisch evenwicht. Het proteïne $\mathrm{C}$ systeem is een belangrijk anticoagulant mechanisme wat een rol speelt bij deze regulatie. Geactiveerd proteine $C$ (APC) is een vitamine-K-afhankelijk eiwit dat de cofactoren van zowel het intrinsiek (FVIIla) als het extrensiek systeem (FVa) inactiveert. Bij deze inactiveringen fungeert proteïne $S$ als cofactor van APC. Bovendien heeft men aangetoond dat FV ook APC-cofactor activiteit bezit in de inactivering van FVIII(a). In sommige gevallen blijkt het plasma resistent te zijn tegenover de regulerende werking van APC. Dit wordt APC-resistentie genoemd. APC-resistentie wordt geassocieerd met een verhoogd risico op veneuze thrombose.

APC-resistentie wordt vaak veroorzaakt door een puntmutatie in het FV gen, die leidt tot de substitutie van een arginine op posistie 506 door een glutamine. Deze mutatie wordt aangeduid als $\mathrm{FV}_{\text {Leiden. Aangezien één van de }}$ APC-splitsingplaatsen hierdoor wordt getroffen, is $\mathrm{FVa}_{\text {Leiden }}$ minder gevoelig voor inactivatie door APC. Aangezien FV ook gesplitst dient te worden door APC bij $\mathrm{Arg}^{506}$ om als cofactor van APC te kunnen fungeren bij de inactivatie van FVIII(a), leidt deze mutatie ook tot een gereduceerde anticoagulante activiteit van FV. Naast de $\mathrm{FV}_{\text {Leiden }}$ mutatie zijn er ook nog andere mutaties in het FV gen mogelijk die APC-resistentie veroorzaken, zoals bijvoorbeeld het R2-haplotype. Het R2-haplotype omvat een reeks van mutaties die altijd samen voorkomen. Deze mutaties hebben echter geen effect op de inactivatie van FVa-R2 door APC, maar treffen specifiek de cofactor activiteit van FV-R2 in de FVIIla inactivering.

Het FV(a) in plasma kan dus zowel een substraat zijn van APC, alsook fungeren als een cofactor voor APC. Mutaties in het FV gen kunnen dus APCresistentie veroorzaken ofwel door de inactivering van $F V a$ te beïnvloeden, ofwel door de cofactor activiteit van FV bij de inactivering van FVIII(a) te reduceren. In dit proefschrift hebben wij ons voornamelijk gericht op de APCcofactor activiteit van FV en zijn rol in APC-resistentie.

Hoofdstuk 2 beschrijft experimenten om te achterhalen waarmee een aminozuur verandering op positie 2194 van het FV molecule, waarbij een asparaginezuur in een glycine verandert, de hoofdoorzaak is voor de gereduceerde FV concentratie in het plasma van mensen met het R2haplotype. Moleculair dynamische en electrostatische computer simulaties geven aan dat de Asp2194Gly mutatie leidt tot een algemene destabilisering van het $\mathrm{C} 2$ domein van FV. Dit wordt veroorzaakt door het feit dat deze mutatie 
de electrostatische interacties tussen Asp2194-Lys2101-Lys2103 verstoort. Onder normale omstandigheden (geen mutatie) zorgen deze interacties ervoor dat het $\mathrm{N}$-terminaal en het $\mathrm{C}$-terminaal deel van het $\mathrm{C} 2$-domein in elkaars buurt komen, waardoor de vorming van een disulfide brug tussen Cys2038 en Cys2193 bevorderd wordt. Dit resulteert in een stabilisatie van het eiwit. Aangezien deze Asp2194Gly mutatie de electrostatische interacties teniet doet, wordt de correcte vouwing van het $\mathrm{C} 2$-domein bemoeilijkt. Dit resulteert in de retentie en degradatie van incorrect gevouwen FV moleculen in het endoplasmatisch reticulum en leidt uiteindelijk tot een verminderde FV expressie. Deze computer data werden bevestigd door middel van experimenten met recombinante eiwitten, waarmee ook aangetoond werd dat niet alleen de Asp2194Gly mutatie maar om het even welke mutatie die de electrostatische interacties tussen Asp2194-Lys2101-Lys2103 treft, leidt tot een sterk verminderde expressie van het FV molecule.

In hoofdstuk 3 hebben we ons geconcentreerd op de anticoagulante activiteit van FV in de inactivering van FVIII(a) door APC en het belang hiervan voor APC-resistentie. Hoewel het nu algemeen aanvaard is dat de gereduceerde inactivering van $F a_{\text {Leiden }}$ door $A P C$ en de verminderde APCcofactor activiteit van $F V_{\text {Leicen }}$ beide bijdragen tot de waargenomen APCresistentie, is de relatieve bijdrage van beide componenten nooit bepaald. Wij hebben aangetoond dat de verminderde anticoagulante werking van $F V_{\text {Leiden }}$ voor de helft verantwoordelijk is voor de APC-resistentie, waargenomen met een klassieke aPTT-based APC-resistentie assay, een test die veel gebruikt wordt in klinische laboratoria. Verder hebben we het belang van de APCcofactor activiteit van FV laten zien door trombine generatie metingen in plasmas met verschillende FV concentraties, in aan en afwezigheid van APC. In aanwezigheid van APC leidt een verhoging van de FV concentratie (boven $60 \%$ van de normale hoeveelheid in plasma) tot een vermindering van de hoeveelheid gevormd trombine. Dit geeft aan dat $60 \% \mathrm{FV}$ genoeg is voor een optimaal procoagulante werking en dat een verdere toename van de FV concentratie resulteert in een toename van anticoaculante eigenschappen van FV. Bij FV Leiden, dat geen APC-cofactor activiteit heeft, gaf een dergelijk experiment geen vermindering in trombine generatie te zien. We hebben ook laten zien dat de APC-resistentie geassocieerd met de R2-haplotype veroorzaakt wordt door een verminderde APC-cofactor activiteit van FV-R2. Hierdoor wordt, in aanwezigheid van APC, in het plasma van een homozygote drager van het R2-polymorfisme twee keer zoveel trombine gevormd als in normaal plasma.

De patho-fysiologische betekenis van de anticoagulante activiteit van FV werd geillustreerd in hoofdstuk 4 , door het vergelijken van plasma van pseudo-homozygote, homozygote en heterozygote $F V_{\text {Leiden }}$ dragers met plasma 
van normale individuen. Met behulp van vier verschillende APC-resistentie testen hebben we een gedetaileerde karakterisatie verricht van het APCresistente fenotype geassocieerd met deze verschillende $F V_{\text {Leiden }}$ genotypes. Op basis van de resultaten kunnen we besluiten dat pseudo-homozygoten en homozygoten van de $\mathrm{FV}_{\text {Leiden }}$ mutatie even resistent zijn voor $\mathrm{APC}$, terwijl heterozygote $F V_{\text {Leiden }}$ dragers beduidend minder resistent zijn voor inactivatie door APC. Deze resultaten worden verklaard door het feit dat FV Leiden geen APC-cofactor activiteit vertoont en dat normaal FV wel als cofactor voor APC fungeert bij de inactivering van FVIII(a). Dit komt volledig overeen met de model experimenten uitgevoerd in hoofdstuk 3 , waarbij deze verschillende $F V_{\text {Leiden }}$ genotypes gesimuleerd werden door FV deficient plasma te reconstitueren met gezuiverd $F V_{\text {Leiden }}$ en/of normaal FV. Verder hebben bijkomende experimenten aangetoond dat wanneer we $F V$, van nature een procoagulant eiwit, titreren in een pseudo-homozygoot plasma, de APC-resistentie van dit plasma geleidelijk afneemt. Deze waarneming impliceert dat de mate waarmee het non-Leiden allel tot expressie komt in een heterozygote $F V_{\text {Leiden }}$ drager in belangrijke mate bijdraagt tot de individuele APC.

Tot slot, in hoofdstuk 5 hebben we APC-resistentie bestudeerd die geassocieerd is met verhoogde protrombine concentraties in plasma. De aPTTbased test bevestigde dat de APC-resistentie in een plasma toeneemt met toenemende protrombine concentraties, zowel in een model systeem als in een populatie gezonde donoren. Hetzelfde was waar voor het model systeem, gemeten met de ETP-based test. Er was echter een discrepantie met de ETPbased test tussen de resultaten van het model systeem en de metingen in de populatie gezonde individuen. Maar na correctie voor de protein $S$ concentraties in de populatie, werden gelijkaardige resultaten bekomen als in het model systeem. Hieruit kunnen we concluderen dat protein S het effect dat verhoogde protrombine heeft op de APC-resistentie tegenwerkt. Met andere woorden, de protein $S$ concentratie in plasma speelt een belangerijke rol bij het moduleren van de APC-resistentie, veroorzaakt door verhoogde protrombine levels. Dit werd bevestigd wanneer we protrombine titreerden in plasmas met verschillende concentraties protein $\mathrm{S}$. Aangezien de protrombine en protein $\mathrm{S}$ concentraties in plasma sterk gecorreleerd zijn, geeft de protrombine/protein $S$ ratio een juister voorspelling van de APC-resistentie dan de protrombine concentratie alleen. Deze bevindingen suggereren ook dat dragers van de protrombine mutatie (G20210A), die een hogere prothrombine/protein $S$ ratio hebben, een hogere risico voor thrombose hebben dan niet-dragers met vergelijkbare protrombine concentraties. 
$\because \quad$ 


\section{List of publications}

Miteva MA, Brugge JM, Rosing J, Nicolaes GAF, Villoutreix BO. Theoretical and experimental study of the $\mathrm{D} 2194 \mathrm{G}$ mutation in the $\mathrm{C} 2$ domain of coagulation factor V. Biophysical Journal. 2004; 86: 488-498

Elisabetta Castoldi, Jeroen M. Brugge, Gerry A. F. Nicolaes, Domenico Girelli, Guido Tans, and Jan Rosing. Impaired APC cofactor activity of factor V plays a major role in the APC resistance associated with the factor $V$ Leiden (R506Q) and R2 (H1299R) mutations. Blood. 2004;103: 4173-4179

Brugge JM, Simioni P, Bernardi F, Tormene D, Lunghi B, Tans $G$, Rosing J, Castoldi $E$. Expression of the normal factor $V$ allele modulates APC resistance phenotype in heterozygous carriers of the factor $V$ Leiden mutation. $J$ Thromb Haemost, 2005; Issue 12: 2695-2702

Brugge JM, Tans G, Rosing J, Castoldi E. Protein $\mathrm{S}$ levels modulate the activated protein $\mathrm{C}$ resistance phenotype induced by elevated prothrombin levels. Thromb Haemost, 2006; in press

\section{Accepted abstracts}

$X I X^{\text {th }}$ Congress of the International Society on Thrombosis and Haemostasis, Birmingham, UK, July 2003

Brugge J, Yamazaki T, Tans G, Dahlback B, Rosing J, Nicolaes GAF. Functional characterization of recombinant factor $\mathrm{V}$ molecules mimicking the R2-haplotype.

Journal of thrombosis and Haemostasis volume 1; supplement 1 Jully: OC258

Castoldi E, Brugge J, Nicolaes GAF, Tans G, Rosing J. Impaired anticoagulant activity of factor $V$ accounts for a large fraction of the APC resistance associated with the FV Leiden (R506Q) and R2 (H1299R) mutations.

Journal of thrombosis and Haemostasis 2003; supplement 1 July: OC256

$X X^{\text {th }}$ Congress of the International Society on Thrombosis and Haemostasis, Sidney, Australia, August 2005

Brugge JM, Simioni P, Bernardi F, Tormene D, Lunghi B, Tans G, Pagnan A, Rosing $\mathrm{J}$ Castoldi $E$. Thrombin generation and activated protein $C$ resistance in factor $V$ Leiden pseudo-homozygous patients.

Journal of thrombosis and Haemostasis volume 3; supplement 1: P1240 



\section{Curriculum vitae}

De auteur van dit proefschrift werd geboren op 31 juli 1976 te Casablanca (Marokko). $\mathrm{Na}$ het behalen van het diploma voor het algemeen secundair onderwijs in 1994 aan het Koninklijk Atheneum te Keerbergen (Belgium), werd in het najaar van 1995 gestart met de opleiding Biologie aan de Rijksuniversiteit van Gent (RUG). Na het behalen van zijn kandidaatsdiploma Biologie in 1998, besloot Jeroen verder te gaan met de opleiding Biotechnologie aan deze universiteit. Hierin slaagde hij met grote onderscheiding, waarna op 5 juli 2000 de titel 'Licentiaat in de Biotechnologie' verkregen werd. In januari 2001 begon hij vervolgens als assistent in opleiding (AlO) aan de Universiteit van Maastricht binnen het Cardiovasculair Onderzoeksinstituut (CARIM), bij de vakgroep Biochemie van Prof. Dr. J. Rosing. Hier heeft hij ruim 4 jaar gewerkt aan een project over APC-resistentie, hetgeen tot dit proefschrift heeft geleid.

The author of this thesis was born on the $31^{\text {st }}$ of July 1976 in the hospital of Casablanca (Morocco). After graduating from the Koninklijk Atheneum in Keerbergen (Belgium) in 1994, Jeroen began to study Biology at the University of Ghent in the autumn of 1995. After receiving his Bachelor degree in Biology in 1998, he decided to continue to study Biotechnology at the same university. Here, he graduated with honors and obtained his Masters degree in Biotechnology on the $5^{\text {th }}$ of July 2000 . In January 2001 he started as a PhD student at the University of Maasticht, within the Cardiovascular Research Institute Maastricht (CARIM) at the department of Biochemistry of Professor Dr. J. Rosing. There he has worked for over 4 years on a project about APCresistance, the results of which are described in this thesis. 


\section{Dankwoord ...}

Het tot stand komen wan dit proefschrift is niet alleen een kroon op het werk dat ik gedaan heb hier in Maastricht, maar vooral een grote kroon op de werk dal door vele mensen samen is verricht. Daarom is die proefschrift niet compleet zonder de mensen te bedanken die dit alles mogelijk hebben gemaakt ${ }$ die hebben bijgedragen tot mijn wetenschappelijke vorming en ook diegenen die voor de noodzakelike afleiding, ontspanning en steun hebben gezorgd.

Jan, jou will ik in eerste instantie bedanken voor hett feit dat ik binnen jouw vakgroep, onder jou directe supervisie mijn promotie onderzoek heb mogen verrichten. Je had altijd een nuchtere en heldere kijk op de situatie en uw wetenschappelijke vraagstellingen bleken keer op keer juist te zijn. Je stelt altijd hoge eisen aan de wetenschappelijke kwaliteit van hetgeen wordt gedaan en geschreven, wat niet altijd even gemakkelijk was, maar het komt het onderzoek zeker ten goede. lk heb veel van je geleerd, niet alleen op wetenschappelijk gebied. Bij een bierje of een glaasje wijn op het lab met wat chips of kaas wist je altijd wel weer leuke anekdotes te vertellen.

Guido, ij bent onmisbaar voor dit lab. Jou kritische blik op het onderzoek draagt zeker bij tot de hoge kwaliteit van waarmee in dit lab wetenschap wordt bedreven. De manier waarop je data kan analyseren en er vervolgens conclusies uit weet te extraheren is buitengewoon. Verder ben jij echt een manusje-van-alles: het maakt niet uit of iemand een wetenschappelijk probleem heeft, een statistisch dilemma of een op hol geslagen computer, Guido weet er wel raad mee.

Betta, aan jou heb ik heel weel te danken; woorden schieten me hierbij tekort! We hebben heel wat tijd samen doorgebracht al pipetterend aan het waterbad. Verdunningen maken van de vele plasma samples die we hebben doorgemeten was voor geen van ons beide een favoriete bezigheid, maar met $z^{\prime \prime} n$ tweeën viel het uiteindelitik best wel mee. Je hebt me veel geleerd, zowel wat labwerk betreft als het neerschrijven van de resultaten. Je bezit ook één van die bijzondere eigenschappen dat je ingewikkelde dingen op een rustig en eenvoudig manier kunt uitleggen. Het was af en toe onzeker of je nog in Maastricht kon blijven, maar ik ben blij dat het toch altijd gelukt is langer te blijven. Ik hoop van harte dat je binnenkort je welverdiende subsidie krijgt, want als iemand hem verdient, dan ben jij het wel.

Gerry, toen ik hier begon was ij degene die "mijn handje vast hield" toen ik mijn eerste stapjes zette in de wereld van de bloedistolling en degene die me de basisprincipes van het stollingsonderzoek heeft bijgebracht. We hebben samen heel wat late uurtjes op het lab doorgebracht met het zuiveren van recombinante eiwitten. Helaas hebben we het project even aan de kant moeten zetten, maar ik hoop dat je weldra de draad weer op kunt pikken, want ik ben er nog steeds van overtuigd dat we in de goede richting zaten.

Tilman, jij lijkt wel het optimisme zelve. Het maakt niet uit of experimenten niet uitkomen volgens de oorspronkelijke hypothese, jij weet er altijd weer een positieve noot aan vast te knoppen. Ook jou veelzijdigheid is een grote troef, waarmee je graag anderen verder helpt. Op jou rust ook de zware taak de vakgroep te voorzien van "frisdrank". Menig vrijdagavonden hebben we dan ook met z'n allen hiervan genoten met chips en grappige, sappige verhalen.

Rory, de DJ van ons lab, kamergenoot tijdens cursussen en congressen en een uitstekende wetenschapper. We hebben samen veel plezier beleefd tijdens de cursussen in Amsterdam, Lunteren, Papendaal en Houthalen. Die auto van jou, waar je na het tanken nog een scheut loodoplossing in moest gooien, vergeet ik nooit. Jij hebt mij] "cultuur" bijgebracht; toen ik hier begon, wist in nauwlijks wat smartlappen waren. Maar na 3 jaar met jou het lab gedeeld te hebben, was zelfs ik een beetje droevig na het overlijden van jouw grote idool, Andre Hazes.

Kristin, je was altijd een beetje stilletjes op de achtergrond aanwezig. Je zel niet zo veel, maar als we eenmaal aan het praten raakten, waren het altijd leuke, 
interessante gesprekken. Met veel dingen was je me een stapje voor (uitkering aanvragen, solliciteren, ...), dus kwam $\mathrm{ik}$ vaak bij jou langs om raad. $\mathrm{k}$ wens je heel veel sterkte met hel afronden van jou promotie onderzoek en ook veel succes in de toekomst.

Stella, ijj was en bent nog steeds het spilfiguur binnen deze groep en dat merk je al gauw op woensdag als je vrij hebt. ledereen maakt gebruik van jou ervaring; ook ik heb veel aan jou gevraagd en veel van jou geleerd. Alleen weet $k \mathrm{k}$ nog steeds niet hoe het jou lukt de mannen wan de technische dienst zo snel op 't lab te krijgen als er lets kapot gaat, want ik moest altijd heel lang wachten vooraleer ze langskwamen. Volgens mij weet jedereen bij de universiteit én in het ziekenhuis, waarschijnlijk zelfs in heel Maastricht wie Stella is. Over een netwerk gesproken... Bedankt ook dat je vaak het voortouw nam bij het regelen van activiteiten buiten het lab om. Bel me als jullie nog eens gaan lasergamen of eten bij de Japanner ofzo.

Elke, het goedlachse meiske uit Mopertingen (over een understatement gesproken (9). Ik ben heel blij dat jij gedurende 4 jaar mijn collega was. Het feit dat ik af en toe de deur tussen onze labs dicht deed, was niet omdat ik boos op je was, maar omdat jou bulderende lach of joul "harde" muziek me uit m" $n$ concentratie haalde tijdens ingewikkelde pipetteerschema's. Maar sinds je hier weg bent, is het hier vrij stil geworden; ik ben altijd blij als ik weer (van ver) jou vrolijke lach hoor naderen.

José, hoewel je vrij snell na mijn komst bent veranderd van groep, was jij altijd een aangename en plezierige collega. Je nam altijd rustig de tijd om dingen uit te leggen en liet iedereen meegenieten van jou jarenlange ervaring in de stollingswereld.

Kristoffer, the "Iceman" from up North. Your stay in our lab was a nice period, with numerous cafes visits, beer and laughter, but also hard work and interesting conversations. Good luck in the future and maybe our paths will cross again some day.

Wencke, de grootste U2-fan die $1 / k$ ken. Je bent altijd vrolijk gestemd maar van die geurtjes die soms uit jouw lab komen, wordt de rest wat minder blii. Het feit dat jou computer naast de printer staat op het lab, maakte dat we regelmatig een gezellig babbeltje konden maken terwijl de printer weer eens vastliep voor de zoveelste keer die dag en weer opnieuw moest opwarmen en kalibreren.

Kenneth, een fijne collega, zowel in als buiten het lab. Ook jil hebt het "genoegen" om met recombinant factor $V$ te mogen werken. Niet altijd even makkelijk als je het mij vraagt, maar met jou gedrevenheid en doorzettingsvermogen zal het wel lukken. Nog veel succes in de toekomst. Bedankt dat je m"n paranimf wou zijn en dat je me een beetje wegwijs hebt gemaakt in de wereld van computersimulaties en computermodellen.

Lisbeth, een babbelaarster eerste klas, maar daarnaast ook een enthousiaste en gedreven onderzookster. Het bickyburger/nagerechten-festijn was een geslaagd feestje, maar" is wacht nog steeds op het recept van die overheerlijke soufflé grand marnier. Ook jou wens ik nog veel succes toe met je promotieonderzoek. Ook jij bedankt dat je vandaag mijn paranimf willde zijn.

Svetlana, I haven't heard you speak any Dutch (yet), but I am convinced you understand more then we think you do. Although your mice might disagree, I think you are a nice and pleasant colleague with a heart for science. I enjoyed our discussions about giving birth at home. As you can see, everything went well. I wish you the best of luck in the future.

Anouk, de laatste nieuwkomer op ons lab. Ook jij bent een vrolijke meid die volgens mij heel wat lol beleeft (maar ook goed werk vericht) op het lab, samen met Wencke. Binnenkort ga je deze afdeling voor een tijdje verlaten. Ik wens je heel veel succes in San Diego en met je verdere carrière. Bedankt nog voor je hulp met het aanmaken van PDF-filetjes.

Paul, I hope your stay in our lab was as pleasant for you as it was for me. I enjoyed your stories about the States and how your inventiveness gave the use of the exhaust hood in the lab a whole new purpose. Salt Lake City ... 
Trees en Mariet, jullie wil ik van harte bedanken voor het regelen varn al de administratieve rompslomp dat komt kijken bij een AlO-aanstelling en de promotie, (vakantiekaarten, cursussen, declaratieformulieren, brieven ...) Trees, als secretaresse van de vakgroep ben jij degene die alles en iedereen in ${ }^{4}$ gareel moet houden er dal whi je ook heel goed. ledereen respecteert éen belangrijke regel. "Wat Trees zegt, is wet" eigenlijk heb jiij op deze afdeling de touwtjes in handen.

Verder wil ik nog iedereen van de vakgroep Biochemie bedanken. Julte waren stuk voor stuk aangename en leuke mensen, ieder met zïn of haar cigen kwalteiten. Met ieder van jullie heb ik wel eens staan praten in de koffiekamer met een sluk waal, of jullie om advies gevraagd over het werk of over andere dingen. Unteindelkk heeft iedereen biligedragen aan het feit dat ik mijn AlO-periode in Maastricht als zeer aangenaam heb ervaren.

I would like to thank. Dr. Villoutreix and his team for their collaboration during the characterization of the effect of the D2194G mutation in the C2-domain of factor $\mathrm{V}$. Asso, I would like to thank Dr. Simioni and his team for sending us the plasma samples for the pseudo-homozygous $F V_{\text {Leiden }}$ study. Furthermore, professor Bernardi and his team ate also gratefully acknowledged for their involvement during this project.

Kris, jou wil ik ook even persoonlijk bedanken. Vertegenwoordigers zijn niet altijd even graag geziene 'gasten' op het lab, maar jij bent en blijt toch wel een van de weinige uitzonderingen. Verder will ik je ook bedanken dat je namens IL het drukken van dit proefschrift hebt gesponcerd. We zullen elkaar zeker nog wel eens in Leuven ziek.

$\mathrm{M} n$ vrienden will ik bedanken voor de steun en aanmoediging die ze mill gegeven hebben, maar vooral ook voor de noodzakelijk ontspanning tussendoor. De weekendjes in de Ardennen, Luxemburg of de Champagne-streek waren leuk en gezellig, evenals de vele barbecue's, spelletjes namiddagen of awondjes dat we gewoon met $z^{\prime \prime} n$ allen iets zijn gaan eten of drinken.

Ook mijn familie en schoonfamilie wil ik graag bedanken, want ook 2 数 hebben bewust en onbewust hun steentje bijgedragen aan het werk dat ik hier geleverd hob. Jullie hebben mij de nodige steun gegeven en interesse getoond in hetgeen ik tijens de afgelopen 5 jaar heb gedaan en gezorgd voor aangename afleiding en ontspanning.

Mama en papa, jullie ben ik heel veel dankbaarheid verschudigd, niew alleen voor al jullie steun en hulp de afgelopen jaren, maar ook voor alies wal jullie voor mil gedaan hebben in de jaren daarvoor. Jullie hebben me altijd geadviseerd, begeleid en gesteund in de keuzes die ik heb gemaakt en geholpen waar het kon. Kk kon alkd opertilk me' jullie praten over miln vragen en problemen, wat zeker fijn was tjdens de moeilijkere periodes. Pap, werken in het bos en "dal luie zweet er uitzweten" zoals je zegt, was voor mij een ideale manier om me af te reageren. Mam, "de liefde van een man gaat door zijn maag", maar het is niet alleen daarom dat ik in het weekend graag naar huis kom.

Liesbeth, milin lieve Liesbeth! Het is vandaag niet alleen een grote dag voor mij, maar ook voor jou. Hetgeen ik bereikt heb, had ik zeker niet gekund zonder jouw steun. je motiverende en geruststellende woorden en vooral je eindeloos geduld gedurende mijn niet altijd even vrolijke momenten. Gelukkig werd je hierin bijgestaan door Woefke en sinds kort ook nog door Jasper. Als het zou bestaan, verdien jij de titel "Doctor in het vrouw zijn van een wetenschapper" en je zou promoveren cum laude ... Je bent miln cofactor, zonder wie ik niet kan functioneren !!! 